\title{
EVALUATING THE SENSITIVITY OF THE LUCI MODEL TO GIS DATASETS TO ENABLE ROBUST FARM MANAGEMENT DECISIONS IN NEW ZEALAND
}

\author{
By \\ Alicia I. Taylor \\ A thesis submitted to the Victoria University of Wellington in partial fulfilment of the \\ requirements for the degree of \\ Master of Science \\ In \\ Physical Geography
}

School of Geography, Environment and Earth Sciences

Victoria University of Wellington 



\begin{abstract}
Degradation of water quality is a major issue in New Zealand, to which the loss of nitrogen, phosphorus and sediment from agriculture into waterways contributes significantly. To predict and manage diffuse pollution from intensive agriculture it is vital that models are able to spatially map the sources, flows and sinks of nutrients in the landscape and spatially target mitigations. This study investigates the application of one such model, the Land Utilisation Capability Indicator (LUCI). Used in conjunction with OVERSEER, LUCI is a powerful tool to support farm scale land management decision-making.

LUCI includes soil, topography and landcover datasets in its analysis. This thesis examines how the quality and resolution of each dataset affects LUCl's output. Six different case studies are examined, across a range of New Zealand farming systems. This is the most comprehensive study, to date, of LUCI's sensitivity to input datasets.

The results suggest that $\mathrm{LUCI}$ nutrient loading estimates are primarily sensitive to soil order, and therefore to changes in order classifications. Utilising different soil datasets in the LUCI model resulted in varying nutrient load predictions. This sensitivity is primarily attributed to the differing hydraulic and phosphorus retention capabilities of the respective soil orders. To test the sensitivity of $L U C I$ to digital elevation model (DEM) resolution, multiple DEMs with varying spatial and vertical resolution were tested. These results strongly indicate that particularly fine resolution DEMs are required to accurately model flat landscapes.
\end{abstract}

It was recognised that $\mathrm{LUCl}$ was not using all of the relevant data available in Landcare Research's S-Map database. LUCI was modified to use more of this information, and alternative methods of incorporating sibling level data in both $\mathrm{LUCl}$ and OVERSEER were investigated. Finally, avenues for future development are suggested. Overall, this thesis highlights the potential LUCI has to play a key role in farm scale environmental management. 
This thesis is dedicated to my parents, Jenny and Rob Taylor.

Thank you for all your support. 


\section{ACKNOWLEDGEMENTS}

I would like to thank a number of people that have supported me through the course of this thesis. Firstly, my supervisors Dr Bethanna Jackson (VUW) and Dr Alister Metherell (Ravensdown) for their advice and support. I would also like to acknowledge financial support from Callaghan Innovation and Ravensdown, as well as support from the wider Ravensdown community in the form of industry training, conferences, and the assistance from Mike White, Ants Roberts and Richard Christie. The support of Dr Deb Maxwell, Dr Martha Trodahl, Keith Miller and the broader VUW Hydrogroup is also acknowledged.

This thesis would not have been possible without the information provided from Environment Canterbury, Otago Regional Council, Greater Wellington Regional Council and Landcare Research. Thanks also go to the farmers who allowed me to model their land as well as Ron Pellow at SIDDC and Lucy Burkitt and Mike Bretherton from Massey University, for the use of Lincoln University Dairy Farm and Tuapaka Agricultural Experimental Station.

Finally, I would like to thank my family, Jenny, Rob and John, and my partner Aidan. Your support and encouragement during this thesis and throughout my earlier years of university study has been amazing. 


\section{TABLE OF CONTENTS}

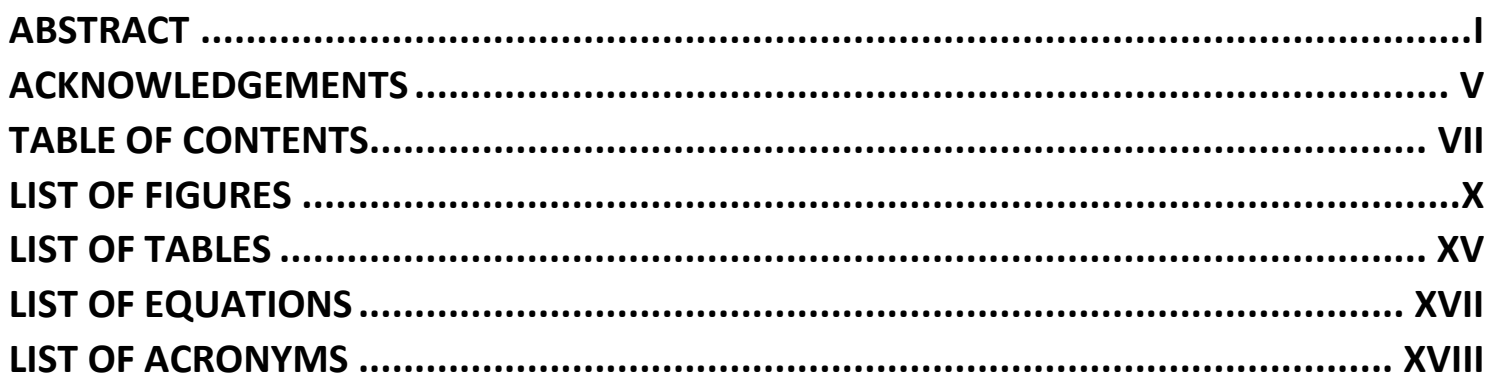

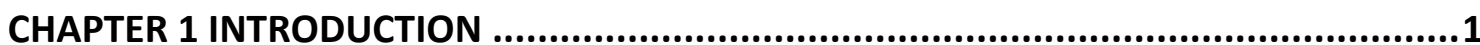

1.1 MODELLING NUTRIENT FLOWS ON AGRICULTURAL LAND USING THE LAND

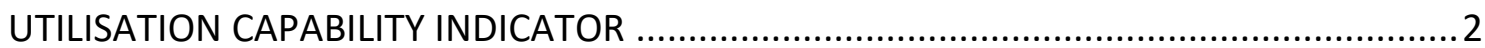

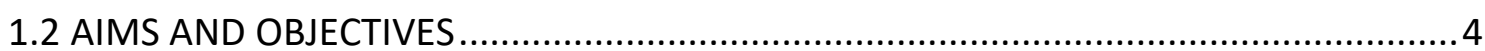

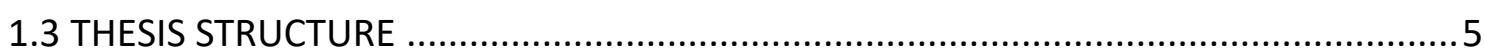

CHAPTER 2 ECOSYSTEM SERVICES AND WATER QUALITY.......................................7

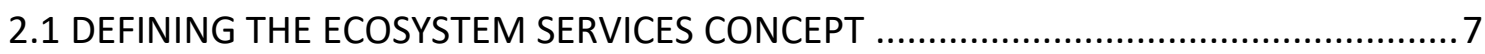

2.1.1 Applying the Ecosystem Services Concept in Decision-making ...........................9

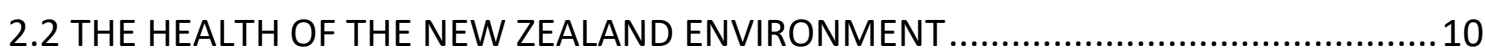

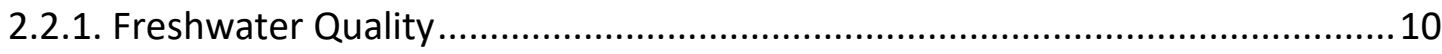

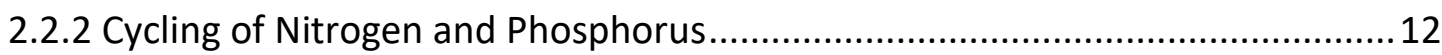

2.2.3. Increased Erosion and Sedimentation .......................................................... 19

CHAPTER 3 WATER QUALITY MODELLING USING LUCI AND OVERSEER ....................22

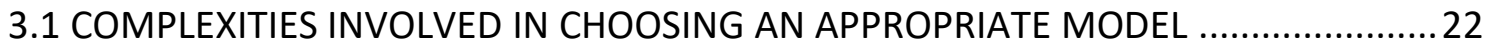

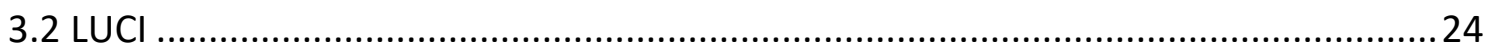

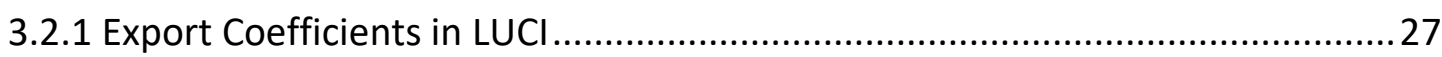

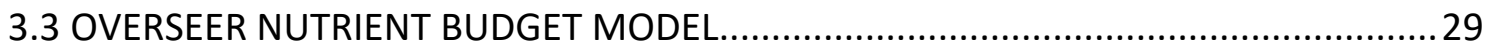

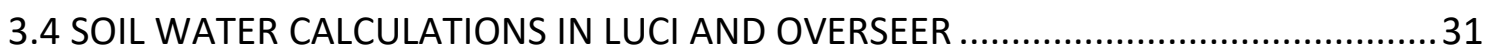

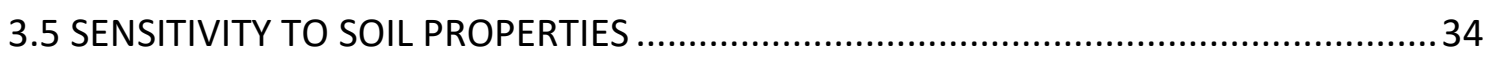

CHAPTER 4 REVIEW OF NEW ZEALAND'S SOIL AND TOPOGRAPHIC DATASETS .........36

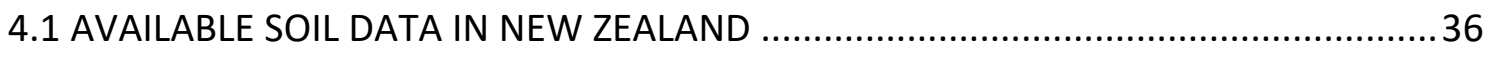

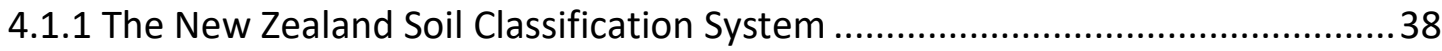

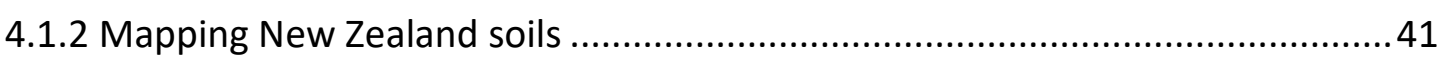

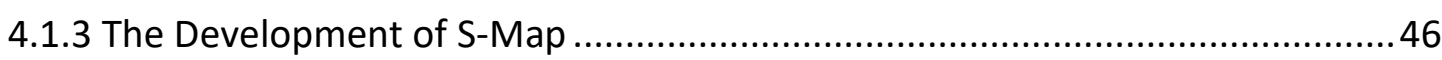

4.1.4 Opportunities for Improving New Zealand's Soil Data ....................................50

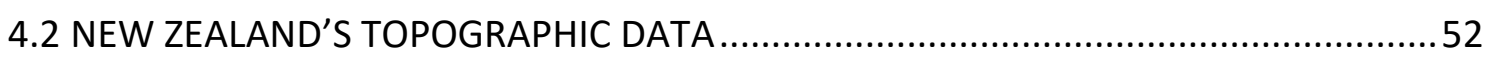

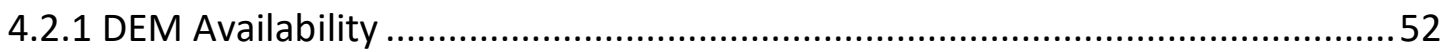

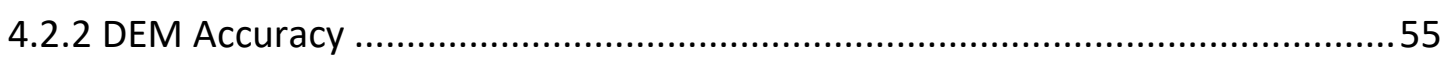




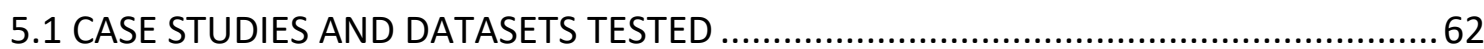

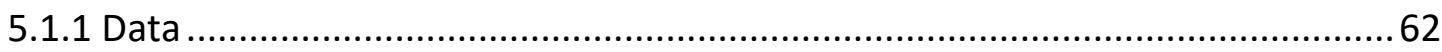

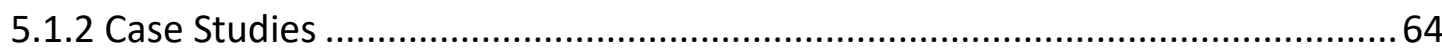

5.1.2.1 Tuapaka Catchment within Tuapaka Agricultural Experimental Station.... 65

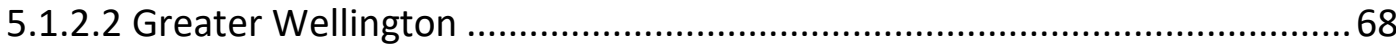

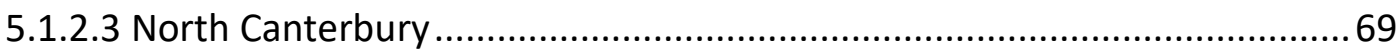

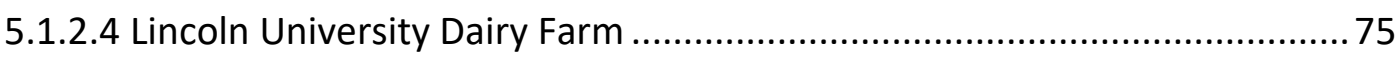

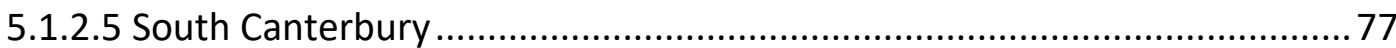

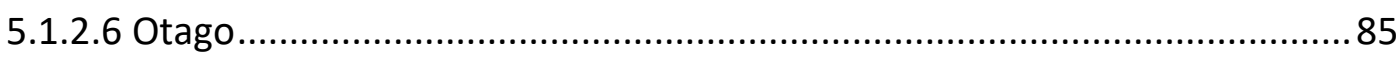

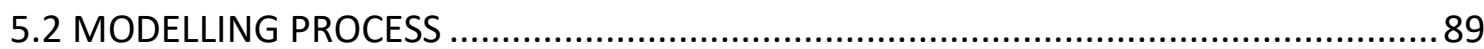

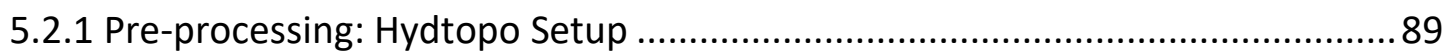

5.2.2 Pre-processing: LUCI Scenario Setup .............................................................. 91

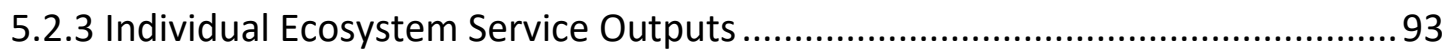

5.2.4 Matlab Analysis to Estimate Total Annual Load of Nitrogen and Phosphorus.. 95

5.2.5 How to Add Farm Specific Soil Data in LUCl ..................................................96

5.2.6 Importance of Including Sibling Information .................................................. 96

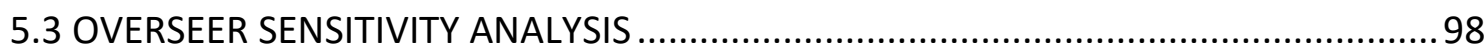

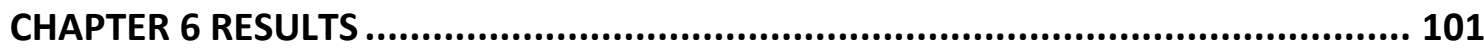

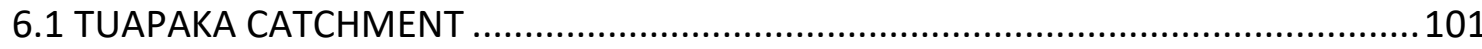

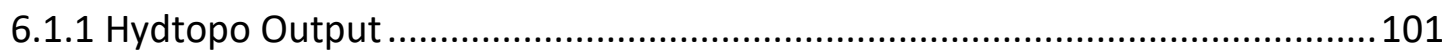

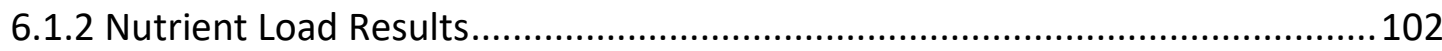

6.1.3 Modelled vs Collected Data Comparison......................................................... 108

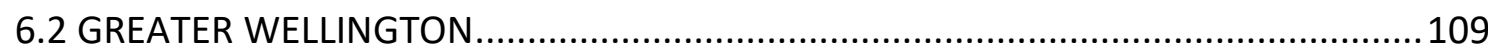

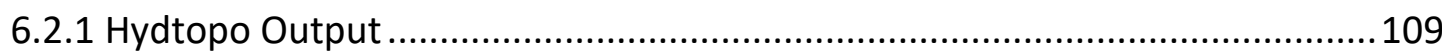

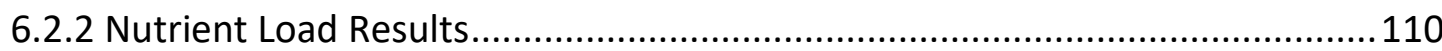

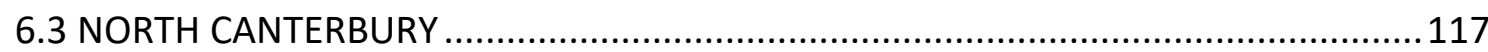

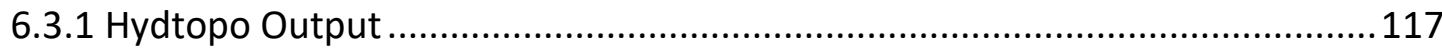

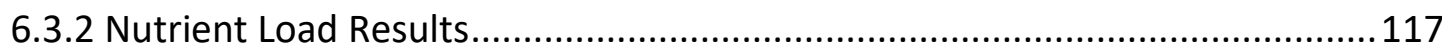

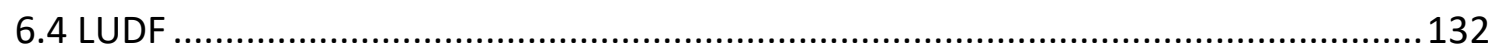

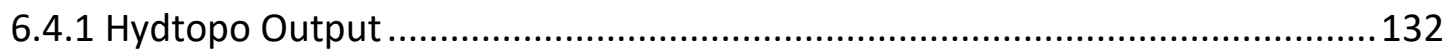

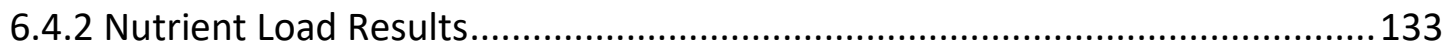

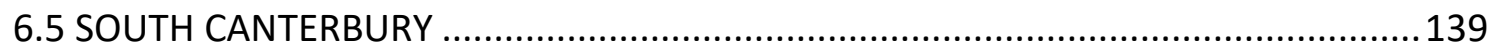

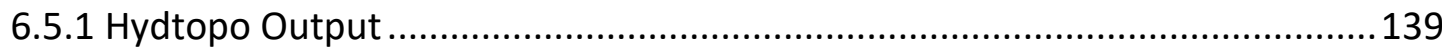

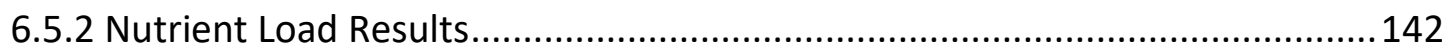

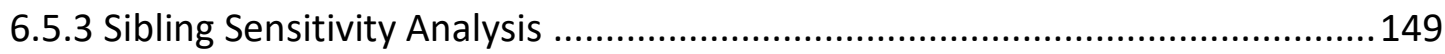

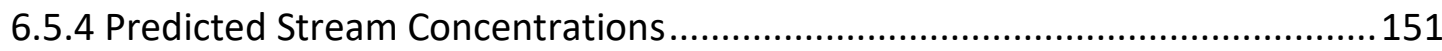

6.5.5 Testing Sibling Variation in OVERSEER ..................................................... 151

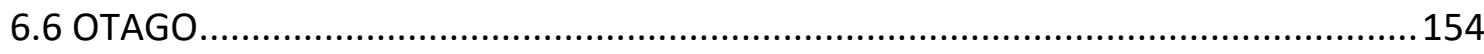

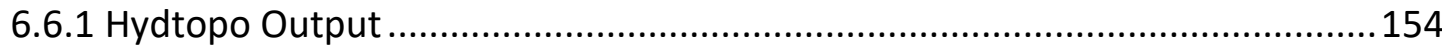

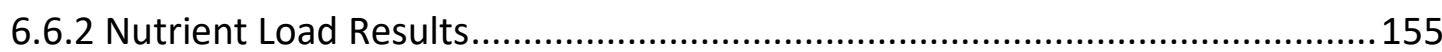

6.6.3 Modelled vs Collected Data Comparison....................................................... 162

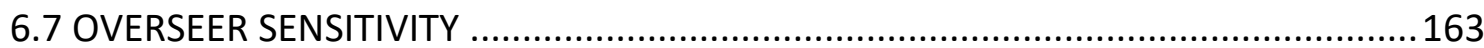


6.7.1 Effect of Changing Management Factors....................................................... 163

6.7.2 Effect of Changing Environmental Factors.................................................. 166

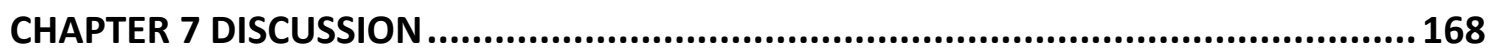

7.1 SENSITIVITY OF LUCI TO SOIL PROPERTIES AND THE RESOLUTION OF ELEVATION

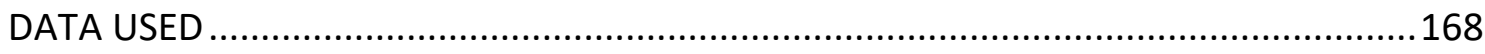

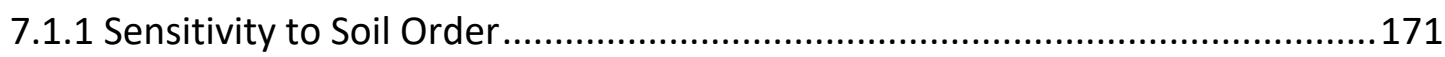

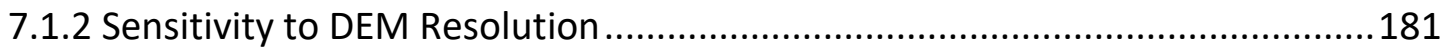

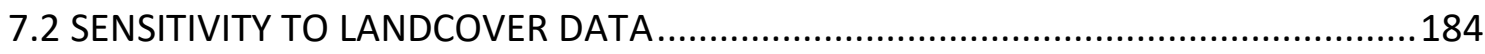

7.3 OBSERVED VS PREDICTED NUTRIENT CONCENTRATIONS ......................................188

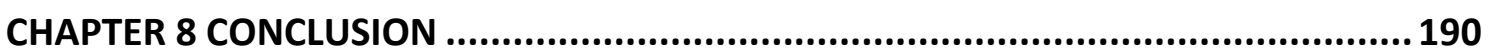

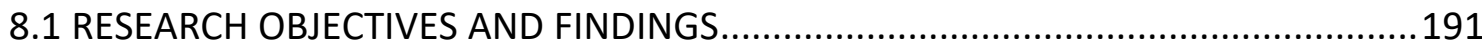

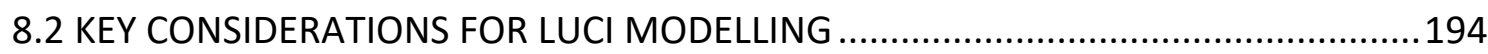

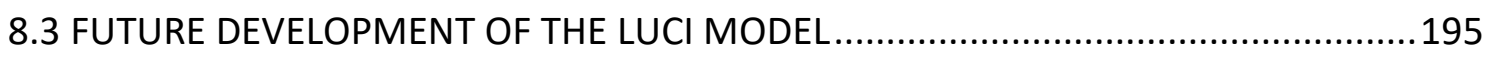

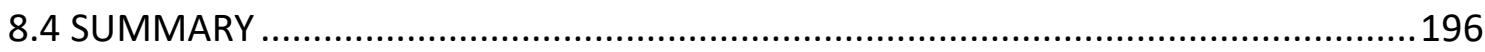

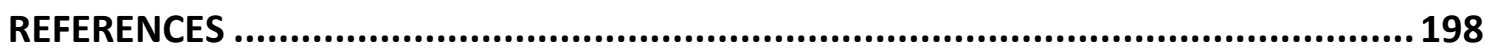

APPENDIX A: THE FIFTEEN KEY ATTRIBUTES USED TO DESCRIBE SOILS IN THE FSL. . 215 APPENDIX B: PAPER SUBMITTED TO MASSEY UNIVERSITY'S FERTILISER AND LIME RESEARCH CENTRE WORKSHOP 2018 ...........................................................218 APPENDIX C: SOIL PROPERTIES BASED ON SOIL ORDER IN OVERSEER. SOURCE:

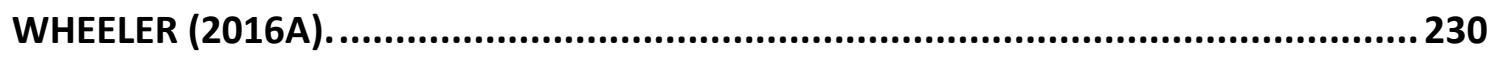




\section{LIST OF FIGURES}

Figure 2.1 Impacts of farm management and landscape management practices on the

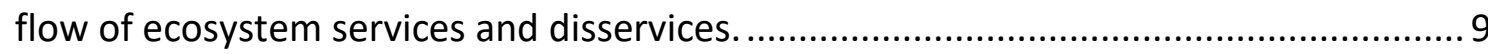

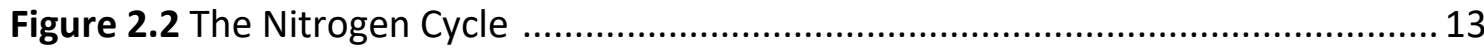

Figure 2.3 The Global Phosphorus Cycle ................................................................. 14

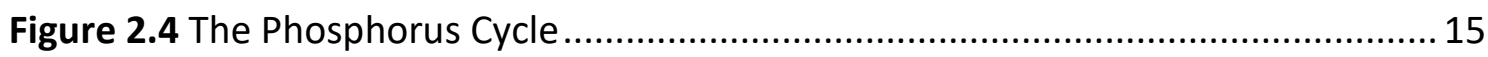

Figure 2.5 Pathways of nitrogen and phosphorus loss ................................................ 16

Figure 2.6 Eutrophication in a Manawatu catchment ............................................. 17

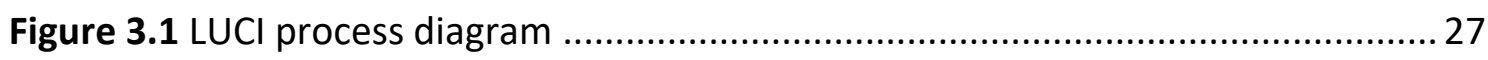

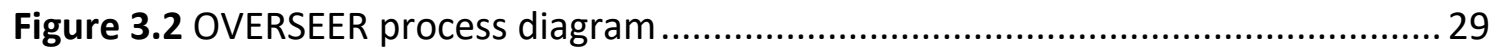

Figure 3.3 Water movement through a soil profile ................................................ 33

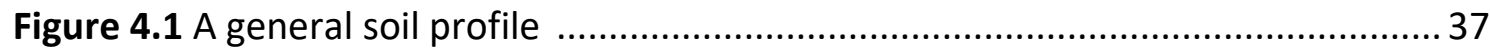

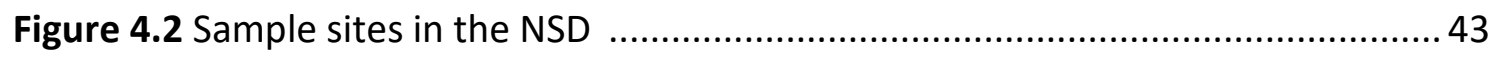

Figure 4.3 Coverage of S-Map over New Zealand ..................................................... 47

Figure 4.4 Coverage of LiDAR over New Zealand ...................................................... 53

Figure 4.5 Comparison of passive and active remote sensors .................................. 56

Figure 4.6 Processing steps to create a DEM from photogrammetry ..........................5 57

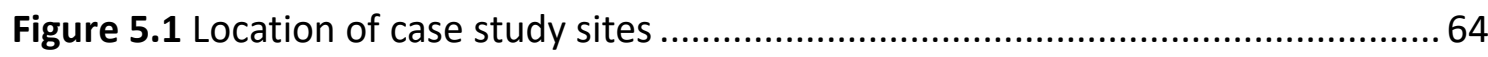

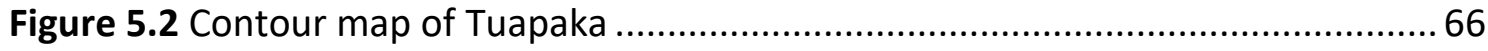

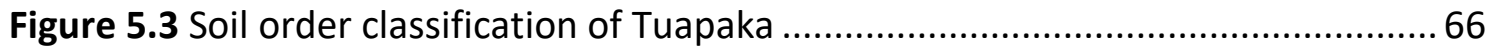

Figure 5.4 Contour map of Greater Wellington.................................................... 68

Figure 5.5 Soil order classification of Greater Wellington............................................69

Figure 5.6 Contour map of North Canterbury ...................................................... 71

Figure 5.7 Soil order classification of North Canterbury ............................................ 71

Figure 5.8 Landcover classification of North Canterbury .......................................... 72

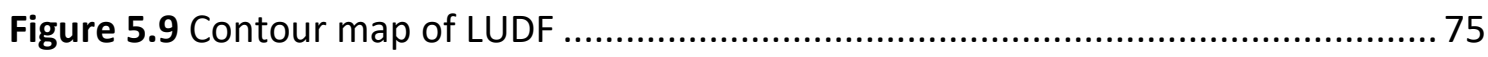

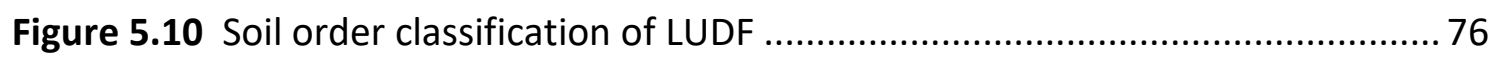




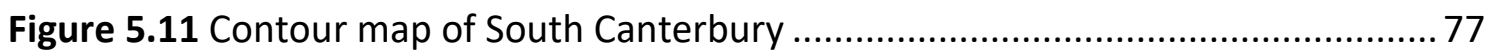

Figure 5.12 Soil order classification of South Canterbury …....................................... 80

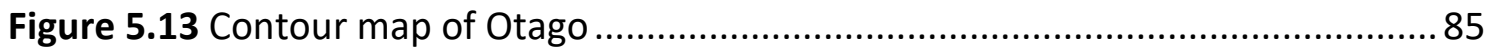

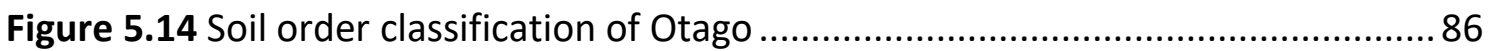

Figure 5.15 OVERSEER management blocks for Otago ........................................... 87

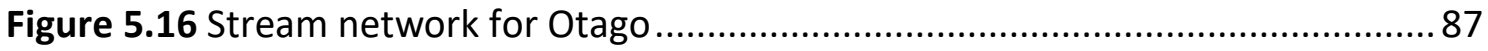

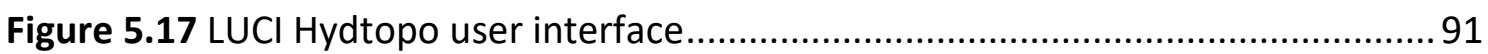

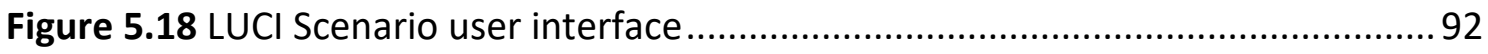

Figure 5.19 Crop rotation for hypothetical farm ................................................... 98

Figure 6.1 LUCl hydrological output for Tuapaka .................................................. 102

Figure 6.2 (a) Proportional occurrence of nitrogen load values, (b) cumulative probability of occurrence of a nitrogen load, (c) proportional occurrence of phosphorus load values, (d) cumulative probability of occurrence of a phosphorus load ............... 104

Figure 6.3 Nitrogen load results for all scenarios in kg N/ha/yr................................. 106

Figure 6.4 Nitrogen accumulated load results for all scenarios ................................ 106

Figure 6.5 Phosphorus load results for all scenarios in $\mathrm{g}$ P/ha/yr ............................ 107

Figure 6.6 Phosphorus accumulated load results for all scenarios ............................. 108

Figure 6.7 LUCI hydrological output for Greater Wellington ................................... 109

Figure 6.8 (a) Proportional occurrence of nitrogen load values, (b) cumulative probability of occurrence of a nitrogen load, (c) proportional occurrence of phosphorus load values, (d) cumulative probability of occurrence of a phosphorus load ...............111

Figure 6.9 Nitrogen load results for all scenarios in $\mathrm{kg} \mathrm{N} / \mathrm{ha} / \mathrm{yr} . . . \ldots \ldots \ldots \ldots \ldots \ldots \ldots \ldots . . . . . . . . . . . . . . .113$

Figure 6.10 Nitrogen accumulated load results for all scenarios .............................114

Figure 6.11 Phosphorus load results for all scenarios in $\mathrm{P}$ P/ha/yr ........................... 115

Figure 6.12 Phosphorus accumulated load results for all scenarios ........................... 115

Figure 6.13 Nitrogen and phosphorus load results for S-Map-FSL Hybrid soil data $+1 \mathrm{~m}$ DEM without farm specific information from an OVERSEER $\mathrm{xml}$ file ......................... 116

Figure $6.14 \mathrm{LUCl}$ hydrological output for North Canterbury .................................... 117

Figure 6.15 (a) Proportional occurrence of nitrogen load values for the soil + DEM scenarios with default landcover, (b) cumulative probability of occurrence of a nitrogen load for the soil + DEM scenarios with default landcover, (c), occurrence of 
nitrogen load values for scenarios with farm specific OVERSEER information, (d) probability of occurrence of a nitrogen load for scenarios with farm specific OVERSEER information 120

Figure 6.16 (a) Proportional occurrence of phosphorus load values for the soil + DEM scenarios with default landcover, (b) cumulative probability of occurrence of a phosphorus load for the soil + DEM scenarios with default landcover, (c), occurrence of phosphorus load values for scenarios with farm specific OVERSEER information, (d) probability of occurrence of a phosphorus load for scenarios with farm specific OVERSEER information

Figure 6.17 Nitrogen load results in $\mathrm{kg} \mathrm{N} / \mathrm{ha} / \mathrm{yr}$ for S-Map and FSL soil data + 2m DEM with farm specific information from an OVERSEER $\mathrm{xml}$ file 124

Figure 6.18 Nitrogen load results for all scenarios without farm specific OVERSEER information in $\mathrm{kg} \mathrm{N} / \mathrm{ha} / \mathrm{yr}$ 125

Figure 6.19 Nitrogen accumulated load results for all scenarios without farm specific OVERSEER information 126

Figure 6.20 Nitrogen accumulated load results for all scenarios without farm specific OVERSEER information using the histogram equalise setting in ArcMap symbology.. 127 Figure 6.21 Phosphorus load results for all scenarios without farm specific OVERSEER information in $\mathrm{kg} \mathrm{P} / \mathrm{ha} / \mathrm{yr}$ 129

Figure 6.22 Phosphorus load results in $\mathrm{g}$ P/ha/yr for S-Map and FSL soil data + 2m DEM with farm specific information from an OVERSEER xml file 130

Figure 6.23 Phosphorus accumulated load results for all scenarios without farm specific OVERSEER information

Figure 6.24 Phosphorus accumulated load results for all scenarios without farm specific OVERSEER information

Figure 6.25 LUCl hydrological output for LUDF

Figure 6.26 (a) Proportional occurrence of nitrogen load values, (b) cumulative probability of occurrence of a nitrogen load, (c) proportional occurrence of phosphorus load values, (d) cumulative probability of occurrence of a phosphorus load 135

Figure 6.27 Nitrogen load results for the S-Map and FSL scenarios in kg N/ha/yr 137

Figure 6.28 Nitrogen load results for the farm scale soil map scenarios in $\mathrm{kg} \mathrm{N} / \mathrm{ha} / \mathrm{yr}$ 
Figure 6.29 Nitrogen accumulated load results for the S-Map and FSL scenarios. 138

Figure 6.30 Nitrogen accumulated load results for the farm scale soil map scenarios 138 Figure 6.31 Phosphorus load results for the S-Map and FSL scenarios in kg P/ha/yr .. 140 Figure 6.32 Phosphorus load results for the farm scale soil map scenarios in $\mathrm{kg} \mathrm{P} / \mathrm{ha} / \mathrm{yr}$

Figure 6.33 Phosphorus accumulated load results for the S-Map and FSL scenarios ..141 Figure 6.34 Phosphorus accumulated load results for the farm scale soil map scenarios

Figure 6.35 LUCI hydrological output for South Canterbury 142

Figure 6.36 (a) Proportional occurrence of nitrogen load values, (b) cumulative probability of occurrence of a nitrogen load, (c) proportional occurrence of phosphorus load values, (d) cumulative probability of occurrence of a phosphorus load 144

Figure 6.37 Nitrogen load results for all scenarios in $\mathrm{kg} \mathrm{N} / \mathrm{ha} / \mathrm{yr}$. 146

Figure 6.38 Nitrogen accumulated load results for all scenarios 147

Figure 6.39 Phosphorus load results for all scenarios in $\mathrm{P} / \mathrm{ha} / \mathrm{yr}$ 148

Figure 6.40 Phosphorus accumulated load results for all scenarios 149

Figure 6.41 (a) Proportional occurrence of nitrogen load values, (b) cumulative probability of occurrence of a nitrogen load, (c) proportional occurrence of phosphorus load values, (d) cumulative probability of occurrence of a phosphorus load 152

Figure 6.42 LUCI hydrological output for Otago. 155

Figure 6.43 (a) Proportional occurrence of nitrogen load values, (b) cumulative probability of occurrence of a nitrogen load, (c) proportional occurrence of phosphorus load values, (d) cumulative probability of occurrence of a phosphorus load 157

Figure 6.44 Nitrogen load results for all scenarios in $\mathrm{kg} \mathrm{N} / \mathrm{ha} / \mathrm{yr}$ 159

Figure 6.45 Nitrogen accumulated load results for all scenarios 159

Figure 6.46 Nitrogen accumulated load results for all scenarios using the histogram equalise setting in ArcMap symbology 160

Figure 6.47 Phosphorus load results for all scenarios in $\mathrm{g} P / \mathrm{ha} / \mathrm{yr}$ 161

Figure 6.48 Phosphorus accumulated load results for all scenarios 161

Figure 6.49 Phosphorus accumulated load results for all scenarios using the histogram equalise setting in ArcMap symbology..... 162 
Figure 7.1 Estimated PAW for all sibling scenarios on the South Canterbury case study

Figure 7.2 Variation in PAW for selected siblings classified as brown soils. Red box indicates range in PAW found at the South Canterbury site. 180

Figure 7.3 Variation in PAW for selected siblings classified as pallic soils. Red box indicates range in PAW found at the South Canterbury site. 181 Figure 7.4 Variation in PAW for selected siblings classified as recent soils. Red box indicates range in PAW found at the South Canterbury site. 181 


\section{LIST OF TABLES}

Table 2.1 Livestock productivity trends from 1990 to 2017 10

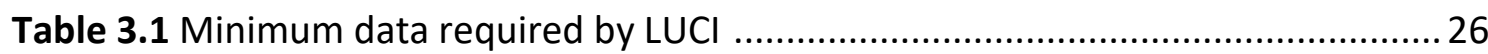

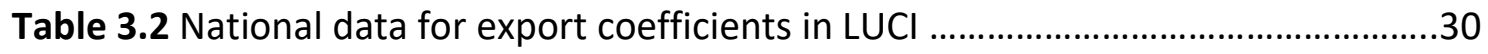

Table 3.3 Relationship between ASC and soil order ............................................... 35

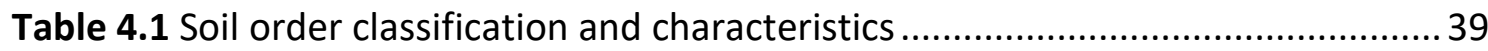

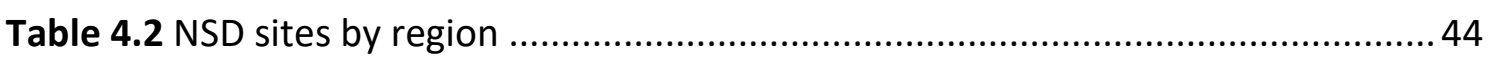

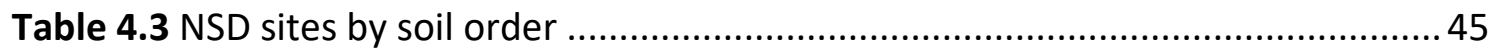

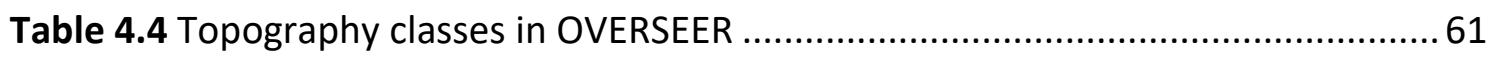

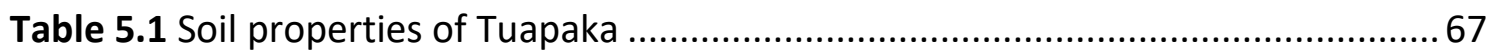

Table 5.2 Soil properties of Greater Wellington......................................................... 70

Table 5.3 Soil properties of North Canterbury ….................................................... 73

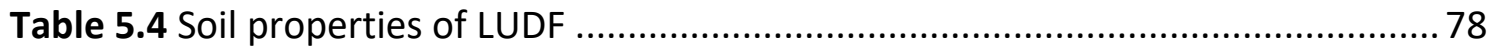

Table 5.5 Soil properties of South Canterbury .......................................................... 81

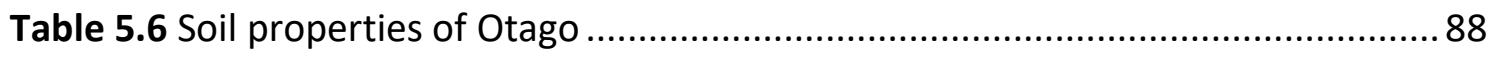

Table 5.7 DEM resolution, vertical accuracy and source for all case study sites ...........90 90

Table 5.8 Soil datasets and source for all case study sites ....................................... 92

Table 6.1 Total nitrogen and phosphorus load results for Tuapaka.......................... 102

Table 6.2 Observed and predicted total nitrogen and phosphorus loads for all scenarios

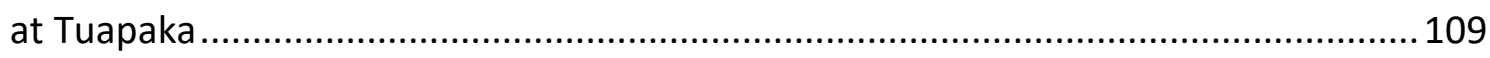

Table 6.3 Total nitrogen and phosphorus load results for Greater Wellington ........... 110

Table 6.4 Total nitrogen and phosphorus load results for North Canterbury.............. 118

Table 6.5 Total nitrogen and phosphorus load results for LUDF.............................. 133

Table 6.6 Total nitrogen and phosphorus load results for South Canterbury..............142

Table 6.7 Total nitrogen and phosphorus load results for all sibling scenarios ........... 151

Table 6.8 Predicted total nitrogen and phosphorus stream concentrations for all sibling

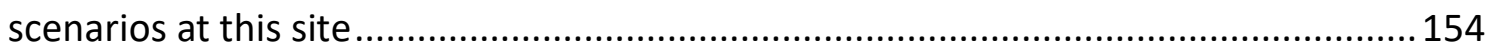


Table 6.9 OVERSEER estimated total nitrogen and total phosphorus load using the dominant and (second sibling) classified in S-Map for three of the South Canterbury pastoral blocks 154

Table 6.10 Total nitrogen and phosphorus load results for Otago 155

Table 6.11 Observed and predicted total nitrogen and phosphorus loads for all scenarios at Otago 163

Table 6.12 Results of management factor scenarios on the hypothetical farm 164

Table 6.13 Results of environmental factor scenarios on the hypothetical farm ........ 166

Table 7.1 Sensitivity of the case study sites to soil and elevation datasets 169 


\section{LIST OF EQUATIONS}

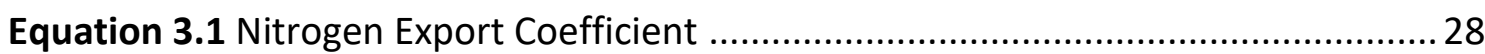

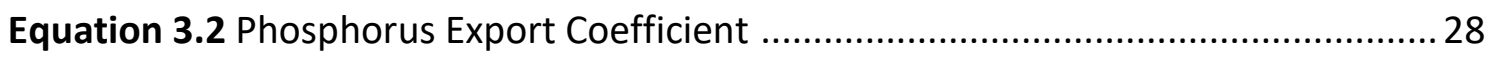

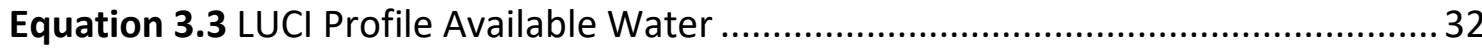

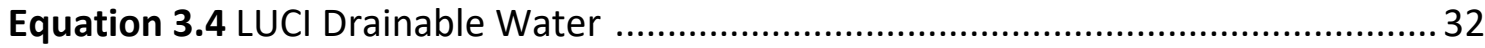

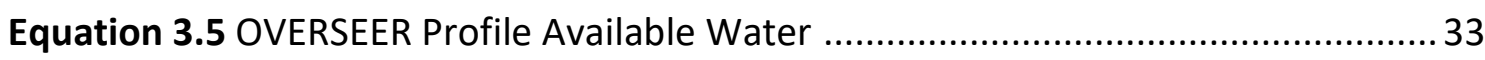

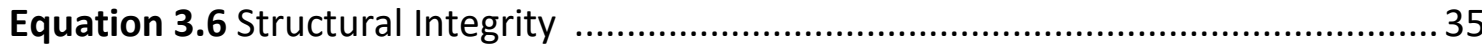

Equation 5.1 Total Nutrient Load from S-Map scenarios ...........................................95

Equation 5.2 Weighted Average of Sibling Properties ............................................. 97 


\section{LIST OF ACRONYMS}

ASC- Anion Storage Capacity

CLUES- Catchment Land Use for Environmental Sustainability

DEM- Digital Elevation Model

DRP- Dissolved Reactive Phosphorus

DTM- Digital Terrain Model

DW- Drainable Water

ePTFs- Ensemble Pedotransfer Functions

FAO- Food and Agricultural Organisation

FC- Field Capacity

FLRC- Fertiliser and Lime Research Centre

FSL- Fundamental Soil Layer

GIS- Geographic Information Systems

GPS- Global Positioning System

Hydtopo- LUCI Hydrology Folder

IDW- Inverse Distance Weighting

LCDB4- Land Cover Database version 4

LiDAR- Light Detecting and Ranging

LINZ- Land Information New Zealand

LRIS- Land Resource Information System

LSD- LUCI Soil Depth

LUCl- Land Utilisation Capability Indicator

LUDF- Lincoln University Dairy Farm

LUNZ- Land Use New Zealand 
LUS- Land Use Suitability Concept

MEA- Millennium Ecosystem Assessment

NIWA- National Institute of Waster and Atmospheric Research

NPS-FM- National Policy Statement on Fresh Water Management

NSD- National Soil Database

NZGS- New Zealand Genetic Soil Classification

NZLRI- New Zealand Land Resource Inventory

NZSC- New Zealand Soil Classification

PAW- Profile Available Water

PTFs- Pedotransfer Functions

RMA- Resource Management Act

RSU- Relative Stock Unit

SIDDC- South Island Dairying Development Centre

SV- Structural Vulnerability

TAW- Total Available Water

WP- Wilting Point 


\section{CHAPTER 1 INTRODUCTION}

The connection between agricultural activities and water quality degradation is not new, with many studies identifying forms of diffuse pollution such as nitrogen, phosphorus, and sediment emitted by intensive agriculture. While the quantities of nutrients lost from agriculture are not large compared to the total nutrient amounts residing in the soil-plant-animal system, the transfer of nutrients from agricultural land to water still causes significant environmental impact (Monaghan et al., 2007). The intensification of agriculture over the last few decades has exacerbated water quality issues and degraded the health of ecosystems, with associated loss of biodiversity and the resilience of habitats occurring at an unprecedented scale (Tscharntke et al., 2005).

Issues of water quality degradation are important in New Zealand as our national economy is reliant on natural resources. The environmentally-based sectors of agriculture, horticulture, viticulture, forestry, and fisheries were responsible for $78.7 \%$ of the income generated from New Zealand's top 20 commodity exports in 2013 (Roberts et al., 2015). Efforts to improve water quality are important, as these industries rely on a functioning ecosystem for the production of goods and to reduce the impact of production (Roberts et al., 2015).

Since agriculture is New Zealand's largest export earner and the dairy industry is its largest component, the ongoing intensification of the dairy sector is a cause for environmental concern. Dairying provides $37 \%$ of New Zealand's total primary industry export value, contributing NZ\$13.2 billion to the economy over 2014/15 period (DairyNZ, 2015).

New Zealand's 'clean green' image plays an important role in the marketing of agricultural products, so any degradation of the natural environment, or in the environmental perceptions consumers have of New Zealand will dramatically affect the export economy. Therefore, it is important that New Zealand's environmental image is maintained. The impact that perceptions of poor water quality could have on 
the economy was highlighted by the Ministry for the Environment (2001) study, which analysed the impact negative environmental perceptions in the Asian market would have on the New Zealand's dairy sector. The study found that $54 \%$ fewer dairy products would be purchased if the environment was perceived to be degraded, amounting to an annual loss of NZ\$241-569 million (Ministry for the Environment, 2001).

While globally New Zealand's river quality is classed as fairly good compared with Europe, North America and Asia, over the past 25 years the health of New Zealand rivers has declined due to the prevalence of both point source and diffuse pollution in catchments (Davies-Colley, 2013). While there have been improvements to our management of point source pollution through the treatment of wastewater from urban and industrial settings, there has been an increase in diffuse pollution that can be linked to the intensification of agriculture (Davies-Colley, 2013). Specifically, diffuse pollution from agriculture is responsible for increased fine sediment load, faecal contamination and nutrient enrichment of New Zealand's lakes and rivers (DaviesColley, 2013).

\subsection{MODELLING NUTRIENT FLOWS ON AGRICULTURAL LAND USING THE LAND UTILISATION CAPABILITY INDICATOR}

With increasing attention on more sustainable land-use practices and mitigating the impact of agricultural intensification on the environment, decision support tools like the Land Utilisation Capability Indicator (LUCI) are well suited to aid agricultural management, at both small and large scales (Trodahl et al., 2017). The collaboration between Victoria University of Wellington and Ravensdown, a farmer owned cooperative, has resulted in the development of a bespoke version of LUCI for use by Ravensdown Environmental consultants. The results of this thesis feed directly into this collaboration, through understanding how LUCI predictions can be used in areas that may be data poor, or areas where there is other uncertainty in the input data.

The nitrogen and phosphorus loads in the version of LUCI used by Ravensdown are trained to data from the well-established OVERSEER model. The OVERSEER model was 
originally developed by the Ministry of Primary Industries, the Fertiliser Association of NZ Inc, and AgResearch to advise farmers and growers on their on-farm nutrient management practices and model nutrient flows onto and off farms (OVERSEER, 2017). Most relevant to this research is OVERSEER's modelled flow of nitrogen and phosphorus. However, it is increasingly used by regional councils to quantify diffuse pollution at the farm level as a basis for nutrient regulations and discharge policies (Journeaux, 2016). Both OVERSEER and LUCI are discussed in detail in the following chapters.

LUCI is a GIS-based (Geographical Information Systems) framework that explores land management scenarios to identify locations where changes in land use might deliver improvements in ecosystem services, or where trade-offs between services are present (Sharps et al., 2017). Ecosystem services are defined in this research as the benefits people gain from an ecosystem (MEA, 2005). The trade-off maps produced by LUCI provide valuable information on where to target mitigation strategies or alter the current farm management practices, such as identifying areas where farmers can target efforts to improve water quality without impacting agricultural production (Trodahl et al., 2017).

The algorithms in $\mathrm{LUCl}$ explore the impacts of land management changes on flood risk, habitat connectivity, erosion and sedimentation, carbon sequestration and agricultural productivity, making it a useful tool to respond to the growing concern surrounding freshwater quality in New Zealand. This research is focused on LUCl's ability to model and track the flow of nitrogen, phosphorus, and sediment across the landscape to waterways. To achieve this, LUCl's representation of landscape hydrology is investigated as water is a key pathway of nutrient movement. More information on LUCl's other tools can be found in Jackson et al. (2013).

Decision support tools that represent the complex relationships between ecosystem services are gaining interest and popularity, as the New Zealand government is moving towards a natural capital approach to managing the country's resources. This paradigm shift in resource management practices is linked to the understanding that an ecosystem services approach provides an integrative way to explore the influence of 
land use and land management practices on natural capital, and the processes that protect and degrade the natural environment (Dominati, 2013).

Models such as LUCI rely on fine spatial scale data to produce high-resolution outputs. The level of accuracy and uncertainty in soil, elevation, climate and land use datasets are known to influence the output of such decision support tools (Trodahl et al., 2017). Understanding the quantitative differences in predictions that arise from the sensitivity of LUCI to different datasets, with varying precision and accuracy, will provide valuable information to model developers, industry specialists and end users. In locations where data is identified as being of poor quality, model users need to increase local stakeholder engagement. Engagement throughout the modelling process will reduce the inaccuracies or generalisations in the low-resolution data, as stakeholders have the best understanding and experience of their surroundings.

Though this thesis is primarily focused on improving freshwater quality through the accurate modelling of nitrogen, phosphorus and sediment movement on farms, understanding the sensitivity of LUCI to the data used in New Zealand will also inform the reliability of LUCI to model other ecosystem services. Understanding the reliability of results will aid the development of $\mathrm{LUCl}$ as a forefront decision support tool, capable of representing the complex interactions between ecosystem services and environmental degradation.

\subsection{AIMS AND OBJECTIVES}

The aim of this research is to examine how the changing quality and resolution of New Zealand's soil, elevation, and landcover datasets impacts the uncertainty in LUCl's output. This aim was accomplished through investigating the sensitivity of the LUCI model to various input datasets with different spatial resolution and detail. Where observational data was available, the LUCI model outputs were compared to actual water quality measurements. Determining the sensitivity of the LUCI model to these datasets provides insight into how robust LUCl's predictions of nitrogen and phosphorus loads entering waterways may be in different regions around New Zealand. 
The objectives to achieve the aim stated above are:

Objective 1: To conduct a review of available soil, topography and landcover datasets that can be used in the LUCI model.

The activities required to achieve Objective 1 are firstly, the identification of drivers of poor water quality in New Zealand and how the LUCI model can improve our understanding of nutrient flows within a farm system. Secondly, the availability of different soil, elevation and landcover datasets and their uncertainties are discussed in relation to their potential application to the LUCI model.

Objective 2: To compare LUCl's Nitrogen to Water and Phosphorus to Water tools for sites covering a variety of climates, topography and rich or poor data environments.

The activities required to achieve Objective 2 are firstly, the identification of six case study sites located in both the North and South Island spanning a variety of climates and agricultural management environments. Secondly, model applications at each site included at least two soil or elevation datasets. This comparison enabled the uncertainties and sensitivities in the model output to be analysed.

Objective 3: To explore whether available datasets are appropriate for accurate model outputs, and how LUCI can be adapted to better use these datasets for improved accuracy where appropriate.

The activities required to achieve Objective 3 are firstly, the comparison of model applications to measured data where available, and secondly, to suggest modifications to LUCl's algorithms to enhance accuracy where detail in the datasets is not fully utilised in the model.

\subsection{THESIS STRUCTURE}

This thesis contains eight chapters. Following this introduction, Chapter $\mathbf{2}$ describes the concept of ecosystem services and the health of New Zealand's freshwater, with a description of the nitrogen and phosphorus cycle and how agricultural practices impact water quality. 
Chapter 3 introduces $\mathrm{LUCl}$ and OVERSEER and how these models can be used to inform decision-making, as well as the relevant equations within each model that determine their representation of soil water dynamics.

Chapter 4 provides an overview of available soil and topographic datasets in New Zealand. The development, limitations and opportunities to improve these datasets are discussed.

Chapter $\mathbf{5}$ describes the research methodology. Data for all six case study sites are presented, as well as the modelling procedure required to produce results from LUCI's Nitrogen to Water and Phosphorus to Water tools. A description of the hypothetical cropping farm setup for this theses' OVERSEER sensitivity analysis is also presented.

Chapter 6 reports the outputs and results for all scenarios tested on the six case study sites. The hydrological output from $\mathrm{LUCl}$ and predicted nutrient load results are detailed, with validation against measured in-stream concentrations for two of the sites. Results produced after LUCI was developed to incorporate sibling level soil information is provided.

Chapter 7 discusses the sensitivity of LUCI to soil properties and the resolution of the DEM used in the modelling process. Sensitivity to landcover data is highlighted, as well as the reliability of $\mathrm{LUCl}$ outputs compared to in-stream measurements.

Chapter 8 concludes this research, and addresses the findings based on each research objective. Key considerations for future applications of the LUCI model and opportunities for development are summarised. 


\section{CHAPTER 2 ECOSYSTEM SERVICES AND WATER QUALITY}

Increasing public awareness of the range of services ecosystems provide encourages responsible resource use. This notion is not new and can be traced back to the $1860 \mathrm{~s}$ with the publication of Man and Nature, in which Marsh (1864) discredits the notion that the Earth's resources are infinite. This chapter outlines the ecosystem services concept, how it can be applied to decision-making, and the 'disservice' agricultural management practices can have on the environment. Next, the health of freshwater quality in New Zealand is discussed, including the regulatory framework in place to control activities and minimise degradation. An overview of the cycling of nitrogen and phosphorus as well as a more detailed description of the environmental impacts of agriculture is provided.

\subsection{DEFINING THE ECOSYSTEM SERVICES CONCEPT}

The understanding that the biotic community and the abiotic environment are intrinsically linked to world economies and food chains has been developed by numerous authors. These contributions to our modern understanding of ecosystem services are summarised in Mooney and Ehrlich (1997). Key published works identified were Lindeman (1942), Vogt (1948) and Leopold (1949). These authors discussed ideas surrounding how the ecosystem is the fundamental ecological unit on which natural relationships depend; the concept of natural capital; and the inability of humans to create a substitute for ecosystem services, ensuring that our role on earth is selfdefeating (Mooney \& Ehrlich, 1997).

It was not until a few decades later that the services an ecosystem provides were explicitly linked to ecosystem function. The Study of Critical Environmental Problems (1970) report Man's Impact on the Environment identified the ecosystem services that would decline if ecosystem function was impacted through loss of biodiversity or other catastrophic changes to the environment. The ecosystem services identified were soil formation, soil retention, cycling of matter, climate regulation, flood control, pest 
control, fisheries, insect pollination and composition of the atmosphere. This list was expanded four years later to include maintenance of soil fertility and maintenance of a genetic library (Mooney \& Ehrlich, 1997).

With the continued challenge of feeding the population sustainably, global food supply needs to be understood as food losses and waste impact other natural resources, such as freshwater, available land for cropping, and fertilisers containing finite natural resources (Kummu et al., 2012). Since the world population is projected to increase by more than a billion people within the next 15 years, reaching 9.7 billion by 2050 and 11.2 billion by 2100 , food production must increase to sustain this growth (United Nations Population Division, 2015). The Food and Agriculture Organization of the United Nations (FAO), predicted that to meet food demand by 2050 , global food production will have to increase by $60 \%$ from $2005-2007$ levels (FAO, 2014). The report goes on to stipulate that the ecosystems needed to produce extra food are already showing signs of stress and degradation.

The latest FAO report recognises not only the importance of healthy ecosystems in food production but also their ability to help mitigate the rise in atmospheric carbon dioxide $\left(\mathrm{CO}_{2}\right)(\mathrm{FAO}, 2016)$. Soils are identified as playing a pivotal role in regulating the emission of $\mathrm{CO}_{2}$ but improving soil quality and the environment through adaptation measures such as reducing deforestation and forest degradation, comes at a cost to the agricultural sector (FAO, 2016). Therefore, it is important to understand trade-offs between ecosystem services, particularly within the agricultural sector, as adaptation and mitigation strategies and outcomes are interlinked.

The complex interaction between agriculture and ecosystem services is represented in Figure 2.1. Since agricultural systems cover $40 \%$ of the terrestrial Earth surface, it is important that landscape management practices are understood by how they impact ecosystem services (Power, 2010). In the past, agriculture was seen as a practice that enhances ecosystem services through the provision of food, forage, bioenergy, and pharmaceuticals. However, management practices can result in 'disservices' to the environment, including loss of habitat for biodiversity; nutrient runoff; sedimentation, and pesticide poisoning (Power, 2010; Zhang et al., 2007). The list of services shaded in 
green in Figure 2.1 indicate ecosystem processes that provide services to both the natural environment and agricultural systems (Power, 2010).

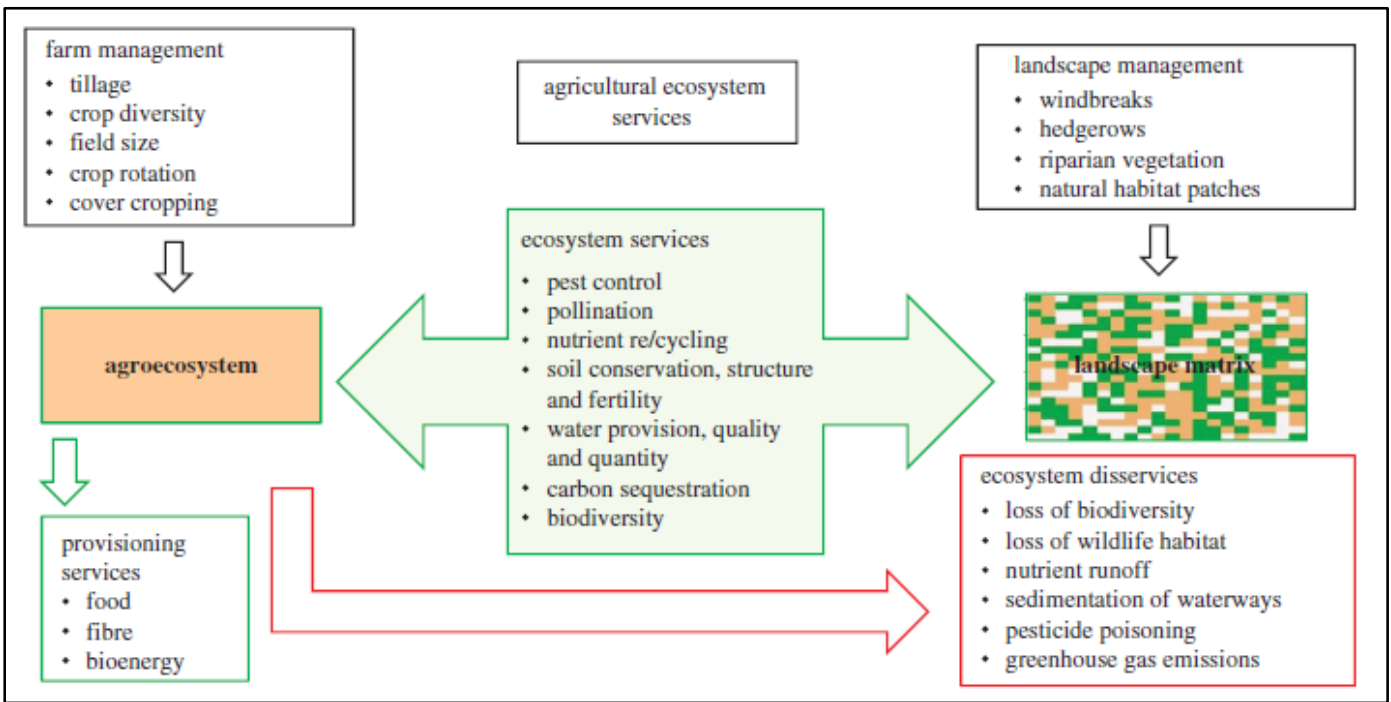

Figure 2.1 Interactions of farm management and landscape management practices on the flow of ecosystem services and disservices. Source: Power (2010).

\subsubsection{Applying the Ecosystem Services Concept in Decision-making}

Not only is it important for decision-makers to understand the interactions between natural processes and the services they provide, but they should also be able to identify and involve those who should be part of the evaluation processes (Wallace, 2007). Models like LUCI provide new approaches for integrating ecosystem services into public and private sector decision-making, as they are designed to be generalisable to any location (Bagstad et al., 2013). The development of intuitive tools that decision-makers can use with relatively little guidance is important, as technical knowledge is not the only way of achieving optimal ecosystem outcomes. Therefore, the decision-makers level of prior knowledge should not influence the usefulness of the tools, as long as they are well-documented and tested before use (Bagstad et al., 2013; Breure et al., 2012). 


\subsection{THE HEALTH OF THE NEW ZEALAND ENVIRONMENT}

With the intensification and expansion of dairy production over the past two decades requiring external inputs such as fertiliser, irrigation and food supplements to enable the higher stocking rates and production increases, negative environmental effects are occurring that are external to the farm system (Foote et al., 2015). Productivity per animal has increased dramatically in pastoral sectors such as sheep and beef farming, with lamb production and performance increasing $104 \%$ and $34 \%$ respectively since 1990 (Table 2.1). Wool production was the only commodity to decrease during this period. This increase in productivity is also seen in the dairy sector, with the amount of agricultural land used for dairying increasing 46\% from 1993 to 2012 (Foote et al., 2015). Dairy cattle numbers have also increased $29.8 \%$ since 2002, from 5.2 million to 6.7 million in 2014 (Statistics New Zealand, 2013). Agriculture is reliant on freshwater to maintain high levels of production; however, the discharge or unintended loss of pollutants into waterways and the removal of water from natural systems for irrigation, are the largest threats to the long-term health of freshwater resources (Ministry for the Environment, 2016).

Table 2.1 Livestock productivity trends from 1990 to 2017. Source: Beef and Lamb New Zealand (2018).

\begin{tabular}{|l|r|r|r|r|}
\hline & Unit & $\mathbf{1 9 9 0 - 9 1}$ & $\mathbf{2 0 1 6 - 1 7}$ & change \\
\hline $\begin{array}{l}\text { Lambing } \\
\text { performance }\end{array}$ & $\begin{array}{r}\text { Lambs/100 } \\
\text { ewes }\end{array}$ & 102 & 126 & +25 \\
\hline Lamb weight & $\mathrm{Kg} / \mathrm{head}$ & 13.9 & 18.6 & $+34 \%$ \\
\hline $\begin{array}{l}\text { Lamb } \\
\text { production }\end{array}$ & $\mathrm{Kg} / \mathrm{ewe}$ & 9.8 & 20.0 & $+104 \%$ \\
\hline $\begin{array}{l}\text { Wool } \\
\text { production }\end{array}$ & $\mathrm{Kg} / \mathrm{head}$ & 5.3 & 5.0 & $-6 \%$ \\
\hline Steer weight & $\mathrm{Kg} / \mathrm{head}$ & 297 & 314 & $+6 \%$ \\
\hline Milk production & $\mathrm{kgMS} / \mathrm{cow}$ & 330 & 381 & $+15 \%$ \\
\hline
\end{tabular}

\subsubsection{Freshwater Quality}

New Zealand's freshwater is recognised internationally for its recreational value and support of a healthy array of flora and fauna. With over 425,000 kilometres of rivers and streams and around 4000 lakes, New Zealand has enough water resources overall to sustain the population (Ballantine \& Davies-Colley, 2014). Issues with inadequate 
supply are therefore linked to the discrepancies in rainfall and demand between regions. Further pressure on water resources through changing land use and population growth will enhance these discrepancies (Ministry for the Environment, 2016).

\section{Legislative and Regulatory Framework}

Legislation sets out the standard for water quality in New Zealand. At the centre of efforts to combat degradation of this natural resource is the Resource Management Act 1991 (RMA), which devolved much of the responsibility of water quality management to the regions. The regions are responsible for ensuring water quality is above a strict minimum standard set in Section 70 of the RMA (FLRC, 2016). The Land and Water Forum was established in 2009 , to advise government on long-term improvements to freshwater management in New Zealand, via stakeholder-led collaboration groups with a vested interest in the health of our freshwater (Ministry for the Environment, 2016). The participants of the Land and Water Forum include industry groups, environmental and recreational NGOs, iwi and scientists (Land and Water Forum, 2017). This group is also joined by observers from local and central government (Land and Water Forum, 2017).

The Ministry for Primary Industries and the Ministry for the Environment co-led the development of the National Policy Statement for Freshwater Management (NPS-FM) in 2011. The NPS-FM directs local governments on how they should manage freshwater sustainably in accordance with their responsibilities set out in the RMA (Ministry for the Environment, 2016). The requirements within this policy statement include but are not limited to: placing a restriction on the discharge of contaminants into streams; setting a minimum acceptable standard for the region through public consultation on the 'use' of the body of water, and regional councils must at least maintain the current state of water quality in their region in cases where it cannot be improved (FLRC, 2016). 


\subsubsection{Cycling of Nitrogen and Phosphorus}

The loss of nitrogen and phosphorus to waterways is a significant driver of water quality degradation. It is important that farmers and those responsible for recommending nutrient inputs to agricultural systems are aware of the different forms, pathways, and stocks of nutrients in the environment (FLRC, 2016). Today, farmers are under pressure to improve nutrient management (especially nitrogen and phosphorus), as target leaching limits may be imposed in large agricultural areas such as Canterbury (Qiu et al., 2016). Landscape variability in such soil properties as clay percentage, cation and anion exchange capacities and water holding capacity, complicate the pattern of nutrient cycling within a farm system. Thus, understanding how to maximise plant uptake of nutrients is vital if nutrient losses to water are to be reduced (Qiu et al., 2016).

\section{The Nitrogen Cycle}

Nitrogen is often a major limit on plant production, as it is an essential component of amino acids and proteins. Therefore, during the growing season, large amounts of nitrogen (200-800 kg N/ha) are taken up by plants (McLaren \& Cameron, 1996). Very little of the total nitrogen present in the earth system is available to plants as around $98 \%$ of nitrogen in the soil is in a water-insoluble, organic form, with only a small amount present in ionic forms in soil solution, or sorbed onto soil particles (McLaren \& Cameron, 1996). Nitrogen gas $\left(\mathrm{N}_{2}\right)$ starts the cycle when it is fixed into plant available forms, ammonium $\left(\mathrm{NH}_{4}{ }^{+}\right)$and nitrate $\left(\mathrm{NO}_{3}{ }^{-}\right)$, ultimately this nitrogen is returned to the atmosphere as $\mathrm{N}_{2}$ (Sustainable Agriculture and Education, 2012).

The nitrogen cycle is shown in Figure 2.2. Under normal conditions, nitrogen in the soil comprises only $2-3 \% \mathrm{NH}_{4}{ }^{+}$and $\mathrm{NO}_{3}{ }^{-}$. Because of this, soil organic nitrogen must be continually decomposed and converted to replenish these ions (FLRC, 2016). The ratio of $\mathrm{NH}_{4}{ }^{+}$and $\mathrm{NO}_{3}{ }^{-}$uptake by plants depends on the temperature and moisture conditions of the soil. Nitrogen is decomposed to $\mathrm{NH}_{4}{ }^{+}$through a process termed ammonification, and the $\mathrm{NH}_{4}{ }^{+}$is then nitrified into $\mathrm{NO}_{3}{ }^{-}$in the presence of oxygen (McLaren \& Cameron, 1996). In aerobic, warm and moist conditions, quantities of $\mathrm{NO}_{3}{ }^{-}$ are higher than $\mathrm{NH}_{4}{ }^{+}$compared to acidic, cold and wet soils, where the nitrification 
rate is slow, and $\mathrm{NH}_{4}{ }^{+}$is the main source of plant available nitrogen (Groffman \& RosiMarshall, 2012).

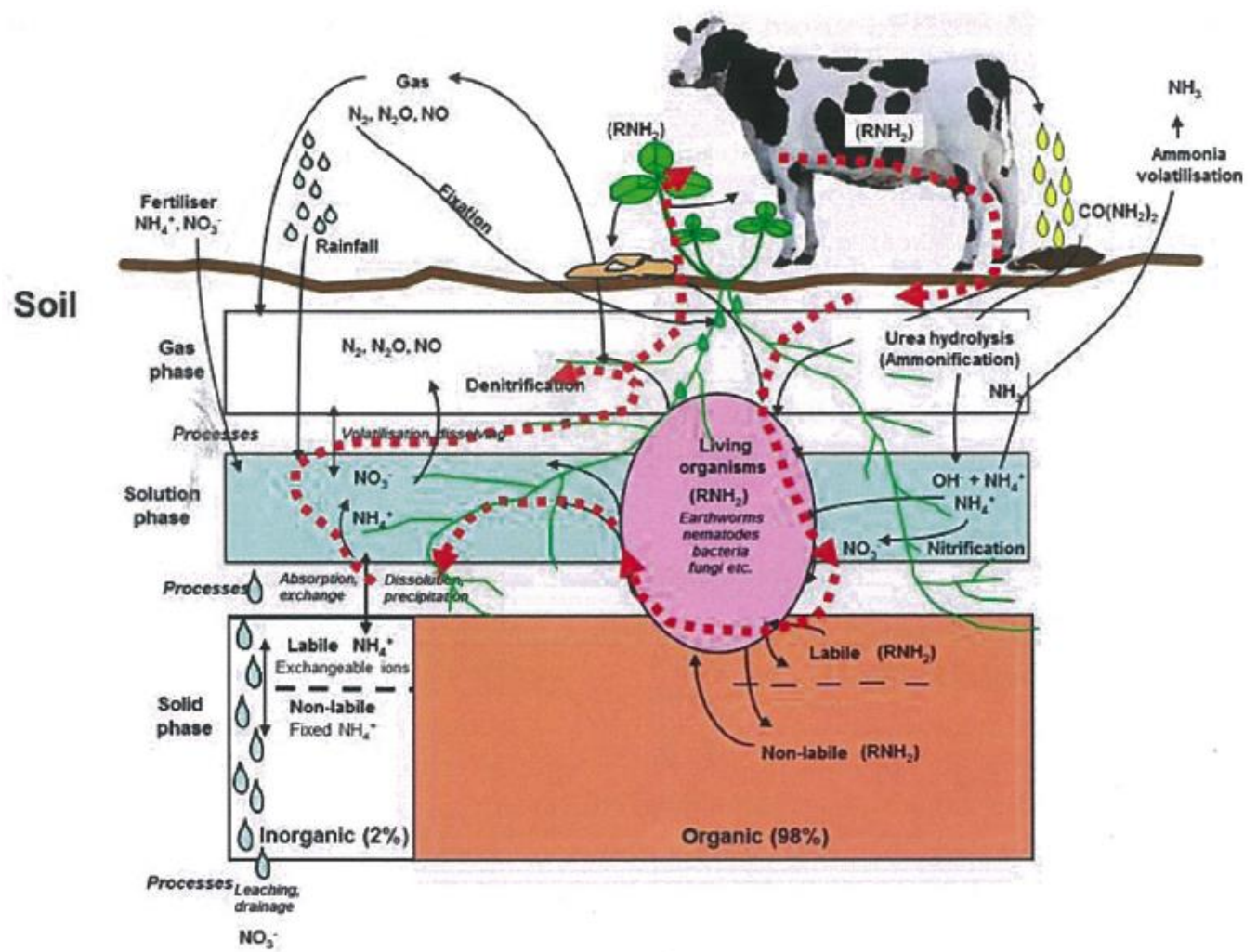

Figure 2.2 The Nitrogen Cycle (R represents an organic molecule). Source: FLRC (2016).

Both available forms of nitrogen can be leached from the soil. $\mathrm{NH}_{4}{ }^{+}$leaches less readily, as it is attracted to the negatively charged soil particles. In contrast, $\mathrm{NO}_{3}{ }^{-}$due to its negative charge is repelled by cation exchange sites, and therefore leaches when water drains through the soil profile (McLaren \& Cameron, 1996).

Nitrogen can also be added to soils through biological fixation by legumes (e.g. white clover). This method of nitrogen fixation provides a renewable source of nitrogen, which over recent decades, has been promoted as a sustainable way of reducing nitrogen fertiliser input (Sulieman \& Tran, 2015). Legumes have a symbiotic relationship with rhizobia bacteria in their root nodules, allowing the biological fixation of $\mathrm{N}_{2}$. Legumes are capable of fixing between $200-600 \mathrm{~kg} \mathrm{~N} / \mathrm{ha} / \mathrm{yr}$ depending on the topography and fertility of the landscape (Sulieman \& Tran, 2015). In clover pasture systems, when the organic nitrogen content of the soil increases, the biological fixation rate decreases. This is a result of decreased legume population over time, due to 
competition from non-legume pasture species (FLRC, 2016). Therefore, farmers need to have a maintenance program to maintain pasture legume levels.

\section{The Phosphorus Cycle}

Phosphorus is the second most common nutrient that limits primary production in terrestrial and aquatic systems. Like nitrogen, amounts available in the soil for plant uptake are often not enough to sustain high agricultural production. To minimise this deficit, additional phosphorus is supplied to the soil through fertiliser applications. Unlike nitrogen which is replenished through an atmospheric component, the supply of phosphorus to the soil occurs over geological timescales through weathering, deposition in the ocean, uplift and erosion (Figure 2.3). On a shorter timescale, plantavailable phosphorus cycles into and out of soil solution through adsorption and desorption on soil particles (Figure 2.4) (Ruttenberg, 2003).

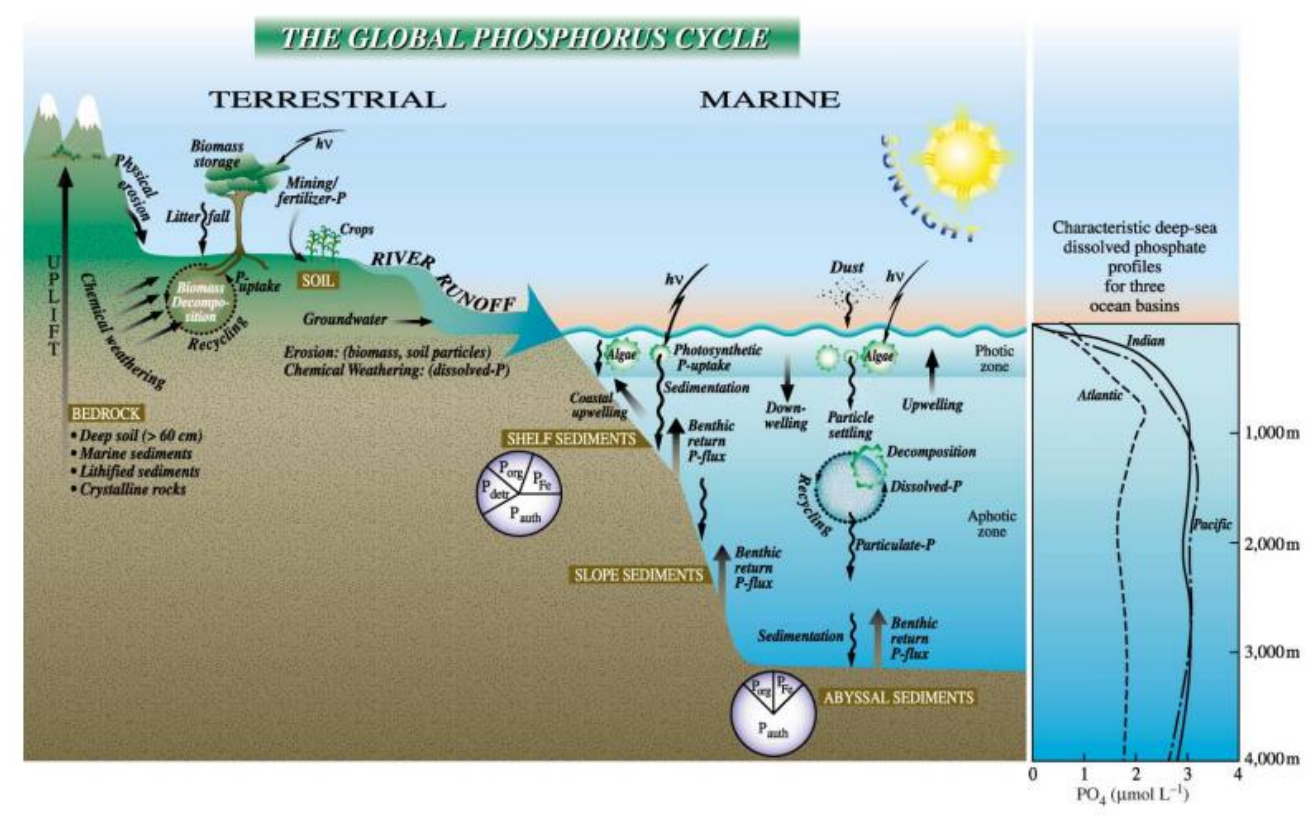

Figure 2.3 The Global Phosphorus Cycle. Source: Ruttenberg (2003). 


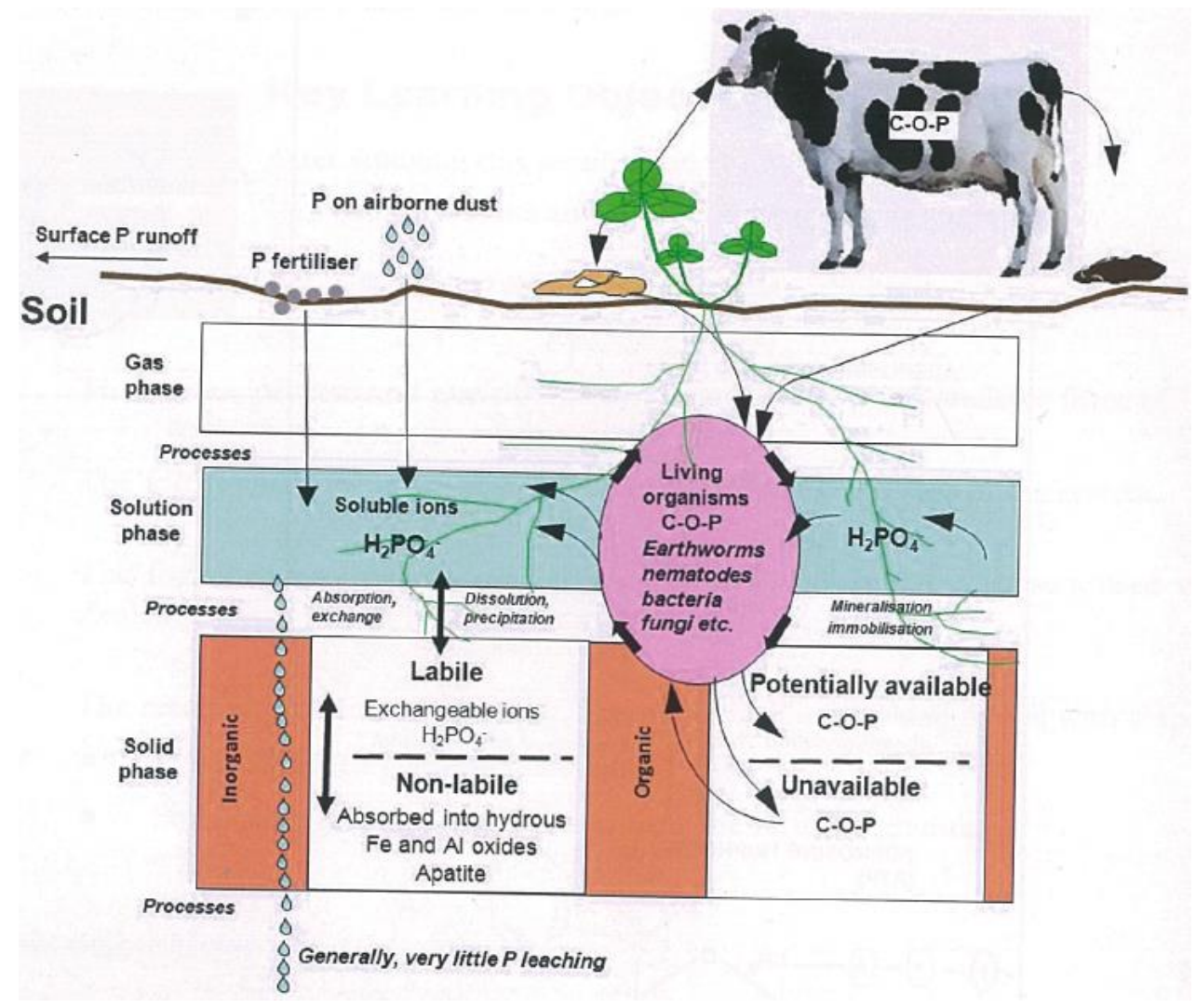

Figure 2.4 The Phosphorus Cycle. Source: FLRC (2016).

When a plant takes up phosphate ions, the concentration of these ions in soil solution drops. The drop in concentration then leads to a flow of ions, either through the movement of soil solution when plants take up water, or diffusion, from areas of high concentration away from the root surface, to areas of low concentration at the root surface (McLaren \& Cameron, 1996). Phosphorus can be added to the soil (through fertiliser, effluent, imported feed, and animal excrement) to increase soil reserves. These reserves are termed as labile (plant available) and non-labile (FLRC, 2016). The relative size of labile and non-labile pools of phosphorus depends on the soil's ability to adsorb ions, owing to the presence of $\mathrm{Al}$ and Fe oxides which vary with soil type (FLRC, 2016).

As phosphorus is mainly lost from soils via runoff and erosion, the 'P retention', also known as Anion Storage Capacity (ASC) of a soil is a key control of phosphorus loss from a farm system (Sustainable Agriculture and Education, 2012). Phosphorus loss to water is dependent on factors which influence erosion, such as meteorological and 
hydrological events, topography and land cover (Sustainable Agriculture and Education, 2012).

\section{Managing Nitrogen and Phosphorus Loss}

Incorrect timing and rate of fertiliser applications in high rainfall (high risk), winter months result in negative environmental effects from increased concentrations of nitrates in groundwater or nitrate and phosphorus enrichment of surface water (Fertiliser Association of New Zealand, 2009). The relative difference in the pathways of nitrogen and phosphorus loss is shown in Figure 2.5 below. To reduce levels of nitrogen and phosphorus in water, farmers are encouraged to use 'good management practices'. Good management practices include: applying fertiliser in smaller, more frequent applications; avoiding fertiliser applications in heavy rain or on waterlogged soils, or, when wind could carry particles to waterways, and restraint in applying fertiliser (particularly phosphorus) near stream boundaries (Fertiliser Association of New Zealand, 2009).
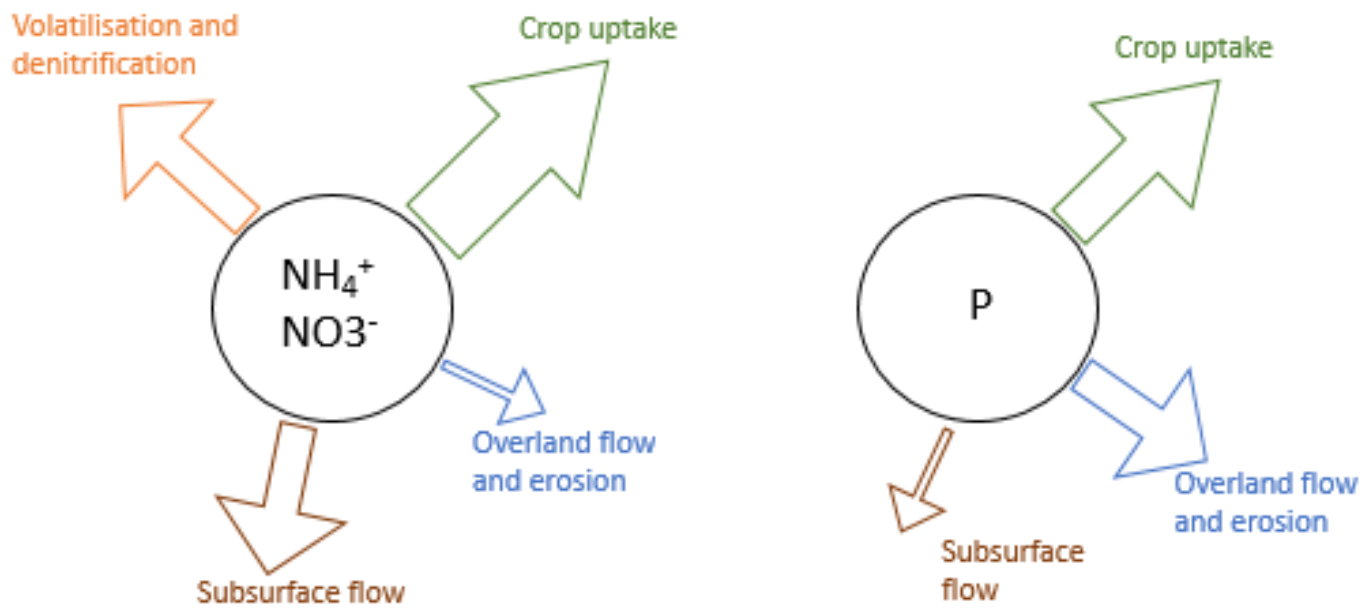

Figure 2.5 Different pathways of nitrogen and phosphorus losses (relative amounts indicated by arrow width). Adapted from Sustainable Agriculture and Education (2012).

\section{Impact of Nitrogen and Phosphorus Contamination from Agriculture}

Given that $46 \%$ of New Zealand rivers run through agricultural land, diffuse pollution from agricultural systems is a major risk to the health of our waterways (Ministry for 
the Environment, 2016). This diffuse (or non-point source) pollution has significant costs to society, as it necessitates the removal of pollutants from drinking water, damages ecosystems and commercial fishing, and degrades the recreational and cultural values associated with rivers, lakes, and groundwater (Parris, 2011).

Increased concentrations of nitrogen and phosphorus in rivers, due to surface and subsurface runoff from agricultural systems, can accelerate eutrophication through 'over fertilisation' of aquatic plants, resulting in excessive plant growth and a reduction in dissolved oxygen levels (Figure 2.6) (Vadas et al., 2015). Monitoring data shows, both at a national and regional scale, that non-point source pollution exceeds point source pollution. This is particularly apparent in Waikato, Southland and Canterbury (Controller and Auditor-General, 2011). This pattern in non-point source pollution is seen in the Waikato between 1992 and 2002, as cow numbers increased 37\%, and during the same period, regional monitoring found a $40 \%$ increase in measured nitrogen and a $25 \%$ increase in measured phosphorus levels (NIWA, 2010, as cited by Controller and Auditor-General, 2011).

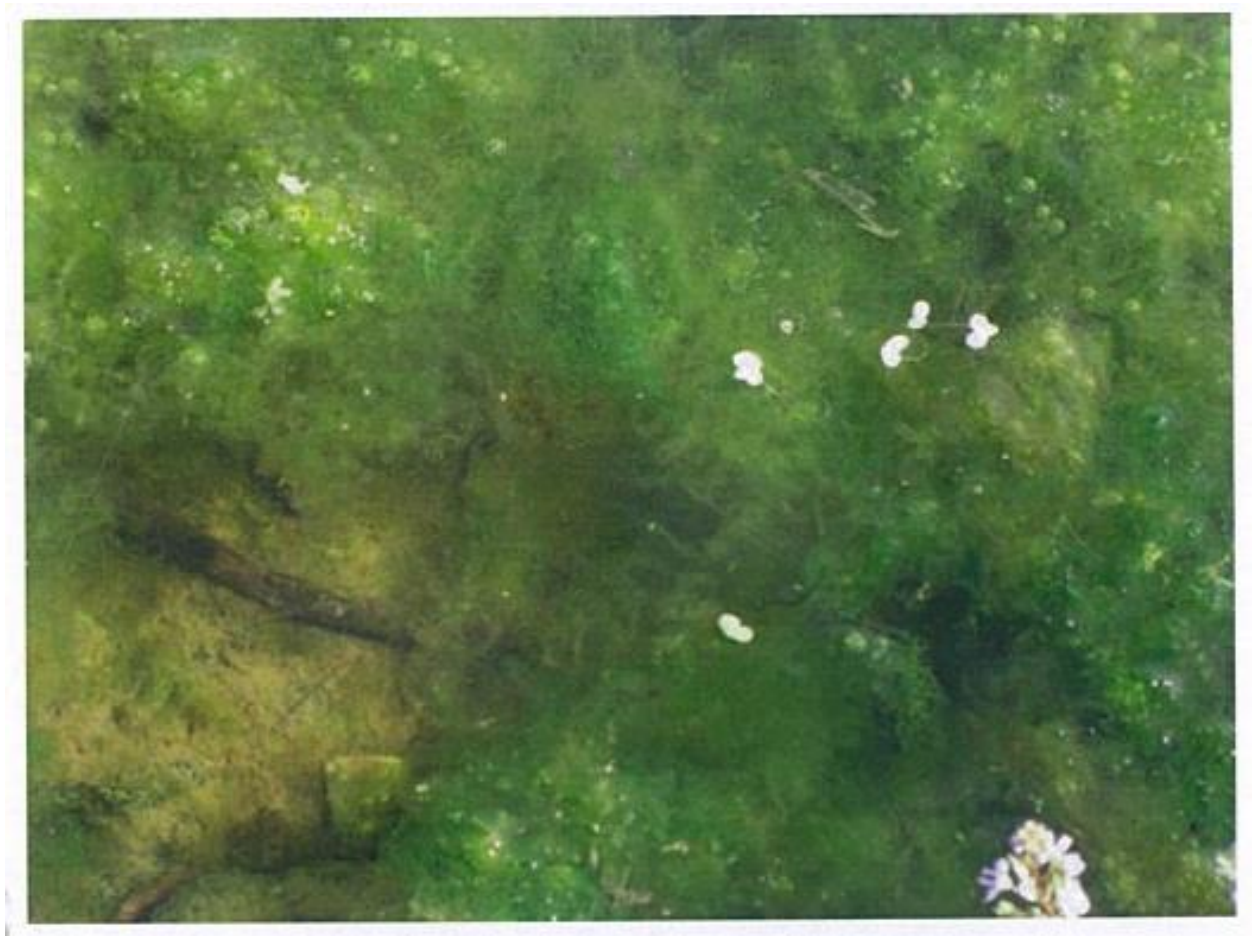

Figure 2.6 Green algae in a stream in the Manawatu catchment. Source: FLRC (2016). 
Eutrophication has impacted lake and stream systems as excess nitrogen and phosphorus promote not only the growth of aquatic plants but also deoxygenation of deeper waters, and stratification within the water column (Abell et al., 2010). Excess plant growth also inhibits natural flow and smothers native plant life, and fish that rely on freshwater systems for food and habitat (Ministry for the Environment, 2016). In 2006, 134 lakes were monitored across New Zealand, 56\% of these were deemed to be in a eutrophic state, with some lakes experiencing major blooms of toxic cyanobacteria (Ministry for the Environment, 2006). A study one year later went on to conclude that $30 \%$ of lakes with an area greater than one hectare have poor to extremely poor water quality as a result of eutrophication (Ministry for the Environment, 2007).

There is a natural accumulation of nutrients over time in freshwater systems, with sources of nitrogen including organic matter from decomposing plants and atmospheric nitrogen fixed by planktonic species in the water column (Abell, et al., 2011). A natural source of phosphorus is through the weathering of apatite minerals (Abell et al., 2011). This natural pattern in the accumulation of nutrients in freshwater ecosystems has been altered by anthropogenic loading of nitrogen and phosphorus, resulting in a shift in ecosystems from their natural state (Paerl, 2009).

The importance of understanding how much nitrogen and phosphorus is lost to freshwater is seen in the Parliamentary Commissioner for the Environment (2012) report, where the concepts of nitrogen-limited and phosphorus-limited systems are discussed. The report identifies the importance of monitoring nitrogen and phosphorus concentrations, and how crucial it is to determine which nutrient is the most effective to target. It is important to identify the limiting nutrient, as for eutrophication to occur there needs to be enough of both nutrients in the right ratio to result in excessive eutrophication (Parliamentary Commissioner for the Environment, 2012).

Moving forward, a report released by the Parliamentary Commissioner for the Environment (2016) states that debates surrounding the impact of farming and pollutants on water quality have died down, with focus shifting to finding solutions. However, while reducing sediment and phosphorus pollution is manageable with on- 
farm changes (e.g. bridging streams and fencing to prevent direct nutrient loss to water), it is much harder to stop nitrogen pollution as it easily leaches, both into surface water and groundwater (Parliamentary Commissioner for the Environment, 2016). Nitrate in groundwater can accumulate over decades, further threatening lake ecosystems, as in many systems this nutrient will continue to enter the lake (impacting water quality) long after the polluting land use has ended (Parliamentary Commissioner for the Environment, 2016).

\subsubsection{Increased Erosion and Sedimentation}

Humans have greatly increased rates of erosion and sedimentation since the transition from hunter-gathers to agrarian societies; now we are arguably the most effective geomorphic agent, able to shape the Earth at a rate that far exceeds the long-term denudation associated with the interaction of climate and tectonic forces (Hooke, 2000). Agriculture is one of the key drivers of erosion related to land use change, as it is responsible for more displacement of sediment than the mining and construction industries (Wilkinson \& McElroy, 2007). The difference between global denudation rates over geologic time and now is that present-day erosion rates are one order of magnitude higher, with geologic rates being tens of metres per million years, and global agriculture today responsible for a rate of hundreds of metres per million years (Cerovski-Darriau \& Roering, 2016). A high rate of erosion is likely to persist after agricultural practices have been halted. On the landscape, past erosion results in a geomorphic legacy, changing the morphology of hillslopes and channels to promote erosion (Cerovski-Darriau \& Roering, 2016).

New Zealand's denudation rate follows a different pattern to the rest of the world as it is naturally unusually high, with New Zealand discharging 1-2\% of the global annual average sediment yields while representing only $0.1 \%$ of the global land mass (Basher, 2013). The high erosion rate is contributed by New Zealand's steep slopes, high rates of tectonic activity, high rainfall, large coastline length to area ratio, and the frequency of high-intensity storms (Basher, 2013). Such high natural erosion rates mask the effect humans have as geomorphic agents, with the pattern further complicated by the different tectonic environments of the North and South Islands. An early study on 
uplift and erosion rates across New Zealand identified that human-accelerated erosion was negligible in the South Island due to the high uplift and erosion rates of the Southern Alps (Adams, 1980). The lower rates of tectonic activity in the North Island combined with the increased impact of human activity through conversion of large areas of forest to agriculture, and the presence of a larger population, makes determining the primary geomorphic agent more difficult (Adams, 1980).

There is pressure on the agricultural industry to take steps to ensure soil conservation is undertaken on pastoral and arable land, with the reestablishment of native habitat through reforestation also promoting carbon cycling and habitat quality (CerovskiDarriau \& Roering, 2016). Therefore, a focus on reducing sediment loading to rivers will not only improve water quality but also have a positive impact on other ecosystem services. Measurements put in place to reduce erosion were estimated in 2001 to have an annual cost of NZ\$24 million, whereas the damage caused by erosion was estimated to be NZ\$ 103 million (Basher, 2013). Soil conservation can reduce the impact of erosion thereby maintaining soil fertility and productivity while also preventing damage to property and ecosystems (Jones et al., 2008). Therefore, maintaining an effective vegetation cover and using land use strategies that result in minimal soil disturbance will help prevent the negative impacts eroded sediment has on the environment. These impacts are outlined below.

\section{$\underline{\text { Impact of Soil Erosion on Agricultural Productivity }}$}

Pasture production levels are often dramatically altered on erosion scars in New Zealand's high country where soil slip erosion is common. One of the first studies into this phenomenon carried out by Trustrum et al. (1984) on Wairarapa hill country, identified that pasture production levels on the younger erosion scars were around $20 \%$ less than uneroded land. As erosion scars are revegetated over time the area never achieves that hillside's original pasture production and instead, on average, eroded slopes result in an overall loss in production of $18 \%$ on the whole hillslope (Trustrum et al., 1984). In Wairoa, pasture recovery after erosion was found to be exponential as ten years after the first slip rapid recovery was measured and over time there was no further increase in production (Douglas \& Trustrum, 1986). 
Not only does soil erosion directly impact pasture productivity but reducing the average soil depth on a slope limits a soil's water holding capacity (Derose et al., 1995). Initially, when only several landslides are present on a slope, the effect on soil water holding capacity will be small. However, over time as the amount of slip scars increase, their cumulative effect will result in pasture productivity being limited due to increased soil moisture deficits between seasons (Derose et al., 1995).

\section{Flooding}

Tollan (2002, as cited in Schilling et al., (2014)) linked the effect of land use change due to agricultural expansion to increased flood severity and frequency within agricultural catchments, contributing this change to reduced infiltration capacity, soil porosity, vegetation cover, and lower evapotranspiration rates. High erosion rates increase the risk of flooding as excess sediment in river systems results in a reduction in channel capacity. A reduced channel capacity increases the risk of flood events breaking river banks and flood protection measures, leading to greater flood damage of the surrounding areas (e.g. farm sedimentation, road damage, bridge collapse and loss of livestock) (Jones et al., 2008).

\section{Water Quality}

Sedimentation affects the chemical, physical, biological and aesthetic characteristics of a water body (Jones et al., 2008). Pollutants (e.g. phosphorus and heavy metals) are bound to soil particles and transported to streams as the landscape is eroded, which changes the natural chemical regime of the water body (Jones et al., 2008). The physical changes associated with sedimentation are increased temperature and decreased visual clarity. Low visual clarity decreases the aesthetics of the water for recreation but also impacts the habitat of aquatic life, through reduced predation efficiency and the build-up of layers of fine sediment (significantly harming benthic habitat as it results in burial and suffocation of benthic biota) (NIWA, 2015). Life in the water column is also impacted as fine suspended sediment damages respiratory structures, through irritation and clogging of the gills of fish (NIWA, 2015). 


\section{CHAPTER 3 WATER QUALITY MODELLING USING LUCI AND OVERSEER}

The above identification of agriculture's effect on water quality and the environment highlights the need for increased understanding of the movement of nitrogen and phosphorus through the landscape. The ecosystem service decision support tools available to farmers and policy makers range in complexity and data input requirements (Bagstad et al., 2013). This chapter describes two such models, LUCI and OVERSEER and how they aid in understanding of the stocks and flows of nutrients in agricultural systems.

\subsection{COMPLEXITIES INVOLVED IN CHOOSING AN APPROPRIATE MODEL}

Ecosystem service models range from spreadsheets, to those that have a mapping component. Spatial mapping ranges from overlays based on lookup tables, to more complex spatial tools that allow quantification and mapping of the relative magnitude of service provisions (LUCl falls into the latter category) (Sharps et al., 2017).

The outputs of ecosystem service models appear to be similar. Nevertheless, when choosing the most appropriate model for your needs Sharps et al. (2017) highlight the importance of evaluating the underlying resolution and assumptions the model was designed for. The need to carefully match a model's function to the decision support activity under assessment is reinforced by the Ferrier et al. (2017) review of scenarios and models of biodiversity and ecosystem services from the IPBES (Intergovernmental Platform for Biodiversity and Ecosystem Services).

Detailed reviews have become the main source of information for users considering the applicability of specific models to their area. Since models are continuously improved, reviews can become quickly become outdated after publication, meaning there is a need for ongoing work to compare ecosystem service models across a range of sites to provide continued support for decision-makers (Sharps et al., 2017). The IPBES review highlighted three key messages surrounding ecosystem service modelling: 
1. Models can contribute significantly to the development of environmental policies.

2. Models need to be applied with care, with the uncertainty in modelled projections being understood by all parties.

3. The need for capacity-building to overcome the challenges in developing and applying ecosystem services models can be met with appropriate planning and investment.

The Ferrier et al. (2017) review described LUCl as a snapshot model which is easy to use and of medium flexibility. Another review was conducted by Bagstad et al. (2013). The authors identified and described many ecosystem service models (including LUCI), with the aim of highlighting their applicability to model multiple ecosystem services and support decision-making in both the public and private sector. Each of the tools reviewed were found to have strengths and weaknesses, with the main determinant of their applicability being the time required to apply the model and the quality of relevant information delivered to the decision-maker (Bagstad et al., 2013).

Not only do decision-makers need to evaluate the tools available to help their understanding of the complexities surrounding ecosystem services and water quality, they must also consider the political and social barriers to enacting water quality and nutrient management policies (Jay, 2007). In New Zealand this can be seen in the pressure on the dairy industry to improve its environmental performance and its associated unwillingness to account for environmental degradation within economic models, owing to a perceived risk to commercial competitiveness in global markets (Jay, 2007). Debate as to how to improve water quality is ongoing, with continual adjustments to the limit setting processes in the NPS-FM likely to incorporate the increased knowledge of the different attenuation factors between contaminants (Tanner et al., 2017).

LUCI and OVERSEER are the two models this thesis focussed on. The primary purpose of this research is to examine how the quality and resolution of New Zealand's soil, elevation, and landcover datasets affect the uncertainty in LUCl's output. LUCI has been trained off a comprehensive OVERSEER database developed by Ravensdown, to 
support the development of LUCI's bespoke functionality, for which Ravensdown Environmental has a period of exclusive commercial use. Understanding how LUCI predictions are impacted by data quality therefore cannot be achieved without also looking at the sensitivity of the OVERSEER model, as LUCI predictions are intrinsically linked to the uncertainties and assumptions of OVERSEER.

\section{$3.2 \mathrm{LUCl}$}

$\mathrm{LUCl}$ is well placed to represent water quality issues in New Zealand. Development of the LUCI model is led by Victoria University, with partners in the agricultural industry and other scientific institutions in New Zealand and overseas (Jackson et al., 2013; Jackson et al., 2016; Emmett et al., 2016; Trodahl et al., 2017). This thesis is not the first application of $L U C I$ to investigate nutrient enrichment from agriculture. One of these applications of LUCI was in the Conwy catchment (Wales), where a reduction in water quality had been observed and was linked to an increase in agricultural production (Emmett et al., 2016). LUCI was used to model multiple ecosystem services within the catchment, to better understand issues of water quality regulation, agricultural production, carbon storage potential, and biodiversity maintenance at the local scale (Emmett et al., 2016).

The tools (sub-models) in the LUCI framework investigate the impact of land use on flood mitigation, water supply, greenhouse gas emissions, biodiversity, erosion, sediment and nutrient delivery to waterways, agricultural production, and quantify trade-offs between such services (Jackson et al., 2016). These tools set LUCl apart from other models, as they can inform policy makers of the cumulative impacts of farm mitigation practices (Jackson et al., 2016).

LUCl can help mitigate nitrogen loading through the identification of nitrogen sources on farms, and targeting pathways through farm systems (pathways identified are where water and nutrients converge on the landscape) (Trodahl et al., 2017). Finding an area to strategically intercept nitrogen, without impacting agricultural productivity, will result in mitigation of all areas of the catchment that meet with the targeted flow path (Trodahl et al., 2017). 
A benefit of using LUCI to model and understand the complex interaction between nutrients, sediment and water quality on a farm system is that it is a spatially explicit (GIS-capable) framework (Jackson et al., 2016). Tools within the framework allow the user to track changes across an entire farm, or within smaller blocks, enabling mitigation strategies to be effectively targeted to improve water quality. $\mathrm{LUCl}$ was recognised, in the Bagstad et al. (2013) evaluation of decision support tools for ecosystem services, as being scalable from landscape to individual sites, assuming there is data available at an adequate resolution for site-scale analysis. $\mathrm{LUCl}$ was the only tool capable of covering multiple scales identified in his review.

The minimum data required for $\mathrm{LUCl}$ is a digital elevation model (DEM) and soil and land cover data (Table 3.1) (Trodahl et al., 2017). These can be sourced from nationally available datasets. The addition of further national or local data along with stakeholder consultation will should improve the accuracy of LUCl's output. This thesis tests the validity of this idea (Figure 3.1). The maps produced by LUCI show areas of the landscape that are currently providing a service, and highlight places where there is significant opportunity to enhance service provision because there is little benefit currently being produced in that area (Jackson et al., 2016).

Soil and elevation datasets used in this sensitivity analysis and their uncertainties are discussed in Chapter 4. Landcover data in the form of the LCDB4 is also compared to OVERSEER farm information for one study site. 
Table 3.1 Minimum data required by LUCI.

\begin{tabular}{|c|c|c|c|}
\hline Data & Period Covered & Resolution & Source \\
\hline National 15m DEM & 2011 & $15 \mathrm{~m} \times 15 \mathrm{~m}$ & http://www.otago.ac.nz \\
\hline Stream network & 2010 & & https://www.niwa.co.nz \\
\hline Rainfall & $1960-2004$ & $1000 \mathrm{~m} \times 1000 \mathrm{~m}$ & Not publicly available \\
\hline Evapotranspiration & $1960-2004$ & $500 \mathrm{~m} \times 500 \mathrm{~m}$ & Not publicly available \\
\hline $\begin{array}{l}\text { Land cover } \\
\text { (LCDB4) }\end{array}$ & $2012 / 13$ & $\begin{array}{l}\text { Designed to a scale of } 1: 50,000 \text { but } \\
\text { variable between regions. }\end{array}$ & https://Iris.scinfo.org.nz \\
\hline NZFSL & Oldest survey dates back to 1960 's. & $\begin{array}{l}\text { Generally, 1:63 } 360 \text { but may be lower } \\
\text { resolution depending on original soil } \\
\text { survey. }\end{array}$ & https://soils.landcareresearch.co.nz \\
\hline S-Map & $\begin{array}{l}\text { Based on same data as FSL and } \\
\text { includes updated soil surveys where } \\
\text { available. }\end{array}$ & $1: 50000$ & https://smap.landcareresearch.co.nz \\
\hline
\end{tabular}




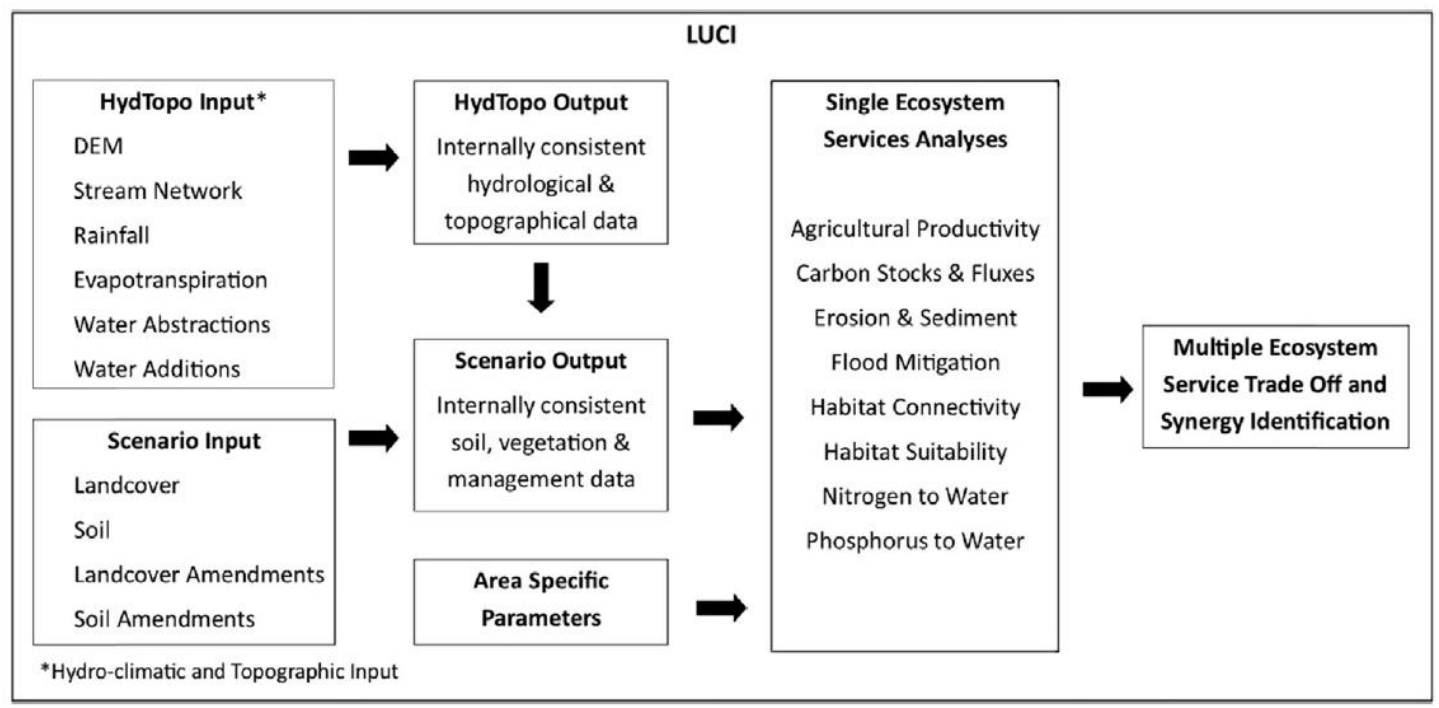

Figure 3.1 LUCI process diagram. Based on Figure 1 in Trodahl et al. (2017).

The LCDB4 is a national thematic classification of New Zealand's landcover containing 33 landcover classes. The classes included in this dataset are urban, rural, wetlands and natural forest catchments. Agriculture is split into four separate landcovers (shortrotation cropland, perennial crops, high-producing grassland and low-producing grassland). These classifications are particularly important when default data is used in LUCl, as discussed for North Canterbury in Chapter 6.

LCDB4 version 4.1 was used in this research; it contains four-time steps (summer 1996/97, summer 2001/02, summer 2008-09 and summer 2012/13) providing the landcover code, and landcover name within a polygon boundary (LRIS, 2018). This dataset was created from SPOT satellite imagery with the polygons digitised directly from the imagery collected or, in some cases, manually digitised (LRIS, 2018).

\subsubsection{Export Coefficients in LUCI}

The Nitrogen to Water and Phosphorus to Water tools in LUCI use an export coefficient approach to model nitrogen and phosphorus lost to water (in $\mathrm{kg} / \mathrm{ha} / \mathrm{yr}$ ). The export coefficient approach describes the rate at which a contaminant is input into a water body per unit of source area. In this case, the unit area is one DEM grid cell (White et al. 2015). These export coefficients are linked to the land cover classification, climate 
and region being modelled, and are commonly used to represent the movement of diffuse pollution in the landscape (Trodahl et al., 2017).

In the LUCI model, spatial data from the DEM and landcover files are used to identify areas where nitrogen and phosphorus losses are caused by a combination of climate and land management variables, after which, export coefficient algorithms (EC) developed by Trodahl (2018) are applied to the data. The algorithms used in this thesis for nitrogen calculations take into consideration rainfall (R), irrigation (I), fertiliser nitrogen (N), effluent nitrogen(EN), and the relative stock unit (RSU). The phosphorus calculations take into consideration rainfall (R), irrigation (I), fertiliser phosphorus (P), effluent phosphorus (EP), Olsen P, and topography (Equations 3.1 and 3.2) (Trodahl, 2018).

$$
N E C_{\text {Pastoral }}=a_{1}(\mathrm{R}+\mathrm{I})^{b 1}+a_{2}(\mathrm{~N}+\mathrm{EN})^{b 2}+a_{3} R S U+c_{1}
$$

Equation 3.1

$$
\begin{gathered}
\text { PEC }_{\text {Pastoral }=}=\left[\left(a_{1} \times S V \times \text { Slope } \times \text { Gravimetric Olsen } P+a_{2} \times D R P\right) \times \max \right. \\
\left(\left[\mathrm{R}+\mathrm{I}-c_{1}\right]^{b 1}, 0\right)+a_{3}(\mathrm{P}+\mathrm{EP})
\end{gathered}
$$

Equation 3.2

The model constants $a x, b x$ and $c$ were derived, for each soil order, from the Ravensdown dataset to minimise the difference between simulated nutrient loss from LUCI and the predicted nutrient loss from OVERSEER (Trodahl, 2018). Structural vulnerability (SV), gravimetric Olsen P and dissolved reactive phosphorus (DRP) were derived from McDowell et al. (2005) and Gray et al. (2016a), with DRP calculated according to the equation described by Wheeler (2016a).

If a farm OVERSEER file is available for the site being modelled in $\mathrm{LUCl}$, the farm data is incorporated by linking the management information held in OVERSEER to a georeferenced block shapefile. This OVERSEER file represents the most accurate representation of the farm system. If an OVERSEER file is not available, LUCI uses regional mean information on rainfall, irrigation, fertiliser, effluent and stocking rate derived from the Ravensdown dataset with Olsen $\mathrm{P}$ set at 25 for all regions. A full 
description of the regional default inputs can be found in Trodahl (2018). Table 3.2 below gives the default values for the regions tested in this study.

\subsection{OVERSEER NUTRIENT BUDGET MODEL}

OVERSEER models pastoral, horticultural, arable and vegetable farm systems and considers seven nutrients in its nutrient budgets (nitrogen, phosphorus, potassium, sulphur, calcium, magnesium and sodium). Greenhouse gas emissions per product or per hectare are also estimated (Watkins \& Selbie, 2015). OVERSEER was designed for use by non-experts, thus the inputs required to create a farm file are readily available. Where information is not available, defaults have been built into the model based on current research into nutrient loss in New Zealand farm environments (Figure 3.2) (Watkins \& Selbie, 2015). The model is based on several key assumptions: the farm is in a steady state; actual and reasonable inputs are entered into the model; output is annual average representation of the farm; good management practices are always followed, and animal production inputs are a factor in pasture production estimates (Watkins \& Selbie, 2015).

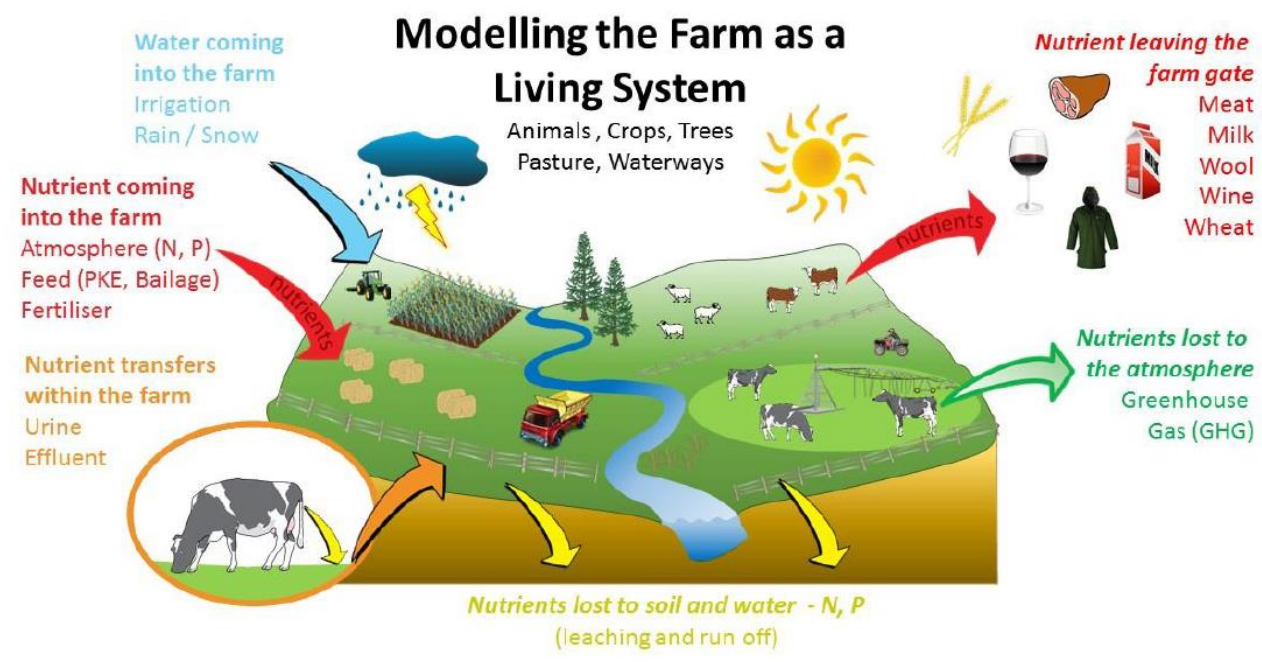

Figure 3.2 OVERSEER process diagram. Source: Arbuckle (2015). 
Table 3.2 National data used as input in the nitrogen and phosphorus coefficients in LUCI. Source: Trodahl (2018).

\begin{tabular}{|c|c|c|c|c|c|c|c|c|}
\hline Region & $\begin{array}{l}\text { Rainfall } \\
\text { (mm/yr) }\end{array}$ & $\begin{array}{l}\text { Irrigation } \\
\text { (mm/yr) }\end{array}$ & $\begin{array}{l}\text { N fertiliser } \\
\text { (kg N /ha/yr) }\end{array}$ & $\begin{array}{l}\text { N effluent } \\
\text { (kg N/ha/yr) }\end{array}$ & $\begin{array}{l}\text { P fertiliser } \\
\text { (kg P /ha/yr) }\end{array}$ & $\begin{array}{l}\text { P effluent } \\
\text { (kg P/ha/yr) }\end{array}$ & $\begin{array}{l}\text { Stocking Rate } \\
\text { (RSU) }\end{array}$ & Olsen $\mathrm{P}$ \\
\hline Manawatu & 1020.6 & 79.4 & 134.3 & 26.9 & 18.9 & 9.4 & 15.8 & 25 \\
\hline $\begin{array}{l}\text { Greater } \\
\text { Wellington }\end{array}$ & 1345 & 32.3 & 130.4 & 26.1 & 18.5 & 9.3 & 12.9 & 25 \\
\hline Canterbury & 729.6 & 352.9 & 159 & 31.8 & 18.3 & 9.2 & 21.6 & 25 \\
\hline Otago & 695.6 & 69.1 & 136.7 & 27.3 & 18 & 9 & 16.4 & 25 \\
\hline
\end{tabular}


These default values and OVERSEER's performance have come under increasing scrutiny to ensure that the model is underpinned by strong science. Therefore, there is a need for continuous OVERSEER development to both maintain current benefits and ensure expansion with new science (Gray et al., 2016b; Journeaux, 2016).

The shift from using OVERSEER as a decision support tool for fertiliser applications to a regulatory tool that is used to set limits on the nitrogen lost from farms has been controversial, as the ongoing development of both the science and the model have resulted in large shifts in nutrient estimates between versions (Duncan, 2017). Arbuckle (2015) outlines this change in the application of OVERSEER from a trusted farm support tool to a regulatory, limit management tool used by regional councils, highlighting the need for regulators to assess whether they are using OVERSEER appropriately in resource management decisions.

Due to the pressure on regional councils to set nutrient limits to meet NPS-FM requirements, it is important that councils are guided on the proper use of OVERSEER and ensures that regulators "fit the policy to the model, not fit the model to the policy" (Arbuckle, 2015 p. 5). Workshops with Waikato Regional Council, Environment Canterbury and Horizons Manawatu found that using 'hard' numbers from OVERSEER (when planning rules and setting regulation limits) results in plans becoming obsolete when OVERSEER is updated. However, using OVERSEER to promote farm environment plans and the development of good management practices by audited farms, ensure that OVERSEER is used in a way that complements its original purpose, to guide farmer decisions surrounding nutrient use (Arbuckle, 2015).

\subsection{SOIL WATER CALCULATIONS IN LUCI AND OVERSEER}

$\underline{\mathrm{LUCl}}$

LUCl uses a water balance equation to infer profile available water (PAW) at certain depths in the soil profile. PAW is defined as the amount of water potentially available for plant uptake that is stored in the soil, and it is expressed in units of millimetres of water. If there is a root barrier then the PAW will be measured to the root barrier as past this depth no water is available for plant uptake. Thus, PAW is calculated to 
either the rooting depth of the vegetation or to the depth of the impeding layer, whichever comes first (B. Jackson, personal communication, 12 March 2018). The term for this is the LUCl soil depth (LSD). A profile available water fraction (PAWf) for each soil sibling is then calculated based on the infiltration capacity of the soil (which is heavily impacted by the topsoil stoniness) and the effective rainfall on the area. Calculating PAW for any sibling is therefore based on Equation 3.3

$$
P A W=L S D \times P A W f
$$

Equation 3.3

A drainable water fraction (DWf) is also calculated to describe the amount of water between field capacity $(\mathrm{FC})$ and saturation. This value represents that amount of water available to run off the landscape (Equation 3.4).

$$
D W=L S D \times D W f
$$

Equation 3.4

A schematic of the movement of water through the soil profile is displayed in Figure

\section{3.}

\section{OVERSEER}

The soil water content in OVERSEER can be defined by the wilting point (WP), FC and saturation in units of $\mathrm{mm}$ of water $/ 10 \mathrm{~cm}$ in the soil profile at three depths $(0-30 \mathrm{~cm}$, $30-60 \mathrm{~cm}$, and $>60 \mathrm{~cm}$ ) (Wheeler, 2016a). WP denotes the minimum required soil moisture before a plant begins to wilt and is defined by the water content at $1500 \mathrm{kPa}$ (McLaren \& Cameron, 1996). Similarly, FC is the water content at $10 \mathrm{kPa}$ and saturation is the water content at $0 \mathrm{Kpa}$ (McLaren \& Cameron, 1996). 


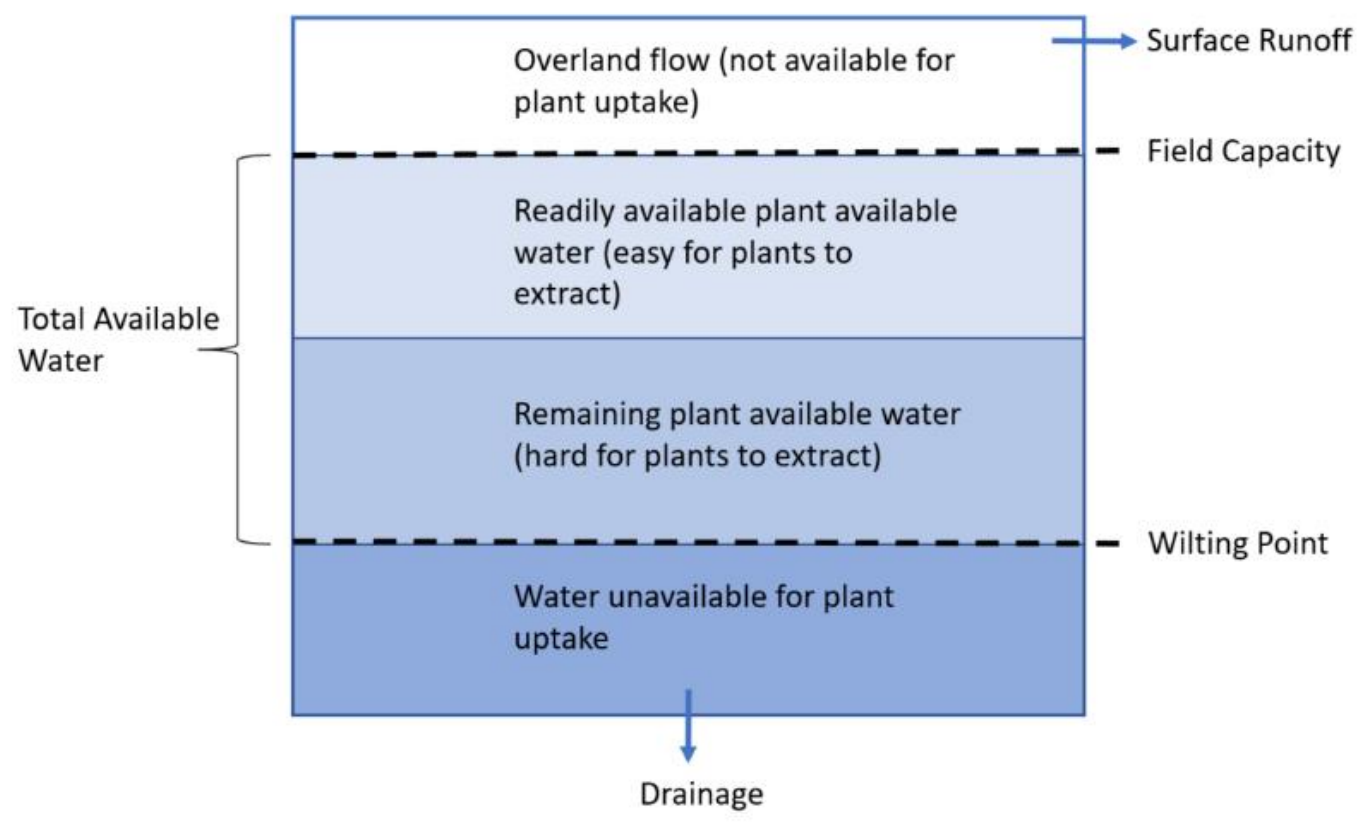

Figure 3.3 Diagram of the movement of water through a soil profile.

There are two ways soil water content can be estimated in OVERSEER. Firstly, if the WP, FC and saturation values of the soil are known, the soil moisture content for each $10 \mathrm{~cm}$ layer (numbered 1-15) is estimated (Wheeler, 2016a). For the layers below the impeded layer, the soil water content is zero (Wheeler, 2016a). If the topsoil of the area is known to be compacted, the top layer $(0-10 \mathrm{~cm})$ soil water content is reduced by $5 \mathrm{~mm}$. When WP, FC and saturation values are not estimated for a soil, the soil water content of the top soil $(0-10 \mathrm{~cm})$ is estimated based on the texture profile of the soil (percentage sand, silt or clay), as calculated in Equations 14 to 17 in Wheeler (2016a). OVERSEER then uses the difference between the estimates of FC and the permanent WP, for each soil type, to estimate total available water (TAW) for plants in the soil profile (Wheeler, 2016a). PAW is the rainfall equivalent depth of TAW within a specified depth in the soil profile (Equation 3.5) (Wheeler, 2016b).

$$
P A W_{D}=\sum_{1}^{z}(S M f C Z-S M w p z)
$$

$D$ is the depth of interest.

SMwp is the WP (mm) of the layer $z$.

SMfC is the FC (mm) of the layer $z$.

( $z$ is the number of $10 \mathrm{~cm}$ layers down to the profile depth). 
This equation is soil-specific and independent of plant type. Nevertheless, if the maximum rooting depth of the plant is reached before the root barrier, then crop available water (CAW) is calculated to the rooting depth. As CAW is calculated by changing the value $z$ in Equation 3.5, estimates of CAW are user-definable by changing the $z$ values of the specified crop type (Wheeler, 2016b). For pastoral blocks, the bottom of the root zone is defined as $60 \mathrm{~cm}$ (Wheeler, 2016a). Since most of the field measurements held in S-Map are taken from pastoral land, soil water estimates in SMap $>60 \mathrm{~cm}$ assume there is no change in the soil profile below $100 \mathrm{~cm}$ (Landcare Research, 2018a). This assumption affects estimates on cropping blocks in OVERSEER, as changing sand, silt and clay percentages at depth in the soil profile will result in over or under estimates of soil moisture.

OVERSEER can also use a drainage class assigned by S-Map to a sibling. A drainage class is assigned from 1-5 to describe how water is drained through the soil profile. These drainage cases are split into three groups: poorly drained (4); imperfectly drained (3); and, well drained (1). Pollacco et al. (2014) investigated the soil parameters in OVERSEER and found that changing the drainage class had no impact on runoff, percolation and evapotranspiration of water through the block and, as such, no impact on denitrification and leaching estimates. The lack of any feedback between saturation and runoff on pasture blocks was identified by Landcare Research as an issue that required further investigation (Pollacco et al., 2014). The release notes of OVERSEER 6.2.3 (OVERSEER, 2018) state that the option of selecting a drainage class has been extended from pasture blocks to crop, cut and carry and to fruit crop blocks. The notes do not mention if the issues Pollacco et al. (2014) highlighted were addressed.

\subsection{SENSITIVITY TO SOIL PROPERTIES}

Based on LUCl's hydrology and nutrient loading algorithms, it is expected that nitrogen results are sensitive to PAW, DW and the permeability of the soil, and the phosphorus model will be sensitive to variations in Olsen P, ASC and the SV of the soil.

PAW and DW describe soil water properties that will affect the amount of nitrogen leached through the soil profile. Variations in these values between soil types will 
impact the stream concentrations estimated by the nitrogen tool. From data obtained by OVERSEER, phosphorus, Olsen $\mathrm{P}$ (the measure of plant available phosphorus in the soil) and ASC values are associated with most soil types. ASC variations will result in different phosphorus estimates, as the phosphorus retention capability of the soil changes with soil type. There are three low, medium and high classes of ASC in New Zealand (McLaren \& Cameron, 1996). The relationship between soil orders and these three classes is shown in Table 3.3.

Table 3.3 Relationship between ASC classes and soil order. Source: McLaren \& Cameron (1996).

\begin{tabular}{|l|l|l|l|}
\hline & Low (0-30\%) & Medium (31-85\%) & High (86-100\%) \\
\hline Soil Order & $\begin{array}{l}\text { Organic } \\
\text { Pallic }\end{array}$ & Brown & Pumice \\
Podzol & Oxidic & Allophanic \\
Semi Arid & Melanic & \\
Recent & Raw & & \\
& Ultic & & \\
\hline
\end{tabular}

* Gley soils have variable $\mathrm{P}$ retention

Estimating the SV for each soil type provides information on the soil strength based on topsoil clay and carbon content (expressed as a percentage), as shown in Equation 3.6. This follows the equation used in McDowell et al. (2005), this corrected in Wheeler (2016a).

$$
S V=1-\frac{\left(\frac{A S C}{100}+\frac{\sqrt{\text { Clay }}}{5}+\frac{\sqrt{\text { Carbon }}}{8.5-0.7}\right)}{2.3}
$$




\section{CHAPTER 4 REVIEW OF NEW ZEALAND'S SOIL AND TOPOGRAPHIC DATASETS}

This chapter describes soil and topographic data that can be used in the LUCI model. Section 4.1 details the available soil data in New Zealand, including the data held in the National Soil Database (NSD) that is fundamental to soil classifications in the Fundamental Soil Layer (FSL) and the newer, S-Map database currently under development by Landcare Research. Section 4.2 describes the availability of DEMs in New Zealand, including low-resolution, national coverage DEMs and high-resolution DEMs produced from LiDAR (Light Detecting and Ranging). DEM accuracy is outlined based on the source of elevation data, the distribution of samples, interpolation techniques, and the chosen grid size of the DEM.

\subsection{AVAILABLE SOIL DATA IN NEW ZEALAND}

The soil is composed of minerals, organic matter, water and air, with the variation in the proportion of these components greatly influencing the physical properties of the soil (McCauley et al., 2005). Soil development is dependent on climate and living matter acting on the parent material, resulting in weathered mineral or organic matter. The weathered material develops into different layers, or horizons, each having a distinct texture, structure, and colour (McCauley et al., 2005). There are four 'master' horizons denoted by the letters $\mathrm{O}, \mathrm{A}, \mathrm{B}$ and $\mathrm{C}$, which correspond to varying depths in the soil. Not all soils will have every horizon, as poorly developed soils will lack a defined $B$ horizon, and in landscapes with high erosion rates, a thin or nonexistent A horizon may be present (McCauley et al., 2005).

These 'master' soil horizons enable the communication of soil properties observed at a site, as outlined below and identified in Figure 4.1.

- The $\mathbf{O}$ horizon is a layer dominated by soil material consisting of fresh, or partially decomposed organic material derived from plants and animals. 
Commonly, this layer is present at the soil

surface, while most common in forest soils this

horizon can make up the entire soil profile in

organic soils (Buol et al., 2011).

- The $\mathbf{A}$ horizon is the mineral horizon, which is the layer most impacted by biological and human activity. This layer is either present at the soil surface or below the O horizon. The layer usually has the highest percentage of soil organic matter resulting from the decomposition of plant residue (Buol et al., 2011).

- The $\mathbf{B}$ horizon is the zone of accumulation, as leached material from the $A$ horizon accumulates and alters the parent material, reddening the soil colour. Accordingly, this part of the subsurface is

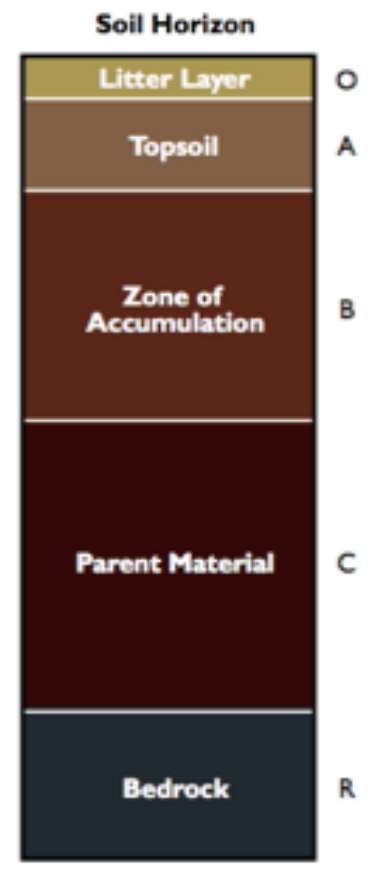

Figure 4.1 A general soil profile. Source: McCauley et al. (2005). significantly different from the material from which it was formed (Buol et al., 2011).

- The $\mathbf{C}$ horizon represents parent material, with little, to no alteration by soil forming processes, and does not show any resemblance to the properties of the $\mathrm{O}, \mathrm{A}$, , or B horizons (Buol et al., 2011).

- Finally, the $\mathbf{R}$ horizon represents layers of bedrock that are strongly cemented (Buol et al., 2011).

The deterioration of soils' physical quality is mainly a result of agricultural activity, as trampling of the soil by livestock leads to degradation through compaction and homogenisation (Drewry, 2006). Machinery use on the landscape also results in damage to soils, but, this is more localised (e.g. deterioration under the tracks of wheeled equipment) (Drewry, 2006). Soil compaction reduces the fractional air volume held within the soil, particularly the volume of macropores, and thus disrupts the soil pore network, decreasing the soil's porosity (Menneer et al., 2001). Increased research and reporting to government agencies is being undertaken on the indicators of soil physical health or condition; these indicators commonly include bulk density of 
the soil (a measure of large soil pore volume), and saturated hydraulic conductivity (Menneer et al., 2001).

\subsubsection{The New Zealand Soil Classification System}

Classification of New Zealand soils was first developed in the New Zealand Genetic Classification (NZGS), which linked soil groups to the environment that most influenced that soil's development (Taylor, 1948). This system linked soils to their surrounding climate, vegetation and geology. The NZGS, while useful at large scales, made it difficult to define the correct class of soil at the field scale, as continuous improvement in scientific knowledge and understanding of characteristics of soil properties advanced beyond the capability of the genetic classification to manage (Landcare Research, 2018b). This led to the development of the New Zealand Soil Classification (NZSC) which has been in use since 1983, from Version 1.0 (Hewitt, 1989) to the current Version 3.0 (Hewitt, 2010).

The classification of an area to a soil type begins with the soil profile. A one metre pit (or depth to rock) is dug with the functional horizons, $\mathrm{pH}$ and other chemical measurements taken. These characteristics of the soil are compared to the definitions of the 15 soil orders (Table 4.1), and the most appropriate order is chosen. Once a soil order is selected, the soil group (of which there are 74 groups based on parent material, drainage status and the soils' physical properties) and relevant soil subgroups are selected (there are 299 possible subgroups based on the environment the soil is located in) (Hewitt,2010; Landcare Research, 2018b). This hierarchal classification system (order, group and subgroup) is also designed to include a fourth category, known as a soil series or family. These series are assigned through the differentiation of the subgroup into three criteria: parent material; particle size, and permeability. 
Table 4.1 Soil Order Classification and their respective characteristics. Source: Landcare Research (2018b).

\begin{tabular}{|c|c|c|}
\hline Soil Development & Soil Order & Soil Characteristics \\
\hline & Organic & $\begin{array}{l}\text { Soils dominated by organic } \\
\text { material }\end{array}$ \\
\hline & Gley & $\begin{array}{l}\text { Grey colours due to reduction of } \\
\text { iron caused by waterlogging } \\
\text { beneath a high-water table }\end{array}$ \\
\hline & Anthropic & $\begin{array}{l}\text { Soils disturbed by people (made } \\
\text { by stripping or mixing the original } \\
\text { soil material to depth or by } \\
\text { addition of fill) }\end{array}$ \\
\hline \multirow{2}{*}{$\begin{array}{l}\text { Minimal Soil Development } \\
\text { Soils on young land surfaces } \\
\text { where rock material or } \\
\text { sediments in which the soils is } \\
\text { formed are fresh and little } \\
\text { altered. }\end{array}$} & Raw & No topsoil or minimal topsoil \\
\hline & Recent & With a distinct topsoil \\
\hline \multirow{5}{*}{$\begin{array}{l}\text { Intermediate Soil } \\
\text { Development } \\
\text { Soils where the rock material } \\
\text { or sediments in which they are } \\
\text { formed are altered but still } \\
\text { recognisable, with a large } \\
\text { proportion of unaltered } \\
\text { minerals. The soils have well- } \\
\text { developed subsoil horizons if } \\
\text { not on shallow rock. }\end{array}$} & Allophanic & $\begin{array}{l}\text { Dominated by allophane (from } \\
\text { volcanic parent materials) }\end{array}$ \\
\hline & Melanic & $\begin{array}{l}\text { Dominated by high calcium or } \\
\text { magnesium (from lime rich rocks) }\end{array}$ \\
\hline & Pumice & $\begin{array}{l}\text { Dominated by pumice or sandy } \\
\text { glassy tephra }\end{array}$ \\
\hline & Semiarid & $\begin{array}{l}\text { Semi-arid climate, rainfall less } \\
\text { than } 500 \mathrm{~mm} / \mathrm{yr}\end{array}$ \\
\hline & Pallic & $\begin{array}{l}\text { Sub humid climate with seasonal } \\
\text { drought }\end{array}$ \\
\hline
\end{tabular}




\begin{tabular}{|l|l|l|}
\hline \multirow{2}{*}{$\begin{array}{l}\text { Strong Soil Development } \\
\text { Soils on land surfaces where } \\
\text { the rock material or sediments } \\
\text { in which the soil is formed are }\end{array}$} & Grown & $\begin{array}{l}\text { Humid climate, rarely dry except } \\
\text { if sandy or stony where soils may } \\
\text { be drier }\end{array}$ \\
\cline { 2 - 3 } mostly transformed to clay. & Sodzol & Super-humid climate \\
\cline { 2 - 3 } & Oxidic & Mainly sedimentary rocks \\
& & $\begin{array}{l}\text { Mainly volcanic rocks, well } \\
\text { developed polyhedral structure }\end{array}$ \\
\hline
\end{tabular}

Soil family and sibling were defined by Web and Lilburne (2011) who recognised the need for more detailed definition of a soils' physical properties than that held at the subgroup level. Each soil family is defined by a combination of attributes including soil order, group, subgroup, parent material, rock class, dominant texture and permeability class (Barringer et al., 2008). The soil classes are then separated into siblings, which are determined by the soil's morphology (soil depth, topsoil stoniness, natural soil drainage, soil texture-profile and a unique sequence of up to six functional horizons) (Webb \& Lilburne, 2011).

The separation of soil families into siblings allows further explanation of soil properties, based on the similarity of measurable properties rather than the soils' presumed genesis (Lilburne, 2011). The six functional horizons in the soil sibling classification denote one or more parallel layers of soil, enabling soil properties of interest to be derived; these layers are defined by stoniness, texture, structure size and soil density (Webb, 2003). The functional horizons describe the base properties of the siblings, with the variability in these properties estimated by probability distribution functions. Expert knowledge and measured data were used to create the probability distribution functions for each soil property within the soil sibling classification (Lilburne et al., 2009). 


\subsubsection{Mapping New Zealand soils}

New Zealand soil data concentrates on two types of soil properties; one is 'inherent soil properties', which vary slowly in time and can be regarded as fixed over human timescales (e.g. clay content) (Hewitt, 2013). The other type, 'dynamic soil properties', vary on daily and yearly timescales and are responsive to short-term environmental drivers, making them important indicators for environmental management (e.g. soil water content or total soil organic carbon) (Hewitt, 2013). Field measurements collect both types of soil information when describing a soil profile, and the data are held within the NSD (Landcare Research, 2017a). The NSD is a point database of soil, physical, chemical and mineralogical characteristics, collected from 1336 soil profile surveys across New Zealand. The oldest soil survey dates in the database back to 1959. (Hewitt, 2013). The soil information contained within the NSD is the basis for the derivation of New Zealand's soil classification system and our understanding of how soil properties vary with geology, rainfall, vegetation and topography (Hewitt, 2013).

Recognition of the need for improved coverage and accuracy of New Zealand's soil information led to the formation of the FSL (LRIS, 2017). The FSL was created by combining features from the New Zealand Land Resource Inventory (NZLRI) with the soil data from the NSD. The NZLRI contains 90000 polygons that cover New Zealand (except for Stewart Island), at a scale of 1:50 000 (LRIS, 2017). These polygons contain physical land resource information, such as soil units for a given area, based on the physical factors of rock, slope, erosion, and vegetation (LRIS, 2017). Information from both the NZLRI and the NSD were combined using expert knowledge and consultations with stakeholders, which determined the fifteen soil attributes described in the FSL (Appendix A).

\section{Limitations of the FSL and NSD}

The soil data used to produce the FSL is of lower resolution than the physical factors of the landscape held in the NZLRI, thus that the scale of the NZLRI had to be reduced to from 1:50 000 to 1:63 360 (Lilburne et al., 2004). In some instances, the incomplete coverage of soil data across New Zealand means that particular areas are only 
represented by a soil map at the scale of 1:253 440 (Hewitt, 2013). Not only is the varying resolution of the FSL an issue, but there are inconsistencies in how much data was collected from each of the soil surveys. For the individual profiles sampled and entered into the NSD, a different number of soil properties were documented, with some having chemical data only, whereas others have a full analysis of the soil profile's chemical, physical and mineralogical characteristics (Wilde, 2003).

The location of the soil profiles entered in the NSD is represented in Figure 4.2. These profiles are clustered around research sites, resulting in a patchy distribution that does not represent of all regions in New Zealand, with most of the surveys taken on agricultural land (Wilde, 2003). The criteria for selecting a site also introduced a bias towards a certain type of landscape, as pedologists chose stable sites with minimum disturbance that have no recent signs of land use change (e.g. scrub/forest converted to pasture) (Wilde, 2003). If the land was converted from pasture to arable, it too would be rejected, as the upper soil horizons would be disturbed, making the soil profile characterisation process difficult (Wilde, 2003). These decisions have led to the NSD mainly representing uneroded sites or very slightly eroded sites, with a stable history of land use. Consequently, when transferring these attributes to the polygons of the NZLRI layer, the data does not reflect the characteristics of the entire polygon, which would have a range of erosion severity and land uses. These discrepancies in the NSD can be seen in Tables 4.2 and 4.3 where regions such as Northland, Hawkes Bay, Taranaki and Tasman are under sampled compared to high producing areas like Waikato and Canterbury. With $25 \%$ of all field samples classified as brown soils, it is clear that further work is required to create a representative database of field measurements.

The patchy distribution is also seen in the soil series recorded. Of the 2000 soil series that have been recognised, less than half are represented in the NSD (Hewitt et al., 2012). How representative the NSD is of real-world conditions has been called into question, as soil water dynamics are not analysed at any of the sites, and only 425 sites include water retention data (Hewitt et al., 2012). The limited understanding of soil water dynamics is thus problematic, as soil water can influence plant growth and the movement of nutrients through the soil (Hewitt et al., 2012). 
Further limitations of this soil dataset arise from a lack of standards for entering soil data into the NSD. Data can be entered both manually and electronically, resulting in incomplete data capture and transcription errors (Hewitt et al., 2012). When the NSD data was held in a card filing system before the establishment of the electronic database, there were strict protocols in place regarding the level of detail needed for each survey, but, these were not always adhered to (Wilde, 2003). Information lost between data collection and entry into the electronic database includes: the rationale for the methods used and the uncertainty associated with measurements; any change to the methods used between sites; and the identification and qualifications of the individuals providing the expert judgement for any uncertainty estimates (Wilde, 2003).

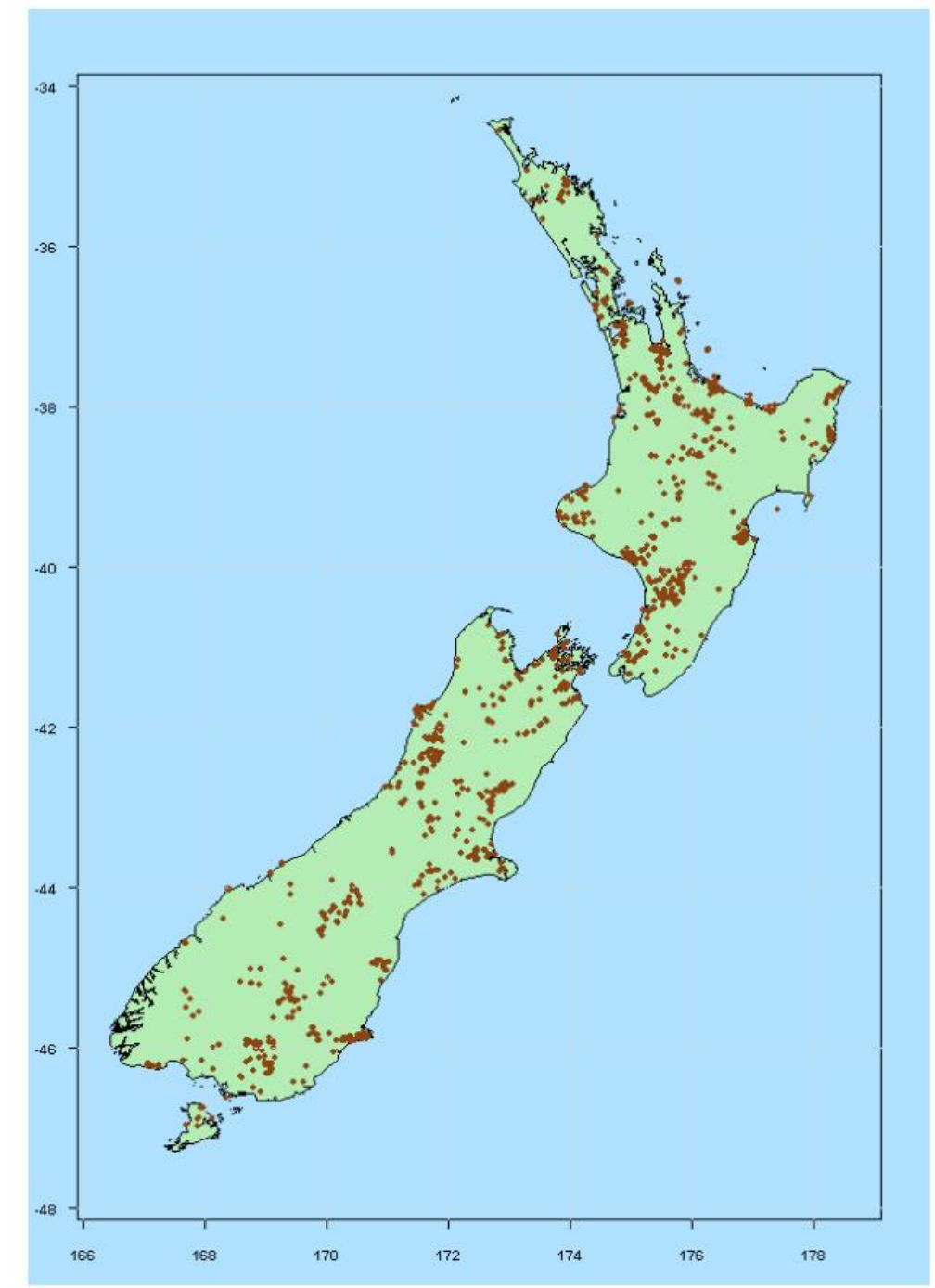

Figure 4.2 Sample site locations of the NSD. Source: Hewitt et al. (2012). 
Table 4.2 NSD sites separated into regions sampled. Source: Landcare Research (2018c).

\begin{tabular}{|c|c|c|c|}
\hline & $\begin{array}{l}\text { New Zealand } \\
\text { Regions }\end{array}$ & $\begin{array}{l}\text { Number of } \\
\text { Survey Sites in } \\
\text { Each Region }\end{array}$ & $\begin{array}{l}\text { Percentage of } \\
\text { Survey Sites in } \\
\text { Each Region }\end{array}$ \\
\hline \multirow[t]{9}{*}{ North Island (49\%) } & Northland & 39 & $3 \%$ \\
\hline & Auckland & 37 & $3 \%$ \\
\hline & Waikato & 128 & $10 \%$ \\
\hline & Bay of Plenty & 85 & $6 \%$ \\
\hline & Gisborne & 43 & $3 \%$ \\
\hline & Hawke's Bay & 31 & $2 \%$ \\
\hline & $\begin{array}{l}\text { Manawatu- } \\
\text { Wanganui }\end{array}$ & 176 & $13 \%$ \\
\hline & Taranaki & 38 & $3 \%$ \\
\hline & Wellington & 75 & $6 \%$ \\
\hline \multirow[t]{7}{*}{ South Island (51\%) } & Marlborough & 84 & $6 \%$ \\
\hline & Tasman & 37 & $3 \%$ \\
\hline & West Coast & 155 & $12 \%$ \\
\hline & Canterbury & 150 & $11 \%$ \\
\hline & Otago & 155 & $12 \%$ \\
\hline & Southland & 103 & $8 \%$ \\
\hline & Total & 1336 & \\
\hline
\end{tabular}

A contributing factor to incomplete data coverage is a significant drop in funding for soil science research since the mid-1980s, which has limited the development of land resource databases and the ongoing maintenance of the NSD (Hewitt et al., 2012). The lack of funding means that research since mid-1990 was no longer incorporated into the NSD, remaining as temporary datasets. Some improvement has been made to the NSD since funding has increased, through the recognition of the Land Resource Information System (LRIS) as a nationally significant dataset by the New Zealand government, and the development of the NSD Improvement Project by Landcare Research (Hewitt et al., 2012). 
Table 4.3 Survey sites classified by soil order in the NSD. Data queried to produce this table was collected between 1959 and 1997. Source: Landcare Research (2018c).

\begin{tabular}{|c|c|c|}
\hline $\begin{array}{l}\text { New Zealand Soil } \\
\text { Classification }\end{array}$ & $\begin{array}{l}\text { Total Amount of Each Soil } \\
\text { Order Present in the } \\
\text { Survey Record }\end{array}$ & $\begin{array}{l}\text { Percentage of Database with } \\
\text { Each Soil Classification }\end{array}$ \\
\hline Organic Soil & 47 & $4 \%$ \\
\hline Granular Soil & 15 & $1 \%$ \\
\hline Raw Soil & 7 & $1 \%$ \\
\hline Melanic Soil & 58 & $4 \%$ \\
\hline Oxidic Soil & 17 & $1 \%$ \\
\hline Semiarid Soil & 23 & $2 \%$ \\
\hline Pallic Soil & 175 & $13 \%$ \\
\hline Allophanic Soil & 98 & $7 \%$ \\
\hline Ultic soil & 32 & $2 \%$ \\
\hline Gley Soil & 175 & $13 \%$ \\
\hline Recent Soil & 159 & $12 \%$ \\
\hline Podzol Soils & 121 & $9 \%$ \\
\hline Pumice Soil & 52 & $4 \%$ \\
\hline Brown Soil & 334 & $25 \%$ \\
\hline Mafic Brown Soil & 23 & $2 \%$ \\
\hline Total & 1336 & \\
\hline
\end{tabular}

Efforts to improve the coverage and accuracy of New Zealand's soil data has focused on critically evaluating the existing FSL and NSD databases, instead of increasing the coverage of the soil profiles analysed. This is because the majority of field techniques are time-consuming and expensive (Wösten et al., 2001). Working off existing databases is the approach Landcare Research has taken with the development of SMap (Landcare Research, 2017b). S-Map will act as a platform for fusion with other environmental layers and new soil data as it is made available, enabling spatial modelling of New Zealand's soil characteristics to an extent that was not possible with previous databases (Lilburne et al., 2004). Improving the NSD fell under Landcare's $\$ 1.52$ M funding investment for 2014/15, labelled the Data Stewardship Infoservices 
Program, to improve the integration of soil attribute data, and parallel efforts to extend the coverage of S-Map across New Zealand (Landcare Research, 2017b).

\subsubsection{The Development of S-Map}

S-Map was created by combining legacy data (previously analysed pedons and older soil surveys held within the NSD) with the work of experienced pedologists on soil variability and soil-landscape relationships, to create web accessible, dynamic, soil factsheets (Hewitt, 2010). Expert knowledge from pedologists was used to sift through the legacy data, extracting information from the soil profile to describe the functional horizons and to estimate the probability distribution of key attributes within soil classes (Hewitt et al., 2010). Uncertainty ratings were attached to express the relative contribution of data and expert judgement involved in the creation of the soil information factsheets. This also identifies where investment is needed to improve areas of lower certainty in the national coverage (Hewitt, 2010).

Advances in information technology mean that S-Map is not just an improvement on previous soil databases, but it is also an information system that can store data at multiple scales and provide rule-based validation checks, automatic taxonomic correlation, data modification history, dynamic fact sheet generation and an image database (Lilburne et al., 2012). This complex soil database is made possible through the development of numerous software models and tools for managing soil data by Landcare Research. Users' ability to create web-based factsheets for a soil or spatial location of interest, makes the data accessible to a wide range of people. The factsheets can be designed to suit the needs of pastoral or cropping farmers and people trained in soil science, or to educate school children (Lilburne et al., 2012).

The coverage of S-map over New Zealand is not complete, and additional funding is being sought from regional and national government and farm servicing agencies. Since each of these have their own interests and goals, funding to dramatically extend the coverage of the soil database is unlikely (Lilburne et al., 2012). The extent of S-map over productive land is shown in Figure 4.3 below. There are evident discrepancies between regions, which indicate the funding and commitment that some councils have invested in understanding the soil properties in their region. Not only should councils 
focus funding to improve the coverage of S-Map, but funding should be allocated by these groups towards further development of the NSD and the soil samples it holds.

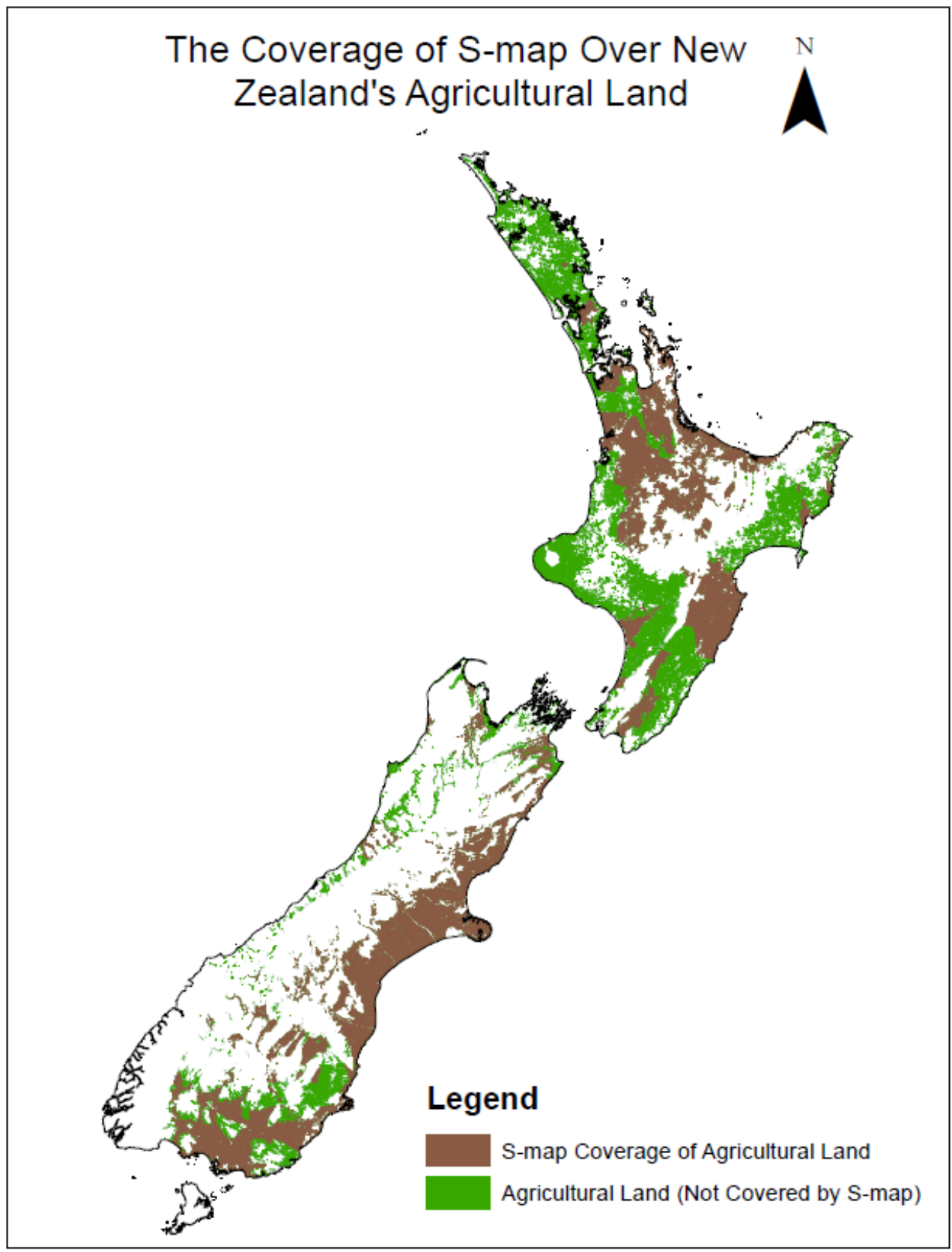

Figure 4.3 Coverage of S-Map over New Zealand. Source: Landcare Research (2018) for S-Map data, and Land Resource Information System (2018) for agricultural classed landcover data.

\section{Pedotransfer Functions and the Improvement with S-Map}

Although S-Map has made advances in the description and representation of soil data, there is still a lack of high-resolution soil information that covers New Zealand. S-Map's 
representation of soil characteristics is strongly linked to the information from a limited number of soil profiles in the NSD. To limit the effect the lack of collected soil data may have on the accuracy of digital soil mapping, pedotransfer functions (PTFs) are used to estimate soil properties that have not been measured in the legacy dataset, or that are difficult/expensive to measure. These properties are instead estimated from their relationship to other soil properties (Giltrap \& Hewitt, 2003). PTFs are used in the NSD to estimate: available water capacity; readily available water capacity; total porosity; macroporosity, and fine earth dry bulk density (Giltrap \& Hewitt, 2003; Lilburne et al., 2014).

The PTFs used in S-Map were developed by Cichota et al. (2013). Information held within the NSD (fractions of sand, silt and clay; organic carbon content and soil bulk density) was collated, then several PTFs for each soil property were combined from PTFs developed from soil data from other regions of the world. The weighting of several PTFs to match local measurements in the NSD is a novel approach termed the ensemble PTF (ePTF) by Webb et al. (2000). This ePTF avoids reliance on a single function and enables the uncertainty of any PTF to be averaged out by the weighted effect of the other members.

To estimate these properties requires data on the percentages of sand, silt and clay in the soil profile, and the soils' dry bulk density (which is used as a predictor variable in PTFs except when it is the target in its own PTF) (Giltrap \& Hewitt, 2003). Understanding the texture of soil is important, as it is the primary determinant of a soil's ability to hold water. If the soil contains many macropores it loses water through gravitational drainage, so there is only a small amount of water available for use before the wilting point is reached (McCauley et al., 2005). The opposite occurs in finetextured soils, as micropores do not freely drain water under gravity and therefore have more plant available water. While the use of texture to approximate soil drainage characteristics excludes the effect biologic activity and clay mineralogy have in developing soil macropores, the use of PTFs to predict hydraulic characteristics does enable experts to quantify the physical, chemical and biological processes active in soil profiles where measurements are unavailable (Wösten et al., 2001). 
Modelling developments within S-Map have incorporated improved PTFs for soil properties with limited data, thus increasing the accuracy of soil-climate and soilclimate-land management models (Lilburne et al., 2014). These improvements came about due to pressure for soil data that could support environment and production models used by industry specialists and policymakers as not only are PTFs associated with water movement through the soil important, and require improvement with new science, but improved PTFs for soil-related vulnerabilities to nutrient leaching and runoff are also required (Lilburne et al., 2014).

The improved PTFs use regression models based on soil order, parent rock, soil functional horizon, and texture. Where appropriate, other relevant soil characteristics are used, such as phosphorus adsorption capacity and nitrogen leaching vulnerability (Lilburne et al., 2014). However, the analytical data held within the NSD are still the basis for all relationships modelled by PTFs. An example is the water retention curve (a key component of all of S-Map's PTFs). This is based on observed differences in soil water tension from the NSD profiles, creating a water tension curve to estimate the value of $1500 \mathrm{kPa}$ (WP) and four other tension points (Lilburne et al., 2014). Use of this curve ensures that modelled water values closely match observed values in the NSD (Lilburne et al., 2014). Therefore, even with past advances in modelling these parameters, the reliance on a small sample of soil profiles with a patchy distribution across New Zealand serves to highlight how important it is to fund the NSD's extension.

\section{Advances in Representing Soil Data Through S-Map}

S-Map's representation of soil types focuses heavily on the identification of functional characteristics (the utility of the soil for management purposes). Other soil characteristics described within the FSL and NSD that are closely related to environmental data (e.g. climate and topography-related variables) are not included (Lilburne et al., 2012). The primary map layer in S-Map consists of polygons labelled with the family name of the soil (Barringer et al., 2008). Soil siblings are expressed in SMap as a list of up to five siblings found inside a family polygon; the estimated 
proportion of each sibling is given, although siblings that make up less than $10 \%$ of the map unit are not listed (Lilburne et al., 2009).

The detailed description of soil properties within each map unit, compared with the single attribute tables associated with the polygons in the FSL, shows the effort Landcare Research has put into representing the variability and uncertainty in New Zealand's soils. S-Map is a considerably larger database than the FSL, with ten attribute tables associated with each map unit. This complexity is needed, as any one soil family identified (comprising more than $85 \%$ of a polygon) could have four or five siblings within it. Since each sibling shows the characteristics of its functional horizon, further tables are required to display this information (Lilburne et al., 2009). If compound map units are used to describe an area, then the data presented to the user is further complicated (Lilburne et al., 2009).

\subsubsection{Opportunities for Improving New Zealand's Soil Data}

The goal of S-Map is to provide easy access to soil data of a consistent scale, with common attributes derived for all soil orders, and data of sufficiently high quality to be applied in both field and national scale research (Barringer et al., 2008). Until this goal is realised, the resolution of the soil data from S-Map or the FSL will affect models based on that data. Pearse et al. (2015) identified the implications and issues with New Zealand's expert-based approach to soil mapping, and emphasises the need for larger datasets of measured soil attributes that can be used both as an input, and to validate the outputs produced. Currently, the lack of data underlying the NSD will have an impact on S-Map ability to provide useful information to users, despite the advances in estimating soil characteristics from measured values.

Research into the appropriate scale to collect soil data was undertaken by Martin et al. (2016). Their study, of chemical variation within the underlying geology across southern Otago and Southland, determined that the ideal grid spacing was $16 \mathrm{~km}$ between each soil profile survey. Nevertheless, a $32 \mathrm{~km}$ grid was thought to be acceptable for a national soil survey, as it provides a compromise between the area covered and the resolution, with only the subtle effects of soil variation lost from the geochemical results (Martin et al., 2016). Higher-resolution farm scale surveys should 
be undertaken where finer detailed soil information is required (e.g. for irrigation, nutrient, soil, sediment and dairy effluent management).

Carrick et al. (2014) developed a national protocol and standard for accurate soil mapping at the farm scale. While extensive farm scale mapping is costly, the benefits associated with using this data to inform mitigation management practices provides maximum benefit for the both the farm, and the catchment. In an earlier study, Carrick et al. (2010) quantified the cost-benefit of farm scale soil mapping as a 1:6 ratio. This accounted for the cost of establishing the soil map, and the benefits of targeted mitigation of nitrogen leaching in the case study catchment on the Mataura River, Southland (Carrick et al., 2010). The cost of producing a farm scale soil map was calculated in Barringer et al. (2016), with a 120 ha farm surveyed in a 40 m grid pattern costing $\$ 12,000$ (10 minutes for each auger sample and labour costs of $\$ 100$ per hour). After sampling, they estimated spending a further $\$ 3,000$ on data processing and mapping.

Landcare Research is currently working to extend the NSD and S-Map by including soil surveys from soil science projects that came after the NSD and thus have not yet been included in the national dataset. Some soil types, however, will still be underrepresented. Efforts to gain additional funding target both regional and national government and farm service agencies. As each organisation has its own interests and goals, opportunities for substantial funding capable of dramatically extending S-Map coverage are limited (Lilburne et al., 2012). Unless S-Map attracts significant investment from a government wanting to provide a stable, national-scale dataset, then the uncertainty associated with derived soil properties will always hinder the advancement of models that use soil data as a base for predictions. This thesis recognises the importance of quantifying the uncertainty in soil data as, for the foreseeable future, New Zealand's soil data will continue to be a source of error and uncertainty for decision support tools such as LUCI, that model nutrient flows across farms. 


\subsection{NEW ZEALAND'S TOPOGRAPHIC DATA}

The topography of a landscape is important, as slope is a key parameter which influences land use and erosion (Barringer \& Lilburne, 1997). DEMs, also known as Digital Terrain Models (DTMs), represent the varying topography of the Earth and are therefore integral to spatial analysis. A DEM represents the bare ground surface of an area with objects, such as plants and buildings, removed (Elkhrachy, 2017). DEM data, which includes slope gradient, aspect, curvature, catchment area and upslope length, is used in a variety of hydrological and geomorphological applications (Thompson et al., 2001). While DEMs contain information on topographic parameters, their ability to represent landscape elements such as slope depends on the accuracy of the DEMs representation of the earth's surface (Barringer \& Lilburne, 1997). This DEM error is rarely measured or estimated in a manner that provides relevant accuracy information to users (Barringer \& Lilburne, 1997).

\subsubsection{DEM Availability}

DEM coverage of New Zealand is not of fine resolution, as national LiDAR coverage is not yet available. Instead, regional councils hold LiDAR data for some or all of their region, which researchers, if given access, can use to create a fine resolution DEM. There are several freely-available DEMs created from LiDAR data held by LINZ; these cover Auckland, the Wellington region, Christchurch and Waimakariri and Selwyn in Canterbury, Tauranga, and the coastline of the Bay of Plenty (Figure 4.4a) (LINZ, 2017b). LINZ is actively procuring LiDAR data from databases held by councils and companies to create and provide access to fine resolution elevation data (LINZ, 2016). Figure $4.4 \mathrm{~b}$ shows areas currently in the process of LiDAR data capture, or where existing LiDAR databases will be transferred to the LINZ Data Service (LINZ, 2017a).

The development of this publicly available LiDAR database by LINZ requires the data to be in a standard format (a $1 \mathrm{~m}$ gridded DEM with a vertical and horizontal accuracy of 95\% and a pulse density greater than $2 \mathrm{pls} / \mathrm{m}^{2}$ ) (LINZ, 2016). Specifying the standard of vertical and horizontal accuracy describes the positional accuracy of an attributes (Elkhrachy, 2017). These two accuracy types cannot be separated, as an error could be 
caused by an incorrect elevation value at the correct position, or by a correct elevation value for the wrong position (Elkhrachy, 2017).
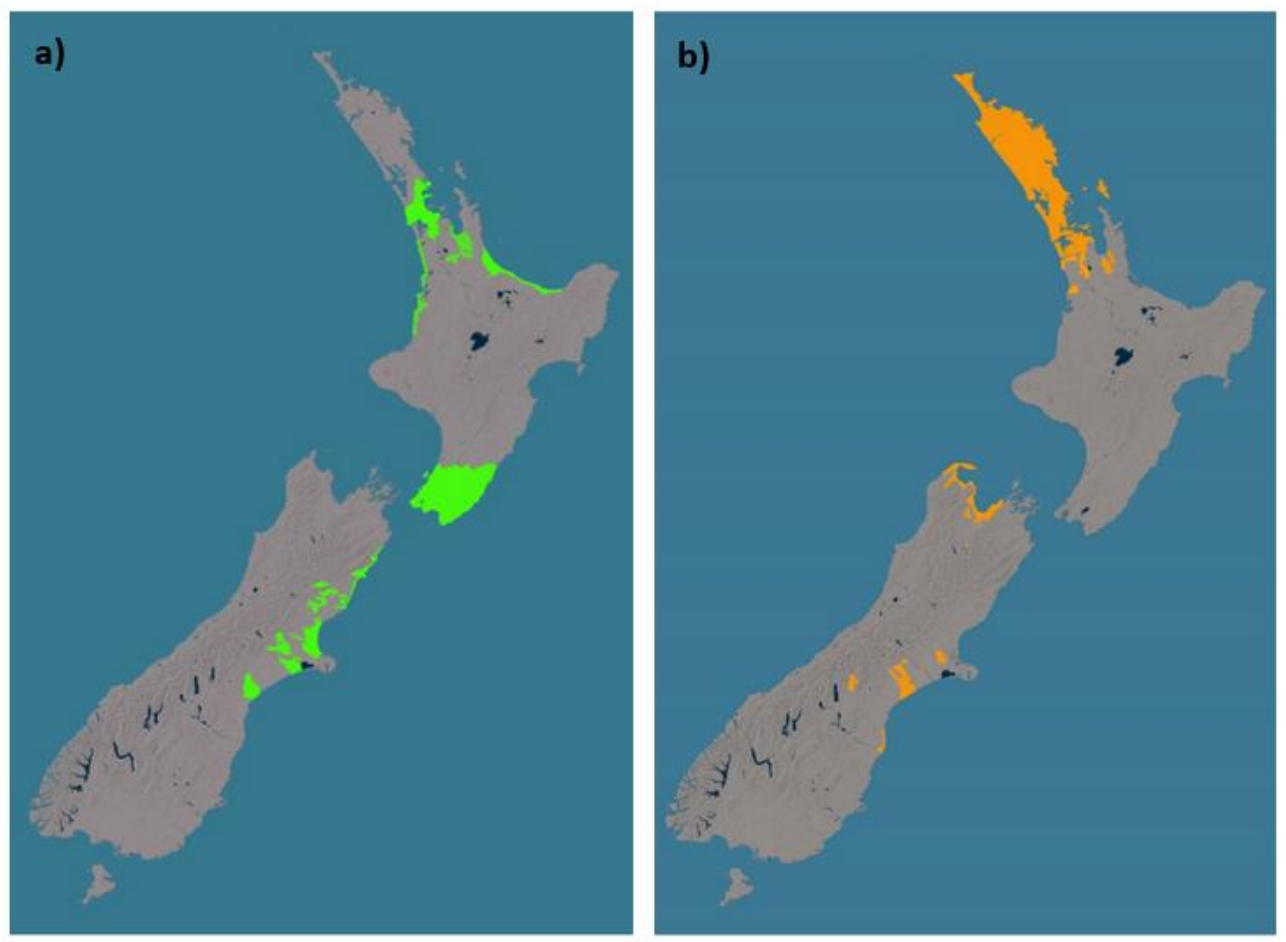

Figure 4.4 (a) Areas covered by LiDAR data available through the LINZ Data Service. Source: LINZ (2017b). (b) Areas where capture and supply of LiDAR data are in progress and will be made available through the LINZ Data Service in the future. Source: LINZ (2017a).

There is currently no publicly available national DEM developed from LiDAR data, but there are two lower-resolution DEMs freely available through the LINZ Data Service:

\section{NZDEM-SoS-v1.0}

Otago University's National School of Surveying created this $15 \mathrm{~m}$ Dem in 2011. The topographic data for this DEM was sourced from the LINZ NZTopo 50 database (a seamless 1:50,000 scale topographic map of the country derived from aerial photographs) (Columbus et al., 2011). Individual tiles (maps) can be downloaded from https://koordinates.com, enabling users to easily store and transfer data for specific areas of the country rather than having to download the entire DEM (Columbus et al., 2011). 
The contour lines and point height data are projected on the New Zealand Transverse Mercator 2000 projection with contour lines that are $20 \mathrm{~m}$ apart. Columbus et al. (2011) interpolated a $15 \mathrm{~m}^{2}$ DEM from this data, providing a fine spatial resolution whilst avoiding a file size too impractical to be used in research. Before the creation of this DEM, the only other nationally available topographic data was the Landcare $25 \mathrm{~m}$ and SRTM 90m (LRIS, 2018; OpenTopography, 2018).

To interpolate the contour lines and height points into a raster grid, the ANUDEM method was chosen (there are numerous interpolation techniques, the advantages and disadvantages of which are detailed below). The ANUDEM method was developed at Australian National University and uses splines to generate a hydrologically correct DEM through the removal of false sinks (a sink is the end of a flow direction pathway) (Columbus et al., 2011).

Arun (2013) found that ANUDEM produced a DEM that represented hilly terrain much better than other methods, as stream and ridgeline areas had a low RMSE value (a comparison of modelled and observed elevation data at test points measured by field survey or a known contour height). This low RMSE value makes ANUDEM an appropriate choice to model New Zealand's topography. The drainage enforcement algorithm in ANUDEM is one of the main innovations that led Columbus et al. (2011) to select it. Their tests showed it produced a DEM with fewer artefacts compared to other methods. This algorithm provides additional outputs that assess the quality of the DEM, optimise the resolution and detect data errors (Hutchinson, 2011). Limiting artefacts in the DEM reduces the need for manual editing of the interpolated grid, and the drainage conditioning of the DEM produces accurate drainage properties based on a small set of surface specific data (Hutchinson, 2011).

\section{NZ 8m DEM}

This DEM was developed in 2012 by Geographx, a map design studio, (Geographx, 2017). It is also derived from the contour line and height point data contained in the LINZ Topo 50. The purpose of this DEM was to describe natural landforms therefore it is primarily a cartographic visualisation tool not suitable for terrain analysis (LINZ, 
2017c). LINZ does note that this DEM can be used for some preliminary analysis when looking at natural landforms to identify areas of interest, before the acquisition of high-resolution data (LINZ, 2017c). This 8m DEM is used in this thesis on several sites where only national DEM data is available.

\subsubsection{DEM Accuracy}

The accuracy of a DEM and the outputs derived depend on: the source of the elevation data (either active or passive sensors); the density and distribution of elevation samples; the method of data interpolation into a network, and the chosen grid size of the DEM (Liu et al., 2007; Thompson et al., 2001). This section considers each of these factors in more detail.

\section{Source of Elevation Data}

With satellite imagery providing bulk, high-speed information about the land surface, elevation data is collected through both passive and active sensors. Passive sensors detect radiation that has been emitted or reflected by an object in visible, nearinfrared, mid-infrared and thermal infrared wavelengths. Active sensors, unlike passive sensors, can direct electromagnetic energy towards the target and detect the reflected energy, enabling data collection independent of atmospheric conditions such as cloud and light conditions (Figure 4.5) (Dong \& Chen, 2017). It is important to note that elevation estimates from both sensor types are based on the visible land surface rather than the ground level, and this could affect the results of spatial models such as LUCl. If errors are present, the DEM may require correction to ensure that elevation at ground level is represented accurately.

\section{Aerial Photography}

Aerial photography is a passive sensor and thus is of variable accuracy as passive sensors are unable to detect the ground in cloudy or low light conditions. Aerial photography was initially conducted using balloons, kites and gliders. Photographs were taken for the first time from an aircraft in 1908, and aerial photography for military reconnaissance developed rapidly during World War I and II (Dong \& Chen, 2017). Aerial imagery became the basis for topographic maps from the 1920s, and as 
colour and infrared imaging was developed, aerial imaging became widely used to interpret the Earth.

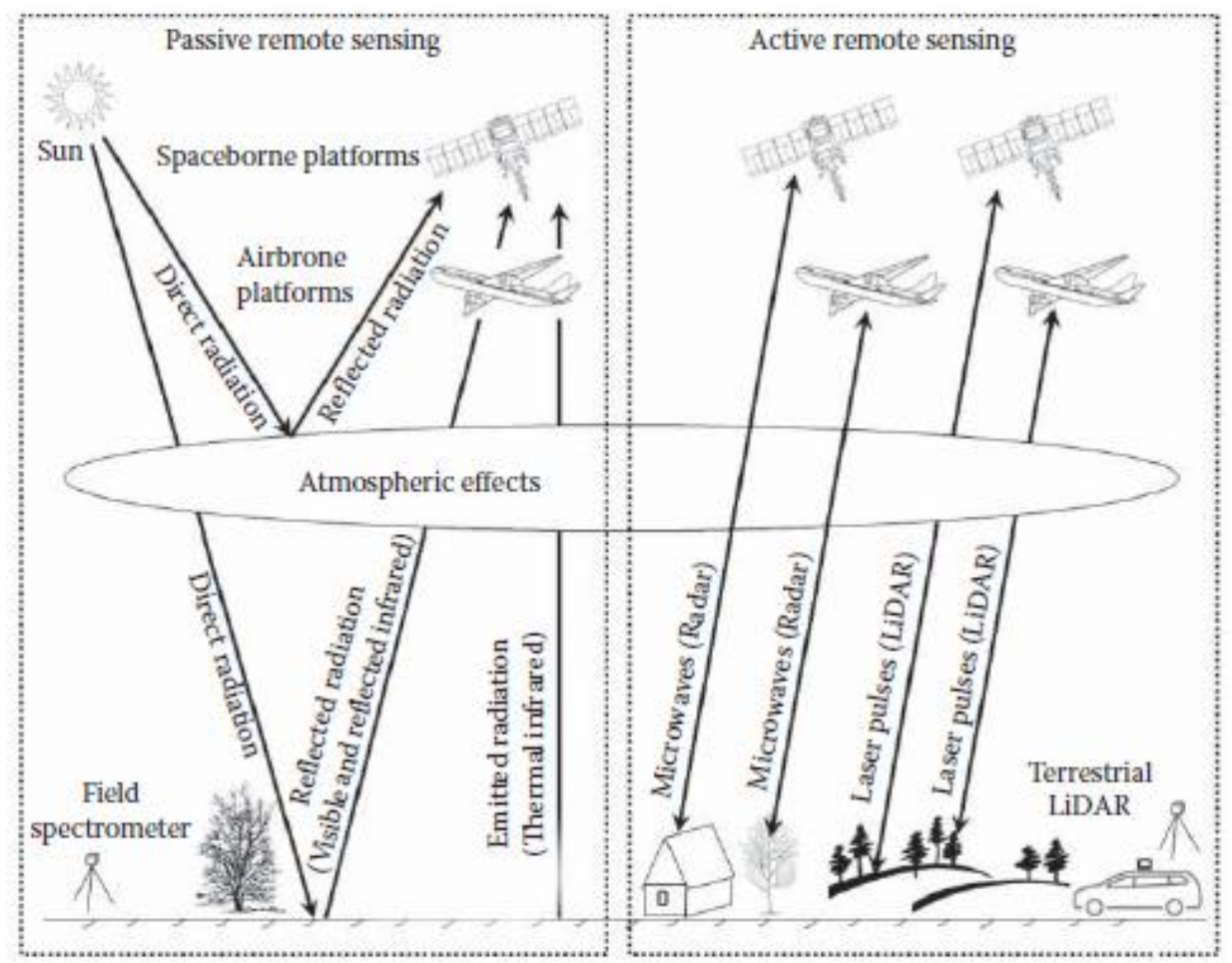

Figure 4.5 A comparison of passive and active remote sensors. Source: Dong \& Chen (2017).

The development of aerial imagery made it possible for researchers to map landscapes in areas that were inaccessible to field researchers, and aid in interpreting ground information through the inclusion of topographic information since infrared photographs provided information that was previously unobtainable (Dong \& Chen, 2017). The construction of a DEM sourced from photogrammetry has many modelling and processing steps (this is true for all DEMs generated from both passive and active sensors) (Figure 4.6). Each of these steps introduces random and systematic errors. Random errors arise from a lack of precision in the triangulation of target points on a photograph, whereas systematic errors include instrumental and pilot errors that cannot be rectified by an interpolation process (Fisher \& Tate, 2006).

\section{$\underline{\text { LiDAR }}$}


Collecting high accuracy terrain data by field survey is costly and time-consuming and, in some places, it may be too difficult to collect (e.g. densely forested or remote regions) (Liu et al., 2007). LiDAR is an alternative method of collecting high accuracy and high precision point data which describes a landscape based on irregular point measurements, which can be converted into a regular grid using interpolation techniques (Lloyd \& Atkinson, 2006). LiDAR is an active sensor and has been in use since the 1960's. The more accurate and dense the data collected, the more accurate the DEM will be (Hodgson et al., 2003). However, Lui et al. (2007) found that LiDAR density can be reduced, to enable easier data handling and storage, without decreasing the accuracy of the DEM. The study compared two $5 \mathrm{~m}$ DEMs, a DEM produced from the original dataset and another using $50 \%$ of the data with a point spacing of $2.4 \mathrm{~m}$. The study concluded that the removal of redundant data enabled faster data processing, but the extent to which researchers can reduce their data depends on the complexity of the terrain (Lui et al., 2007).

PROCESS

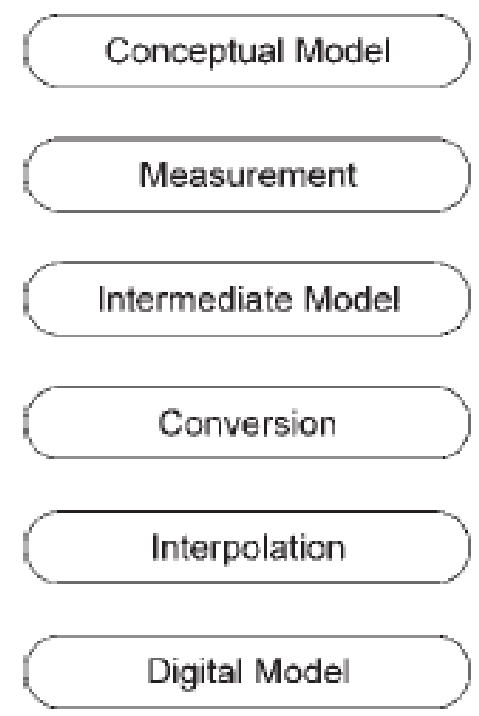

EXAMPLE

The Land Surface

Photogrammetric Survey

Contour Map

Digitization of Contours

TIN interpolation

DEM

Figure 4.6 Processing steps to create a DEM from photogrammetry. Source: Fisher \& Tate (2006).

A LiDAR system consists of an aircraft equipped with a scanning laser sensor, the position of which is continuously monitored by GPS (Hodgson et al., 2003). The laser scanner records the distance to the surface and the location of the surface is 
calculated by the spatial $(x, y, z)$ location and the angle of the laser scanner for that measurement. From $4000 \mathrm{ft}(1219 \mathrm{~m})$ a pulsed LiDAR beam will project a $24-60 \mathrm{~cm}$ diameter area on the surface. These are discrete measurements and can be separated by up to several metres (Hodgson et al., 2003). The density of these points along a flight line makes up a key component of the accuracy of the DEM produced from this data.

Elevation measurements by the methods discussed above have a horizontal error defined by the accuracy of the horizontal coordinates, and a vertical accuracy defined as the linear error of the datasets coordinate (Octariady et al., 2017). The vertical accuracy of DEMs produced from LiDAR data have been found to be better than that of DEMs from satellite imagery, with vertical accuracy achievable to less than $30 \mathrm{~cm}$ in LiDAR DEMs with varying horizontal accuracy (Octariady et al., 2017). To reach these levels of accuracy, ground-filtering algorithms are applied to determine point returns from ground and non-ground features (Meng et al., 2010). In regions with high surface variability (natural relief change, dense forests and urban areas), determining the actual height to ground can be challenging.

Shrub-covered areas are commonly mislabelled as ground surface by the filtering algorithms. This is because shrubs are usually less then $1 \mathrm{~m}$ in height, meaning that elevations differences between individual ground points and neighbouring shrubs are similar, especially if the underlying topography is variable (Meng et al., 2010). In situations with dense vegetation cover, vertical accuracy is affected as there are few actual ground point measurements available within the dataset for the filtering algorithms to use, thereby increasing the vertical error in the LiDAR data (Holmes et al., 2000).

\section{Distribution of Samples}

The level of processing required after the collection of point measurements using LiDAR or photogrammetry depends on the distribution of samples. If resources are available, LiDAR or photogrammetry can be used to collect measurements in a uniform grid, meaning that little data processing is required. However, if the source data is irregular, further errors can be introduced to the final DEM, as variations in the spacing 
between data points requires interpolation to recorded height measurements at all grid points (Fisher \& Tate, 2006).

Not only does the interpolation technique used on the sampled elevation data have the potential to introduce errors in addition to the random and systematic errors discussed above, but it also controls the final resolution of the DEM. Fisher \& Tate (2006) describe the resolution of a DEM as a discrete sampling of a continuous function, meaning information is lost at distances smaller than the sampling interval and data is altered at distances greater than the sampling interval. This can be seen with the changes in slope and aspect when four DEMs are compared with $100 \mathrm{~m}, 50 \mathrm{~m}$, $25 \mathrm{~m}$ and $5 \mathrm{~m}$ resolution in the Kienzle (2004) study. This study compared DEMs produced from the same data using the same interpolation technique and found that modelled soil erosion and slope increased with a decrease in DEM grid size, with the largest DEM grid cell estimating $21.4 \mathrm{t} \mathrm{ha}^{-1} \mathrm{yr}^{-1}$ compared to the smallest DEM grid size estimate of $35.4 \mathrm{t} \mathrm{ha}^{-1} \mathrm{yr}^{-1}$ (Kienzle, 2004). These results are also reflected in Zhang \& Montgomery (1994); Kienzle (1994); and Elsheikh \& Guercio (1997). When modelling sediment-bound nutrients like phosphorus, researchers must take these factors into account as erosion soil loss equations such as the one used by $\mathrm{LUCl}$ will be impacted by the resolution of the DEM.

\section{Data Interpolation}

Interpolating elevation points within a sampled dataset provides a representation of land surfaces between point measurements and enables spatial models to be applied to an area (Anderson et al., 2005). Each of these interpolation methods is based on the principle of spatial autocorrelation, where closer points are more similar compared to points farther away (Arun, 2013). These are split into two categories; deterministic and geospatial. Deterministic interpolation creates a surface from the measured points without incorporating statistical analysis on the spatial properties of the data. As such, they are particularly useful at handling large datasets (Anderson et al., 2005). Geospatial, as the name suggests, utilises statistical properties of the provided sample points to estimate the elevation of unsampled areas through spatial correlation (Cressie, 1993). 
Examples of deterministic interpolation methods are inverse distance weighting (IDW) and nearest neighbour. IDW calculates a point through the influence of the local measured points around it; this influence decreases with distance (Watson, 1992; Anderson et al., 2005). A user-defined parameter is used to determine the level of influence the nearest points have in the calculation (Arun, 2013). Nearest neighbour uses the surrounding samples to estimate the value of missing elevation data; it does not create troughs or peaks that are not represented in the data and has been found to work in irregularly and regularly spaced datasets (Arun, 2013). Unlike IDW, there is no user input required. Geospatial interpolation techniques, like kriging, are seen as a more rigorous approach to develop a DEM. Kriging uses the correlation of data points as the source of its estimates (like IDW, closer measured points have more weight in the calculation then points farther away) rather than the actual data values (Anderson et al., 2005).

\section{The Grid Size of a DEM}

Once a DEM is produced, issues arise as there is little control over how the DEM is used for research, and if the limitations of the DEM are properly considered (Fryer et al., 1994; Moore et al., 1991). More recently, the importance of scale in remotely sensed datasets has been highlighted, as the coarser the DEM, the greater the risk of high-value and low areal extent landscapes to be overlooked when mapping ecosystem services (Konarska et al., 2002). Researchers need to address the scale their work is focusing on and the patterns their study is attempting to explain, as the detail required to model ecosystem services varies greatly depending on the question asked. The scale used in remotely sensed landcover datasets shows that as the grid size is altered, the amount of area covered by each landcover class changes, with increasing land fragmentation known to occur as the grid size becomes coarser (Liu et al., 2007).

DEM based modelling at the farm or watershed scale is increasingly being used by policymakers at regional or national scales. This causes problems as upscaling or downscaling a model reduces the accuracy of the inputs' representativeness of the landscape and reduces a model's ability to represent the heterogeneity in the landscape (Shepherd et al., 2013). DEMs are used in LUCl and other models that 
estimate non-point source pollution to delineate watersheds, identify terrain features and other hydrological parameters. In the OVERSEER model, a DEM is not required. Instead of using a DEM, the model calculates nitrogen and phosphorus loss using transport factors such as drainage class, slope class and rainfall (OVERSEER, 2018). The four separate slope classes, ranging from flat to steep, were based on combinations of LRI slope classes, originally selected for modelling the effect of animal behaviour on excreta transfer, and are defined by the user for each block they are modelling (Table 4.4) (Comforth \& Sinclair, 1982; Metherell \& Morrison, 1984). This means that the OVERSEER model is unable to identify critical source areas as the model is not spatially explicit.

Table 4.4 Topography classes in OVERSEER. Source: Gray et al. (2016a).

\begin{tabular}{|l|l|l|}
\hline Topography Class & Slope & Comments \\
\hline Flat & $0^{\circ}-7^{\circ}$ & \\
\hline Rolling & $8^{\circ}-15^{\circ}$ & Area mostly navigable by tractor \\
\hline Easy Hill & $16^{\circ}-25^{\circ}$ & $>50 \%$ area navigable by tractor \\
\hline Steep Hill & $>26^{\circ}$ & $<50 \%$ area navigable by tractor \\
\hline
\end{tabular}

In models such as $\mathrm{LUCl}$, which investigate a landscape's potential to provide benefits through the configuration of landscape elements and their biophysical properties, the scale of the DEM is immensely important, as finding the correct DEM for an application is a balance between computational efficiency and accuracy. Previous applications of LUCI have suggested that a $5 \mathrm{~m}$ DEM is an adequate resolution to make decisions at a field scale (Jackson et al., 2013). Nevertheless, the impact lower resolution DEMs may have on the hydrology, sediment and chemical routing algorithms in LUCI needs to be investigated, as well as the benefit of using finer scale $1 \mathrm{~m}$ or $2 \mathrm{~m}$ DEMs on the nitrogen and phosphorus results produced. 


\section{CHAPTER 5 METHODS}

This chapter outlines the modelling process for the six case study farms included in the sensitivity study for this research. Section 5.1 discusses the data requirements, site selection process and the background information for each site modelled. Section 5.2 describes the modelling process, including the pre-processing steps and outputs of the LUCI model. Next, the statistical analysis of the nutrient load estimates is discussed, followed by the steps involved to add farm specific soil data in $\mathrm{LUCl}$. Finally, the method developed to include scenarios with multiple siblings in $\mathrm{LUCl}$ is presented.

\subsection{CASE STUDIES AND DATASETS TESTED}

\subsubsection{Data}

While national spatial information is available on land use classifications and management practices, there is no dataset of fine detail. Rutledge et al. (2009) evaluates the geospatial information available to inform land use classifications and argues that New Zealand lacks comprehensive and consistent information covering natural, production and urban landscapes. In the current policy and resource planning environment, the spatial information available does not bridge critical data gaps at national, regional and local scales (Rutledge et al., 2009).

Such data gaps impact the ability of LUCI to accurately model a landscape, as the model relies on information pertaining to precipitation, slope, land cover, soil variability and land management practices (stocking rates and irrigation or fertiliser applications). If these datasets are poor representations of a catchment or farm system, then LUCl's nutrient estimates will be inaccurate.

The data requirements of $\mathrm{LUCl}$ are, at a minimum, cover soil, land cover and a DEM of the area of interest. These can be sourced from nationally available datasets (many are available as default inputs in LUCI if a data license has been obtained by the user, and are discussed in Chapter 3) or, if available, site-specific soil and landcover data can be used in the form of a farm scale survey map and an OVERSEER Nutrient Budget. 
Many national scale datasets are freely available or are provided under license. The LUCI package used in this research includes soil data from FSL, S-Map, landcover data from the LCDB4 and a Ravensdown Hybrid Layer of FSL and S-Map data for OVERSEER. The LUCI data folder also contains NIWA's annual average evaporation and annual average rainfall from 1981-2010. The annual average evaporation dataset was calculated using the accepted Penman-Monteith method outlined in Burman \& Pochop (1994). These datasets were provided under license from Victoria University of Wellington and Ravensdown.

It is outside the scope of this research to investigate the uncertainty in all datasets LUCI uses to estimate nutrient loss on farm systems. However, it should be noted that the accumulation of water and associated nutrients is heavily reliant on the accuracy and representativeness of LUCl's default rainfall dataset. While this thesis focuses on the use of soil, elevation and landcover datasets in $\mathrm{LUCl}$, further work to understand the uncertainty in LUCI's output could consider the representativeness of rainfall averages at catchment scale and farm scale.

Climate, soil, slope and land cover data is available for LUCI model input however, spatial land use data is also available in the form of Land Use New Zealand (LUNZ) created by Landcare Research. This dataset addresses the need for a nationally consistent representation of rural land use and was developed in the Catchment Land Use for Environmental Sustainability (CLUES) project (Rutledge et al., 2009). The dataset expands on landcover classes in the national LCDB4 by splitting land classes up into smaller sub-classes based on the contaminant yield of an area (Semandeni-Davies et al., 2015). Splitting up land class units enables the differentiation of specific types of farming practices (hill country sheep and beef, lowland intensive or high country as well as different crop products). The information on these farming systems was provided to Landcare by land use statistics held in Agribase (Semandeni-Davies et al., 2015). LUNZ is not included in the LUCI model due to the need to maintain land owner privacy, but it does highlight the need for investment in datasets such as LUNZ, to provide models such as $\mathrm{LUCl}$ with specific georeferenced land management information. 


\subsubsection{Case Studies}

To begin to understand the uncertainty in $\mathrm{LUCl}$ outputs linked to the uncertainty in input data, a range of farm environments over both the North and South Island were selected (Figure 5.1). Soil and elevation data combinations using both coarse, nationally available, and farm specific data are tested with the potential uncertainty that could propagate through the modelling process discussed in Chapter 4. These farms were modelled in ArcMap 10.4.1 with the spatial analyst extension as currently $\mathrm{LUCl}$ is not available as a standalone package.

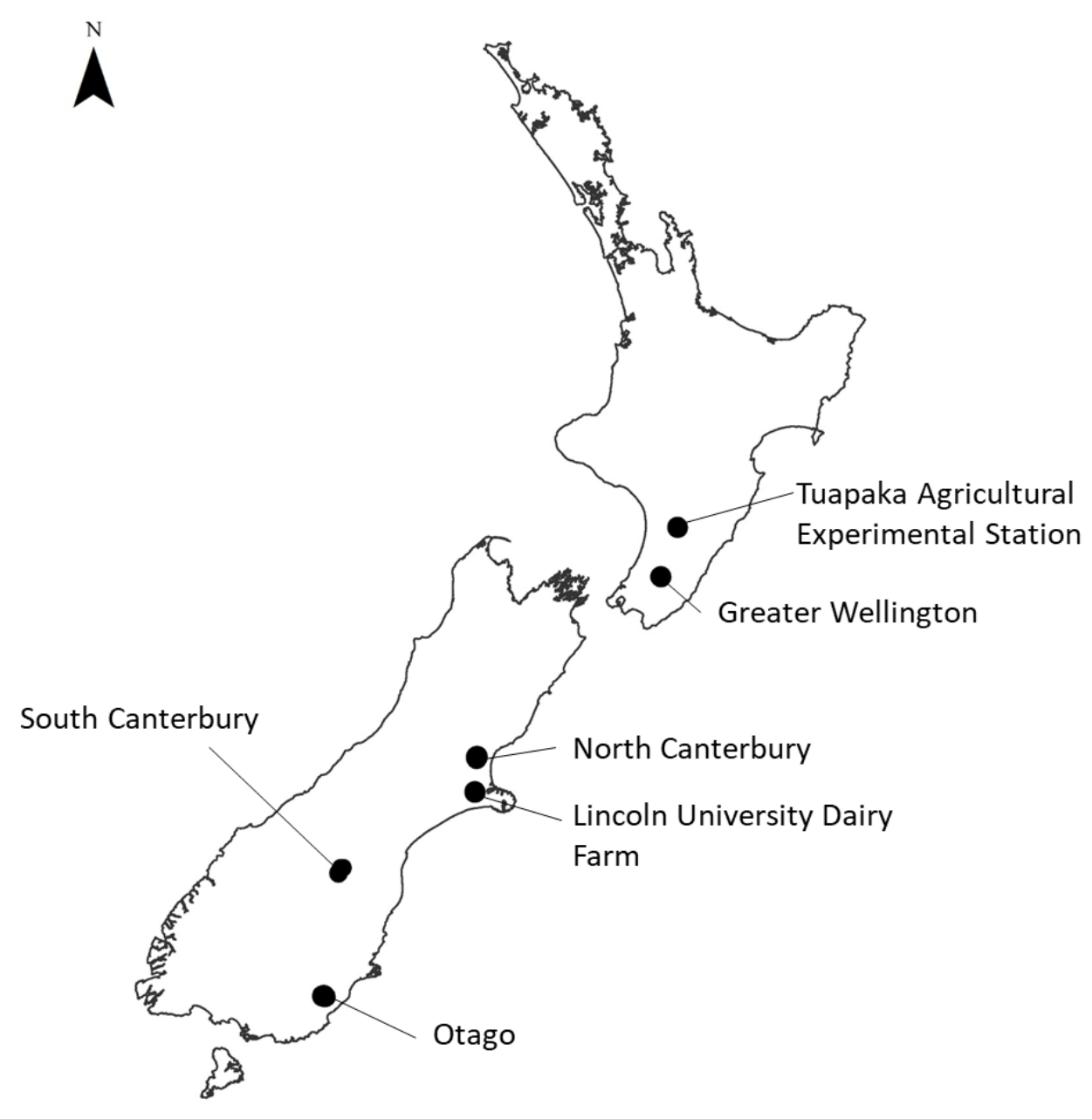

Figure 5.1 Location of case studies used in this sensitivity analysis.

The requirements for sites to be included in this research were that at least two different types of soil and elevation data are available. The sites also need to be clients of Ravensdown. This is due to the commercial sensitivity of the bespoke Ravensdown functionality included within the LUCI model version used here, and to allow access to 
farm specific data for all sites from OVERSEER files produced by Ravensdown Consultants. An OVERSEER Nutrient Budget was used at all sites to provide LUCI with information on the cropping practices, fertiliser and irrigation management, as these factors influence nitrogen and phosphorus lost from farm systems.

To protect the privacy of the farm owners, only University-owned case study sites are identified by their proper name, as these farms have already been widely publicised in previous research. Privately owned farms are referred to by their region. All farms are incorporated into various components of the sensitivity analysis, depending on the data available at each site. Below is a description of each farms enterprise, climate, and topography and the datasets available to model these farms in $\mathrm{LUCl}$.

\subsubsection{Tuapaka Catchment within Tuapaka Agricultural Experimental Station}

This site is a 85 ha sheep and beef farm located east of Palmerston North and is a small catchment within the 476 ha Tuapaka farm platform owned by Massey University. This catchment was selected due to the presence of ongoing water quality monitoring and the ability of this study to complement previous work by Trodahl (2018) comparing LUCl estimates to nitrogen and phosphorus estimates from OVERSEER. The farm is in the foothills of the Tararua ranges and the terrain is rolling to steep hill country (Figure 5.2). Soil at this site is classed as a mix of pallic (poorly drained) and brown (well drained) soil orders (Figure 5.3). Average annual rainfall in this region ranges from $1100-1200 \mathrm{~mm}$ with a mean temperature of $12.2^{\circ} \mathrm{C}$. Soil data available at this site is FSL and a detailed farm scale soil map developed by Massey University (Pollok \& McLaughlin, 1986).

Research at this site includes cow efficiency projects, body condition scoring and wintering systems (Massey University, 2018; Cosgrove et al., 2003; McRae, 2003). Ongoing monitoring of sediment and nutrients from this hill country, sheep and beef environment has been carried out, with monthly in-stream water quality samples collected over the 2013-2015 period summarised in Burkitt et al. (2016). Two DEMs (the national $15 \mathrm{~m}$ and the national $8 \mathrm{~m}$ ) as well as the two soil maps (FSL and Farm Scale) are tested. The classification of the different soil polygons in each dataset is shown in Table 5.1. 


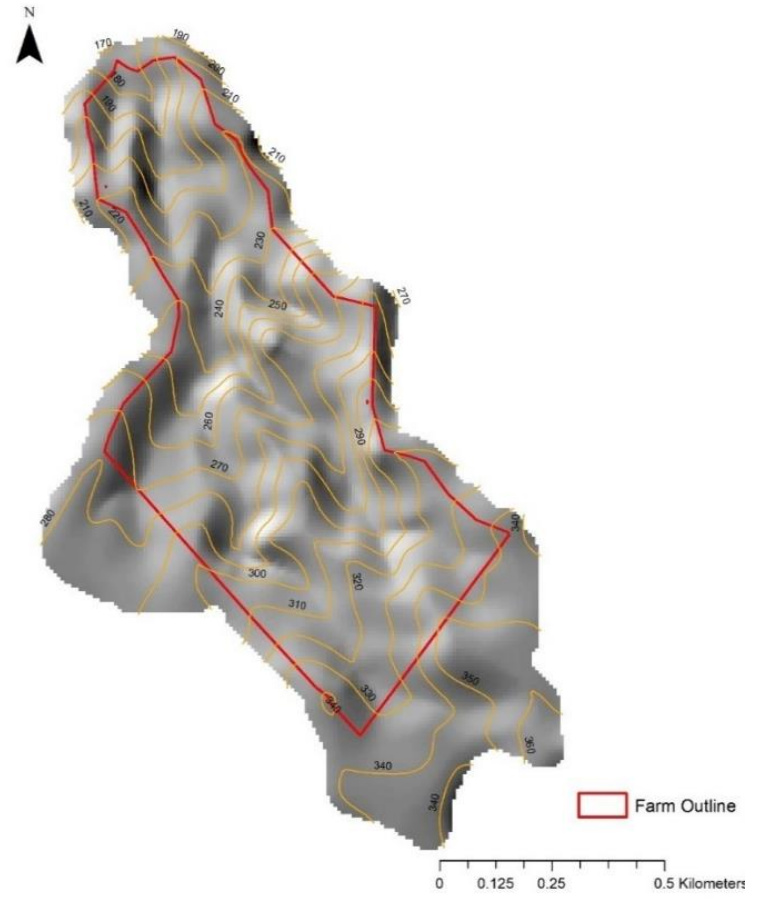

Figure 5.2 Contour map of Tuapaka Catchment.
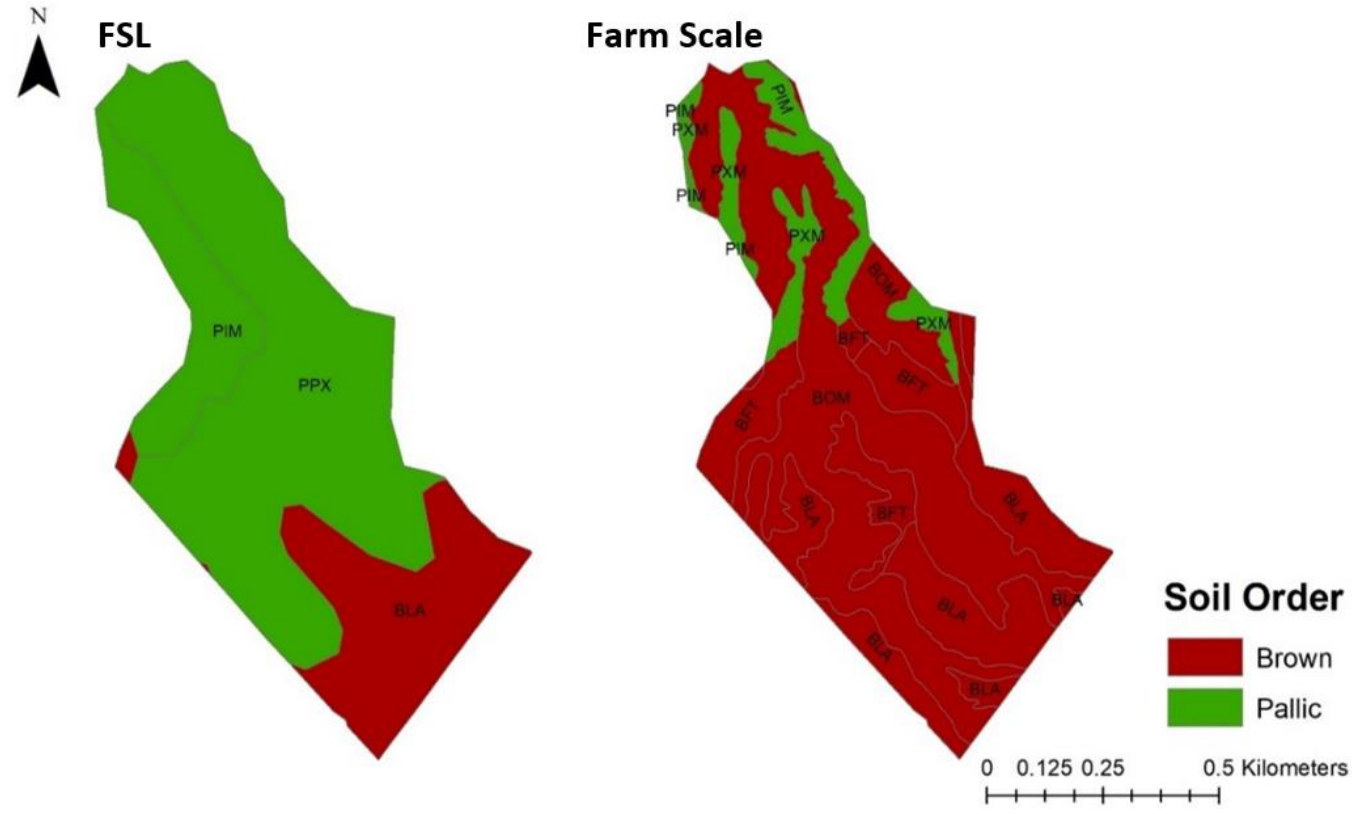

Figure 5.3 Soil order classifications in FSL and the farm scale soil map for Tuapaka, with the labels representing different soil subgroups. 
Table 5.1 Soil properties of the Tuapaka case study held in both the FSL and Farm Scale datasets. Only dominant siblings are shown in the table.

\begin{tabular}{|c|c|c|c|c|c|c|}
\hline Data Source & NZSC Soil Order & NZSC Classification & NZSC Subgroup & Series & Soil Description & $\begin{array}{l}\text { Area } \\
\text { (ha) }\end{array}$ \\
\hline \multirow[t]{3}{*}{ FSL } & Pallic & PXM & Mottled Fragic Pallic Soils & Halcombe & fine sandy loam & 39 \\
\hline & Pallic & PIM & Typic Fluvial Recent Soils & Tuapaka & fine sandy loam & 9 \\
\hline & Brown & BLA & Acidic Allophanic Brown Soils & Ramiha & silt loam & 15 \\
\hline \multirow[t]{5}{*}{ Farm Scale } & Brown & BFT & Typic Firm Brown Soils & Korokoro & silt loam & 8 \\
\hline & Brown & BLA & Acidic Allophanic Brown Soils & Ramiha & silt loam & 15 \\
\hline & Pallic & PXM & Mottled Fragic Pallic Soils & Shannon & silt loam & 4 \\
\hline & Pallic & PIM & Typic Fluvial Recent Soils & Tuapaka & fine sandy loam & 4 \\
\hline & Brown & BOM & Mottled Orthic Brown Soils & Makara & stony loam & 33 \\
\hline
\end{tabular}




\subsubsection{Greater Wellington}

This is a 99 ha dairy farm located west of Carterton in the Mangaterere Catchment. Also located in the foothills of the Tararua ranges it has a mix of flat to rolling topography (Figure 5.4). Annual rainfall in the region is $1500 \mathrm{~mm}$ with an average annual temperature of $12^{\circ} \mathrm{C}$. The soil types are predominantly brown (well drained) soils with recent (well drained) soils located along the stream boundaries. The only major change between the soil datasets is a classification change from all brown soils in the original FSL soil dataset to the inclusion of 10 ha of recent soils with the updated S-Map data on half of the farm (Figure 5.5, Table 5.2).

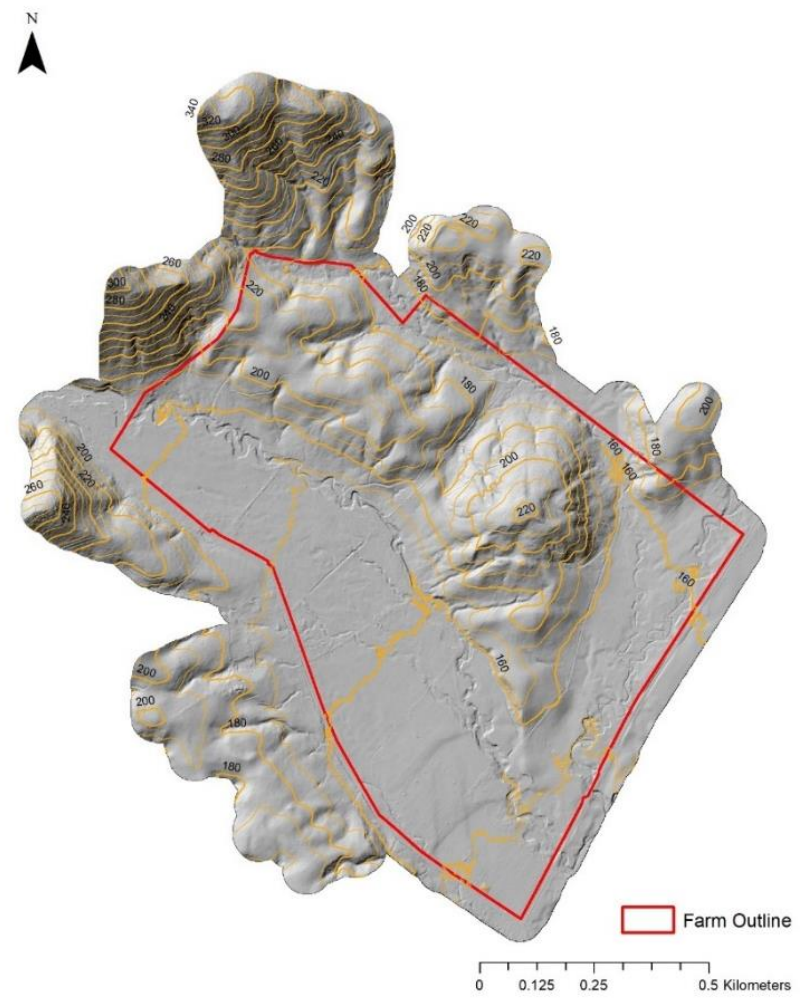

Figure 5.4 Contour map of the Greater Wellington case study. 

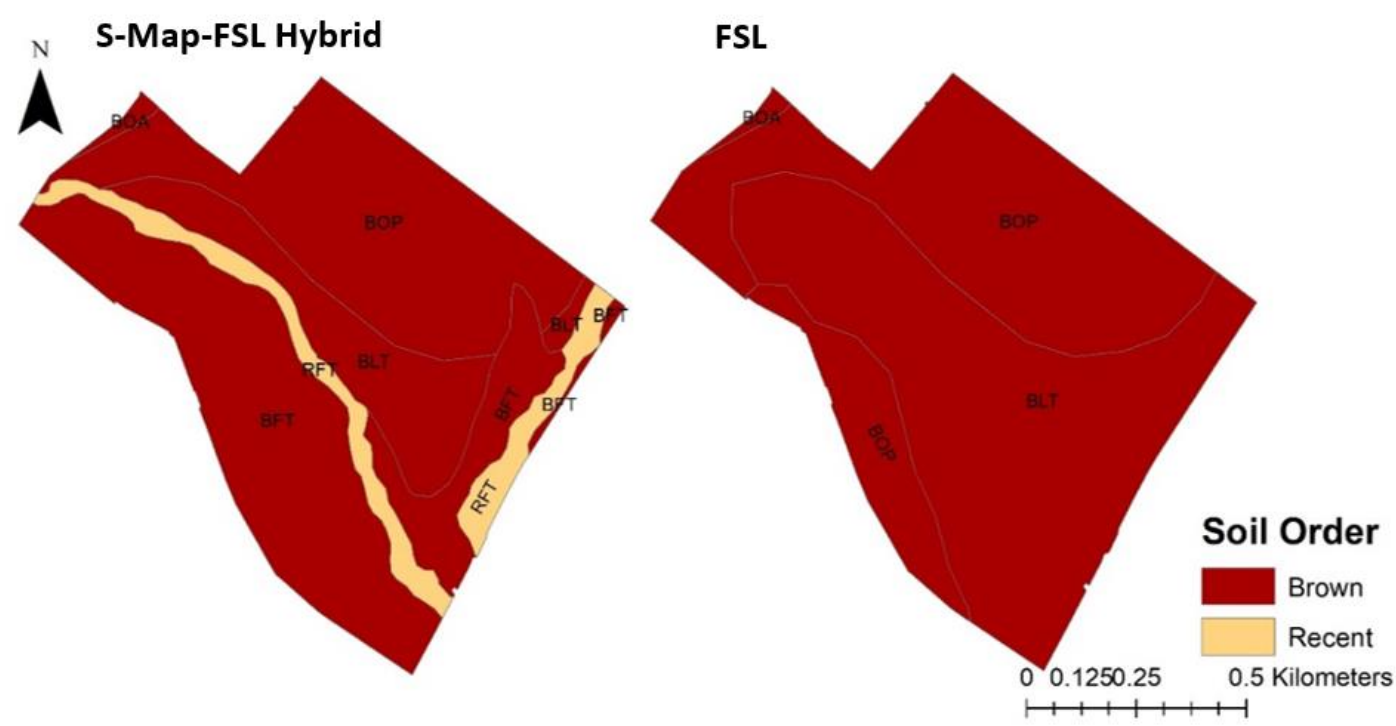

Figure 5.5 Soil order classifications in the S-Map-FSL Hybrid and FSL for Greater Wellington, with the labels representing different soil subgroups.

\subsubsection{North Canterbury}

This site is a 309ha sheep and beef farm located in North Canterbury in the Ashley Watershed. The terrain is mostly flat (Figure 5.6), with a mix of brown (well drained), pallic (poorly to moderately well drained) and recent (well drained) soil orders. The area classified as brown, pallic and recent soils changes between the FSL and S-Map datasets (Figure 5.7). The area classified as brown soil changed from 89ha in FSL to 167ha in S-Map (Table 5.3); this change will impact the drainage properties of the soil and may result in differences in LUCl's estimates of nitrogen loss between soil scenarios. 
Table 5.2 Soil properties of the Greater Wellington case study held in both the FSL and S-Map datasets. Only dominant siblings are shown in the table.

\begin{tabular}{|c|c|c|c|c|c|c|c|}
\hline $\begin{array}{l}\text { Data } \\
\text { Source }\end{array}$ & $\begin{array}{l}\text { NZSC Soil } \\
\text { Order }\end{array}$ & $\begin{array}{l}\text { NZSC } \\
\text { Classification }\end{array}$ & NZSC Subgroup & $\begin{array}{l}\text { NZSC Family } \\
\text { and Sibling }\end{array}$ & Series & Soil Description & Area (ha) \\
\hline \multirow[t]{3}{*}{ FSL } & Brown & BLT & Typic Allophanic Brown Soils & & Kohinui & loam & 49 \\
\hline & Brown & $\mathrm{BOP}$ & Pallic Orthic Brown Soils & & Kaikouta & silt loam & 43 \\
\hline & Pallic & BOA & Acidic Orthic Brown Soils & & Ruahine & stony silt loam & 0.5 \\
\hline \multirow[t]{5}{*}{$\begin{array}{l}\text { S-Map-FSL } \\
\text { Hybrid }\end{array}$} & Recent & RFT & Typic Fluvial Recent Soils & $\begin{array}{l}\text { Huangaruaf' } \\
\text { (Sib 1) }\end{array}$ & & shallow, well drained, silty loam & 10 \\
\hline & Brown & BFT & Typic Firm Brown Soils & Kohinuif' (Sib 4) & & shallow, well drained, silty loam & 39 \\
\hline & Brown & BLT & Typic Allophanic Brown Soils & & Kohinui & loam & 14 \\
\hline & Brown & BOP & Pallic Orthic Brown Soils & & Kaikouta & silt loam & 30 \\
\hline & Brown & $\mathrm{BOA}$ & Acidic Orthic Brown Soils & & Ruahine & stony silt loam & 1 \\
\hline
\end{tabular}




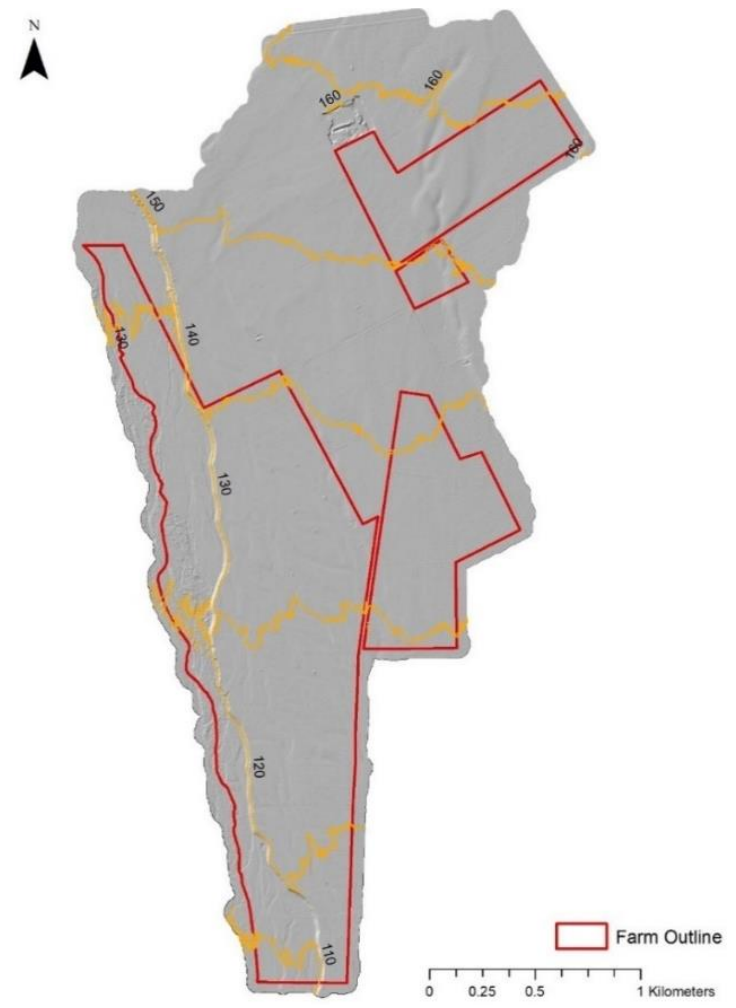

Figure 5.6 Contour map of the North Canterbury case study.
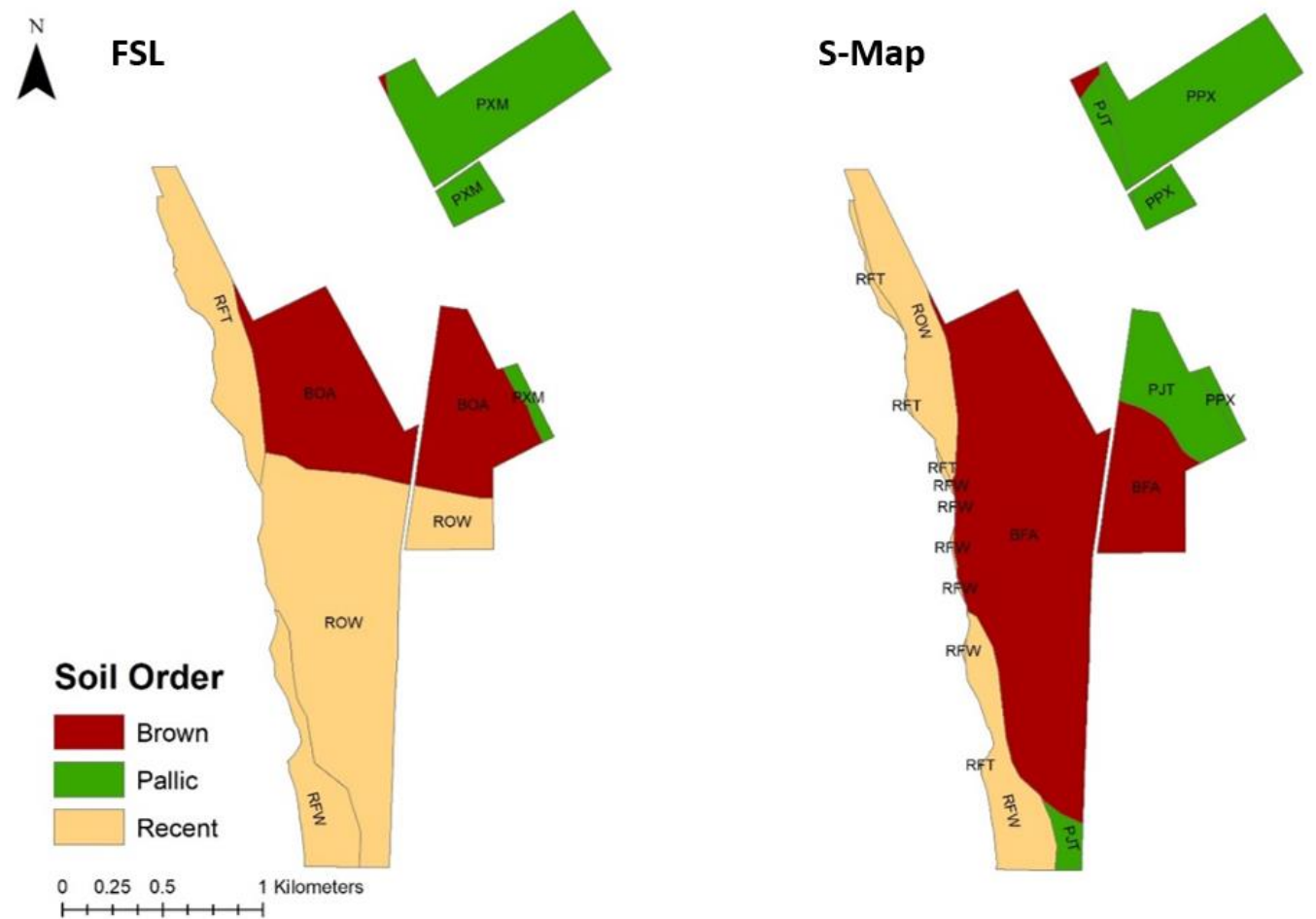

Figure 5.7 Soil order classifications in FSL and S-Map for North Canterbury, with the labels representing different soil subgroups. 
Annual rainfall in the region is between $800-900 \mathrm{~mm}$ and a median annual average temperature of $11-12{ }^{\circ} \mathrm{C}$ (Mascara, 2016). There is one permanent stream running north to south along the western boundary, with 19ha of the total farm area classified as the river bed. Landcover data was taken from the LCDB4 database with $67 \%$ of the farm classed as high producing grassland and $23 \%$ classed as rotational cropland (Figure 5.8). The other smaller areas classified were exotic forest, gorse and deciduous hardwoods. The area classed as exotic forest in the image below is covering a steep escarpment between the main farm block and the river flat, which would normally be an area at risk of erosion and subsequent phosphorus loss. The forest, however, is stabilising the soil. Datasets available to model this farm in LUCl are two soil datasets, FSL and S-Map; two DEMs (the national scale $15 \mathrm{~m}$ DEM and a $2 \mathrm{~m}$ DEM produced from the 2005 Waimakariri LiDAR survey).
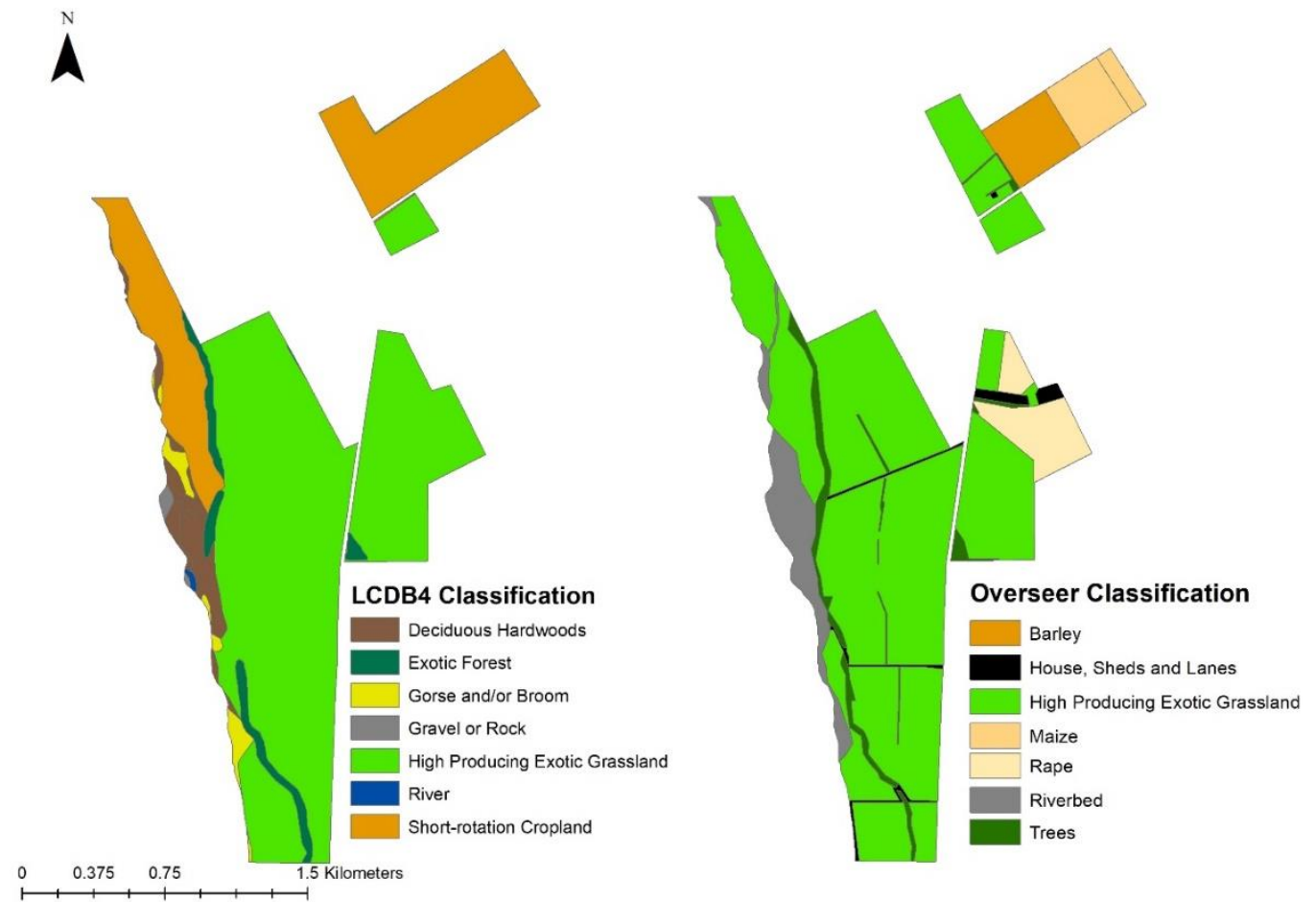

Figure 5.8 Land cover classifications in LCDB4 and OVERSEER. The OVERSEER classification specifies the type of crop grown in each crop block and also splits High Producing Exotic Grassland into Main, Cottage, Yard, South and North River Flat Blocks, which have different management practices. 
Table 5.3 Soil properties of the North Canterbury case study held in both the FSL and S-Map datasets. Only dominant siblings are shown in the table.

\begin{tabular}{|c|c|c|c|c|c|c|c|}
\hline $\begin{array}{l}\text { Data } \\
\text { Source }\end{array}$ & $\begin{array}{l}\text { NZSC Soil } \\
\text { Order }\end{array}$ & $\begin{array}{l}\text { NZSC } \\
\text { Classification }\end{array}$ & NZSC Subgroup & $\begin{array}{l}\text { NZSC Family } \\
\text { and Sibling }\end{array}$ & Series & Soil Description & Area (ha) \\
\hline \multirow[t]{5}{*}{ FSL } & Pallic & PXM & $\begin{array}{l}\text { Mottled Fragic Pallic } \\
\text { Soils }\end{array}$ & & Mairaki & silt loam & 51 \\
\hline & Recent & RFT & Typic Fluvial Recent Soils & & Waimakariri & very stony sandy loam & 29 \\
\hline & Brown & $\mathrm{BOA}$ & Acidic Orthic Brown Soils & & Hororata & very stony silt loam & 89 \\
\hline & Recent & ROW & $\begin{array}{l}\text { Weathered Orthic } \\
\text { Recent Soils }\end{array}$ & & Eyre & shallow silt loam & 108 \\
\hline & Recent & RFW & $\begin{array}{l}\text { Weathered Fluvial } \\
\text { Recent Soils }\end{array}$ & & Waimakariri & sandy loam & 19 \\
\hline \multirow[t]{5}{*}{ S-Map } & Pallic & PJT & Typic Argillic Pallic Soil & Darnleyf' (Sib 7) & & $\begin{array}{l}\text { shallow, moderately well } \\
\text { drained, silty loam }\end{array}$ & 27 \\
\hline & Pallic & PJT & Typic Argillic Pallic Soil & Darnleyf' (Sib 1) & & $\begin{array}{l}\text { shallow, moderately well } \\
\text { drained, silty loam }\end{array}$ & 4 \\
\hline & Recent & RFT & Typic Fluvial Recent Soils & $\begin{array}{l}\text { Rangitataf' (Sib } \\
6)\end{array}$ & & $\begin{array}{l}\text { shallow, well drained, sandy } \\
\text { loam }\end{array}$ & 2 \\
\hline & Recent & RFW & $\begin{array}{l}\text { Weathered Fluvial } \\
\text { Recent Soils }\end{array}$ & Rakaiaf' (Sib 2) & & shallow, well drained, loam & 23 \\
\hline & Brown & BFA & Acidic Firm Brown Soils & $\begin{array}{l}\text { Ruapunaf' (Sib } \\
\text { 2) }\end{array}$ & & shallow, well drained, silty loam & 167 \\
\hline
\end{tabular}




\begin{tabular}{|l|l|l|l|l|l|l|}
\hline & Pallic & PPX & $\begin{array}{l}\text { Fragic Perch-gley Pallic } \\
\text { Soils }\end{array}$ & $\begin{array}{l}\text { Claremontf' (Sib } \\
1)\end{array}$ & $\begin{array}{l}\text { moderately deep, poorly } \\
\text { drained, silty loam }\end{array}$ \\
\cline { 2 - 5 } & Recent & ROW & $\begin{array}{l}\text { Weathered Orthic } \\
\text { Recent Soils }\end{array}$ & Eyref' (Sib 3) & shallow, well drained, silty loam
\end{tabular}




\subsubsection{Lincoln University Dairy Farm}

The Lincoln University Dairy Farm (LUDF) is a 120ha dairy farm located outside Lincoln, Canterbury. This farm is owned by Lincoln University and managed by the South Island Dairying Development Centre (SIDDC) and as such, there is a multitude of published work on the farms nutrient management, fertiliser and cropping practices, and the physical properties of the soil (Moir et al., 2007; Van Bysterveldt, 2005; Longhurst \& Roberts, 2000; Barringer et al., 2016).

This farm has a flat topography and no streams inside its boundary (Figure 5.9), with the entire area classed as high producing grassland in the LCDB4. Average annual rainfall is $666 \mathrm{~mm}$ with a mean annual temperature of $11.8^{\circ} \mathrm{C}$ (SIDDC, 2018). The soil data available at this site includes FSL, S-Map, and a detailed farm scale soil map developed by Barringer at al. (2016) (Figure 5.10). The farm scale soil map was created from a survey of 723 auger holes across the farm, excluding the east block.

Accordingly, the east block was removed in this analysis to ensure the comparison of LUCI's outputs between soil datasets occurs over the same area.

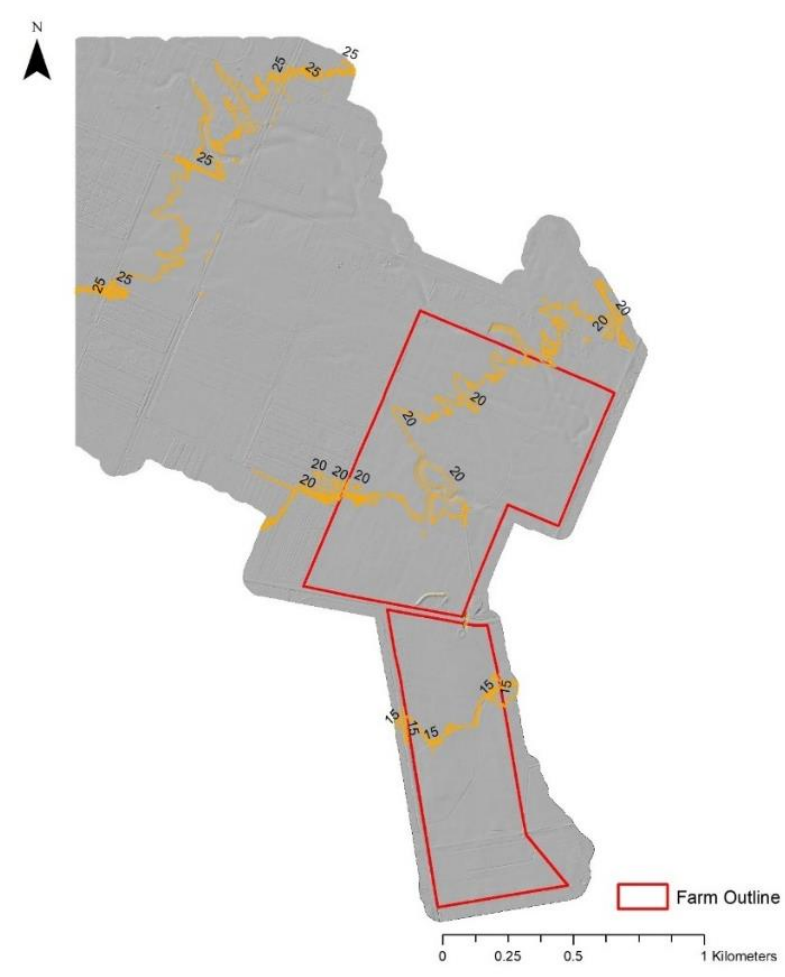

Figure 5.9 Contour map of the LUDF case study. 

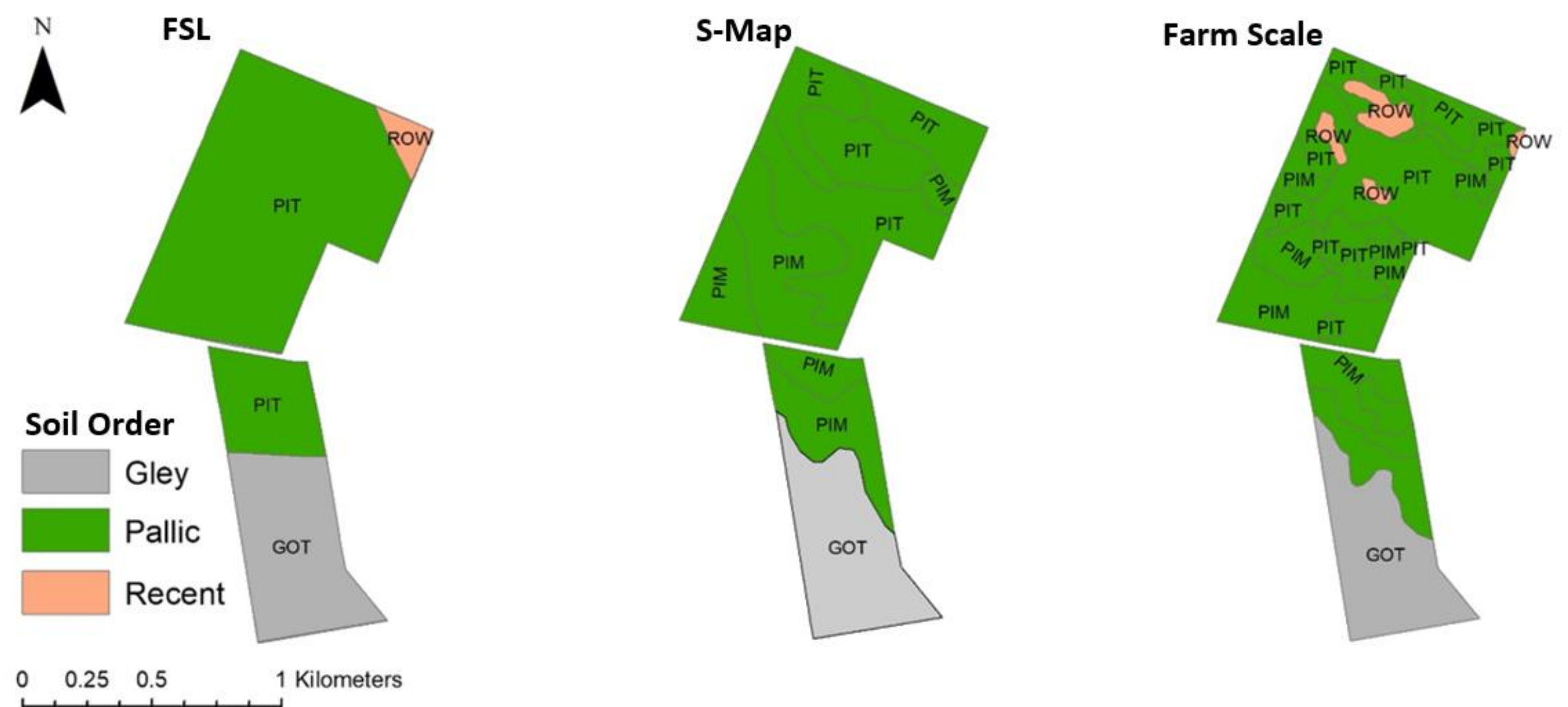

Figure 5.10 Soil order classifications in FSL, S-Map and the farm scale soil map for LUDF, with the labels representing different soil subgroups. 
The soil at this site is characterised as gley (poorly drained), pallic (poorly drained) and recent soils (well drained). The level of information pertaining to these soil characteristics varies between soil datasets with four soil siblings identified in the FSL; 12 siblings in S-Map (seven dominant and five subdominant), and eight soil siblings in the farm scale soil map (Barringer et al., 2016) (Table 5.4). Two DEMs are tested against the different soil datasets, these are the national $15 \mathrm{~m}$ DEM and a $1 \mathrm{~m}$ DEM produced from the 2017 LiDAR survey owned by Environment Canterbury.

\subsubsection{South Canterbury}

This is a 2,969 ha sheep and beef farm located on the shores of Lake Benmore, South Canterbury. It has a mix of flat and steep hill topography (Figure 5.11), with a mean annual rainfall of $520 \mathrm{~mm}$ and an annual temperature of $10^{\circ} \mathrm{C}$. Soil types on this site are a mix of predominantly pallic and recent soils, with brown soils classified in the FSL database and reclassified as recent soils with the update to S-Map (Figure 5.12, Table 5.5). A small area of semiarid soils is also defined in FSL on the flat sections of the site. This will be tested with a 10m DEM produced from photogrammetry from the 2013-14 rural aerial survey licensed by Aqualinc limited as well as the national 15m DEM.

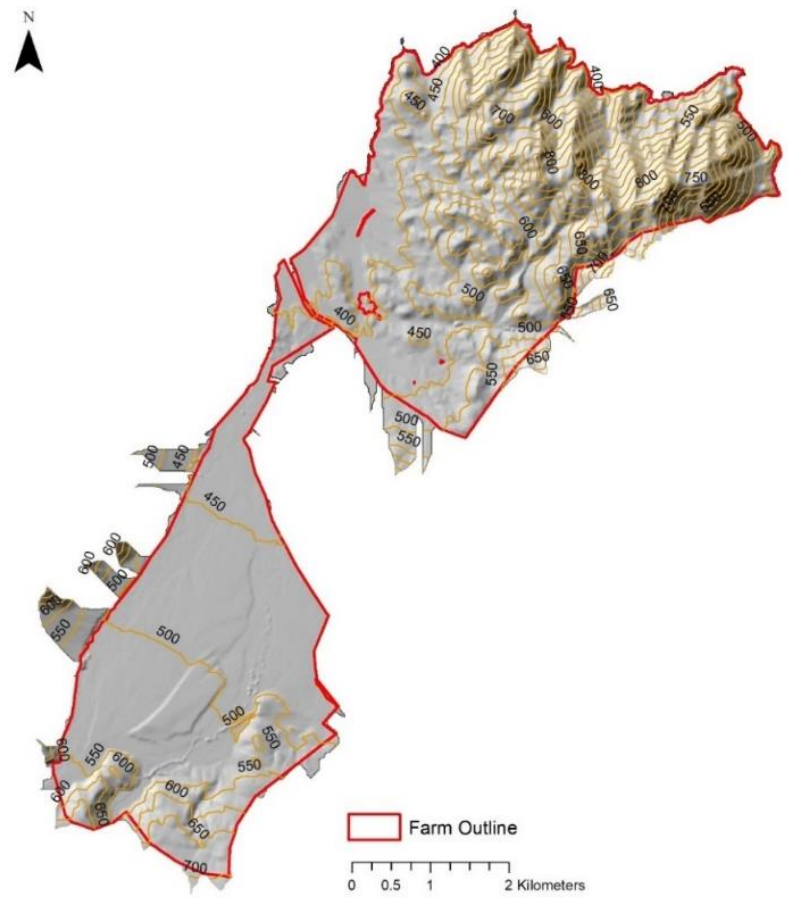

Figure 5.11 Contour map of the South Canterbury case study. 
Table 5.4 Soil properties of the LUDF case study held in both the FSL, S-Map and Farm Scale datasets. Only dominant siblings are shown in the table.

\begin{tabular}{|c|c|c|c|c|c|c|c|}
\hline $\begin{array}{l}\text { Data } \\
\text { Source }\end{array}$ & NZSC Soil Order & $\begin{array}{l}\text { NZSC } \\
\text { Classification }\end{array}$ & NZSC Subgroup & $\begin{array}{l}\text { NZSC Family and } \\
\text { Sibling }\end{array}$ & Series & Soil Description & Area (ha) \\
\hline \multirow[t]{3}{*}{ FSL } & Recent & ROW & $\begin{array}{l}\text { Weathered Orthic Recent } \\
\text { Soils }\end{array}$ & & Paparua & stony sandy loam & 3 \\
\hline & Gley & GOT & Typic Orthic Gley Soils & & Temuka & silt loam & 28 \\
\hline & Pallic & PIT & Typic Immature Pallic Soils & & Templeton & silt loam & 88 \\
\hline \multirow[t]{7}{*}{ S-Map } & Pallic & PIM & $\begin{array}{l}\text { Mottled Immature Pallic } \\
\text { Soils }\end{array}$ & Wakanuif' (Sib 3) & & $\begin{array}{l}\text { deep, imperfectly drained, silty loam } \\
\text { over sandy loam }\end{array}$ & 23 \\
\hline & Pallic & PIT & Typic Immature Pallic Soils & Templetonf' (Sib 4) & & $\begin{array}{l}\text { moderately deep, moderately well } \\
\text { drained, silty loam }\end{array}$ & 10 \\
\hline & Pallic & PIT & Typic Immature Pallic Soils & Templetonf' (Sib 1) & & $\begin{array}{l}\text { deep, moderately well drained, silty } \\
\text { loam }\end{array}$ & 21 \\
\hline & Pallic & PIT & Typic Immature Pallic Soils & Templetonf' (Sib 2) & & $\begin{array}{l}\text { moderately deep, moderately well } \\
\text { drained, silty loam }\end{array}$ & 9 \\
\hline & Pallic & PIT & Typic Immature Pallic Soils & Barrhillf' (Sib 5) & & $\begin{array}{l}\text { deep, well drained, loam over sandy } \\
\text { loam }\end{array}$ & 10 \\
\hline & Pallic & PIM & $\begin{array}{l}\text { Mottled Immature Pallic } \\
\text { Soils }\end{array}$ & Wakanuif' (Sib 1) & & deep, imperfectly drained, silty loam & 19 \\
\hline & Gley & GOT & Typic Orthic Gley Soils & Flaxtonf' (Sib 4) & & $\begin{array}{l}\text { deep, poorly drained, silty loam over } \\
\text { clay }\end{array}$ & 26 \\
\hline
\end{tabular}




\begin{tabular}{|c|c|c|c|c|c|c|}
\hline \multirow[t]{8}{*}{$\begin{array}{l}\text { Farm } \\
\text { Scale }\end{array}$} & Recent & ROW & $\begin{array}{l}\text { Weathered Orthic Recent } \\
\text { Soils }\end{array}$ & Eyref' (Sib 2) & shallow, well drained, loam & 5 \\
\hline & Pallic & PIT & Typic Immature Pallic Soils & Templetonf' (Sib 1) & $\begin{array}{l}\text { deep, moderately well drained, silty } \\
\text { loam }\end{array}$ & 13 \\
\hline & Pallic & PIT & Typic Immature Pallic Soils & Barrhillf' (Sib 5) & $\begin{array}{l}\text { deep, well drained, loam over sandy } \\
\text { loam }\end{array}$ & 63 \\
\hline & Pallic & PIM & $\begin{array}{l}\text { Mottled Immature Pallic } \\
\text { Soils }\end{array}$ & Wakanuif' (Sib 3) & $\begin{array}{l}\text { deep, imperfectly drained, silty loam } \\
\text { over sandy loam }\end{array}$ & 11 \\
\hline & Pallic & PIM & $\begin{array}{l}\text { Mottled Immature Pallic } \\
\text { Soils }\end{array}$ & Wakanuif' (Sib 1) & deep, imperfectly drained, silty loam & 23 \\
\hline & Pallic & PIM & $\begin{array}{l}\text { Mottled Immature Pallic } \\
\text { Soils }\end{array}$ & Ballancef' (Sib 6) & $\begin{array}{l}\text { moderately deep, imperfectly drained, } \\
\text { silty loam over clay }\end{array}$ & 2 \\
\hline & Gley & GOT & Typic Orthic Gley Soils & Temukaf' (Sib 57) & deep, poorly drained, clay & 24 \\
\hline & Pallic & PIM & $\begin{array}{l}\text { Mottled Immature Pallic } \\
\text { Soils }\end{array}$ & Ballancef' (Sib 7) & $\begin{array}{l}\text { moderately deep, imperfectly drained, } \\
\text { silty loam over clay }\end{array}$ & 7 \\
\hline
\end{tabular}




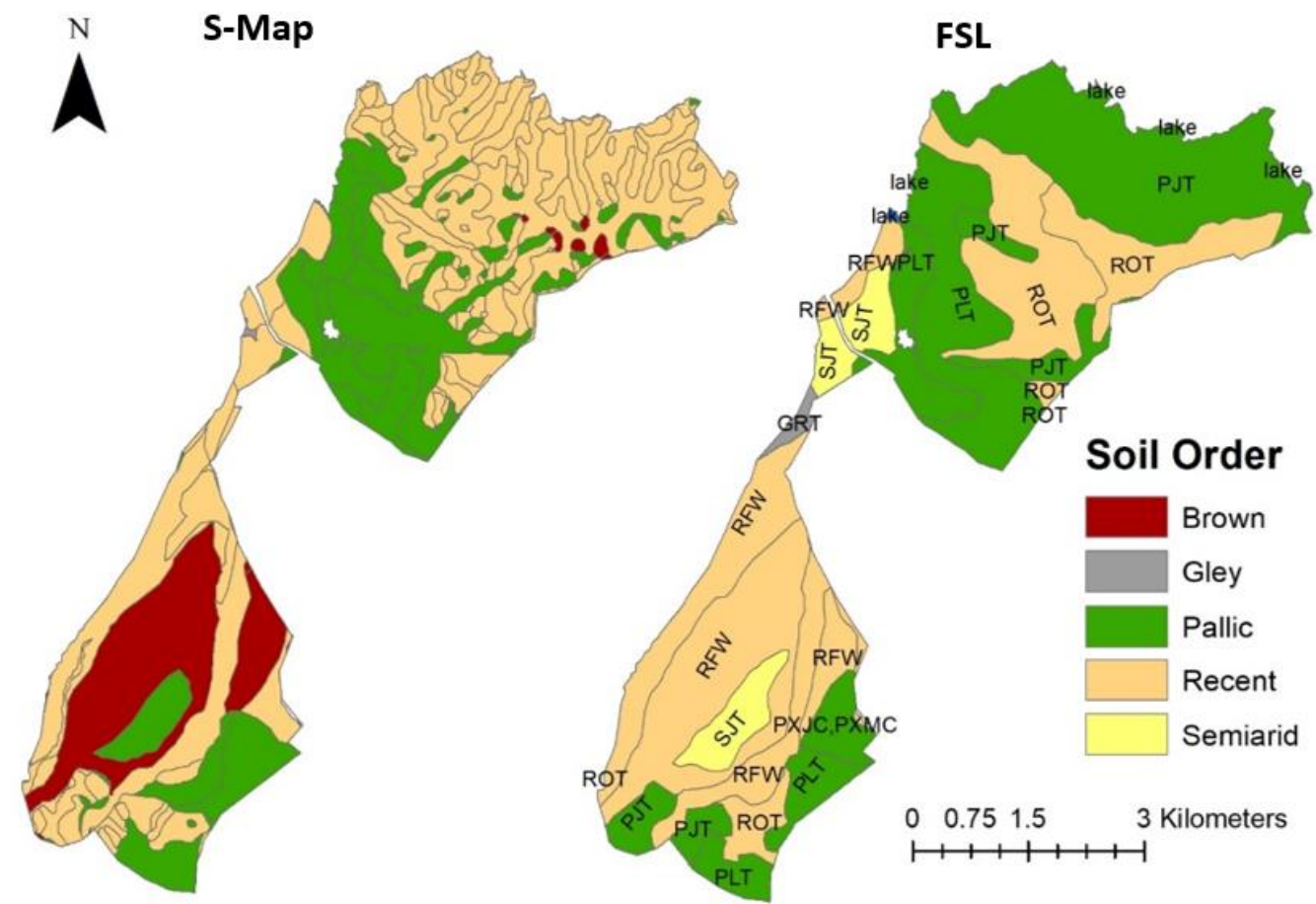

Figure 5.12 Soil order classifications in S-Map and FSL for South Canterbury, with the labels representing different soil subgroups. 
Table 5.5 Soil properties of the South Canterbury case study held in both the FSL and S-Map. Only dominant siblings are shown in the table.

\begin{tabular}{|c|c|c|c|c|c|c|c|}
\hline $\begin{array}{l}\text { Data } \\
\text { Source }\end{array}$ & $\begin{array}{l}\text { NZSC Soil } \\
\text { Order }\end{array}$ & $\begin{array}{l}\text { NZSC } \\
\text { Classification }\end{array}$ & NZSC Subgroup & $\begin{array}{l}\text { NZSC Family and } \\
\text { Sibling }\end{array}$ & Series & Soil Description & Area (ha) \\
\hline \multirow[t]{7}{*}{ FSL } & Pallic & PJT & $\begin{array}{l}\text { Typic Argillic Pallic } \\
\text { Soil }\end{array}$ & & Waitaki & shallow silt loam & 726 \\
\hline & Recent & ROT & $\begin{array}{l}\text { Typic Fluvial } \\
\text { Recent Soils }\end{array}$ & & Omarama & silt loam on clay loam & 559 \\
\hline & Pallic & PLT & $\begin{array}{l}\text { Typic Orthic } \\
\text { Recent Soils }\end{array}$ & & Otematata & silty loam & 569 \\
\hline & Recent & RFW & $\begin{array}{l}\text { Weathered } \\
\text { Fluvial Recent } \\
\text { Soils }\end{array}$ & & Eweburn & sandy loam & 827 \\
\hline & SemiArid & SJT & $\begin{array}{l}\text { Saline Argillic } \\
\text { Semiarid Soils }\end{array}$ & & Ranfurly & fine sandy loam & 178 \\
\hline & Gley & GRT & $\begin{array}{l}\text { Typic Recent Gley } \\
\text { Soils }\end{array}$ & & Dobson & shallow soils & 17 \\
\hline & Pallic & PXJC & $\begin{array}{l}\text { Argillic Fragic } \\
\text { Pallic Soils }\end{array}$ & & & Grampians & 66 \\
\hline S-Map & Brown & BOA & $\begin{array}{l}\text { Acidic Orthic } \\
\text { Brown Soils }\end{array}$ & Benmoref' (Sib 2) & & $\begin{array}{l}\text { shallow, well drained, } \\
\text { silty loam }\end{array}$ & 15 \\
\hline
\end{tabular}




\begin{tabular}{|c|c|c|c|c|c|}
\hline Brown & BOP & $\begin{array}{l}\text { Pallic Orthic } \\
\text { Brown Soils }\end{array}$ & $\begin{array}{l}\text { Mackenzief' (Sib } \\
\text { 7) }\end{array}$ & $\begin{array}{l}\text { very shallow, well } \\
\text { drained, loam }\end{array}$ & 419 \\
\hline Brown & BOP & $\begin{array}{l}\text { Pallic Orthic } \\
\text { Brown Soils }\end{array}$ & $\begin{array}{l}\text { Mackenzief' (Sib } \\
\text { 9) }\end{array}$ & $\begin{array}{l}\text { shallow, well drained, } \\
\text { sandy loam }\end{array}$ & 1 \\
\hline Gley & GRT & $\begin{array}{l}\text { Typic Recent Gley } \\
\text { Soils }\end{array}$ & Te Kakahif' (Sib 7) & $\begin{array}{l}\text { shallow, very poorly } \\
\text { drained, silty loam }\end{array}$ & 2 \\
\hline Pallic & PIT & $\begin{array}{l}\text { Typic Immature } \\
\text { Pallic Soils }\end{array}$ & Glenrockf' (Sib 5) & $\begin{array}{l}\text { shallow, well drained, } \\
\text { silty loam }\end{array}$ & 121 \\
\hline Pallic & PJM & $\begin{array}{l}\text { Mottled Argillic } \\
\text { Pallic Soils }\end{array}$ & Salixf' (Sib 7) & $\begin{array}{l}\text { deep, imperfectly } \\
\text { drained, clay }\end{array}$ & 1 \\
\hline Pallic & PJT & $\begin{array}{l}\text { Typic Argillic Pallic } \\
\text { Soils }\end{array}$ & $\begin{array}{l}\text { Otematataf' (Sib } \\
\text { 1) }\end{array}$ & $\begin{array}{l}\text { very shallow, well } \\
\text { drained, silty loam }\end{array}$ & 43 \\
\hline Pallic & PJT & $\begin{array}{l}\text { Typic Argillic Pallic } \\
\text { Soils }\end{array}$ & $\begin{array}{l}\text { Culverdenf' (Sib } \\
\text { 8) }\end{array}$ & $\begin{array}{l}\text { very shallow, well } \\
\text { drained, silty loam }\end{array}$ & 71 \\
\hline Pallic & PJT & $\begin{array}{l}\text { Typic Argillic Pallic } \\
\text { Soils }\end{array}$ & $\begin{array}{l}\text { Culverdenf' (Sib } \\
\text { 5) }\end{array}$ & $\begin{array}{l}\text { very shallow, well } \\
\text { drained, silty loam }\end{array}$ & 0.7 \\
\hline Pallic & PJT & $\begin{array}{l}\text { Typic Argillic Pallic } \\
\text { Soils }\end{array}$ & $\begin{array}{l}\text { Otematataf' (Sib } \\
\text { 2) }\end{array}$ & $\begin{array}{l}\text { shallow, well drained, } \\
\text { silty loam }\end{array}$ & 406 \\
\hline Pallic & PJT & $\begin{array}{l}\text { Typic Argillic Pallic } \\
\text { Soils }\end{array}$ & Mayfieldf' (Sib 25) & $\begin{array}{l}\text { deep, moderately well } \\
\text { drained, silty loam over } \\
\text { clay }\end{array}$ & 0.6 \\
\hline
\end{tabular}




\begin{tabular}{|c|c|c|c|c|c|}
\hline Pallic & PJT & $\begin{array}{l}\text { Typic Argillic Pallic } \\
\text { Soils }\end{array}$ & $\begin{array}{l}\text { Culverdenf' (Sib } \\
\text { 5) }\end{array}$ & $\begin{array}{l}\text { shallow, well drained, } \\
\text { silty loam }\end{array}$ & 0.1 \\
\hline Pallic & PJT & $\begin{array}{l}\text { Typic Argillic Pallic } \\
\text { Soils }\end{array}$ & $\begin{array}{l}\text { Otematataf' (Sib } \\
\text { 3) }\end{array}$ & $\begin{array}{l}\text { moderately deep, well } \\
\text { drained, silty loam }\end{array}$ & 51 \\
\hline Pallic & PJT & $\begin{array}{l}\text { Typic Argillic Pallic } \\
\text { Soils }\end{array}$ & $\begin{array}{l}\text { Otematataf' (Sib } \\
\text { 2) }\end{array}$ & $\begin{array}{l}\text { shallow, well drained, } \\
\text { silty loam }\end{array}$ & 113 \\
\hline Recent & RFT & $\begin{array}{l}\text { Typic Fluvial } \\
\text { Recent Soils }\end{array}$ & $\begin{array}{l}\text { Rangitataf' (Sib } \\
41)\end{array}$ & $\begin{array}{l}\text { very shallow, well } \\
\text { drained, sandy loam }\end{array}$ & 13 \\
\hline Recent & RFT & $\begin{array}{l}\text { Typic Fluvial } \\
\text { Recent Soils }\end{array}$ & $\begin{array}{l}\text { Rangitataf' (Sib } \\
15)\end{array}$ & $\begin{array}{l}\text { very shallow, well } \\
\text { drained, sandy loam }\end{array}$ & 17 \\
\hline Recent & RFW & $\begin{array}{l}\text { Weathered } \\
\text { Fluvial Recent } \\
\text { Soils }\end{array}$ & Wairauf' (Sib 3) & $\begin{array}{l}\text { very shallow, well } \\
\text { drained, sandy loam }\end{array}$ & 186 \\
\hline Recent & RFW & $\begin{array}{l}\text { Weathered } \\
\text { Fluvial Recent } \\
\text { Soils }\end{array}$ & Rakaiaf' (Sib 6) & $\begin{array}{l}\text { shallow, well drained, } \\
\text { silty loam }\end{array}$ & 4 \\
\hline Recent & RFW & $\begin{array}{l}\text { Weathered } \\
\text { Fluvial Recent } \\
\text { Soils }\end{array}$ & Wairauf' (Sib 2) & $\begin{array}{l}\text { shallow, well drained, } \\
\text { sandy loam }\end{array}$ & 155 \\
\hline Recent & RFW & $\begin{array}{l}\text { Weathered } \\
\text { Fluvial Recent } \\
\text { Soils }\end{array}$ & Rakaiaf' (Sib 1) & $\begin{array}{l}\text { shallow, well drained, } \\
\text { loam }\end{array}$ & 0.1 \\
\hline
\end{tabular}




\begin{tabular}{|c|c|c|c|c|c|}
\hline Recent & RFW & $\begin{array}{l}\text { Weathered } \\
\text { Fluvial Recent } \\
\text { Soils }\end{array}$ & Wairauf' (Sib 3) & $\begin{array}{l}\text { very shallow, well } \\
\text { drained, sandy loam }\end{array}$ & 52 \\
\hline Recent & ROW & $\begin{array}{l}\text { Weathered Orthic } \\
\text { Recent Soils }\end{array}$ & Eyref' (Sib 25) & $\begin{array}{l}\text { shallow, well drained, } \\
\text { silty loam }\end{array}$ & 35 \\
\hline Recent & RXT & $\begin{array}{l}\text { Typic Rocky } \\
\text { Recent Soils }\end{array}$ & $\begin{array}{l}\text { OmaramaRockf' } \\
\text { (Sib 8) }\end{array}$ & $\begin{array}{l}\text { very shallow, well } \\
\text { drained, silty loam }\end{array}$ & 1,138 \\
\hline Recent & RXT & $\begin{array}{l}\text { Typic Rocky } \\
\text { Recent Soils }\end{array}$ & Bogroyf' (Sib 1) & $\begin{array}{l}\text { very shallow, well } \\
\text { drained, loam }\end{array}$ & 50 \\
\hline
\end{tabular}




\section{$\underline{\text { 5.1.2.6 Otago }}$}

This is a 276 ha dairy farm in the Lake Tuakitoto and Dull Burn catchments, South Otago. It has rolling topography (Figure 5.13), with a mix of brown (well drained) and pallic (poorly drained soils) (Figure 5.14, Table 5.6). Landcover information, from an OVERSEER file completed for this farm, details the cropping, effluent and fertiliser practises occurring (Figure 5.15), and separates the farm into different management block units.

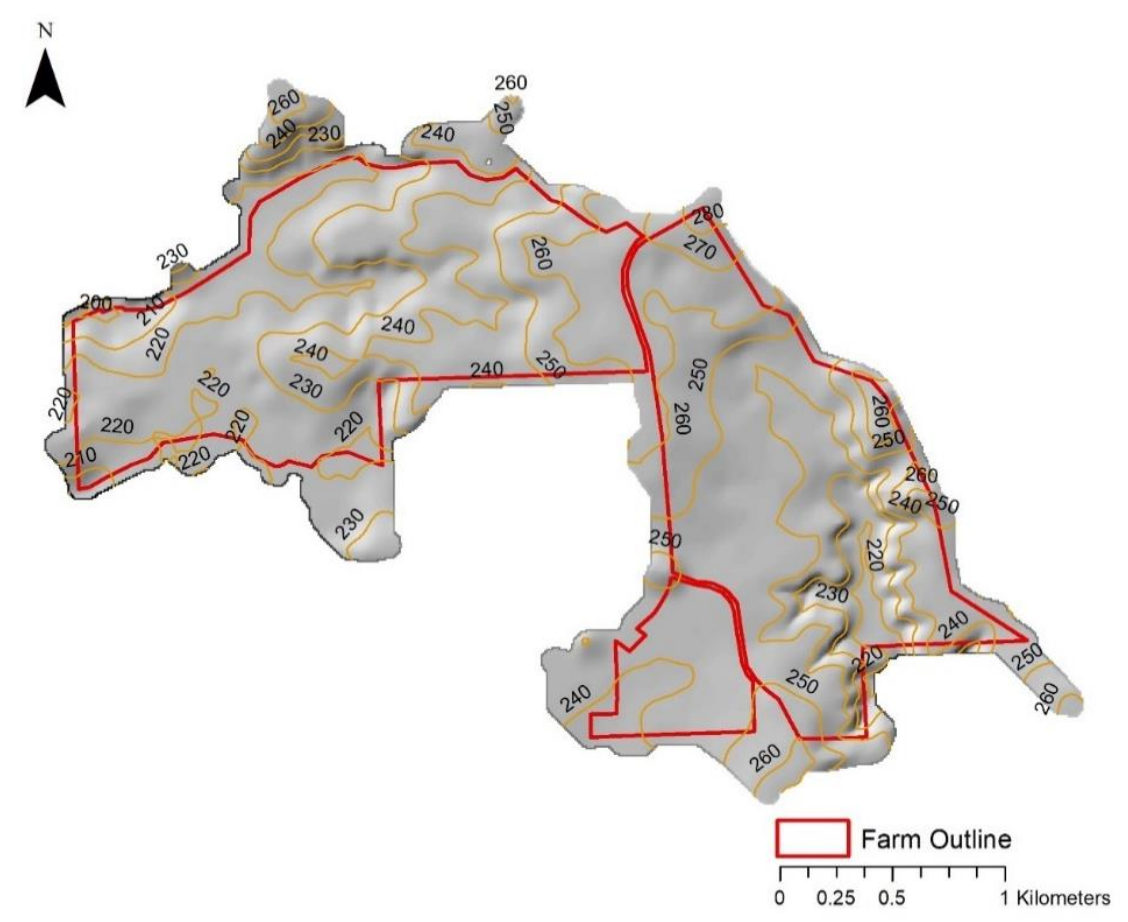

Figure 5.13 Contour map of the Otago case study.

Annual rainfall in the region is $800-900 \mathrm{~mm}$ of $9{ }^{\circ} \mathrm{C}$ (Mascara, 2015). There is a network of streams running through this property (Figure 5.16), making it an excellent site to test the accuracy of streams generated in $\mathrm{LUCl}$ during the Hydtopo pre-processing step as well as the in-stream estimates of nitrogen and phosphorus predicted by LUCI. 
$\hat{A}_{\text {FsL }}^{N}$

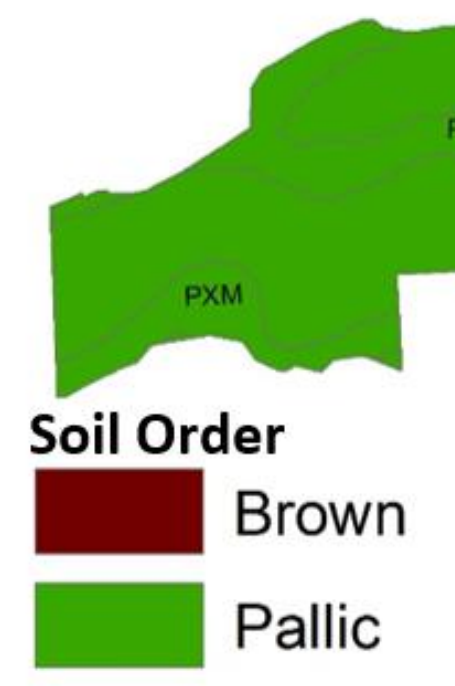

\begin{tabular}{lll}
$0,0.5$, & 1 \\
\hline
\end{tabular}

\section{S-Map}

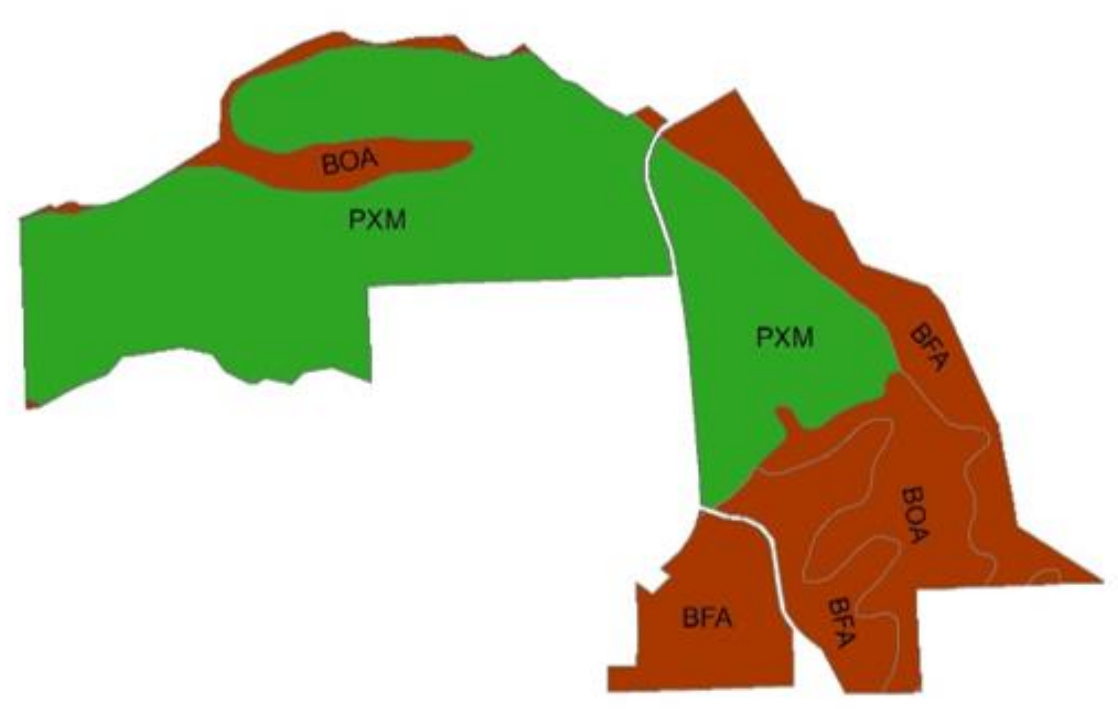

Figure 5.14 Soil order classifications in FSL and S-Map for Otago, with the labels representing different soil subgroups. 


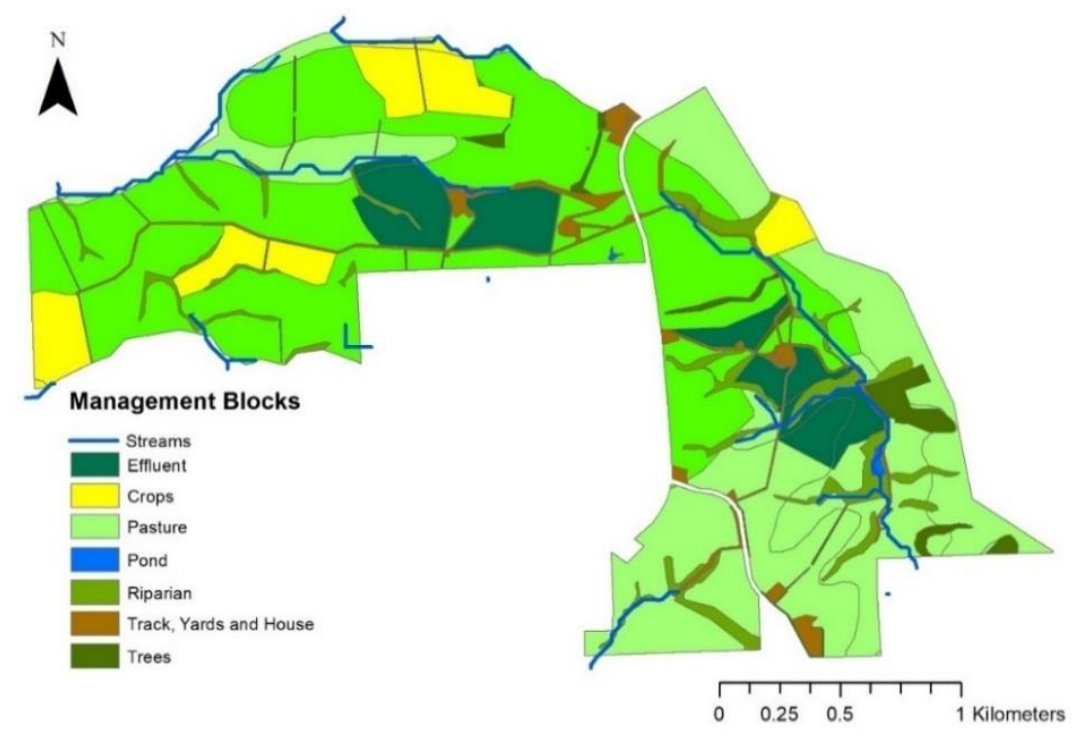

Figure 5.15 The different management blocks on the farm classified in OVERSEER.

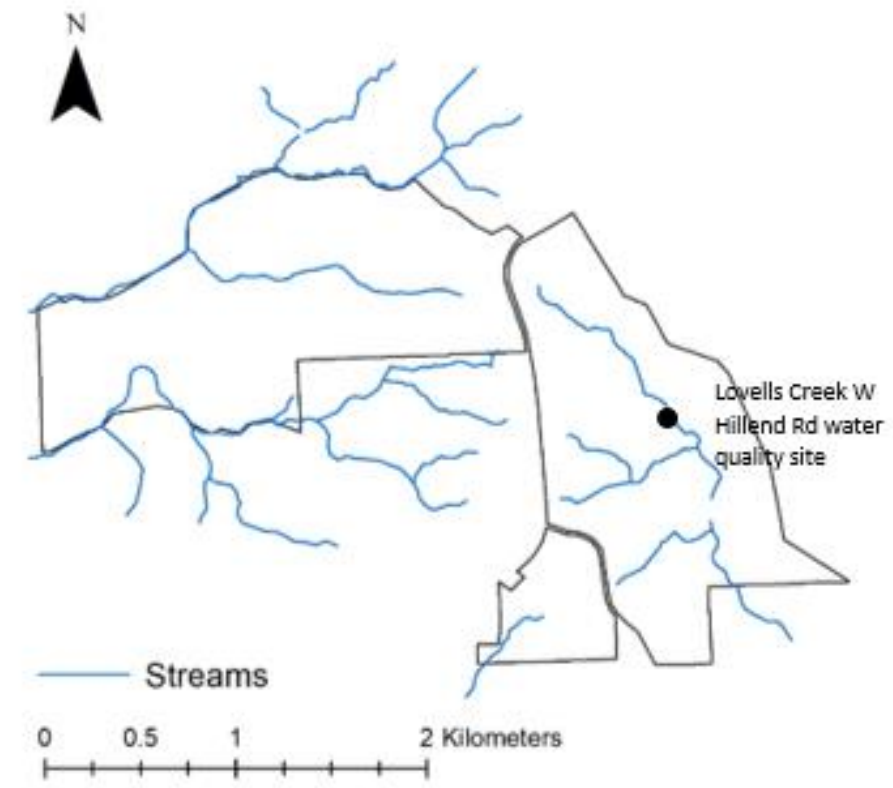

Figure 5.16 Stream network on this case study farm and the Otago Regional Council's water quality site.

Monthly in-stream measurements of nitrogen (in both nitrate and ammonia forms and total nitrogen), phosphorus (DRP and total phosphorus load) and E.coli is available for this site. This water quality data is from the Otago Regional Council's (2014) study into the water quality and ecosystem health of Lake Tuakitoto. The monthly data is averaged, to provide an average total load that is then compared to LUCl's stream concentration estimates. 
Table 5.6 Soil properties of the Otago case study held in both the FSL and S-map. Only dominant siblings are shown in the table.

\begin{tabular}{|c|c|c|c|c|c|c|c|}
\hline $\begin{array}{l}\text { Data } \\
\text { Source }\end{array}$ & $\begin{array}{l}\text { NZSC Soil } \\
\text { Order }\end{array}$ & $\begin{array}{l}\text { NZSC } \\
\text { Classification }\end{array}$ & NZSC Subgroup & $\begin{array}{l}\text { NZSC Family and } \\
\text { Sibling }\end{array}$ & Series & Soil Description & Area (ha) \\
\hline \multirow[t]{2}{*}{ FSL } & Brown & BOA & $\begin{array}{l}\text { Acidic Orthic Brown } \\
\text { Soils }\end{array}$ & & Tuapeka & No description provided & 5 \\
\hline & Pallic & PXM & $\begin{array}{l}\text { Mottled Fragic Pallic } \\
\text { Soils }\end{array}$ & & Waitahuna & No description provided & 443 \\
\hline \multirow[t]{3}{*}{ S-Map } & Brown & BOA & $\begin{array}{l}\text { Acidic Orthic Brown } \\
\text { Soils }\end{array}$ & Gladstonef' (Sib 57) & & $\begin{array}{l}\text { moderately deep, well drained, } \\
\text { silty loam }\end{array}$ & 65 \\
\hline & Pallic & PXM & $\begin{array}{l}\text { Mottled Fragic Pallic } \\
\text { Soils }\end{array}$ & Timaruf' (Sib 30) & & $\begin{array}{l}\text { moderately deep, imperfectly } \\
\text { drained, silty loam }\end{array}$ & 269 \\
\hline & Brown & BFA & $\begin{array}{l}\text { Acidic Firm Brown } \\
\text { Soils }\end{array}$ & Kakahuf' (Sib 17) & & deep, well drained, silty loam & 114 \\
\hline
\end{tabular}




\subsection{MODELLING PROCESS}

The LUCI model has been used in many studies to model the trade-offs between ecosystem services, with this thesis following the work of: Jackson et al. (2013); Jackson et al. (2016); Trodahl et al. (2017), and Sharps et al. (2017). The method described below is similar to that used in their research, as the input of spatial datasets and the modelling process is completed in a standard format for all LUCI users. A detailed description of the pre-processing steps in $\mathrm{LUCl}$ and how to interpret results can be found in the LUCI v0.4 Help documentation developed by B. Jackson and collaborators. This research, however, requires the use of multiple datasets including several that do not have built in input options, therefore sections of the method described below vary from past applications of LUCI.

\subsubsection{Pre-processing: Hydtopo Setup}

This Hydtopo file needs to be generated at the start of the modelling process to create the input hydrological and topographical information required for LUCl's ecosystem services tools (Figure 3.1). Hydtopo setup needs to be run once for any site and data combination (usually one Hytopo folder is sufficient for each farm), but, in this research, multiple Hydtopo folders, representing the different elevation datasets, were created. The different DEM's used in this research and the sites they were applied to are listed in Table 5.7. 
Table 5.7 DEM resolution and source of data for all case study sites.

\begin{tabular}{|c|c|c|c|}
\hline DEM Resolution & Data Source & Case study & $\begin{array}{l}\text { Vertical } \\
\text { Accuracy }\end{array}$ \\
\hline $15 \mathrm{~m}$ & $\begin{array}{l}\text { National 15m DEM, University } \\
\text { of Otago School of Surveying }\end{array}$ & All study sites & $\pm 5 m$ \\
\hline $10 m$ & Aqualinc $10 \mathrm{~m}$ DEM & $\begin{array}{l}\text { South } \\
\text { Canterbury }\end{array}$ & $\pm 0.8 \mathrm{~m}$ \\
\hline $8 m$ & National 8m DEM, Geographx & $\begin{array}{l}\text { Otago, } \\
\text { Tuapaka }\end{array}$ & $\pm 10 \mathrm{~m}$ \\
\hline $2 m$ & $\begin{array}{l}2005 \text { LiDAR Survey, } \\
\text { Waimakariri District Council } \\
\text { and Environment Canterbury }\end{array}$ & $\begin{array}{l}\text { North } \\
\text { Canterbury }\end{array}$ & $\pm 0.2 \mathrm{~m}$ \\
\hline \multirow[t]{2}{*}{$1 \mathrm{~m}$} & 2005 LiDAR Survey, LINZ & $\begin{array}{l}\text { Greater } \\
\text { Wellington }\end{array}$ & $\pm 0.2 \mathrm{~m}$ \\
\hline & $\begin{array}{l}2017 \text { LiDAR Survey, } \\
\text { Environment Canterbury. }\end{array}$ & LUDF & $\pm 0.2 \mathrm{~m}$ \\
\hline
\end{tabular}

The user connects to the DEM covering the area of interest and a study area mask (which must be smaller than DEM extent). The Hydtopo tool then creates a hydrologically consistent DEM from the standard user-provided DEM (Jackson et al., 2013). The DEM is corrected by filling in sinks to remove any hydrologic inconsistencies and streams are generated based on the stream initiation threshold the user selects (default values will be used if no threshold is provided). This threshold determines the hectares above which flow accumulation is assumed to result in stream generation (Jackson et al., 2013). If available, stream vector data for a site can be input by the user under 'additional Hydtopo parameters', then that stream network is "burnt in" to the DEM using the Agree method (Jackson et al., 2013; Maidment, 2002).

The saved Hydtopo file will be used as an input in all tools in the LUCI model (Figure 5.17). It is important, therefore, to look at the Hydtopo output generated and analyse if the modelled output is reflective of the farm's actual stream network. If the modelled water flow is incorrect, then the subsequent estimates of nitrogen and 
phosphorus loss will not reflect the real-world characteristics of the site. For this research, the Hydtopo tool was run multiple times with different stream and river initiation values, until the modelled stream network matched as close as possible the actual network at each site (in some instances, no streams were present on a farm, so the initiation threshold was increased to an unrealistic value resulting in no stream generation).

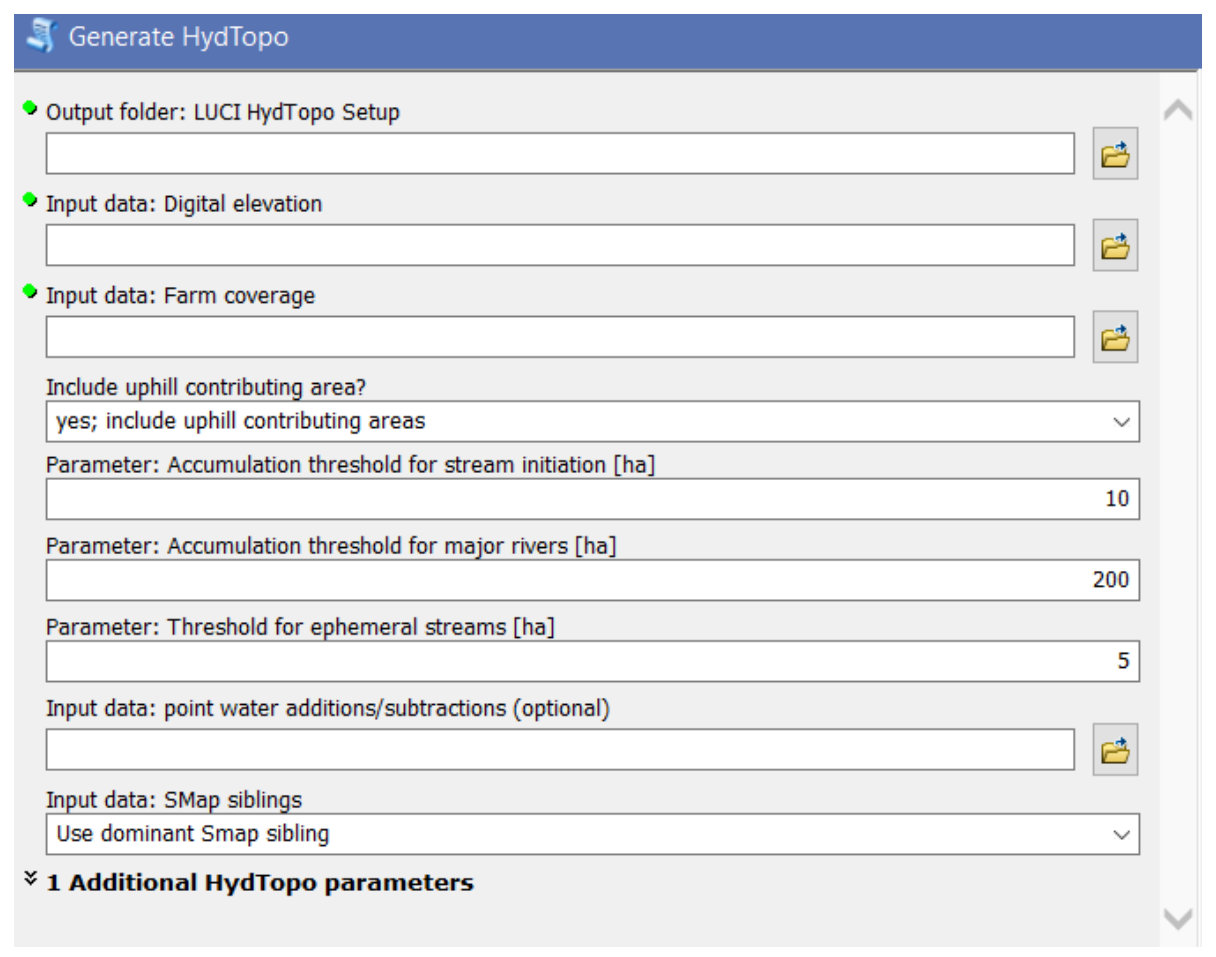

Figure $5.17 \mathrm{LUCl}$ user interface displaying Hydtopo setup.

\subsubsection{Pre-processing: LUCI Scenario Setup}

Currently there are two versions of the $\mathrm{LUCl}$ model. The original LUCI has been predominantly used by researchers, and an associated commercial LUCI framework is being developed for use by Ravensdown Environmental consultants (LUCIRav). Significant investment has gone into the development of LUCIRav, to enable more options for data input such as the use of an OVERSEER Nutrient Budget. The inclusion of OVERSEER results provides site-specific landcover and farm management practices to $\mathrm{LUCl}$. Comparing the two versions of $\mathrm{LUCl}$ is outside the scope of this research. LUCIRav is linked to a Hybrid S-Map- FSL layer created by Ravensdown with a license from Landcare Research. To access this layer, all modelled scenarios were completed using this LUCIRav version (Figure 5.18). 
A description of the soil datasets used can be seen in Table 5.8. It is important to note that an OVERSEER file was incorporated into the scenario of every site, however, the Greater Wellington and North Canterbury case studies investigated the effect of just having the national LCDB4 dataset as well as different soil datasets.

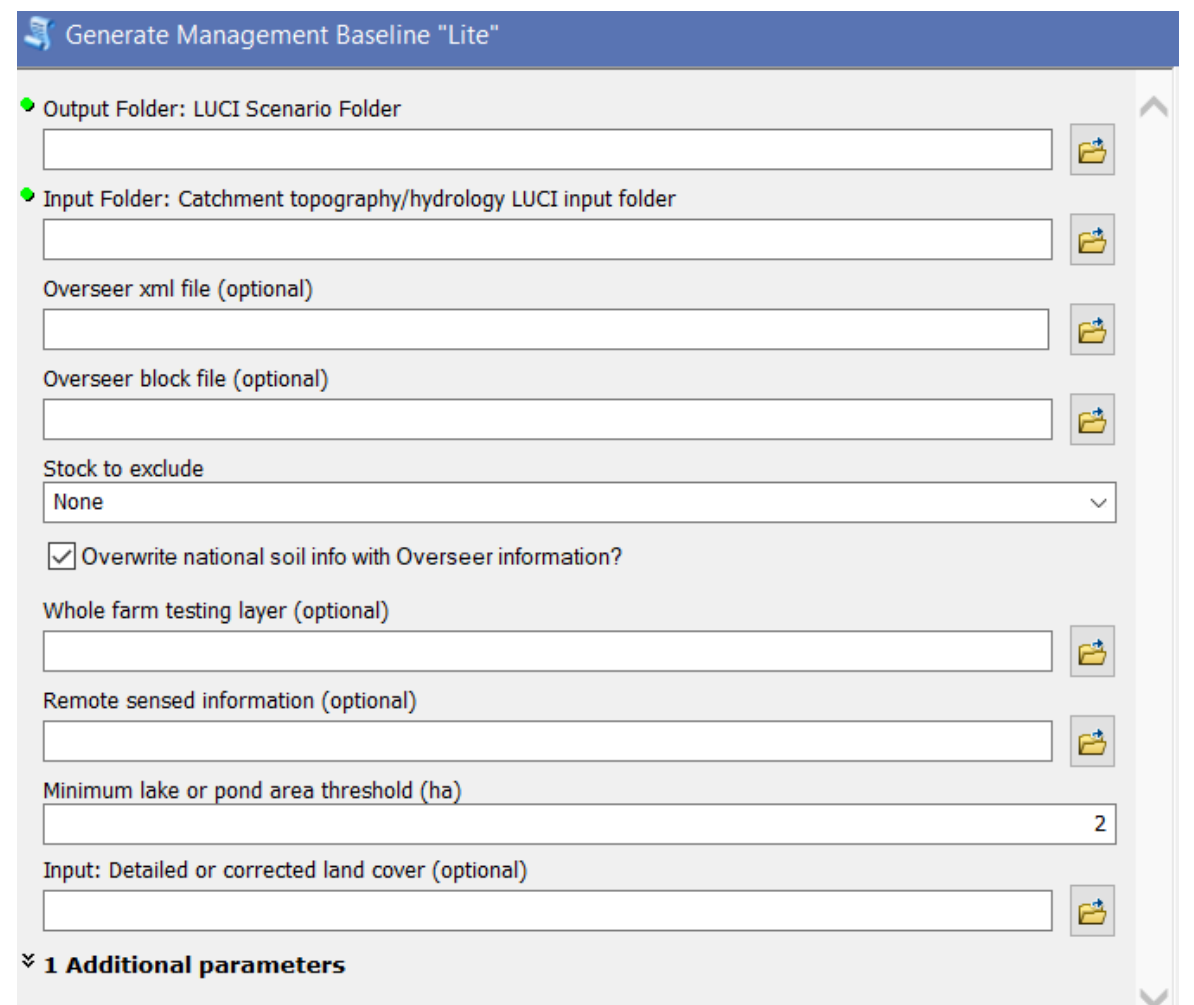

Figure 5.18 LUCIRav user interface displaying Scenario setup.

Table 5.8 Soil datasets and their source for all case study sites.

\begin{tabular}{|l|l|l|}
\hline Soil Dataset & Source & Case study \\
\hline FSL & $\begin{array}{l}\text { Landcare Research } \\
\text { https://Iris.scinfo.org.nz/ }\end{array}$ & All study sites \\
\hline S-Map & $\begin{array}{l}\text { Landcare Research } \\
\text { https://Smap.landcareresearch. } \\
\text { co.nz/ }\end{array}$ & $\begin{array}{l}\text { Wellington only has partial } \\
\text { coverage) }\end{array}$ \\
\hline $\begin{array}{l}\text { Lincoln University } \\
\text { Soil Map }\end{array}$ & Barringer et al. (2016) & LUDF \\
\hline $\begin{array}{l}\text { Massey University } \\
\text { Soil Map }\end{array}$ & Pollok and McLaughlin (1986) & Tuapaka \\
\hline
\end{tabular}


The scenario setup file combines the hydrologically consistent DEM from the Hydtopo file with soil and landcover information for the site. Once this step is complete, then LUCl's Nitrogen to Water and Phosphorus to Water tools can be used. The soil data used for this research was both S-Map and FSL as mentioned above, inputting the FSL dataset into $\mathrm{LUCl}$ requires a soil data source and soil linking code to enable $\mathrm{LUCl}$ to read the correct columns in the FSL attribute table. These linking codes are also required to connect to the landcover data in the LCDB4 database (the correct codes for soil and landcover datasets can be found in the LUCI v.04 Help documentation). No linking codes are required when generating a scenario using S-Map-FSL hybrid as, if an OVERSEER file is not provided, LUCIRav is automatically linked to relevant columns in the dataset and the LCDB4.

\subsubsection{Individual Ecosystem Service Outputs}

The Nitrogen to Water and Phosphorus to Water tools use an export coefficient approach to model nitrogen and phosphorus lost to water in $\mathrm{kg} / \mathrm{ha} / \mathrm{yr}$. The export coefficient approach describes the rate at which a contaminant is input into a water body per unit of source area. In this case, the unit area is one DEM grid cell (White et al. 2015). These export coefficients are linked to the land cover classification, climate and region being modelled and are commonly used to represent the movement of diffuse pollution in the landscape (Trodahl et al., 2017).

Topographic routing of water through the landscape and the effective precipitation for the area enable estimates of the accumulated water flow over the landscape, and the delivery of water at certain points along the modelled stream network. For every grid cell (based on DEM grid size) in the landscape, the nitrogen and phosphorus amount exported to water is calculated based on the land cover classification, soil properties and farm management variables at that point (Jackson et al., 2013). Cumulative flow based on modelled export from grid cells and nutrients removed through interception processes are then used to calculated total nutrient concentration moving through the stream network (Jackson et al., 2016). This approach considers both dissolved (bound to water) and particulate (bound to sediment) nutrients which are tracked separately through the landscape (Jackson et al., 2016). The separation of dissolved and 
particulate nutrients is calculated through a ratio entered by the user (or, if unknown, a default ratio is used). This ratio is required in the model, as the export coefficient approach assumes the total amount exported from a cell, rather than the amount of dissolved vs particulate nutrient removed.

The remaining options that require input before the model can be run all have default values; these values should not be altered, unless the user understands the system and knows a more appropriate value for that site (in this research, no default values were changed). These default values pertain to the nutrient concentration/nutrient loading threshold below which the concentration is not considered to be a concern; nutrient concentration/nutrient loading threshold above which the concentration is a significant concern (based on drinking water standards for nitrogen); and the attenuation factor in both the root zone and the stream network, which is used to calculate the nutrient amounts remaining in water.

\section{Model Outputs}

The model results are in the form of maps and tables that can be easily shown and discussed with land owners and stakeholders. Currently, a 'traffic light system' is used to distinguish between the categories of ecosystem service provision, with other colour schemes, black/white printing and colour-blind options under development. The traffic light colour scheme implies that areas in green indicate high existing service provision (optimum utilisation of the land), so decisions makers should think carefully before changing the current management plan. Red indicates that there is an opportunity to significantly improve service provisions in that area as it is currently underutilised, so decision-makers are advised to make changes to current land management practices to increase the potential service provision of the area.

The PDF file produced by the Nitrogen to Water and Phosphorus to Water tools contains several colour coded maps of a farmer's land and a table of estimates of the nutrient load and concentration at any exit points on the farm. Exit points include but are not limited to: where a stream enters a property; where a stream crosses a farm boundary, and the final exit points where the stream leaves the farm. The maps detail 
both the total nutrient load generated at any point in the landscape $(\mathrm{kg} / \mathrm{ha} / \mathrm{yr})$ and the accumulated total nutrient load, considering not just the load at a point but the load contributed from neighbouring cells ( $\mathrm{kg} / \mathrm{yr})$. Other maps generated by these tools go into detail on the classified nutrient loads based on the thresholds specified in the model setup. This thesis, however, focuses only on total and accumulated load output for each case study site.

For accumulated load results, a comparison of relative differences between the modelled locations of load pathways is discussed. Therefore, the difference between individual accumulated load estimates at a point is not within the scope of this thesis. Accumulated load results for the higher resolution DEMs (1m and $2 \mathrm{~m}$ ) are aggregated so that the pathways represented in the maps below are the same width and the national DEMs, enabling easy comparison between scenarios. As such, the results presented in this thesis differ from automatically generated outputs.

\subsubsection{Matlab Analysis to Estimate Total Annual Load of Nitrogen and Phosphorus}

Because it is difficult to directly compare the maps produced between different data input scenarios based solely on the patterns in estimated nutrient loads, the nitrogen and phosphorus loss estimates were exported to Matlab for statistical analysis. In Matlab, the total nutrient load in $\mathrm{kg} / \mathrm{yr}$ for the whole farm is calculated by summing the estimated load of every grid cell covering the farm area. These results provide information on the distribution of load estimates and the probability of a particular load value's occurrence on the landscape. Matlab analysis provides supporting evidence to the conclusions drawn from the mapped patterns in nitrogen and phosphorus loading.

In order to analyse the load estimates between different DEM grid size scenarios, the area component of the estimates needs to be removed (Equation 5.1).

$$
\text { Load } \mathrm{X}_{(\mathrm{N}, \mathrm{P})} \mathrm{kg} / \mathrm{yr}=\frac{\operatorname{Load} \mathrm{X} \mathrm{kg} / \mathrm{ha} / \mathrm{yr}}{10,000 \times \text { cell area }(\mathrm{ha})}
$$


Once the estimates from each cell are in $\mathrm{kg} / \mathrm{yr}$, all cell unit values are summed across the farm system. Normalising the nitrogen and phosphorus load estimates enables the probability of the proportion of data with a particular load value to be calculated, as well as the cumulative probability of a load value at or below a certain point.

\subsubsection{How to Add Farm Specific Soil Data in LUCI}

Because two of the case study farms have farm scale soil maps over some or all of their area, this site-specific data must be added manually to the LUCI model. While in the future, $\mathrm{LUCl}$ development may lead to an input option for user defined soil maps, this thesis is one of the first applications of $\mathrm{LUCl}$ using an alternative soil dataset to FSL or S-Map. In order to add this soil data into LUCI, the S-Map-FSL Hybrid layer that LUCIRav is connected to must be intersected with the new soil data.

\subsubsection{Importance of Including Sibling Information}

Both LUCI and OVERSEER model nutrients lost from farm systems by using the soil properties held at the sibling level in S-Map. These sibling classifications hold information on the combination of drainage class, topsoil stoniness, soil depth, texture contrasts, and a sequence of up to six functional horizons for each soil order (Web \& Lilburne, 2011). LUCI currently reads information only on the dominant sibling listed for each polygon, and it is standard practice to only select the dominant sibling in OVERSEER. Nevertheless, each soil polygon could be described by up to five siblings (Lilburne et al., 2009). Information on S-Map's sibling level classification can be found in Section 4.1.3.

OVERSEER has the ability to access S-Map properties directly from the soil database, enabling the model to link to the relevant parts, if available, of the S-map dataset (Carrick et al., 2014). OVERSEER's ability to target specific information within S-map's factsheets ensures that the nutrient budget model stays up to date with the latest available soil data in New Zealand (Carrick et al., 2014). LUCI has the ability to link to an OVERSEER Nutrient Budget and therefore can access the same sibling information provided by S-Map. Currently S-Map and OVERSEER use different approaches to LUCI when calculating soil water content of the soil. 


\section{Modelling Multiple Sibling Options in LUCI}

Since neither LUCI or OVERSEER currently model areas based on more than the information from the dominant soil sibling, the development of $\mathrm{LUCl}$ to incorporate different levels of sibling information represents a progression in LUCl's ability to realistically model farm systems. The recently released OVERSEER FM model incorporates a user defined selection of multiple siblings per block.

This research tested three different methods of incorporating sibling data into LUCl's soil water calculations on two study sites in Canterbury. Sibling data from S-Map and a farm scale survey map were included and the sibling management options were:

1. Maintain the status quo, using information from the dominant sibling.

2. Calculate a weighted average representation of the siblings $(i)$ in a polygon using the sibling proportion values estimated when each soil map was created as per Equation 5.2.

$$
\text { Weighted avg }=\sum_{i=1}^{i=5} \text { Proportion of } i \times \text { soil properties of } i
$$

Equation 5.2

3. Assign all siblings present in a soil polygon a value from 1 to 5 , and using a random number generator, randomly select a sibling to represent that whole polygon.

Currently LUCl's estimates of nitrogen and phosphorus loads are parameterised by soil order. Because of this, adapting LUCl's code to incorporate additional data will not result in changing load estimates if the siblings are characterised as the same order. Instead, the additional suborder information will alter the modelled hydrology of the farm as PAW and DW properties vary between all sibling types. This is shown through changing stream concentration estimates of nitrogen and phosphorus concentrations and maps of PAW across the farm. 
For the South Canterbury site, management blocks on the farm are highlighted that have multiple soil siblings of varying orders. This information, when linked into the model, may result in changing nitrogen load estimates due to the altered hydrology of the site. For phosphorus, $\mathrm{LUCl}$ will be adapted to include ASC values for each sibling which could impact the models estimates of phosphorus lost from the system.

While initial results were generated in this thesis for one case study farm, further analysis is required at multiple sites to fully understand the impact of adding suborder soil data into the LUCI model.

\subsection{OVERSEER SENSITIVITY ANALYSIS}

To test the sensitivity of OVERSEER to different farm management and environmental factors, a hypothetical cropping farm was created. Characteristics for this hypothetical farm were chosen to give moderate to high nitrogen and phosphorus losses, so that sensitivity to parameter changes can be demonstrated.

The hypothetical farm is located in the Otago region; $100 \mathrm{~km}$ from the coast; has a rolling topography; an effective area of 1000 ha; a climate of $1000 \mathrm{~mm} / \mathrm{yr}$ rainfall with temperature and PET set to default values; pallic soil, and a history of 10 years in pasture prior to the reporting year, with prior land useas grazed pasture by non-farm animals (sheep and/or deer). These values were selected to promote nitrogen and phosphorus loss with a slightly higher than average rainfall, which is $800-900 \mathrm{~mm}$ for the region (Mascara, 2015).

The crop rotation was set up as spring wheat (sown in September; 10 T/ha yield; conventional cultivation practice at sowing and residue management selected as removed), with no fertiliser application or grazing by animals (Figure 5.19).

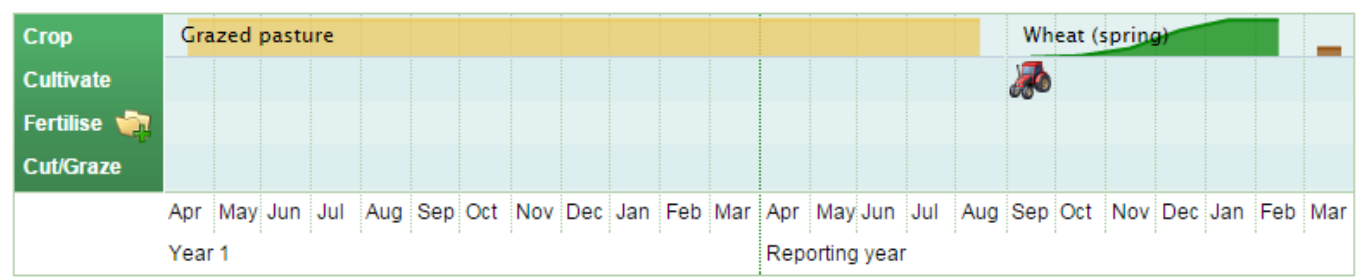

Figure 5.19 Crop rotation for the hypothetical farm. 
Some of the scenarios used in the sensitivity test may not be realistic for the type of soil/soil properties and/or climate of the region selected. This sensitivity test, however, aims to determine if the changes in modelled nitrogen and phosphorus lost from the system make sense, given the variation in chosen input factors.

The following management and environmental factors were altered to show the sensitivity of the nitrogen and phosphorus sub models in OVERSEER, with only one management or environmental factor being altered from the original farm at a time (except for the brown soil scenarios with varying amount of rainfall). This allowed the comparison between the sensitivities to moderate variation in input parameters, rather than a comparison between extreme differences.

\section{Management Factors}

- Incorporating fertiliser at the time of sowing (soluble fertiliser with $50 \mathrm{~kg} \mathrm{~N} / \mathrm{ha}$ and $20 \mathrm{~kg} \mathrm{P} / \mathrm{ha})$.

- Doubling the amount of fertiliser incorporated at the time of sowing to $100 \mathrm{~kg}$ $\mathrm{N} / \mathrm{ha}$ and $40 \mathrm{~kg} \mathrm{P} / \mathrm{ha}$.

- An additional surface application of soluble fertiliser with $50 \mathrm{~kg} \mathrm{~N} / \mathrm{ha}$ and $20 \mathrm{~kg}$ $\mathrm{P} /$ ha one month after the previous scenarios rate of fertiliser was incorporated.

- Changing the cultivation practice at the time of sowing to direct drilled.

- Changing the block history by reducing the number of years spent in pasture to five.

- Changing the block history to continuous cropping (zero years in pasture) with prior land use selected as crop.

- Changing the crop rotation to include two months of fallow before planting.

- Changing the crop rotation to be fallow only (cultivated wheat the month after planting).

\section{Environmental Factors}

- Increasing the ASC of the soil from the default value of 21 to 50.

- Decreasing the ASC of the soil from the default value of 21 to 10. 
- Entering in an Olsen $\mathrm{P}$ test of 20 under the specify soil tests in the crop rotation window.

- Entering in an Olsen P test of 100 under the specify soil tests in the crop rotation window.

- Decreasing the amount of annual rainfall to $400 \mathrm{~mm}$.

- Decreasing the amount of annual rainfall to $600 \mathrm{~mm}$.

- Decreasing the amount of annual rainfall to $800 \mathrm{~mm}$.

- Changed the soil order of the farm from pallic to brown, with a medium soil texture group.

- Decreased the amount of annual rainfall to $800 \mathrm{~mm}$.

- Increased the amount of annual rainfall to $1200 \mathrm{~mm}$.

- Increased the amount of annual rainfall to $1400 \mathrm{~mm}$. 


\section{CHAPTER 6 RESULTS}

This chapter details the results produced for each of the six case study farms used in this analysis to achieve Objective 2 in this research. Different data combinations tested at each site include varying levels of local vs national detail, with four soil maps and six DEMs tested. The level of analysis at each site varies based on the available input data, but generally includes the hydrological output from the first step in LUCl; nutrient load results from the nitrogen and phosphorus tools; comparison of measured nitrogen and phosphorus concentrations to LUCl estimates where available; analysis of the effect of incorporating sibling level soil properties into the LUCI model; and finally, the results from the OVERSEER sensitivity analysis are presented.

\subsection{TUAPAKA CATCHMENT}

\subsubsection{Hydtopo Output}

The hydrology of this farm consists of one watershed and exit point at the base of the catchment (Figure 6.1). Both the $8 \mathrm{~m}$ and $15 \mathrm{~m}$ DEMs estimates similar catchments, with the watershed outline of the lower resolution 15m DEM detailed by an uneven line due to the larger grid size of the $15 \mathrm{~m}$ DEM. The $8 \mathrm{~m}$ DEM is also estimating a larger catchment area on the western side of the farm, resulting in an additional stream channel in this area. Comparing the predicted stream pathway to the actual stream channels presented in Burkkitt et al. (2016), the 15m DEM estimates the most accurate stream pattern. 

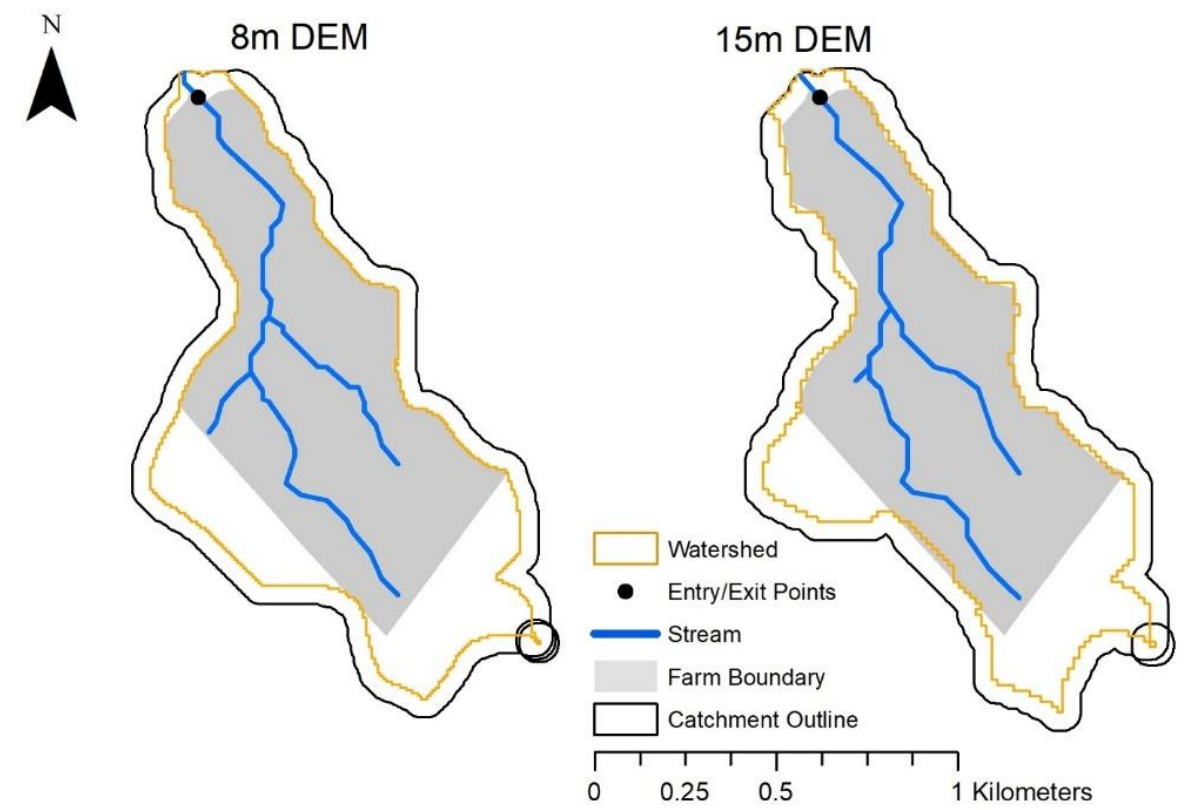

Figure 6.1 Hydrological output of both DEM resolutions tested at this site.

\subsubsection{Nutrient Load Results}

The results for all scenarios run on the Tuapaka Catchment are presented below in Table 6.1. Here it can be seen that the total nitrogen results are similar across all scenarios ranging from $380 \mathrm{~kg} \mathrm{~N} / \mathrm{yr}$ for the $\mathrm{FSL}+15 \mathrm{~m}$ to $392 \mathrm{~kg} \mathrm{~N} / \mathrm{yr}$ for the Farm Scale $+8 \mathrm{~m}$ DEM. The major difference between scenarios is shown in the phosphorus results with a reduction in total load when the farm scale soil data was used. This reduction in phosphorus load is because the farm scale soil map reduced the area of land classified as pallic soil and reclassified the area as brown soil, resulting in a $10 \mathrm{~kg} \mathrm{P} / \mathrm{yr}$ reduction in phosphorus loss over this catchment.

Table 6.1 Total nitrogen and phosphorus load results for all scenarios.

\begin{tabular}{|l|r|r|}
\hline LUCI Applications & Nitrogen (kg N/yr) & Phosphorus (kg P/yr) \\
\hline FSL $+8 m$ & 389 & 23 \\
\hline FSL+ 15m & 380 & 22 \\
\hline Farm Scale $+8 m$ & 392 & 13 \\
\hline Farm Scale $+15 \mathrm{~m}$ & 384 & 13 \\
\hline
\end{tabular}


While total load results indicate that nitrogen loss is similar between all scenarios, Figure $6.2 \mathrm{a}-\mathrm{b}$ show there is variation in load estimates between the different soil and DEM resolutions tested. All estimated nitrogen loads range from 6.05 to $6.9 \mathrm{~kg} / \mathrm{ha} / \mathrm{yr}$ with the two FSL scenarios estimating the majority of their data between 6.1-6.3 $\mathrm{kg} / \mathrm{ha} / \mathrm{yr}$ and the farm scale soil map scenarios data estimated between 6.2-6.3 $\mathrm{kg} / \mathrm{ha} / \mathrm{yr}$. For phosphorus, a few unique load values were calculated between 180-210 $\mathrm{g} / \mathrm{ha} / \mathrm{yr}$ and 420-450 g/ha/yr (Figure $6.2 \mathrm{c}-\mathrm{d}$ ). The two FSL scenarios estimated around $80 \%$ of their results between $420-450 \mathrm{~g} / \mathrm{ha} / \mathrm{yr}$, whereas the farm scale scenarios only estimated $20 \%$ of their data to be within this range. This is a result of the increased soil area classified as pallic soil in the FSL and, due to the nature of pallic soil properties, these areas are modelled with a high risk of phosphorus loss.

\section{$\underline{\text { Nitrogen }}$}

Nitrogen load and nitrogen accumulated load results for this site are presented below in Figure 6.3. While the load estimates do not have a broad range, LUCI is still able to highlight the variations in the landscape. The areas classified as high loads (red) in Figure 6.3 indicate the areas of brown soil in both scenarios. For FSL, the spatial distribution of $6-6.2 \mathrm{~kg} / \mathrm{ha} / \mathrm{yr}$ nitrogen load is on areas of pallic soils close the stream network. The load on these areas increases to $6.2-6.4 \mathrm{~kg} / \mathrm{ha} / \mathrm{yr}$ with the change to the farm scale soil map. This change in load classification is due to the changing classification from pallic to brown soil. The difference between the $8 \mathrm{~m}$ and $15 \mathrm{~m}$ DEM is seen in the resolution of the boundaries between load estimates. However, when looking at the accumulated load (Figure 6.4), the nutrient flow pathways estimated between the two DEMs are similar, as they both have highlighted four main pathways of nutrient movement where mitigations could be targeted. 

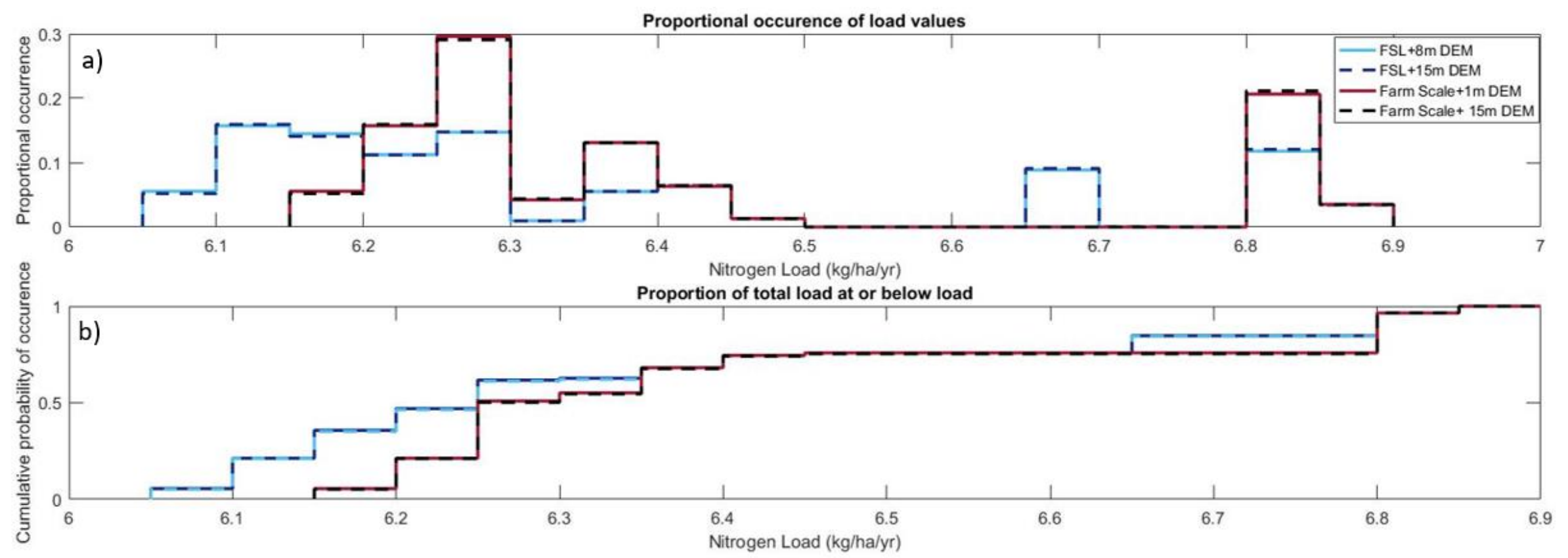

Figure 6.2 (a) Proportional occurrence of nitrogen load values in $\mathrm{kg} \mathrm{N} / \mathrm{ha} / \mathrm{yr}$, (b) cumulative probability of occurrence of a nitrogen load at or below a specified load value, (c) proportional occurrence of phosphorus load values in $\mathrm{g} P / \mathrm{ha} / \mathrm{yr}$, (d) cumulative probability of occurrence of a phosphorus load at or below a specified load value. 

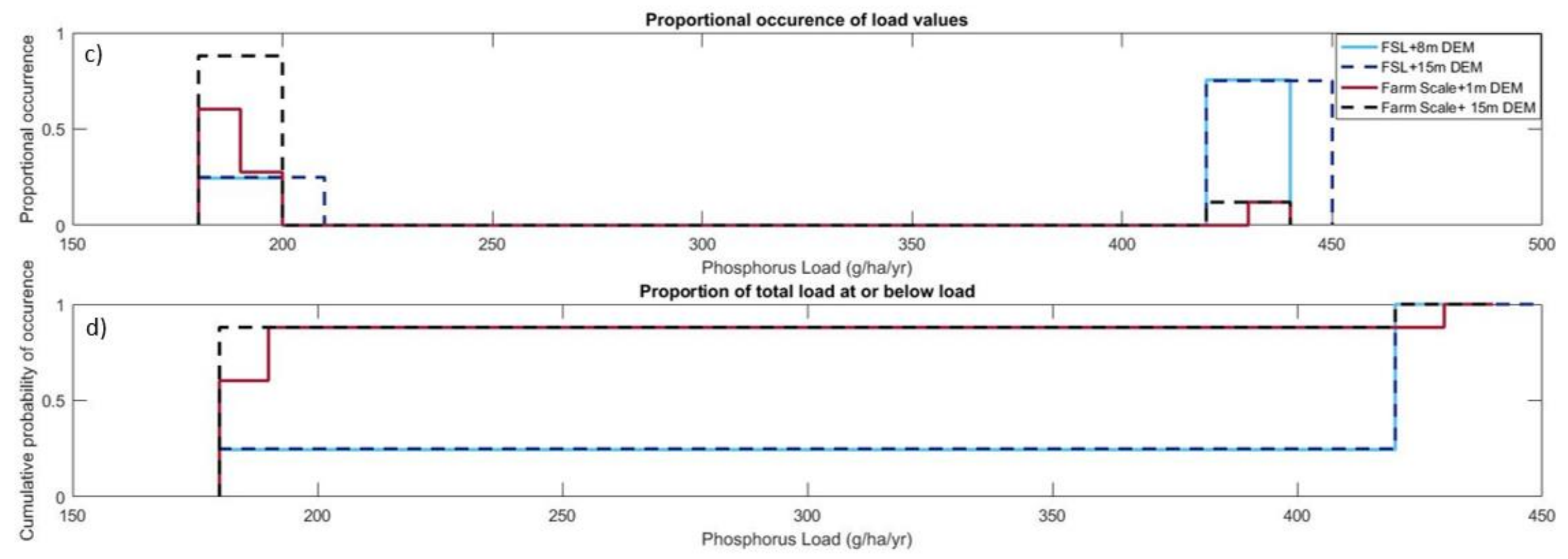

Figure 6.2 Continued. 


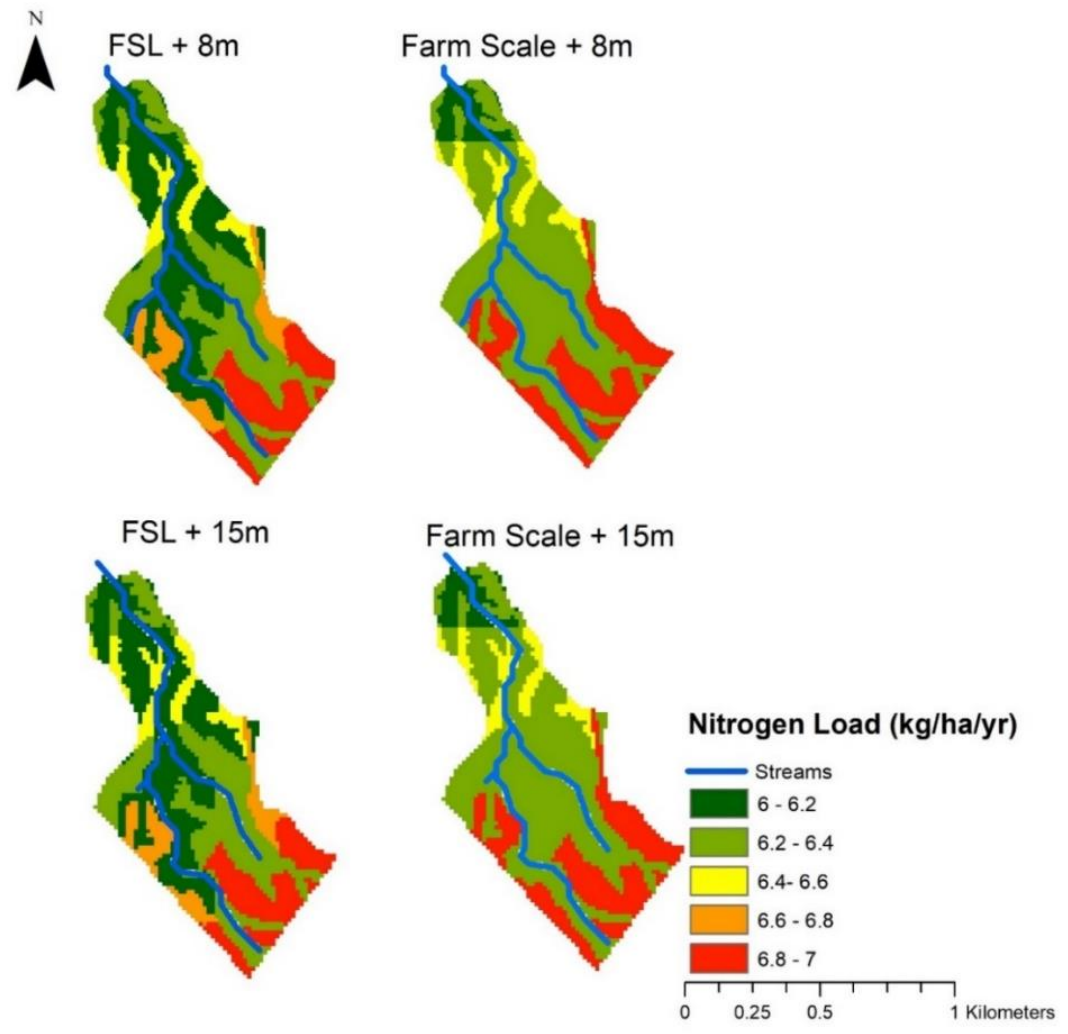

Figure 6.3 Nitrogen load results for all scenarios in $\mathrm{kg} \mathrm{N} / \mathrm{ha} / \mathrm{yr}$.
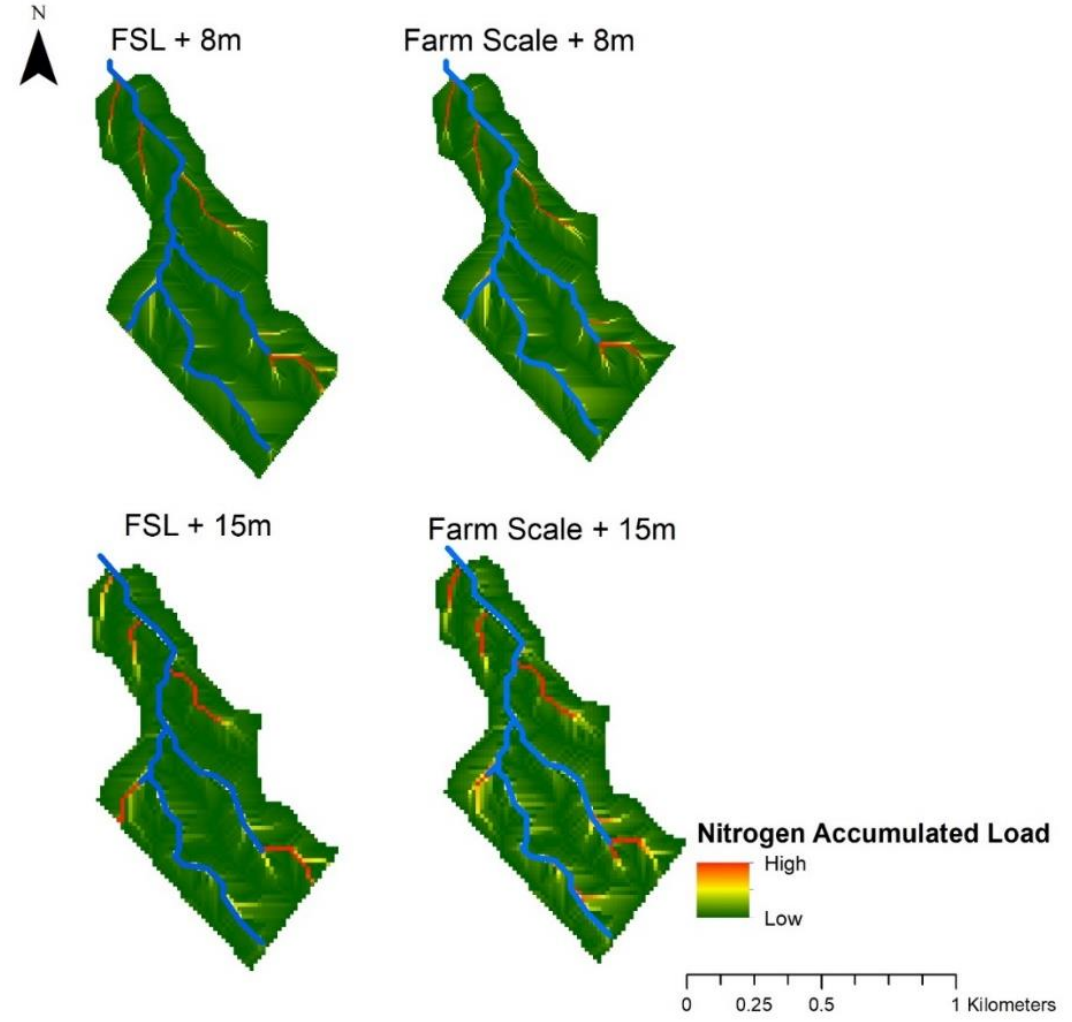

Figure 6.4 Nitrogen accumulated load results for all scenarios. 


\section{Phosphorus}

Phosphorus loss for this site, unlike nitrogen, is clustered into two contrasting low/high ranges of nutrient load estimates, with no moderate loads. Low values (0-200 g/ha/yr) are modelled on brown soil with high values (400-450 g/ha/yr) modelled on the pallic soil (Figure 6.5). These outputs therefore clearly show the impact of farm scale soil mapping on this catchment. In these results, the impact of slope is insignificant compared to LUCl's more marked response to the changes in soil properties between these specific two soil orders.
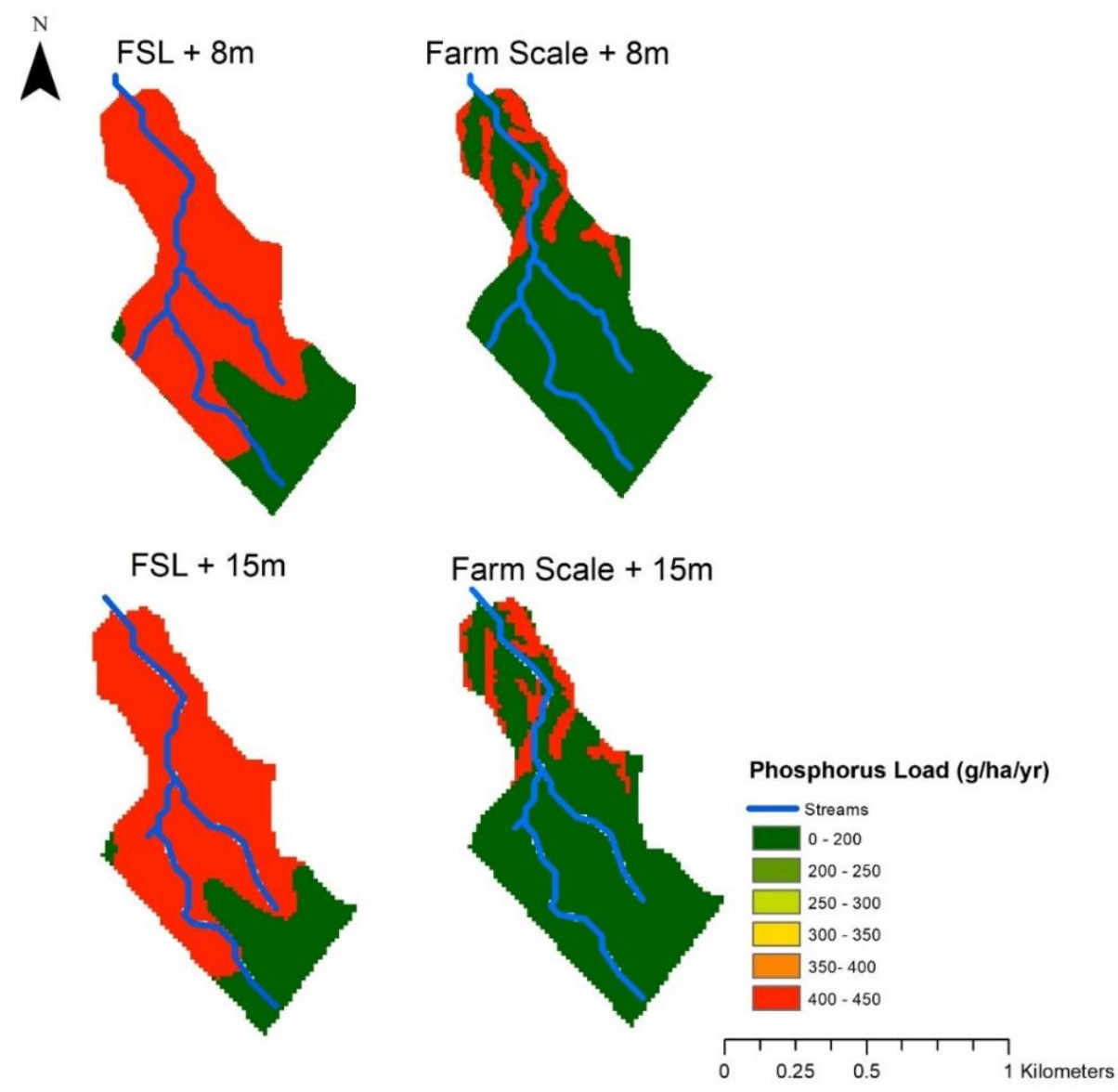

Figure 6.5 Phosphorus load results for all scenarios in $\mathrm{g} \mathrm{P} / \mathrm{ha} / \mathrm{yr}$.

For accumulated load, the four pathways modelled are similar to the accumulated nitrogen load output (Figure 6.6), as the hydrology and topography of this farm route the water down defined paths, meaning that mitigations put in place to target nitrogen loss will also reduce phosphorus loss from this system as well. 


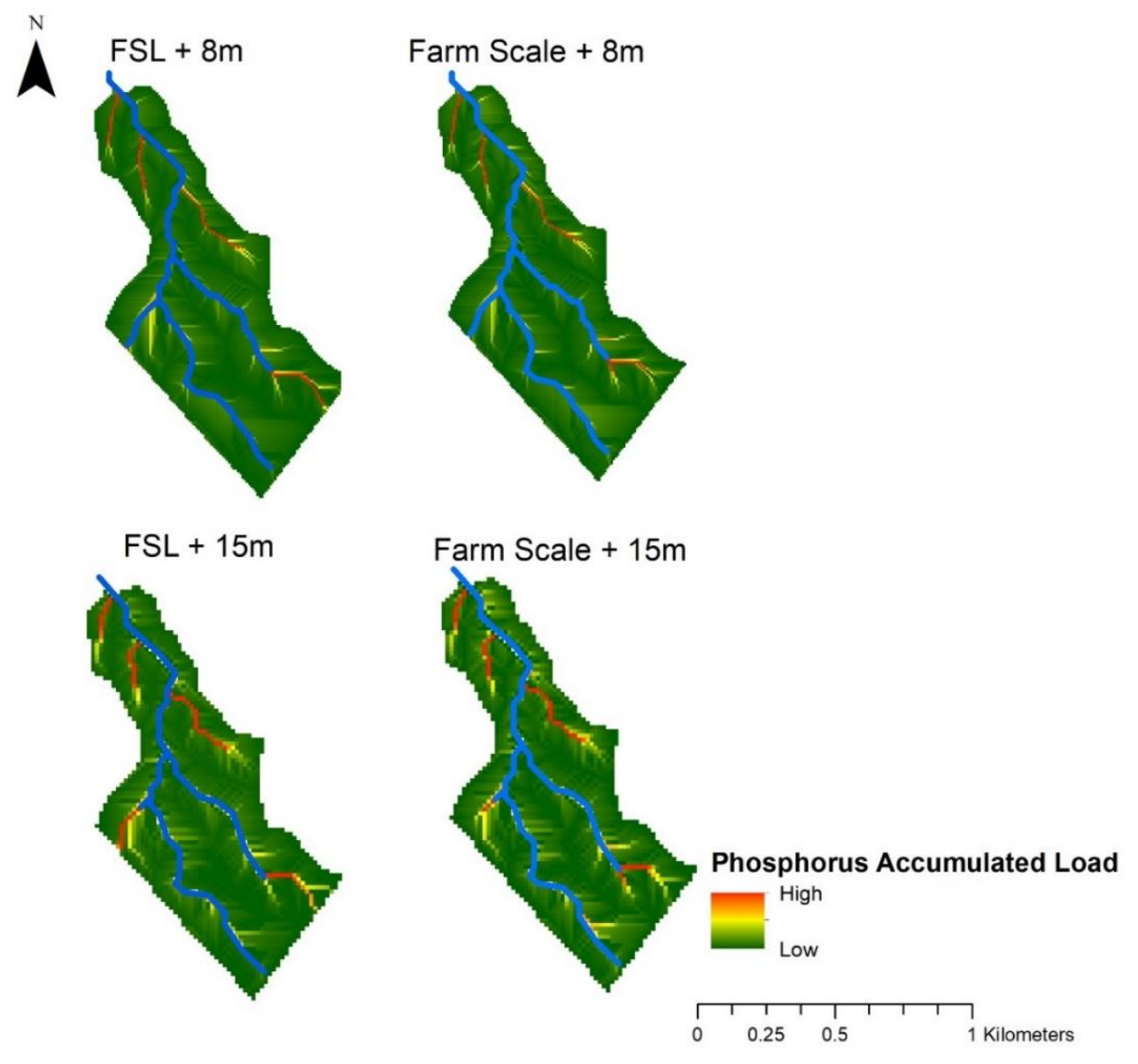

Figure 6.6 Phosphorus accumulated load results for all scenarios.

\subsubsection{Modelled vs Collected Data Comparison}

Average concentration from measured water quality data was calculated from instream measurements taken over a two-year period (June 2013-June 2015). These results are shown in Table 6.2, row 1, with average $L U C l$ stream estimates shown in rows $2-5$. Using the farm scale soil map and the $8 \mathrm{~m}$ DEM resulted in the closest concentration $(0.93 \mathrm{mg} \mathrm{N} / \mathrm{l})$ to the measured value $(0.61 \mathrm{mg} \mathrm{N} / \mathrm{l})$, with phosphorus estimates identical between the soil maps used $(0.06 \mathrm{mg}$ P/I for FSL outputs and 0.03 $\mathrm{mg} \mathrm{P} / \mathrm{I}$ for the farm scale soil map). Regardless of the DEM and soil map used, LUCI estimates are all reasonably close to the measured values. 
Table 6.2 Observed and predicted total nitrogen and phosphorus loads for all scenarios at this site.

\begin{tabular}{|l|l|l|}
\hline Data Source & Total Nitrogen (mg/L) & Total Phosphorus (mg/L) \\
\hline $\begin{array}{l}\text { Burkitt et al. (2016); Trodahl } \\
\text { (2018) }\end{array}$ & 0.61 & 0.025 \\
\hline LUCI FSL + 8m DEM & 1.32 & 0.06 \\
\hline LUCI FSL + 15m DEM & 1.25 & 0.06 \\
\hline LUCI Farm Scale + 8m DEM & 0.93 & 0.03 \\
\hline LUCI Farm Scale + 15m DEM & 0.97 & 0.03 \\
\hline
\end{tabular}

\subsection{GREATER WELLINGTON}

\subsubsection{Hydtopo Output}

The hydrology of this farm can be seen in Figure 6.7. The different DEM resolutions delineate different catchment areas and stream networks for this farm. The $1 \mathrm{~m}$ DEM estimated four watersheds, where the $15 \mathrm{~m}$ DEM only modelled two. This difference in modelled watersheds impacts the stream network generated, with the northernmost stream modelled to exit the farm in the $1 \mathrm{~m}$ DEM, whereas that same stream in the $15 \mathrm{~m}$ is modelled to exit and then re-enter farther along the farm boundary. From aerial imagery and a discussion with the farmer, the actual stream profile more accurately resembles the $1 \mathrm{~m}$ DEM network.
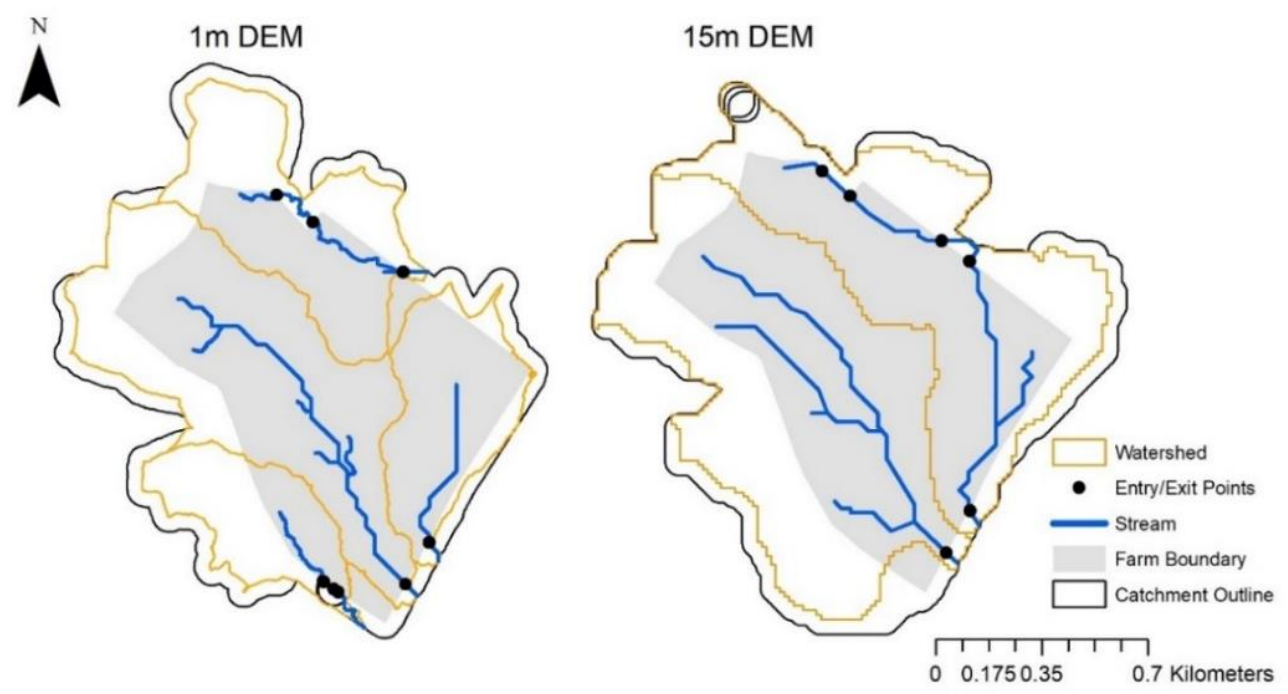

Figure 6.7 Hydrological output of both DEM resolutions tested at this site. 


\subsubsection{Nutrient Load Results}

The results for all the scenarios run on the Greater Wellington case study are presented in Table 6.3. For this site, all four of the S-Map-Hybrid and FSL scenarios included an OVERSEER $\mathrm{xml}$ file, with the S-Map-FSL hybrid soil layer rerun without this farm's specific landcover information. For both nitrogen and phosphorus results, there is little variation between scenarios as there was little variation in the classification of soil by order between soil datasets. Total nitrogen loads for the S-Map-FSL hybrid with different DEM resolutions are 1,284 kg N/yr and 1,229 N/yr for the $1 \mathrm{~m}$ and $15 \mathrm{~m}$ DEM respectively. For the FSL $1 \mathrm{~m}$ and $15 \mathrm{~m}$ scenarios, total nitrogen loads were 1,279 $\mathrm{kg}$ $\mathrm{N} / \mathrm{yr}$ and $1224 \mathrm{~kg} \mathrm{~N}$ yr. Phosphorus also shows little variation in results with total estimates ranging from $10 \mathrm{~kg} \mathrm{P} / \mathrm{yr}$ to $8 \mathrm{~kg} \mathrm{P} / \mathrm{yr}$ between scenarios. When the OVERSEER file was removed from the S-Map-FSL hybrid 1m DEM scenario, total nitrogen load changed from 1,284 kg N/yr to 1,521 kg N/yr and phosphorus increased from $10 \mathrm{~kg} \mathrm{P} / \mathrm{yr}$ to $24 \mathrm{~kg} \mathrm{P} / \mathrm{yr}$, indicating that regional default landcover data overestimates nutrient load values.

Table 6.3 Total nitrogen and phosphorus load results for all scenarios.

\begin{tabular}{|l|r|r|}
\hline LUCI Applications & Nitrogen (kg N/yr) & Phosphorus (kg P/yr) \\
\hline S-Map-FSL Hybrid + 1m & 1,284 & 10 \\
\hline S-Map-FSL Hybrid + 15m & 1,229 & 9 \\
\hline FSL + 1m & 1,279 & 9 \\
\hline FSL+ 15m & 1,224 & 8 \\
\hline S-Map-FSL Hybrid + 1m +LCDB4 & 1,521 & 24 \\
\hline
\end{tabular}

In Figure 6.8a-d, the distribution of data indicates that similar results are grouped based on the same DEM resolution, rather than on the soil dataset used. When the OVERSEER file was removed, it can be seen that both nitrogen and phosphorus load results change dramatically. For nitrogen, load estimates are now clustered between 15-16 kg N/ha/yr (Figure 6.8a) with no other unique values present, and for phosphorus, the proportional occurrence of load values is mostly around $200 \mathrm{~g} \mathrm{P} / \mathrm{ha} / \mathrm{yr}$ with a small proportion of estimates at the high end of $600 \mathrm{~g} / \mathrm{ha} / \mathrm{yr}$ (Figure 6.8c). 
Proportional occurence of load values

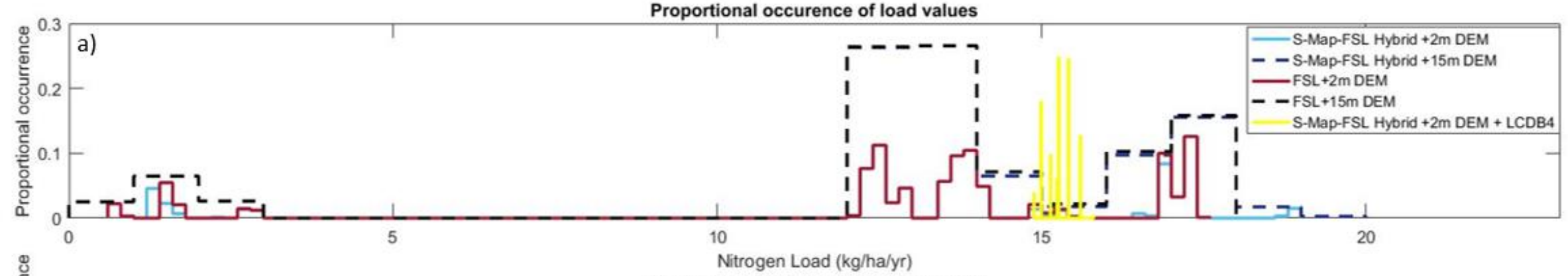

Proportion of total load at or below load

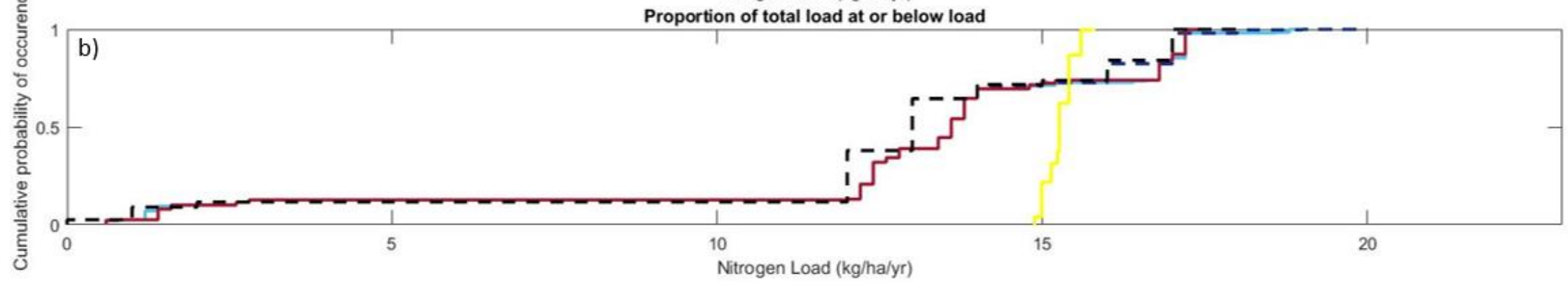

Figure 6.8 (a) occurrence of nitrogen load values in $\mathrm{kg} \mathrm{N} / \mathrm{ha} / \mathrm{yr}$, (b) cumulative probability of occurrence of a nitrogen load at or below a specified load value, (c) proportional occurrence of phosphorus load values in $\mathrm{g} P / \mathrm{ha} / \mathrm{yr}$, (d) cumulative probability of occurrence of a phosphorus load at or below a specified load value. 


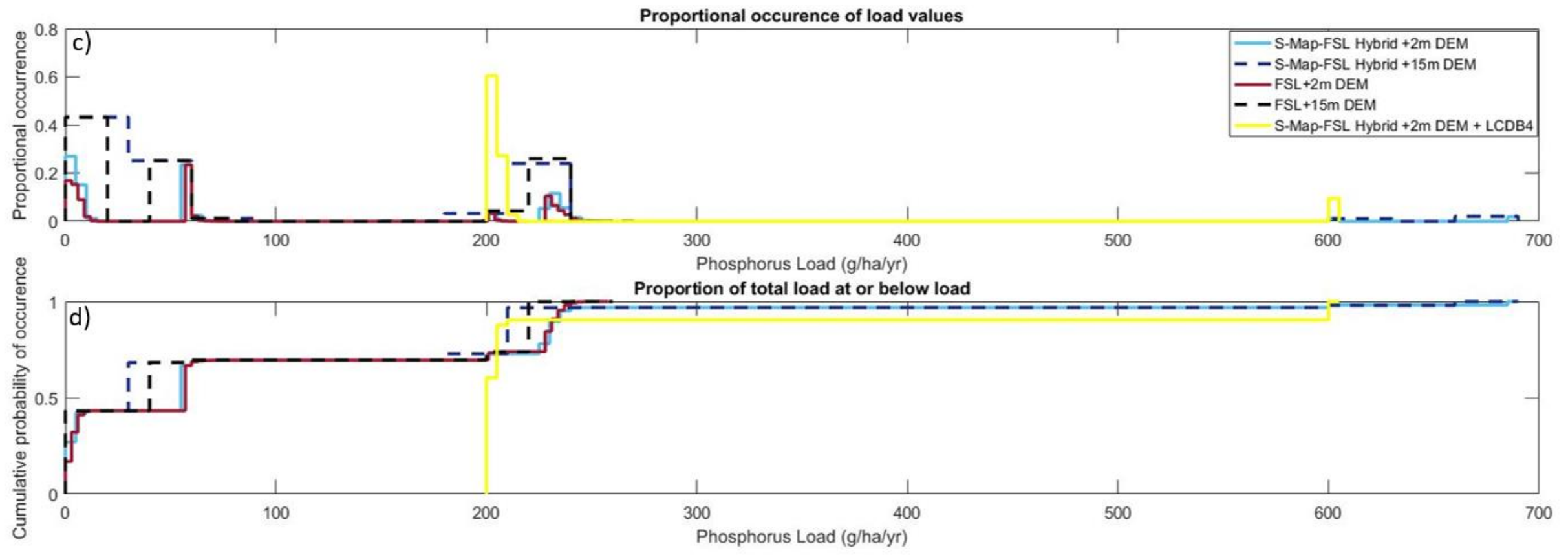

Figure 6.8 Continued. 


\section{Nitrogen}

Results from LUCl's nitrogen model for this site are presented below. In Figure 6.9, the areas where high nitrogen loads are estimated are similar between outputs using the two soil maps. The red areas occupy the flat parts of the farm with lower loads (orange) estimated on the rolling topography. The green areas near the streams indicate lower nitrogen loading between $0-5 \mathrm{~kg} / \mathrm{ha} / \mathrm{yr}$. This similarity in LUCl's nitrogen load estimates for both soil datasets for this site are also present in the model's estimates of accumulated load (Figure 6.10). Accumulated load pathways in all scenarios show more pathways present on the south west side of the property using the $15 \mathrm{~m}$ DEM, however, on the north-east side of the property the $1 \mathrm{~m}$ and $15 \mathrm{~m}$ DEM estimate pathways in the same locations.
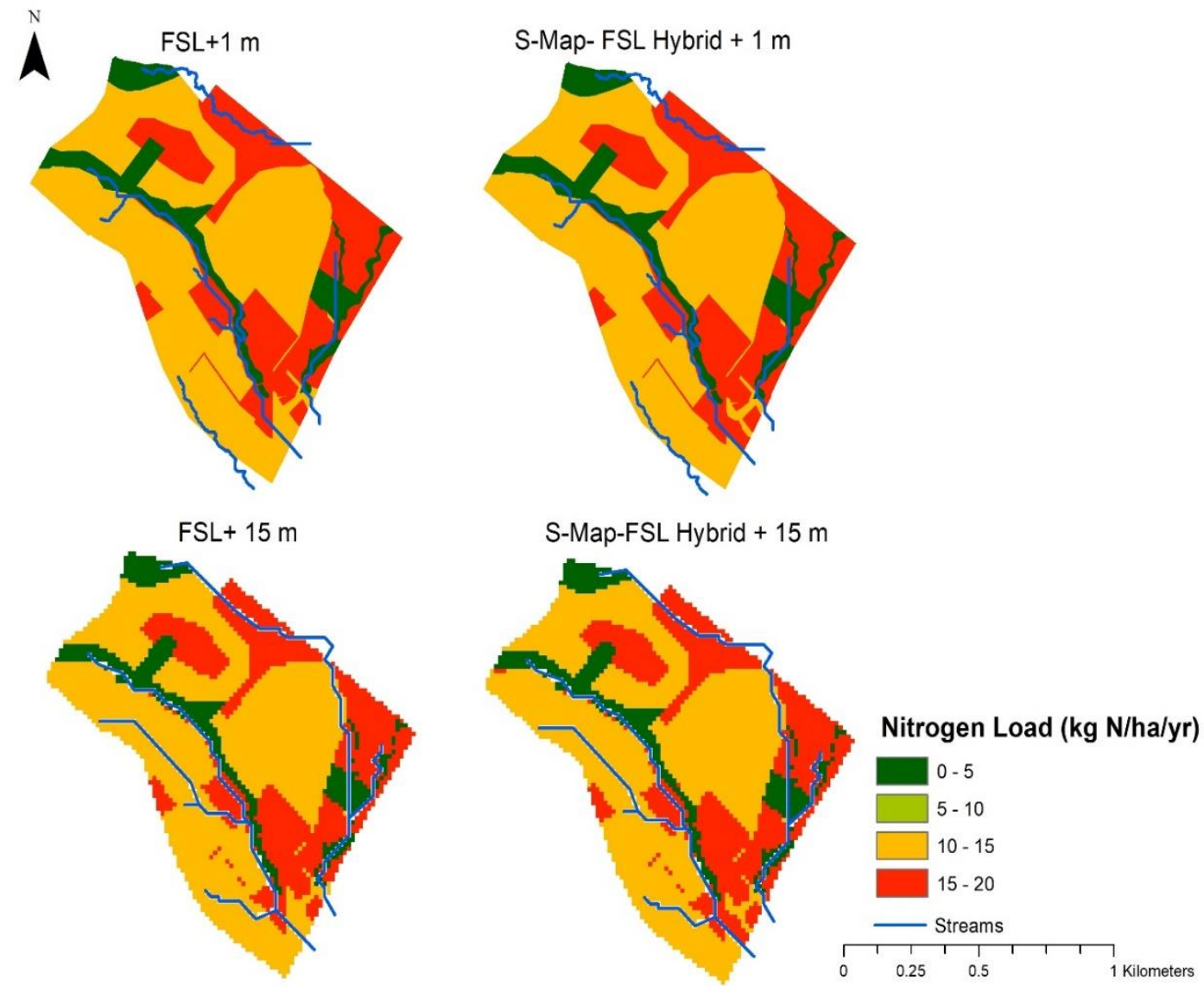

Figure 6.9 Nitrogen load results for all scenarios in $\mathrm{kg} \mathrm{N} / \mathrm{ha} / \mathrm{yr}$. 

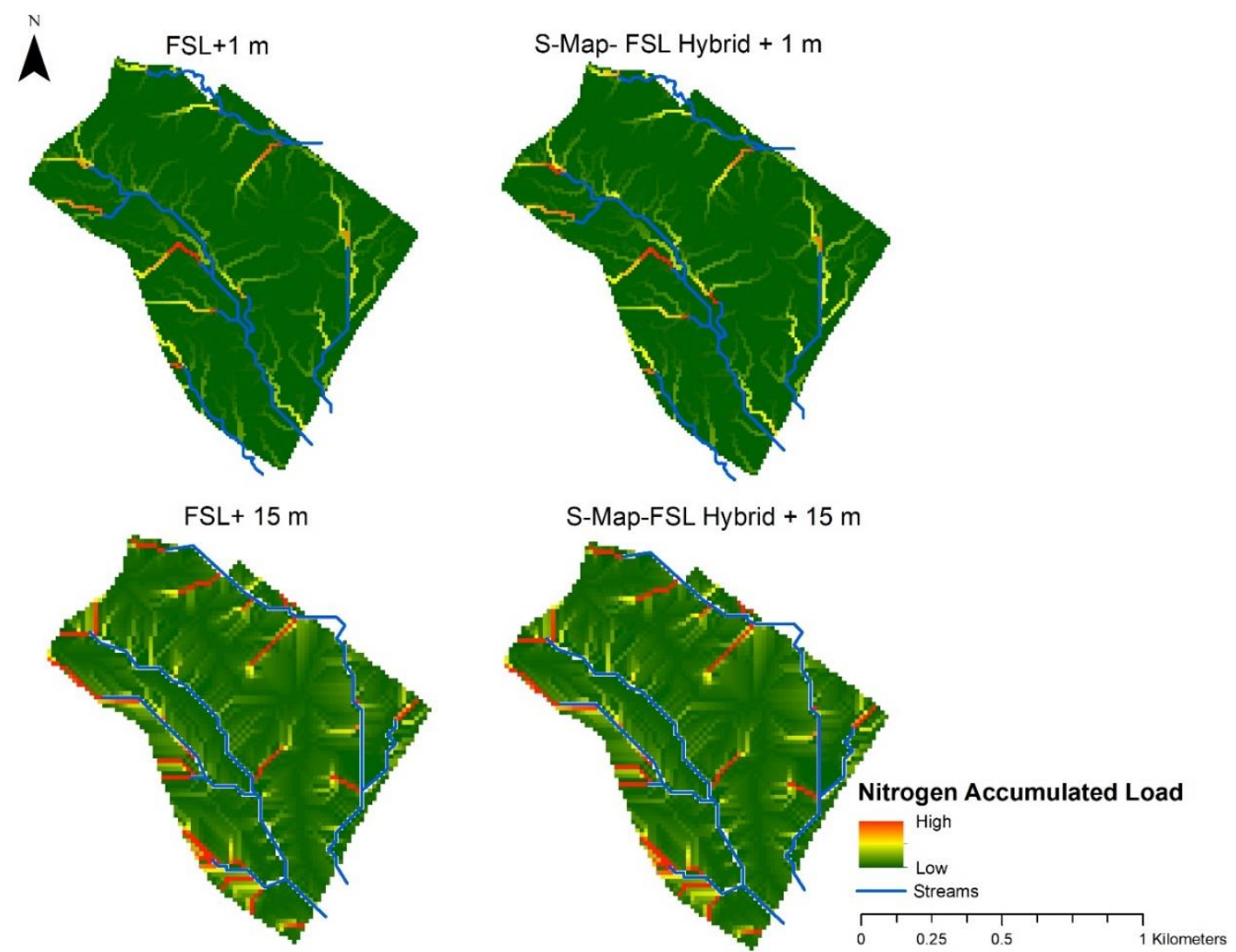

Figure 6.10 Nitrogen accumulated load results for all scenarios.

\section{Phosphorus}

For phosphorus, the pattern of the soil order is present, with the strip of recent soils along the stream boundary displaying higher phosphorus loads of 600-700 g P/ha/yr then areas of brown soil (which range from 0-100 and 200-300 g P/ha/yr) (Figure 6.11). The pattern in phosphorus accumulated load (Figure 6.12) demonstrates similar pathways of nutrient movement to the nitrogen results presented above. 

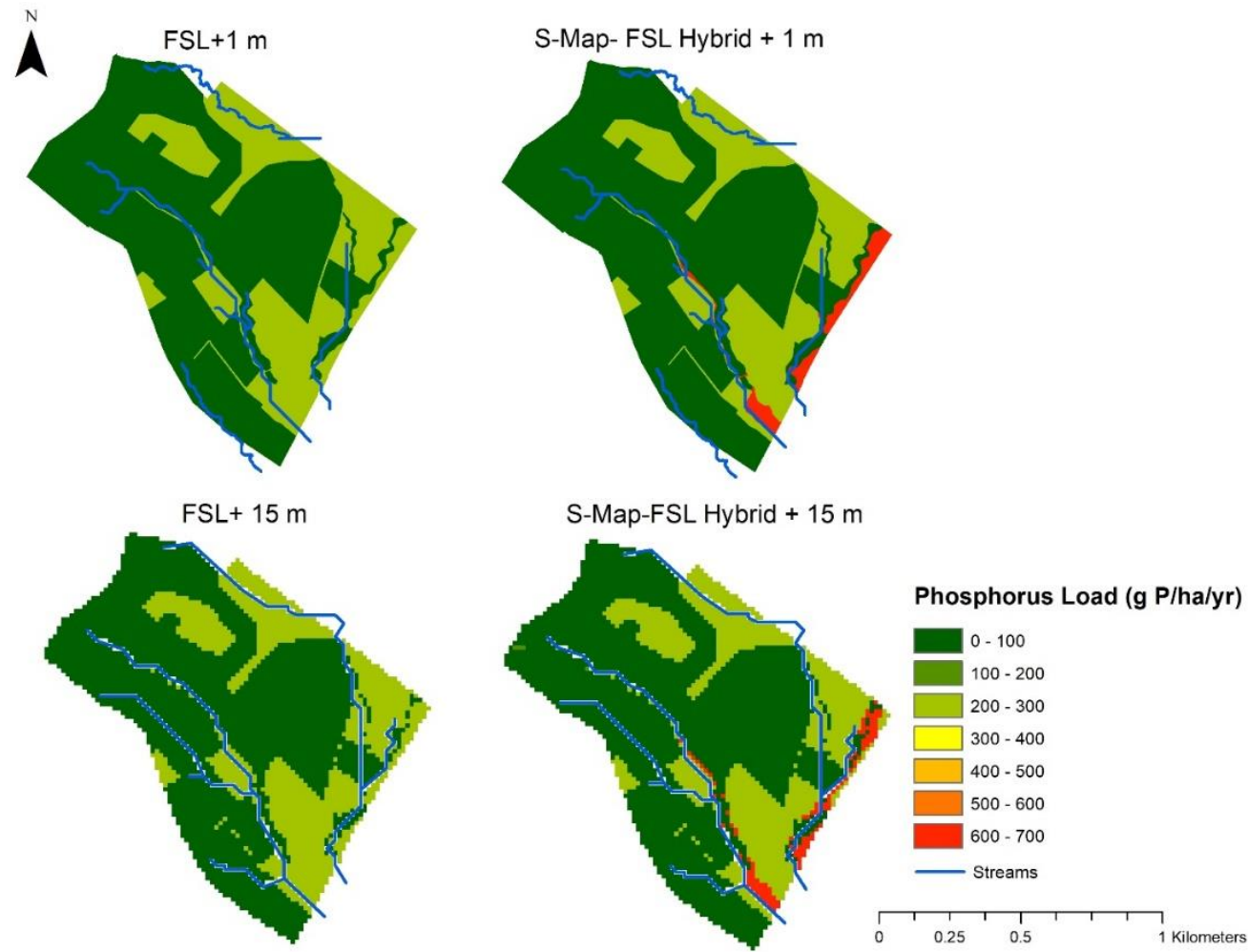

Figure 6.11 Phosphorus load results for all scenarios in $\mathrm{g} P / \mathrm{ha} / \mathrm{yr}$.
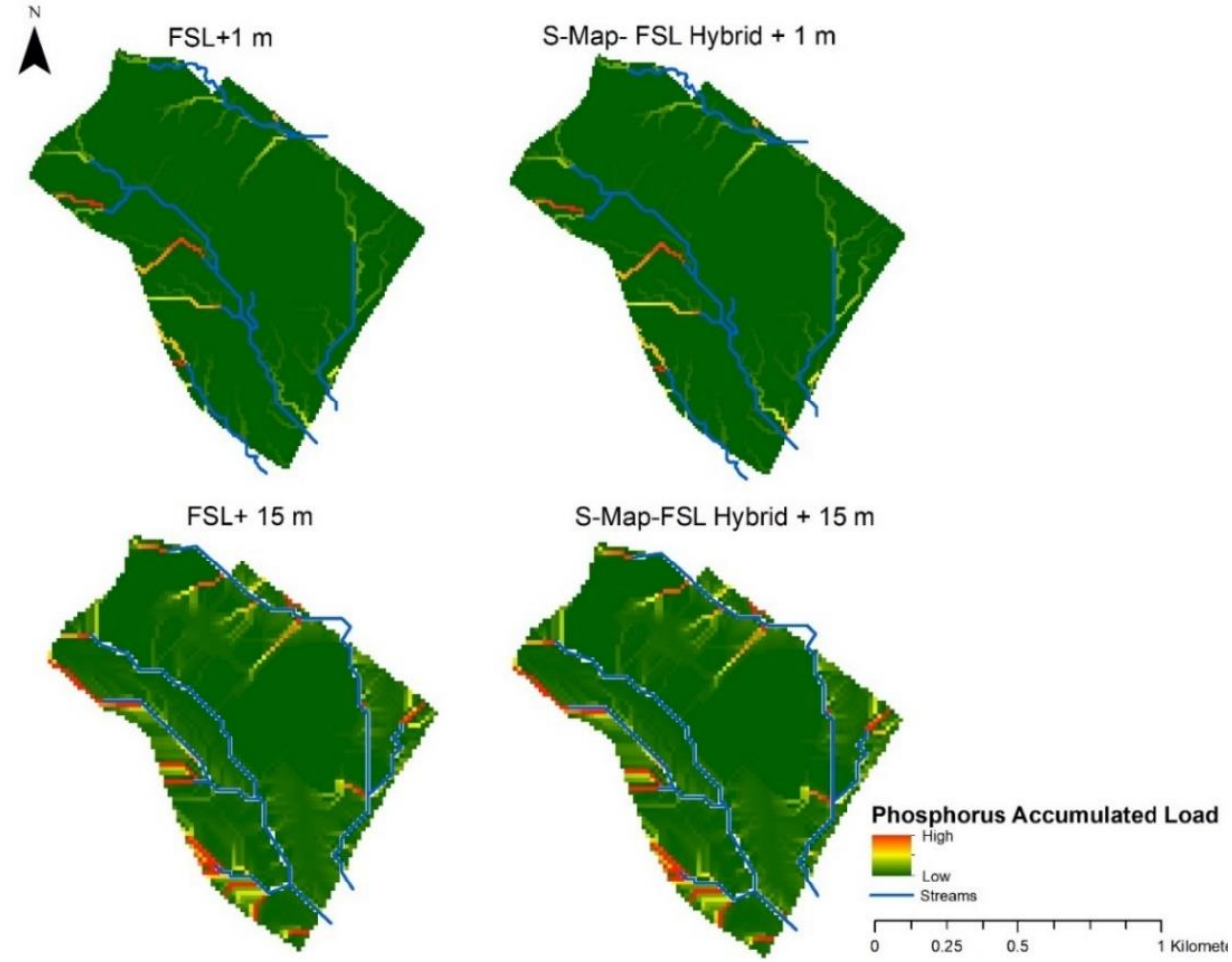

Figure 6.12 Phosphorus accumulated load results for all scenarios. 


\section{$\underline{\text { National Landcover Data }}$}

When the OVERSEER file is removed from the S-Map- FSL Hybrid + 1m scenario, the results produced differ from those presented above. In Figure 6.13a below, nitrogen loads can be seen to follow the pattern in the NIWA gridded rainfall dataset that LUCI connects to if no site-specific climate data is available. Since the soil order of the SMap-FSL Hybrid for this site is mostly brown soils and some recent soil, the removal of landcover information from OVERSEER means that only default landcover information is used. In this case, the LCDB4 database shows the whole farm as high producing grassland. Therefore, the gridded rainfall data is the only input data used in this scenario that has any variation that would result in different nitrogen load estimates. For phosphorus (Figure 6.13b), impacts from variations within the gridded rainfall network are not evident. Instead, the recent and brown soil classifications are the cause of the variation in phosphorus loads.
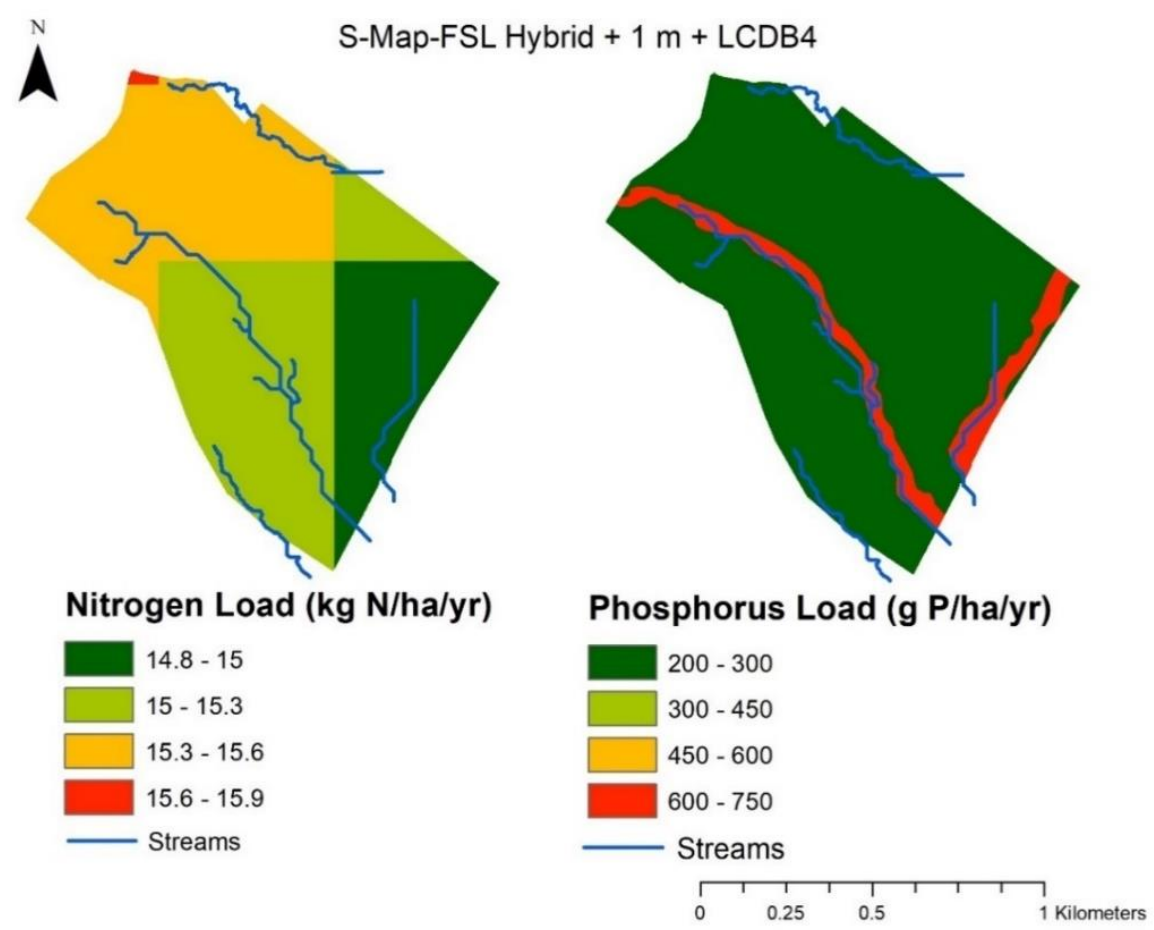

Figure 6.13 Nitrogen and phosphorus load results for S-Map-FSL Hybrid soil data + 1m DEM without farm specific information from an OVERSEER xml file. 


\subsection{NORTH CANTERBURY}

\subsubsection{Hydtopo Output}

Using the $2 \mathrm{~m} \mathrm{DEM}$, it can be seen in Figure 6.14 that the watershed is larger than the watershed estimated by the $15 \mathrm{~m} \mathrm{DEM}$, and the $2 \mathrm{~m}$ DEM models the stream running north to south along the property boundary. This stream outline is more realistic than the $15 \mathrm{~m}$ DEM which models the stream north of its actual position and cuts across the property. The catchment boundary represented by the black outline also varies with the DEM used and this impacts LUCI's nutrient load estimates as the model calculates nutrients contributed from 'uphill sources' when calculating accumulated load.
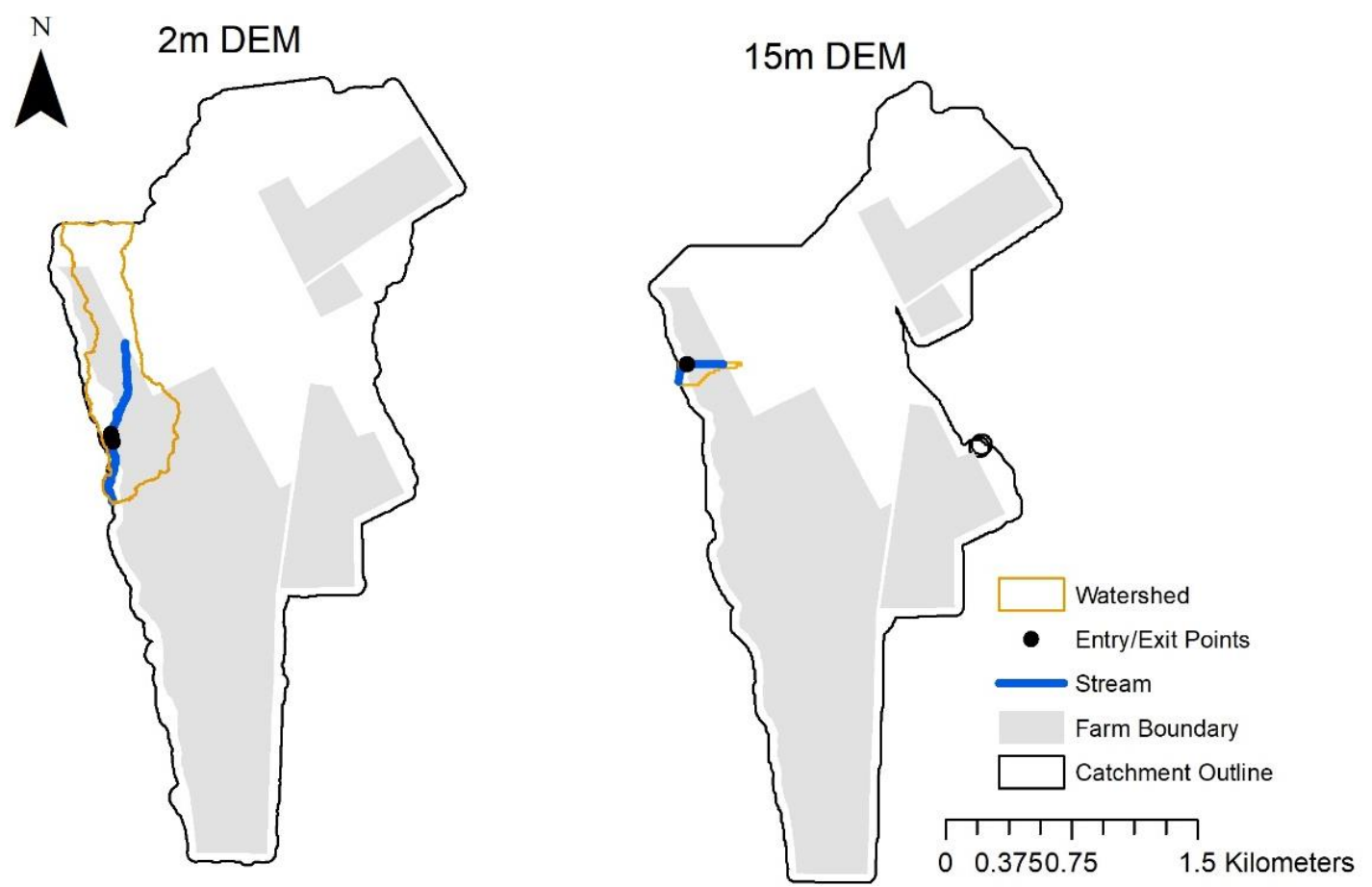

Figure 6.14 Hydrological output of both DEM resolutions tested at this site.

\subsubsection{Nutrient Load Results}

The results from the North Canterbury case study are presented below from scenarios using S-Map and a $2 \mathrm{~m}$ DEM, S-Map and a $15 \mathrm{~m} \mathrm{DEM}$, FSL and a $2 \mathrm{~m} \mathrm{DEM}$, and finally FSL and a $15 \mathrm{~m}$ DEM. The S-Map and FSL datasets were also tested with a detailed farm specific soil map from OVERSEER. Both nitrogen and phosphorus results were calculated with the total loads shown in Table 6.4. These results have been presented in a paper of which I was the lead author (Taylor et al., 2018- Appendix B). 
Table 6.4 Total nitrogen and phosphorus load results for all scenarios.

\begin{tabular}{|c|c|c|}
\hline LUCI Applications & $\begin{array}{l}\text { Total Nitrogen Load } \\
\text { (kg N/yr) }\end{array}$ & $\begin{array}{l}\text { Total Phosphorus Load } \\
\text { (kg P/yr) }\end{array}$ \\
\hline S-Map+2m+ OVERSEER & 1,954 & 92 \\
\hline $\mathrm{FSL}+2 \mathrm{~m}+$ OVERSEER & 2,000 & 115 \\
\hline S-Map + 2m & 3,691 & 57 \\
\hline S-Map + 15m & 3,713 & 58 \\
\hline $\mathrm{FSL}+2 \mathrm{~m}$ & 4,401 & 89 \\
\hline $\mathrm{FSL}+15 \mathrm{~m}$ & 4,443 & 90 \\
\hline
\end{tabular}

The data produced from all the scenarios with the nitrogen tool is shown in Figure

6.15a-d. Here it can be seen that the distribution of data is similar between the scenarios using the same soil data, with data clumped between 1-3 $\mathrm{kg} \mathrm{N} / \mathrm{ha} / \mathrm{yr}$ and 19 $22 \mathrm{~kg} \mathrm{~N} / \mathrm{ha} / \mathrm{yr}$ for the two FSL scenarios, and data clumped between 1-3 kg N/ha/yr and $17-18 \mathrm{~kg} \mathrm{~N} / \mathrm{ha} / \mathrm{yr}$ for the two S-Map scenarios (Figure 6.15a). Figure 6.15b describes the proportion of that scenario estimating at or below a load value. Here it can be seen that at a load value of $17 \mathrm{~kg} \mathrm{~N} / \mathrm{ha} / \mathrm{yr}$, approximately $40 \%$ of the load data in the FSL scenarios estimate this load or below, and for the S-Map scenarios approx. $95 \%$ of the load data is at this load or below. When OVERSEER landcover information is added to the model (Figure $6.15 \mathrm{c}-\mathrm{d}$ ), the difference in the distribution of load values between S-Map and FSL $2 \mathrm{~m}$ scenarios is minimal, with both scenarios estimating around $30 \%$ of load values at $8 \mathrm{~kg} \mathrm{~N} / \mathrm{ha} / \mathrm{yr}$.

Phosphorus results for all scenarios can be seen in Figure 6.16. As with nitrogen, S-Map scenarios are estimating a high proportion of load values from 0.2 to $0.5 \mathrm{~kg} \mathrm{P} / \mathrm{ha} / \mathrm{yr}$ (Figure $6.16 \mathrm{~b}$ ), with FSL scenarios having $40 \%$ of their load estimates at the high range of $0.6 \mathrm{~kg} \mathrm{P} / \mathrm{ha} / \mathrm{yr}$. Including the OVERSEER file in the S-map $+2 \mathrm{~m}$ and $\mathrm{FSL}+2 \mathrm{~m}$ scenarios did not lead to similar results for phosphorus loads between the two soil datasets, unlike the results from the nitrogen model. In Figure $6.16 \mathrm{~d}$, S-Map is estimating a higher proportion of its data at or below $0.5 \mathrm{~kg} \mathrm{P} / \mathrm{ha} / \mathrm{yr}$ like the results shown in the S-Map scenarios with default landcover. 


\section{Nitrogen}

Using the OVERSEER file instead of default landcover data results in a lower total nitrogen load with the S-Map $+2 \mathrm{~m}+$ OVERSEER scenario estimating 1,954 kg N/yr and the FSL $+2 m+$ OVERSEER estimating a slightly higher nitrogen load of 2,000 kg N/yr. The four scenarios where default landcover data was used range from 3,691 kg N/yr for S-Map $+2 \mathrm{~m}$ to $4,443 \mathrm{~kg} \mathrm{~N} / \mathrm{yr}$ for S-Map $+15 \mathrm{~m}$. Between all the scenarios, the two FSL applications estimated a higher total nitrogen load, indicating that the source of the soil data plays a significant role in producing nutrient load results.

Nitrogen loads from the two applications with OVERSEER data are shown in Figure 6.17. The distribution of high and low loads again shows the errors associated with using regional default data as the areas of high nitrogen loads are located on the laneways and yards, with the low nitrogen loads not clearly separated into different soil orders. As a result, the S-Map and FSL outputs are similar with lower loads in the pallic areas of the farm. 

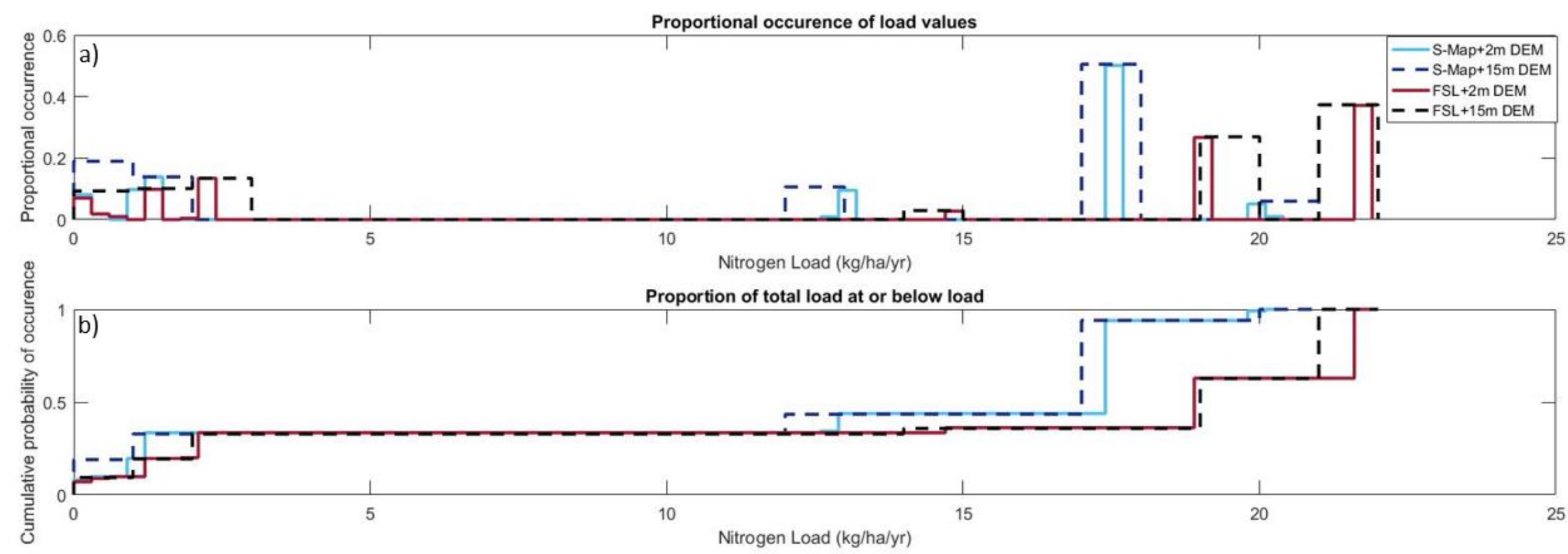

Figure 6.15 (a) occurrence of nitrogen load values in $\mathrm{kg} \mathrm{N} / \mathrm{ha} / \mathrm{yr}$ for the soil + DEM scenarios with default landcover, (b) cum ulative probability of occurrence of a nitrogen load at or below a specified load value for the soil + DEM scenarios with default landcover, (c), occurrence of nitrogen load values in $\mathrm{kg} \mathrm{N} / \mathrm{ha} / \mathrm{yr}$ for scenarios with farm specific OVERSEER information, (d) probability of occurrence of a nitrogen load at or below a specified load value for scenarios with farm specific OVERSEER information. 


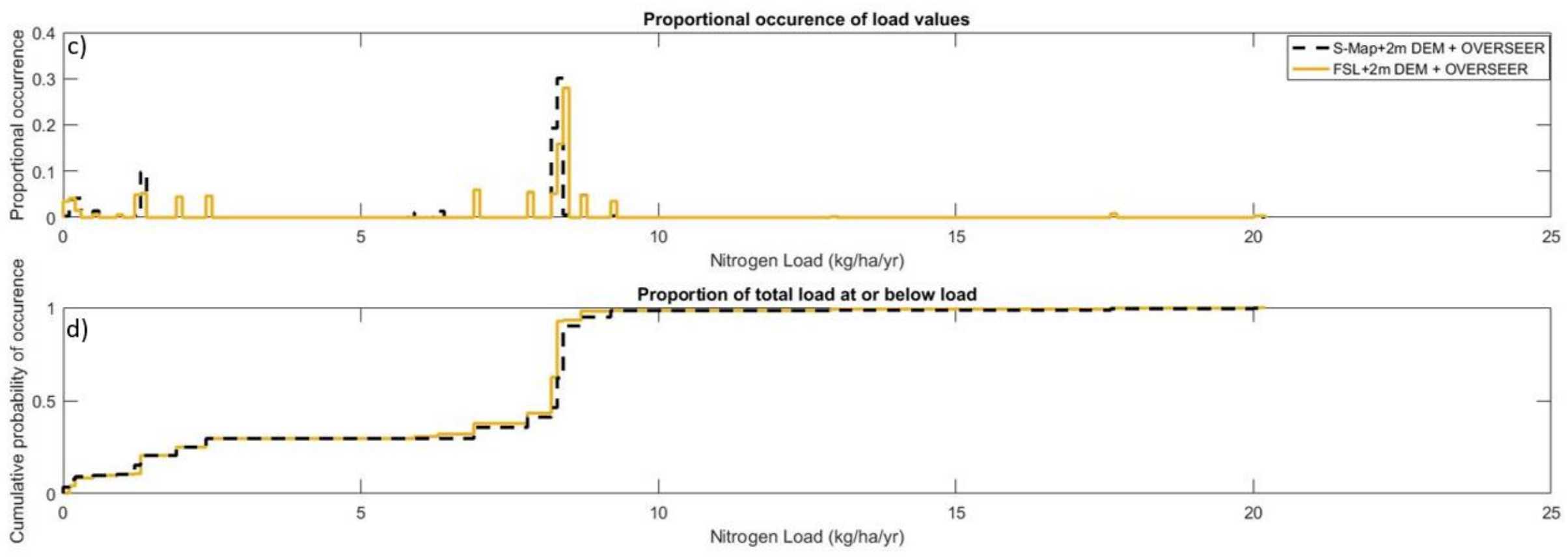

Figure 6.15 Continued. 


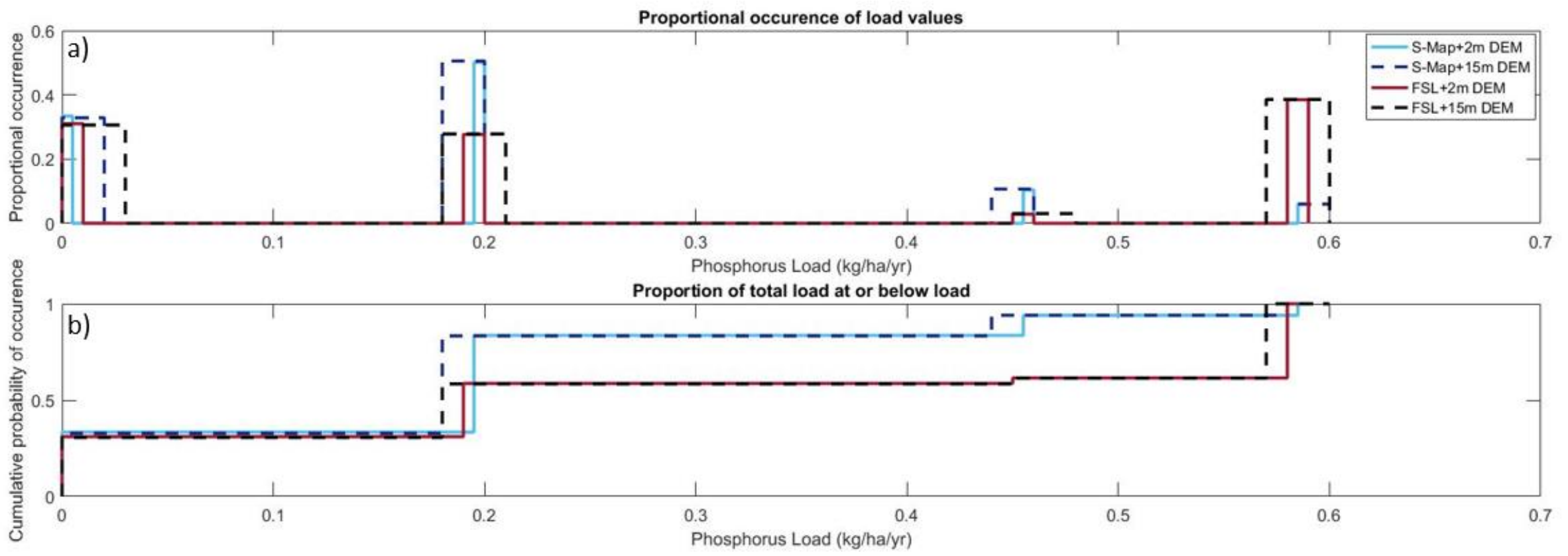

Figure 6.16 (a) occurrence of phosphorus load values in kg P/ha/yr for the soil + DEM scenarios with default landcover, (b) cumulative probability of occurrence of a phosphorus load at or below a specified load value for the soil + DEM scenarios with default landcover, (c), occurrence of phosphorus load values in $\mathrm{kg} \mathrm{P} / \mathrm{ha} / \mathrm{yr}$ for scenarios with farm specific OVERSEER information, (d) probability of occurrence of a phosphorus load at or below a specified load value for scenarios with farm specific OVERSEER information. 

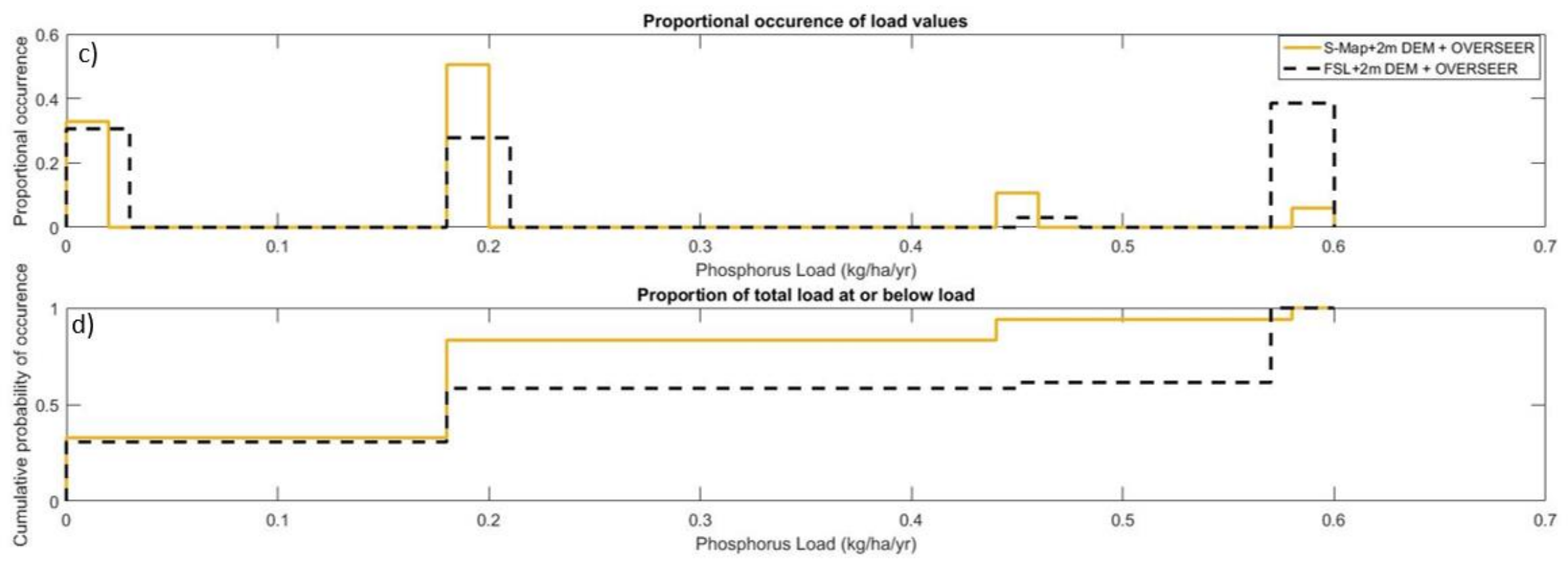

Figure 6.16 Continued. 

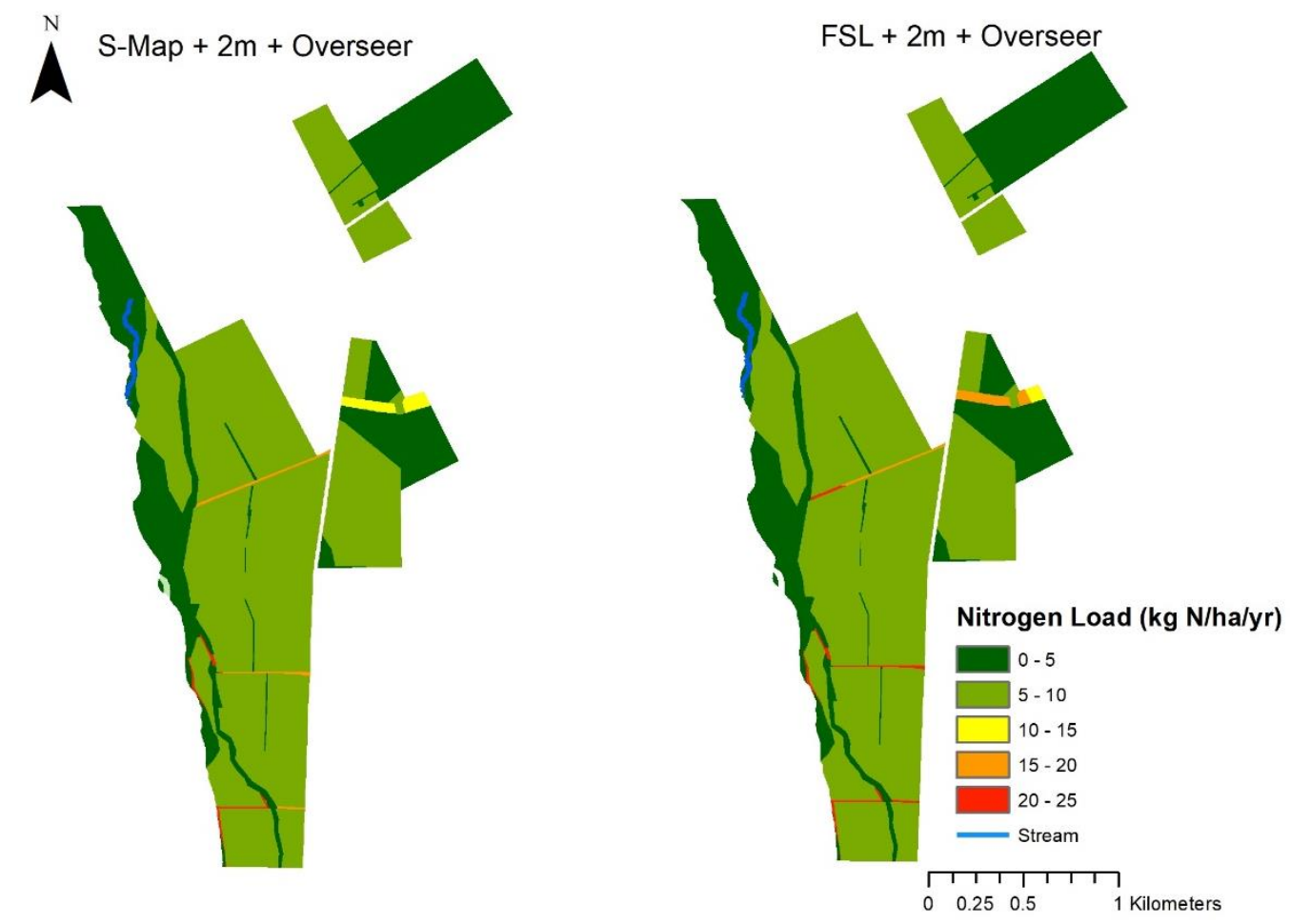

\subsection{Nitrogen load results in $\mathrm{kg} \mathrm{N} / \mathrm{ha} / \mathrm{yr}$ for S-Map and FSL soil data $+2 \mathrm{~m}$ DEM with farm specific information from an OVERSEER xml file.}

The four applications with regional land cover data are shown in Figure 6.18, with the nitrogen accumulated load shown in Figure 6.19. The distribution of high and low nitrogen loads can be seen to follow the pattern of each applications' input soil data. The changing ratio of brown, pallic and recent soil order classifications across the farm when using the newer, S-Map dataset, resulted in a reduction in the areas classed as having high nitrogen loads. This reduction in high load estimates is linked to the changing classification of recent soils in the FSL to brown soils in S-Map. The area classified as pallic soil remained as a low nitrogen load. Changing soil classification between datasets resulted in pallic soil area increasing from 51 ha in the FSL to 75 ha in S-Map over the farm, recent soils reduced from 156 ha to 25 ha and brown soils increasing from 89 ha to 167 ha. 

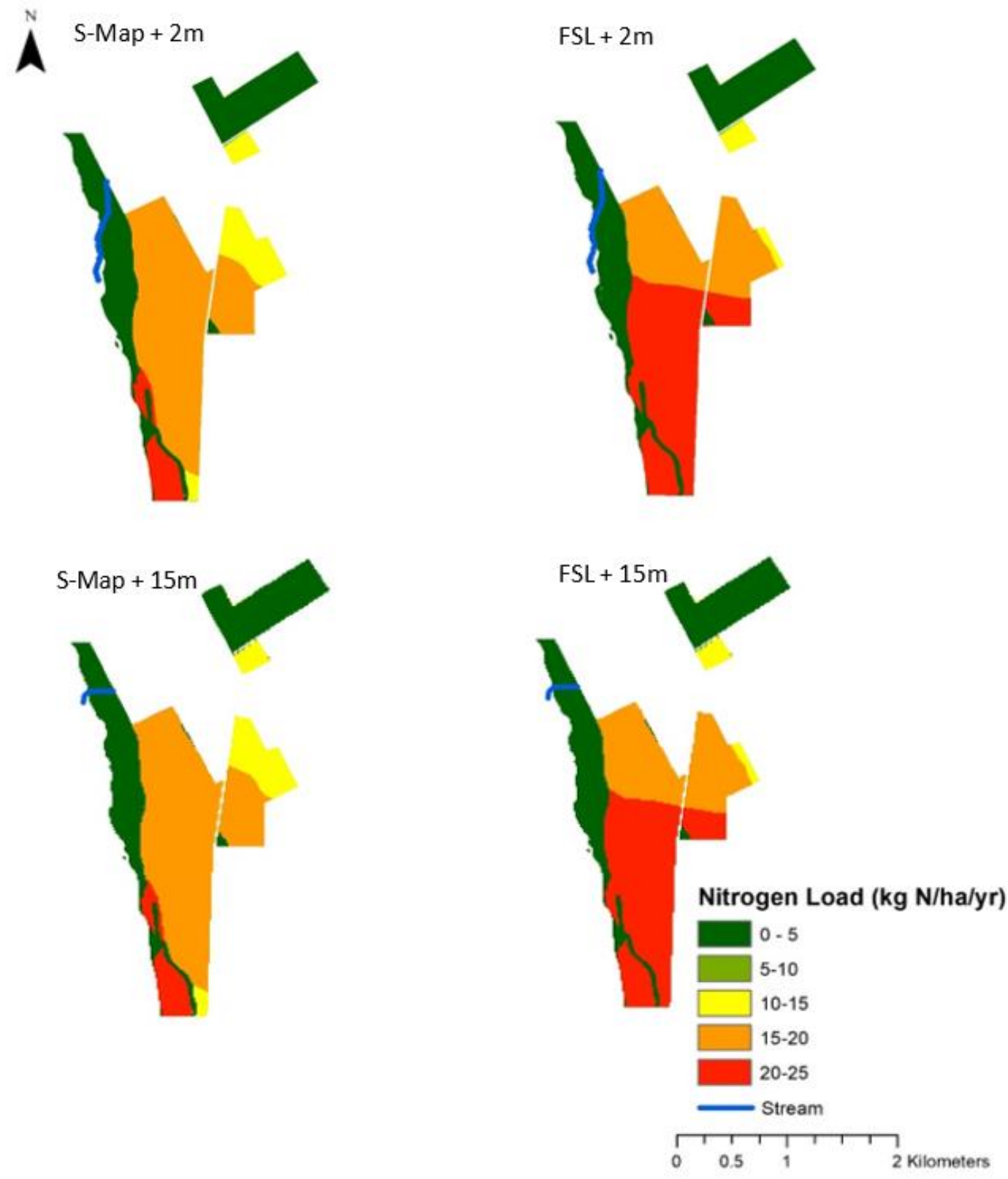

Figure 6.18 Nitrogen load results for all scenarios without farm specific OVERSEER information in $\mathrm{kg} \mathrm{N} / \mathrm{ha} / \mathrm{yr}$.

However, when looking at the outputs of accumulated nutrient load on the landscape, the effect of the different soil datasets is not apparent. Instead, the changing resolution of the DEM is the main cause of difference between the applications. When looking at the accumulated loads of S-Map $2 \mathrm{~m}$ and S-Map $15 \mathrm{~m}$, it is apparent that the $15 \mathrm{~m}$ DEM is estimating different pathways to the $2 \mathrm{~m}$ DEM and this is the same when comparing FSL $2 \mathrm{~m}$ and FSL $15 \mathrm{~m}$. Since LUCl estimates accumulated load using a topographic routing algorithm that associates soil, climate, slope based on the grid size 
of the DEM provided, when using a lower resolution DEM, the microtopography present on the farm is not present in the input data so cannot be picked up by the algorithm and the accumulated load patterns are not realistic in this relatively flat landscape.
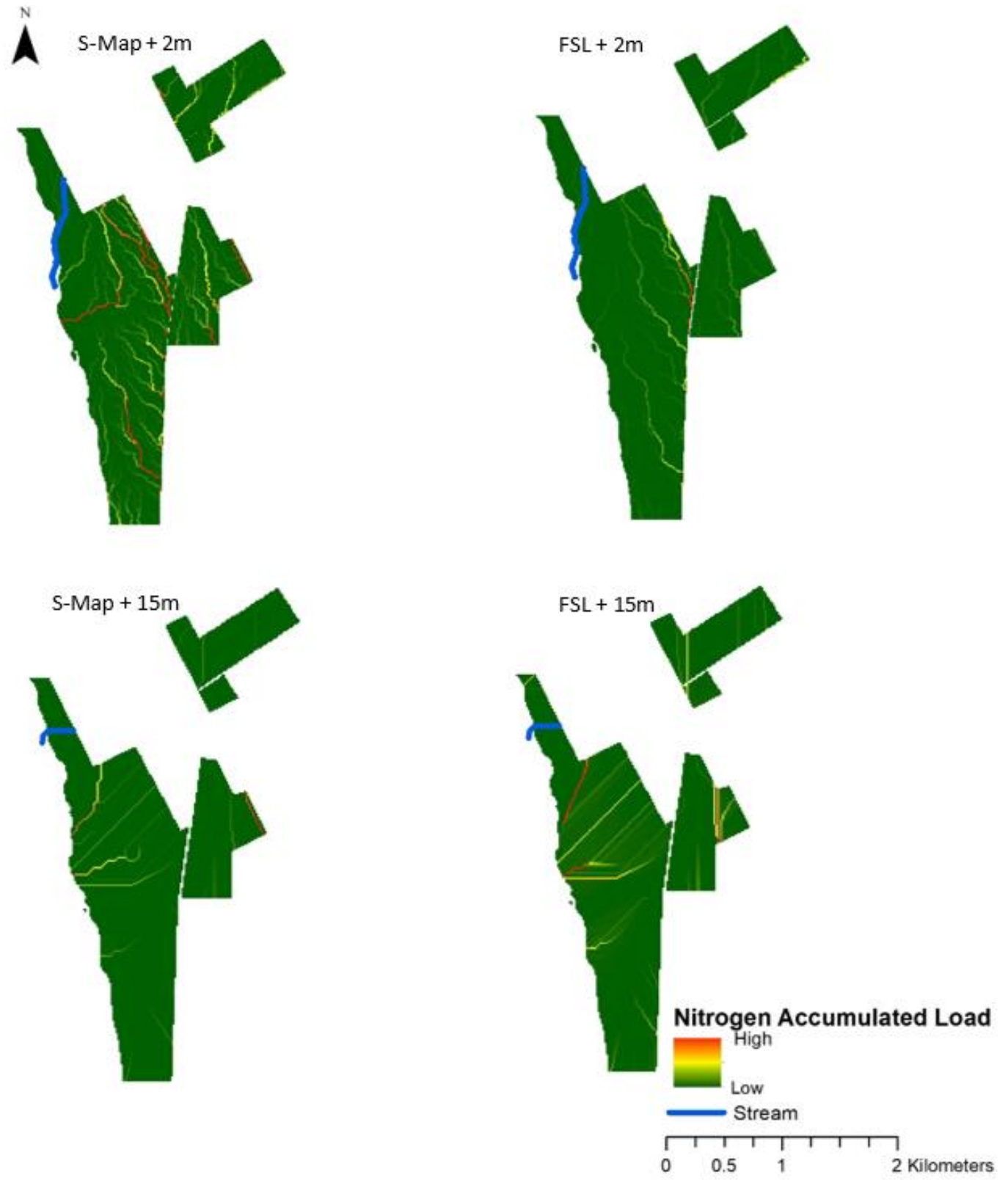

Figure 6.19 Nitrogen accumulated load results for all scenarios without farm specific OVERSEER information.

Another important factor to consider is the different ways data can be represented on a landscape, as default symbology in ArcMap software separates estimated accumulated loads into different classes by standard deviation. Figure 6.20 below 
highlights issues in data presentation as the underlying data is the same as the accumulated load scenarios presented above, but instead of classifying high and low loads through standard deviation, the histogram equalize setting was used. Depending on what setting the user defines, the resultant pathways where mitigations could be targeted change greatly between the input soil datasets selected.
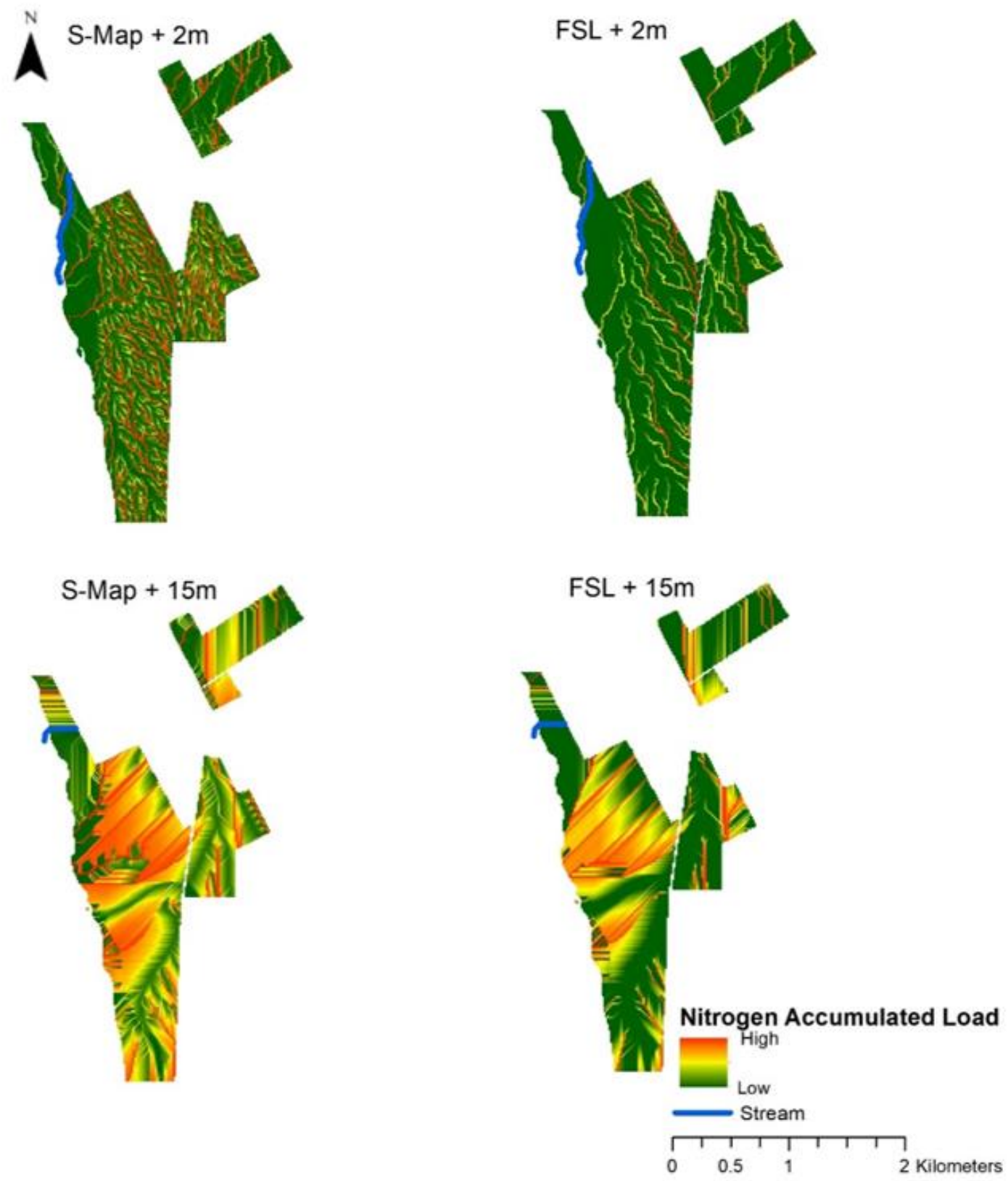

Figure 6.20 Nitrogen accumulated load results for all scenarios without farm specific OVERSEER information using the histogram equalise setting in ArcMap symbology.

Not only is soil classification affecting LUCl's estimates of nitrogen loads but the landcover classification in the LCDB4 has resulted in load inconsistencies. The 
estimates of nitrogen load along the river flat on the western edge of the farm vary despite being classed as recent soils in both FSL and S-Map datasets. The reason for the different loading estimates along this block is the classification of the upper northern part as cropland and the southern half as high producing grassland. In reality, the entire river flat is covered by high producing grassland, which shows the importance of understanding (and correcting where possible) errors in the underlying data used in models such as LUCl and the importance of using high-resolution, sitespecific land cover data wherever it is available.

\section{Phosphorus}

Phosphorus load estimates also follow the pattern in soil input data (Figure 6.21). Again, FSL+2m and FSL $+15 \mathrm{~m}$ estimate higher phosphorus loads than their S-map counterparts, with FSL+2m estimating $89.2 \mathrm{~kg} \mathrm{P} / \mathrm{yr}$ and S-Map+ 2m estimating $57.2 \mathrm{~kg}$ $\mathrm{P} / \mathrm{yr}$ (Table 6.4). Comparing loads of individual cells with the same soil order between applications shows that the load values are similar. Therefore, the reason for the $32 \mathrm{~kg}$ $\mathrm{P} / \mathrm{yr}$ difference between S-Map and FSL applications can be attributed to the classification change from recent to brown soil over the main block of the farm (this is the most significant area of difference between the two soil maps). Areas of recent soils are classified as having a phosphorus load of $0.45-0.6 \mathrm{~kg} \mathrm{P} / \mathrm{ha} / \mathrm{yr}$, and brown soils have an estimated load of $0.15-0.3 \mathrm{~kg} \mathrm{P} / \mathrm{ha} / \mathrm{yr}$. 

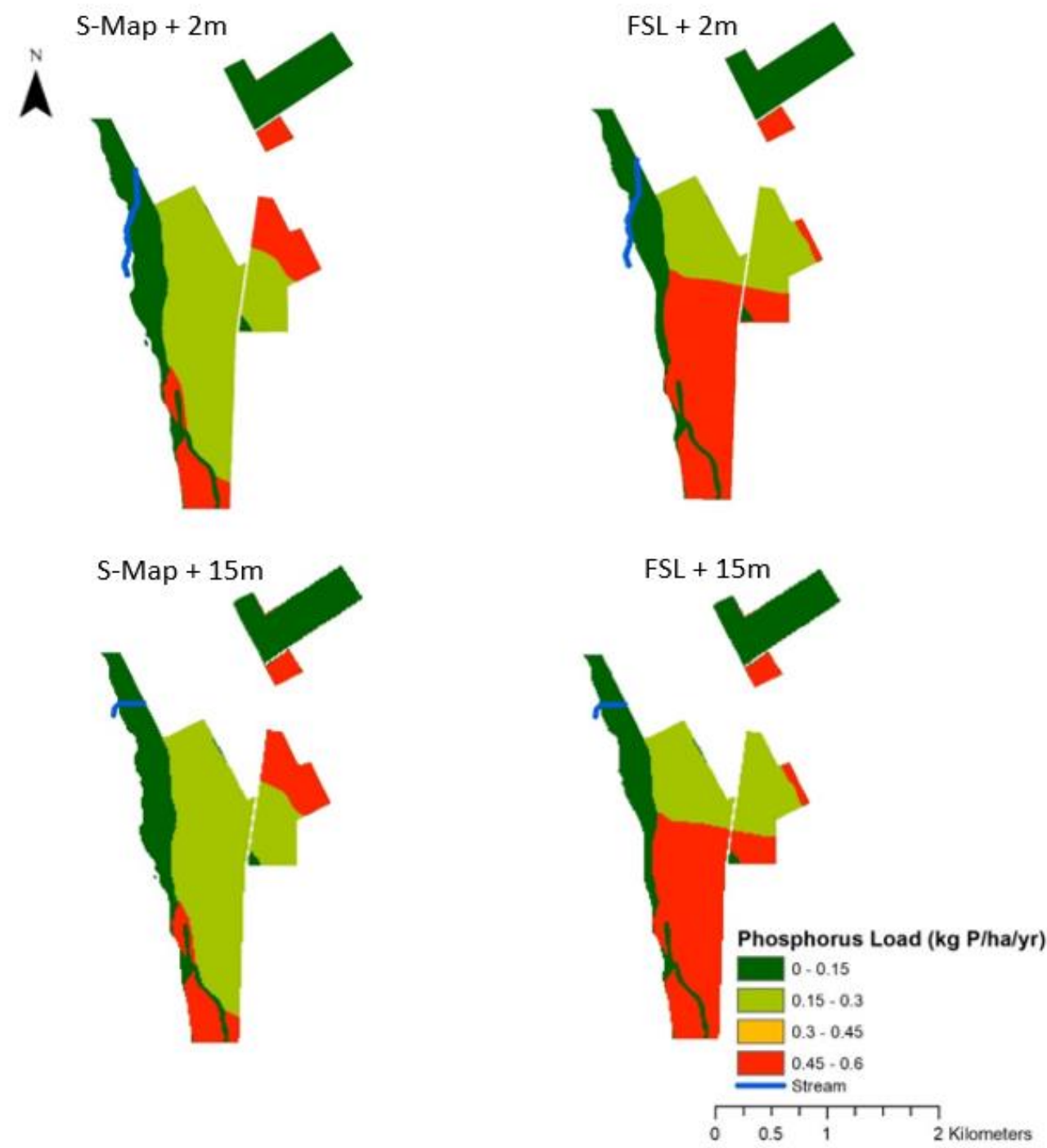

Figure 6.21 Phosphorus load results for all scenarios without farm specific OVERSEER information in $\mathrm{kg} \mathrm{P} / \mathrm{ha} / \mathrm{yr}$.

Unlike nitrogen, when OVERSEER farm specific landcover information is provided, LUCI estimates higher total phosphorus loads than the other four soil and DEM scenarios. The total phosphorus load estimated using regional data is 57 (58) kg P/yr using S-Map (FSL) and the $2 \mathrm{~m}$ DEM. When an OVERSEER file is added, this value is increased to 92 $\mathrm{kg} / \mathrm{ha}$ and $115 \mathrm{~kg} \mathrm{P} /$ ha respectively (Table 6.4). When adding in the OVERSEER file, the pattern in the different loads based on the different soil orders present is not masked by the reduced stocking rate compared to national data (Figure 6.22). 

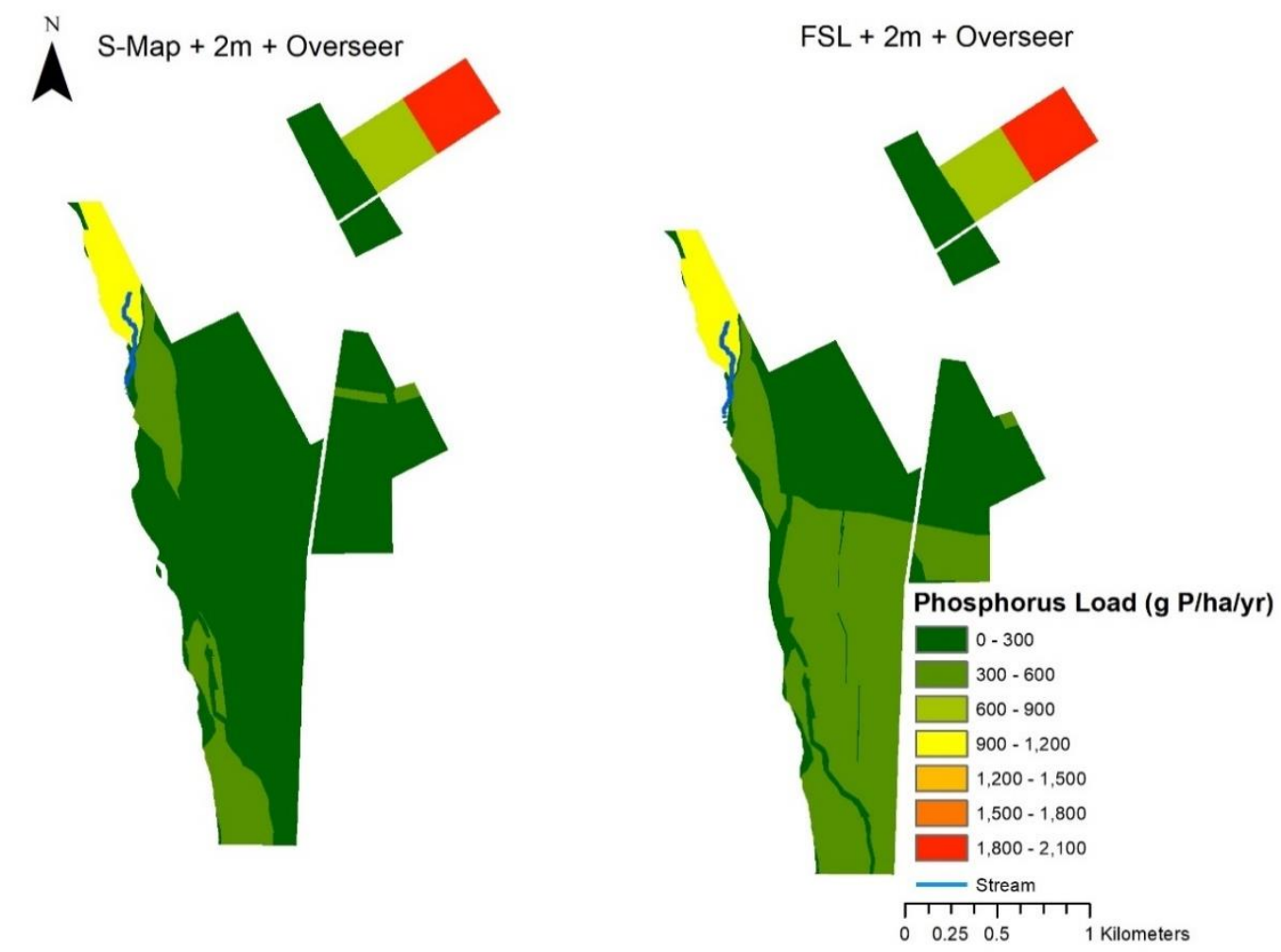

Figure 6.22 Phosphorus load results in g P/ha/yr for S-Map and FSL soil data $+2 \mathrm{~m}$ DEM with farm specific information from an OVERSEER $\mathrm{xml}$ file.

The accumulated phosphorus load results show a similar pattern to the accumulated nitrogen load output, where the effect of the lower resolution DEM results in a different representation of accumulated load across the landscape (Figure 6.23). In this figure, accumulated load pathways can be seen running north to south along the farm, with S-Map producing a load pathway perpendicular to the other load pathways running east to west, terminating below the modelled stream. Again, when mapping the results using a different symbology setting in ArcMap, a greater number of nutrient pathways are highlighted as having high loads, similar to the results from the nitrogen accumulated loads using the same standard deviation symbology (Figure 6.24). 


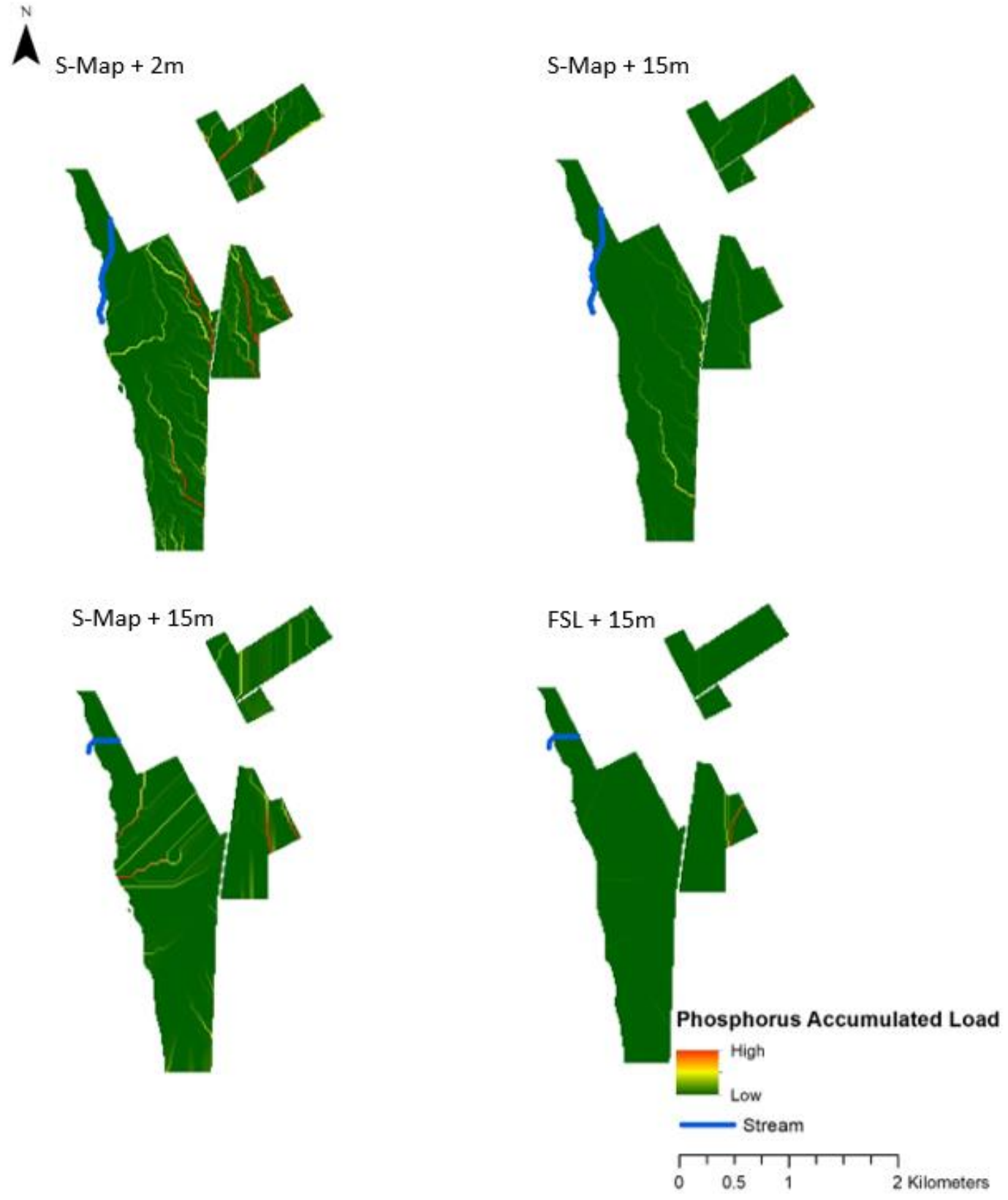

Figure 6.23 Phosphorus accumulated load results for all scenarios without farm specific OVERSEER information. 

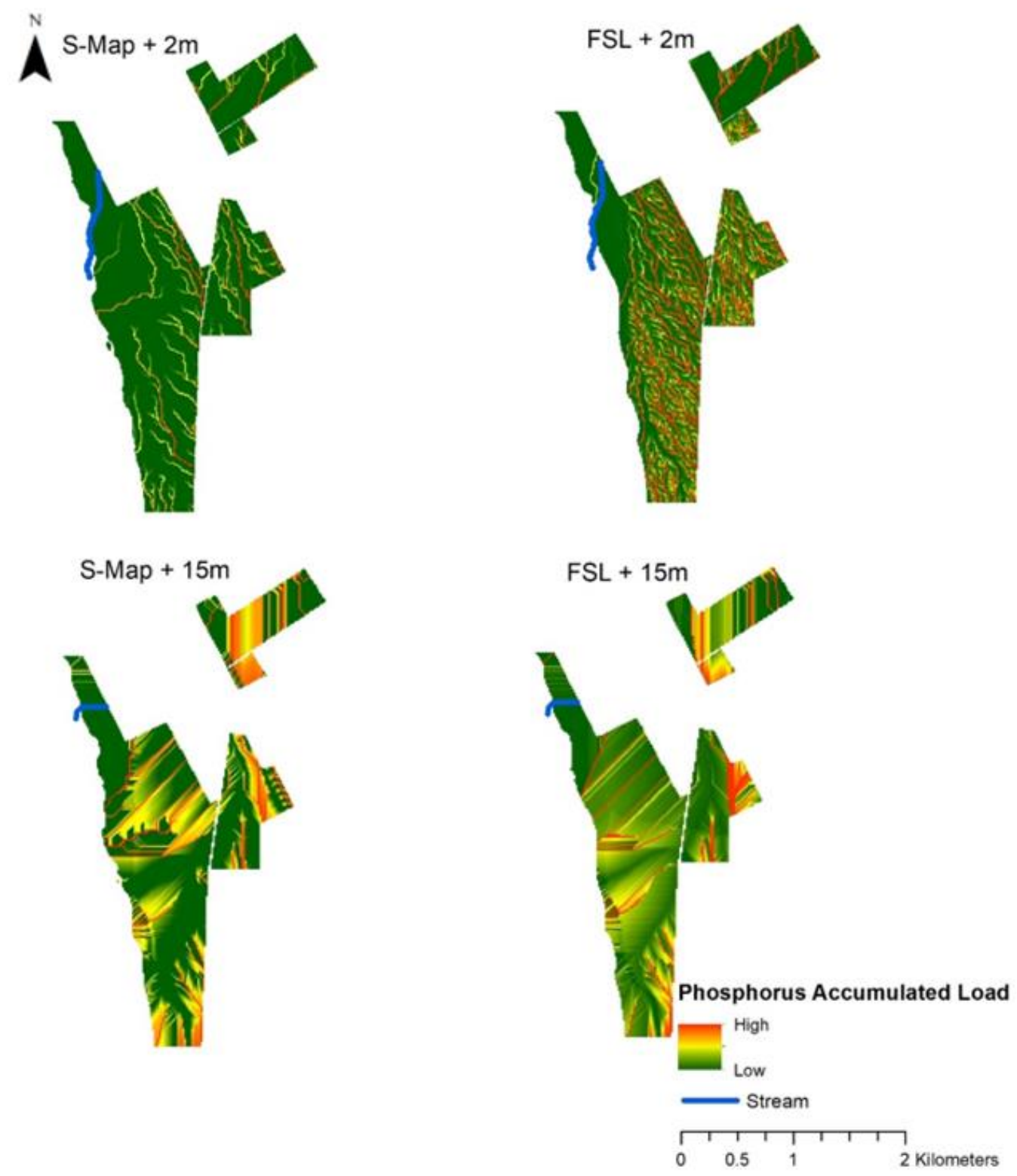

Figure 6.24 Phosphorus accumulated load results for all scenarios without farm specific OVERSEER information using the histogram equalise setting in ArcMap symbology.

\subsection{LUDF}

\subsubsection{Hydtopo Output}

This site has no permanent streams on the property (Figure 6.25), and therefore no watersheds have been modelled, making the hydrology at this site simpler to interpret than other farms modelled in this study. 


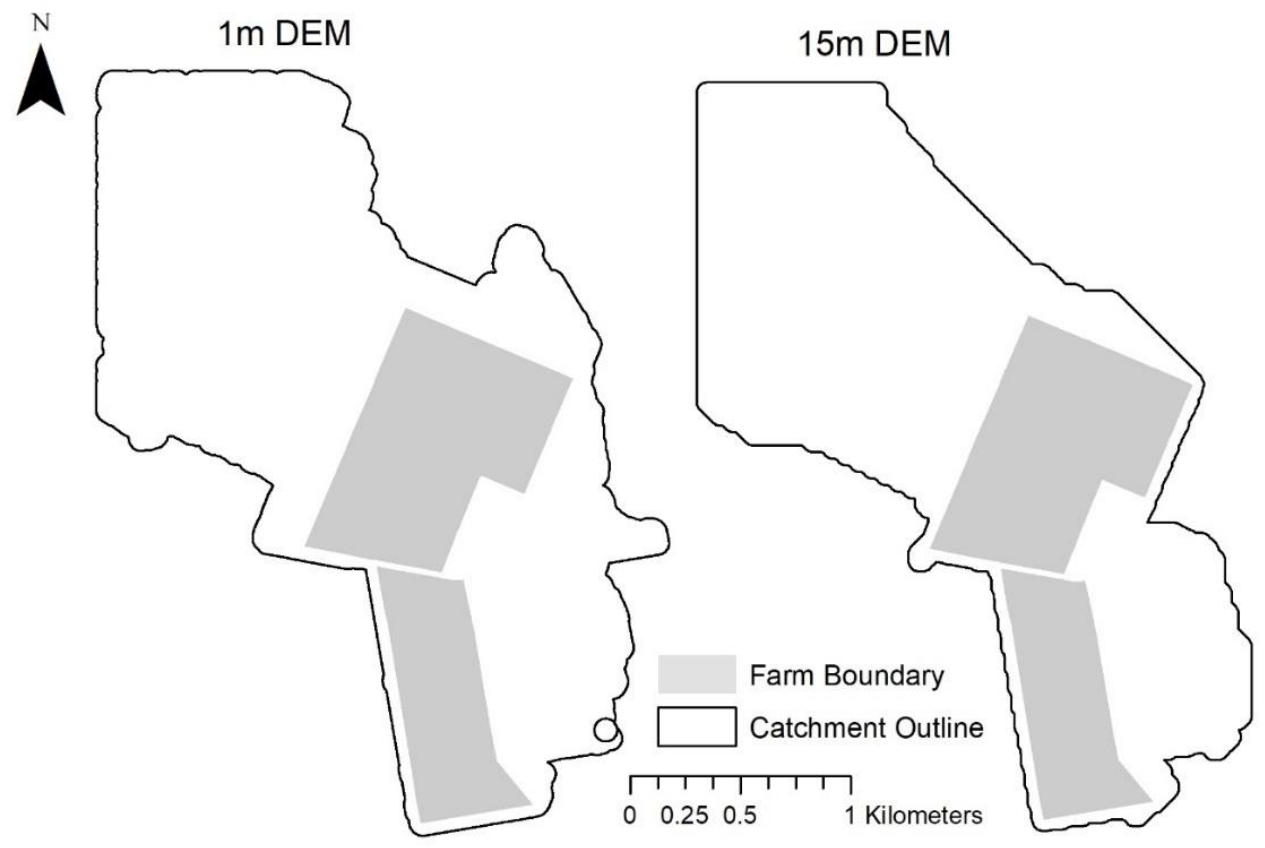

Figure 6.25 Hydrological output of both DEM resolutions tested at this site.

\subsubsection{Nutrient Load Results}

The total nutrient results are presented below in Table 6.5. Here it can be seen that the total load results for nitrogen and phosphorus for all scenarios do not vary greatly, with the lowest nitrogen load estimated by S-Map $+1 \mathrm{~m}$ of $1,828 \mathrm{~kg} \mathrm{~N} / \mathrm{yr}$ and the highest nitrogen load estimated by Farm Scale $+1 \mathrm{~m}$ of 1,890 kg N/yr. For phosphorus, total load estimates range from $58 \mathrm{~kg} \mathrm{P} / \mathrm{yr}$ to $61 \mathrm{~kg} \mathrm{P} / \mathrm{yr}$; this is due to the area classed as pallic soil remaining of similar size between the three soil maps tested.

Table 6.5 Total nitrogen and phosphorus load results for all scenarios.

\begin{tabular}{|l|r|r|}
\hline LUCl Applications & Nitrogen (kg N/yr) & Phosphorus (kg P/yr) \\
\hline S-Map + 1m & 1,828 & 59 \\
\hline S-Map $+15 m$ & 1,829 & 58 \\
\hline FSL $+1 m$ & 1,857 & 58 \\
\hline FSL $+15 m$ & 1,857 & 58 \\
\hline Farm Scale $+1 \mathrm{~m}$ & 1,890 & 61 \\
\hline Farm Scale $+15 \mathrm{~m}$ & 1,856 & 61 \\
\hline
\end{tabular}


While the total nitrogen loads are similar between all scenarios, the distribution of load estimates shows the connection between the two different DEM resolutions tested. In Figure $6.25 a-b$, the three $15 \mathrm{~m}$ DEM scenarios estimate $25 \%$ of their nitrogen loads between $14-17 \mathrm{~kg} / \mathrm{ha} / \mathrm{yr}$, whereas all three $1 \mathrm{~m}$ scenarios estimate $10 \%$ of their values within that range. For phosphorus (Figure 6.25c-d), the distribution of the different, loads is similar with all scenarios estimating phosphorus loads between 50 $100 \mathrm{~g} / \mathrm{ha} / \mathrm{yr}, 300-350 \mathrm{~g} / \mathrm{ha} / \mathrm{yr}$ and $700-750 \mathrm{~g} / \mathrm{ha} / \mathrm{yr}$.

\section{Nitrogen}

Nitrogen load results display the pattern of recent soil order classification in the three soil maps, with the red area (25-30 kg N/ha/yr) evident in the FSL (Figure 6.27) and Farm Scale (Figure 6.28) scenarios. Other patterns besides soil order are evident in these outputs, with the landcover information provided by OVERSEER resulting in the non-effluent pivot having a lower estimated nitrogen load of 10-15 kg N/ha/yr compared to the effluent pivot area, which has a nitrogen load of $15-20 \mathrm{~kg} \mathrm{~N} / \mathrm{ha} / \mathrm{yr}$.

For nitrogen accumulated load (Figure 6.29 and Figure 6.30), the location of the pathways modelled are similar between all soil maps tested, the variation between scenarios can instead be seen between the resolution of the $1 \mathrm{~m}$ and $15 \mathrm{~m}$ DEMs used. Given this farm's flat topography, the $15 \mathrm{~m}$ DEM produced unrealistic flow pathways including a series of diagonal nutrient flow pathways. 
Proportional occurence of load values
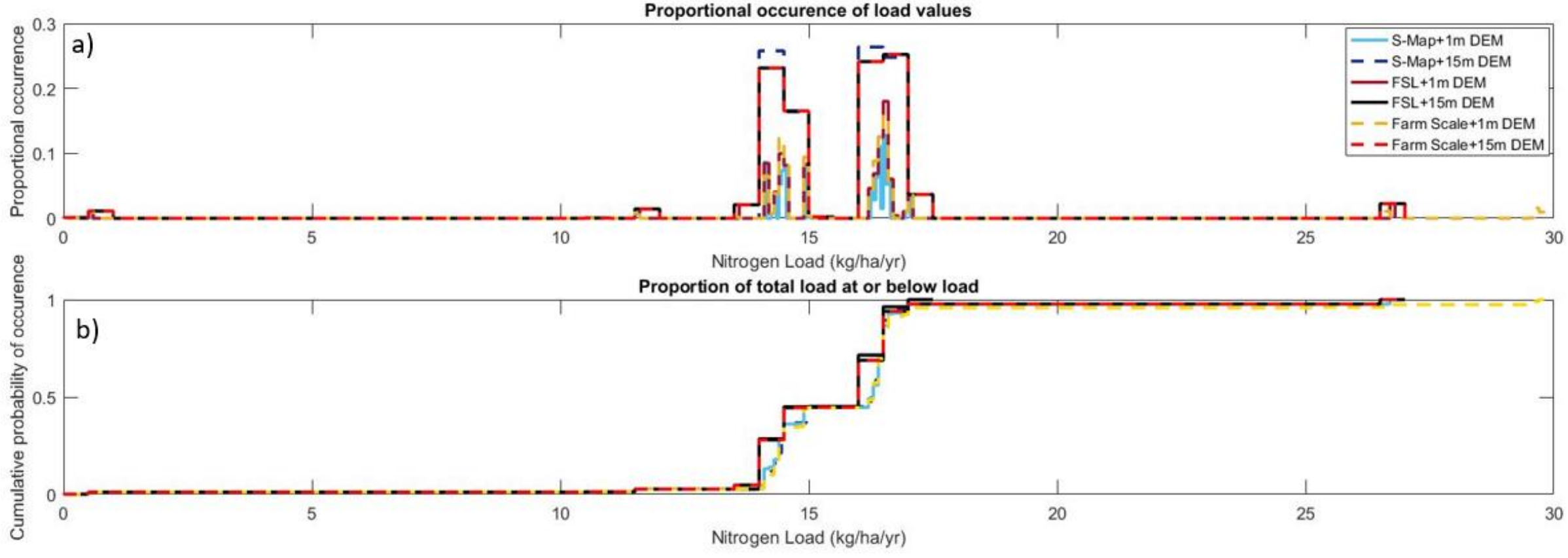

Figure 6.26 (a) proportional occurrence of nitrogen load values in $\mathrm{kg} \mathrm{N} / \mathrm{ha} / \mathrm{yr}$, (b) cumulative probability of occurrence of a nitrogen load at or below a specified load value, (c) proportional occurrence of phosphorus load values in $\mathrm{g} P / \mathrm{ha} / \mathrm{yr}$, (d) cumulative probability of occurrence of a phosphorus load at or below a specified load value. 
Proportional occurence of load values
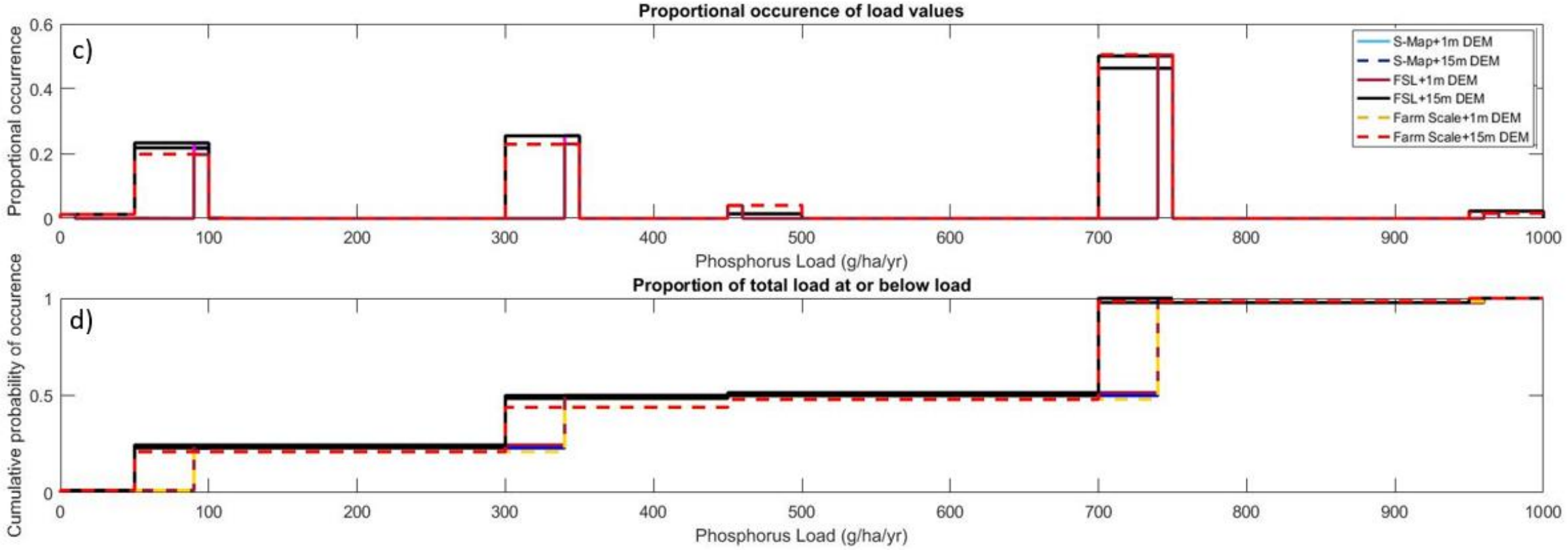

Figure 6.26 Continued. 


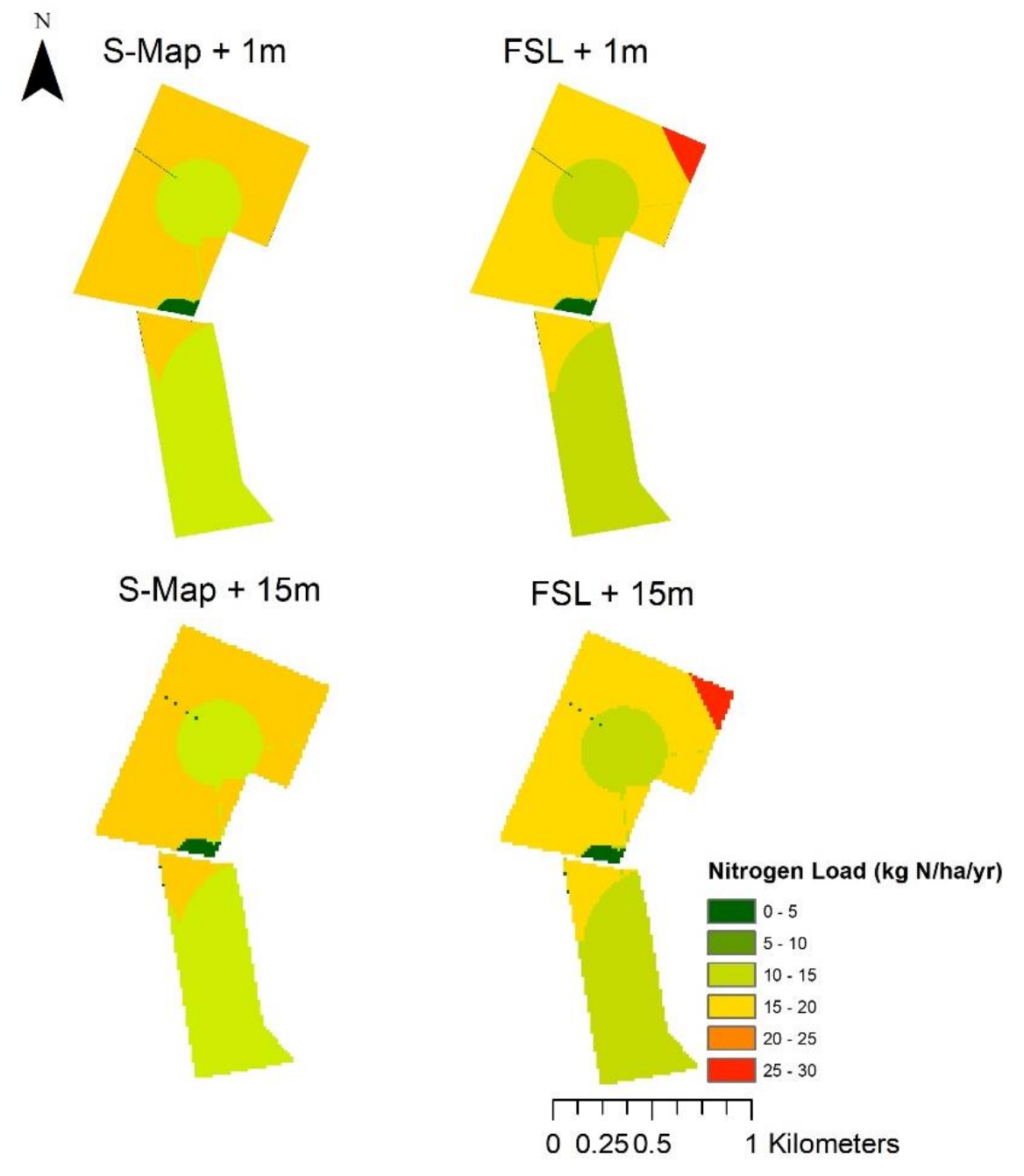

Figure 6.27 Nitrogen load results for the S-Map and FSL scenarios in $\mathrm{kg} \mathrm{N/ha/yr.}$

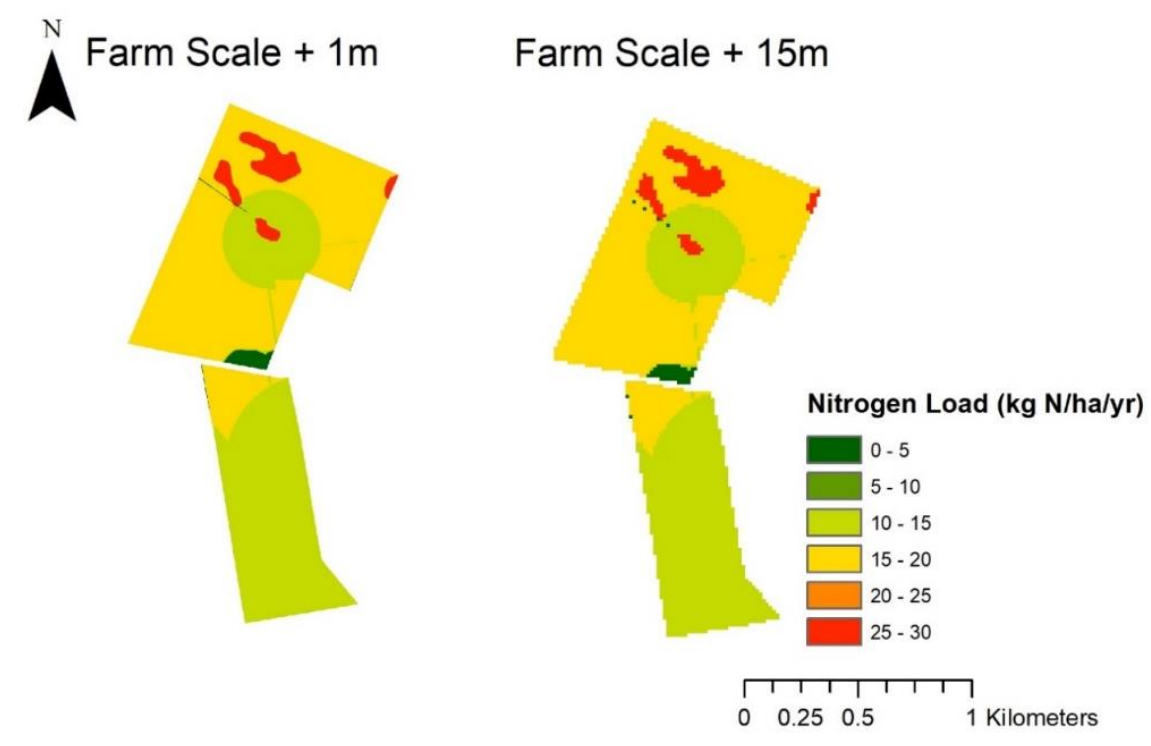

Figure 6.28 Nitrogen load results for the farm scale soil map scenarios in $\mathrm{kg} \mathrm{N} / \mathrm{ha} / \mathrm{yr}$. 

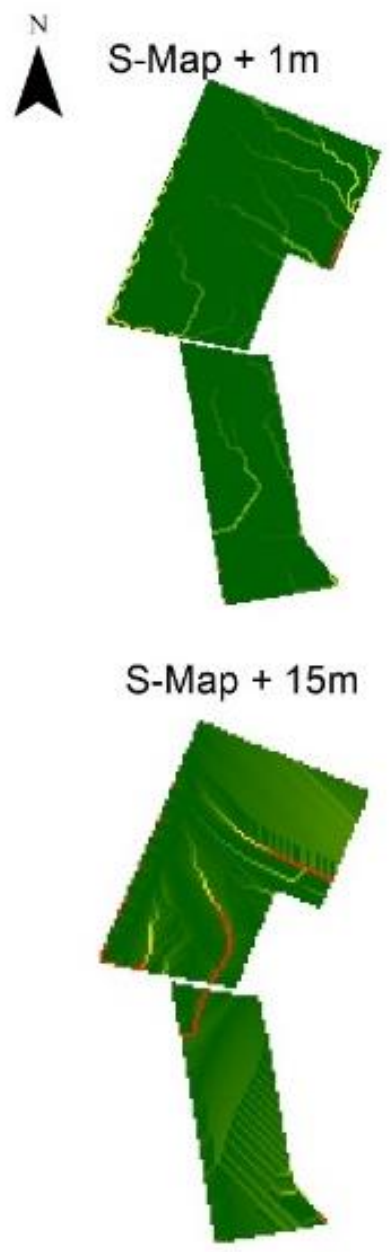
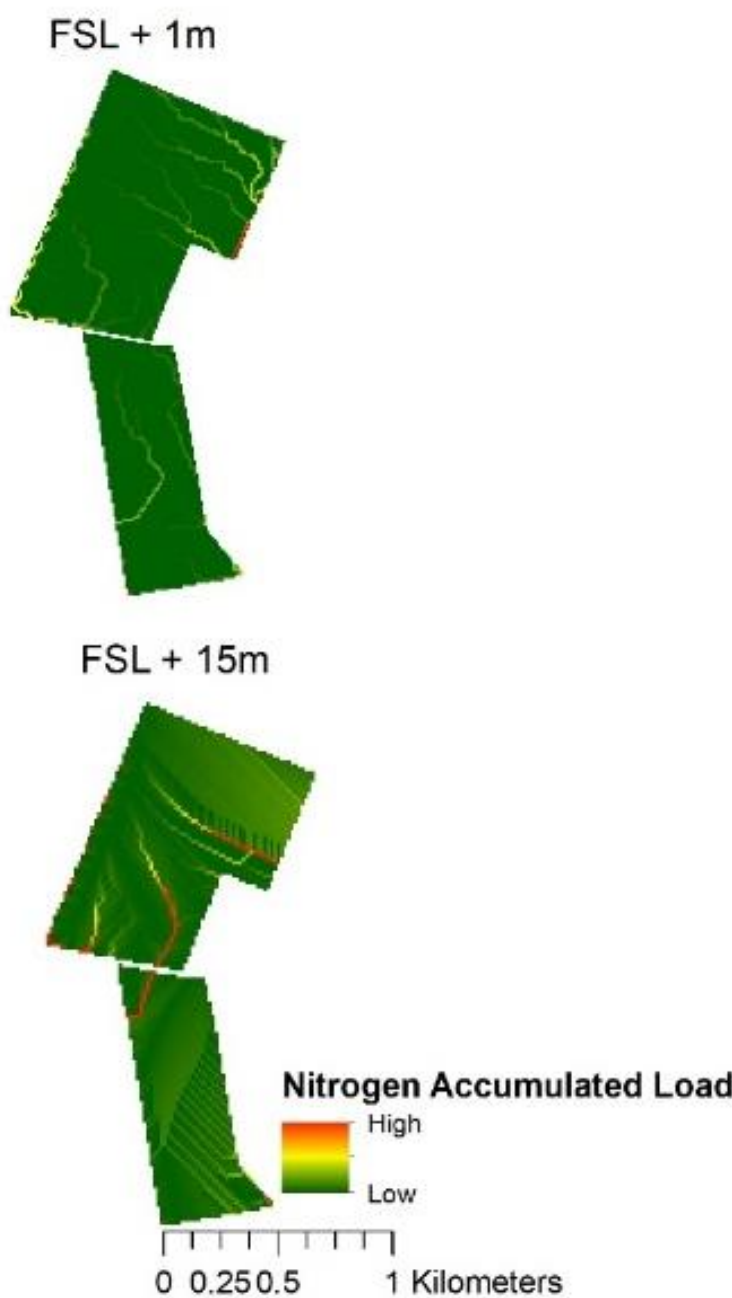

Figure 6.29 Nitrogen accumulated load results for the S-Map and FSL scenarios.
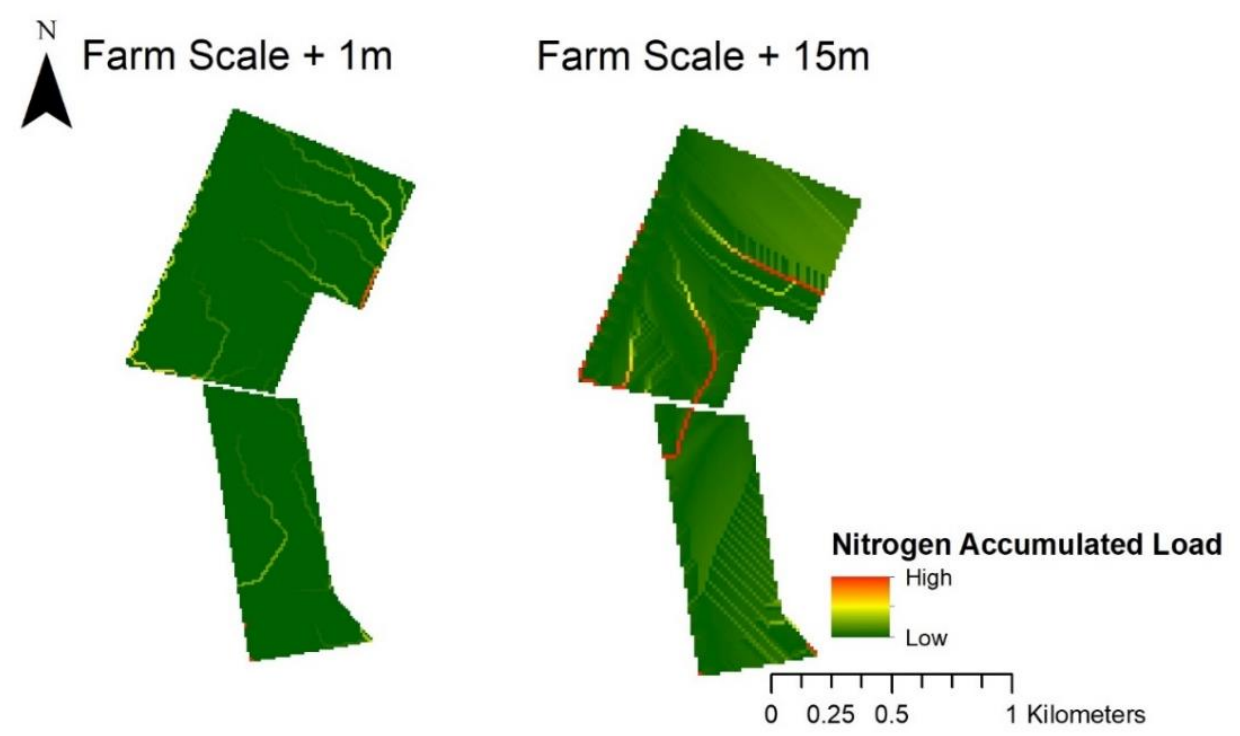

Figure 6.30 Nitrogen accumulated load results for the farm scale soil map scenarios. 


\section{Phosphorus}

Phosphorus load outputs highlight the differences in the soil maps and the landcover data from the OVERSEER $\mathrm{xml}$ file. The areas with the lowest estimates of phosphorus loss on all soil maps are the areas classed as gley soil, with the highest estimates shown on recent and pallic soils (Figure 6.31 and Figure 6.32). The pivot outline is also identified with the non-effluent area having a higher phosphorus load of 600-750 $\mathrm{g} / \mathrm{ha} / \mathrm{yr}$ compared to the effluent pivot block with 30-450 g/ha/yr. This variation between effluent and non-effluent areas is a result of different fertiliser applications on this block. No phosphorus fertiliser is applied on the effluent area, whereas under the pivot that is not receiving effluent $500 \mathrm{~kg} / \mathrm{ka} / \mathrm{yr}$ Superphosphate is applied in October.

The farm tracks and lanes are identified in these figures as these areas are connected to national data, not the landcover information provided for the farm. For the phosphorus accumulated load outputs, like nitrogen, the main difference between the nutrient pathways identified in the model is between the low and high-resolution DEM scenarios (Figure 6.33 and Figure 6.34).

\subsection{SOUTH CANTERBURY}

\subsubsection{Hydtopo Output}

The hydrology of this farm consists of a network of streams and watersheds. The $10 \mathrm{~m}$ and $15 \mathrm{~m}$ DEMs produce similar hydrological results along the flat and steep sections of the property (Figure 6.35). One difference between the outputs is the extra land area included in the catchment in the $15 \mathrm{~m}$ DEM to the west of the property, as well as the $15 \mathrm{~m} \mathrm{DEM}$, estimating a greater number of stream entry and exit points. Based on discussions with others who have visited the site for previous $\mathrm{LUCl}$ development, the location of the estimated streams closely resembles the location of the actual streams (B. Jackson, personal communication, 17 May 2018). 

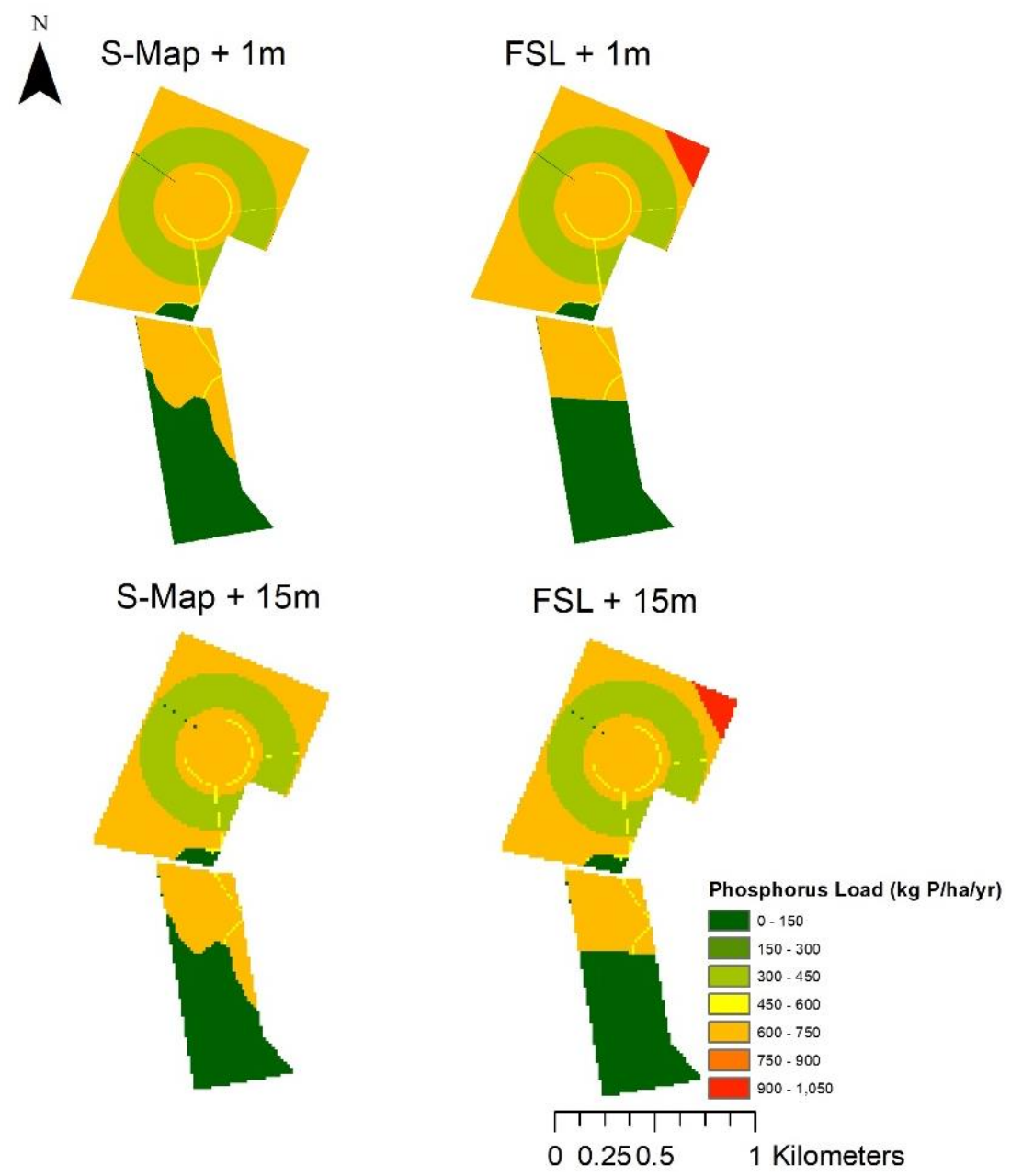

Figure 6.31 Phosphorus load results for the S-Map and FSL scenarios in $\mathrm{kg} P / \mathrm{ha} / \mathrm{yr}$.
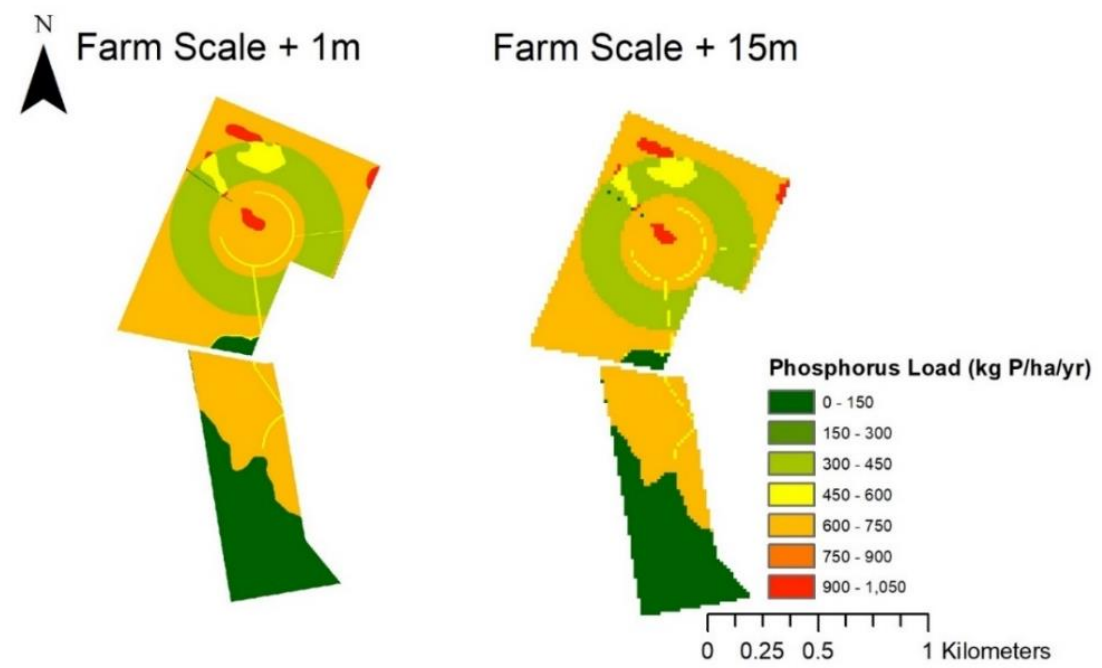

Figure 6.32 Phosphorus load results for the farm scale soil map scenarios in $\mathrm{kg}$ $\mathrm{P} / \mathrm{ha} / \mathrm{yr}$. 

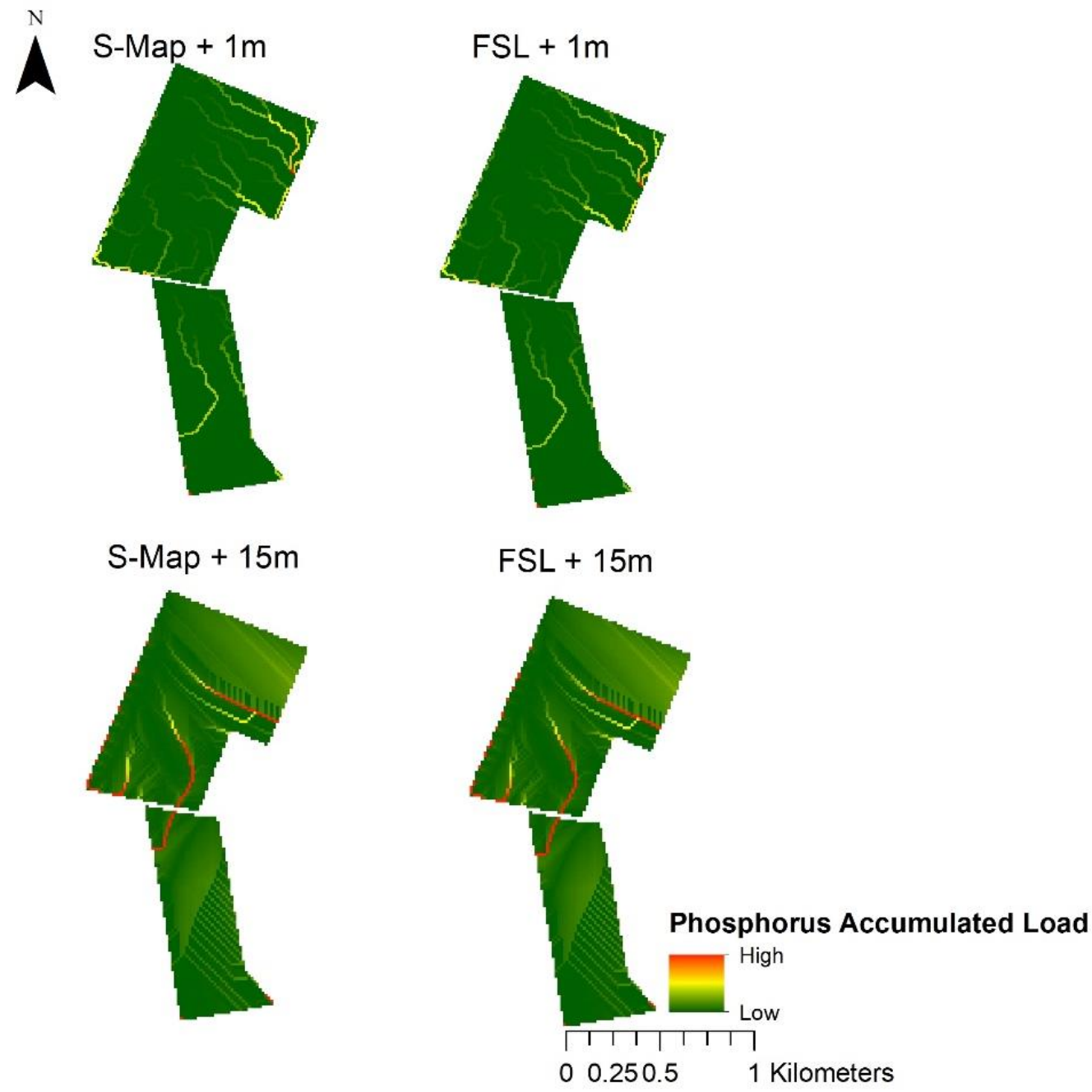

Figure 6.33 Phosphorus accumulated load results for the S-Map and FSL scenarios.
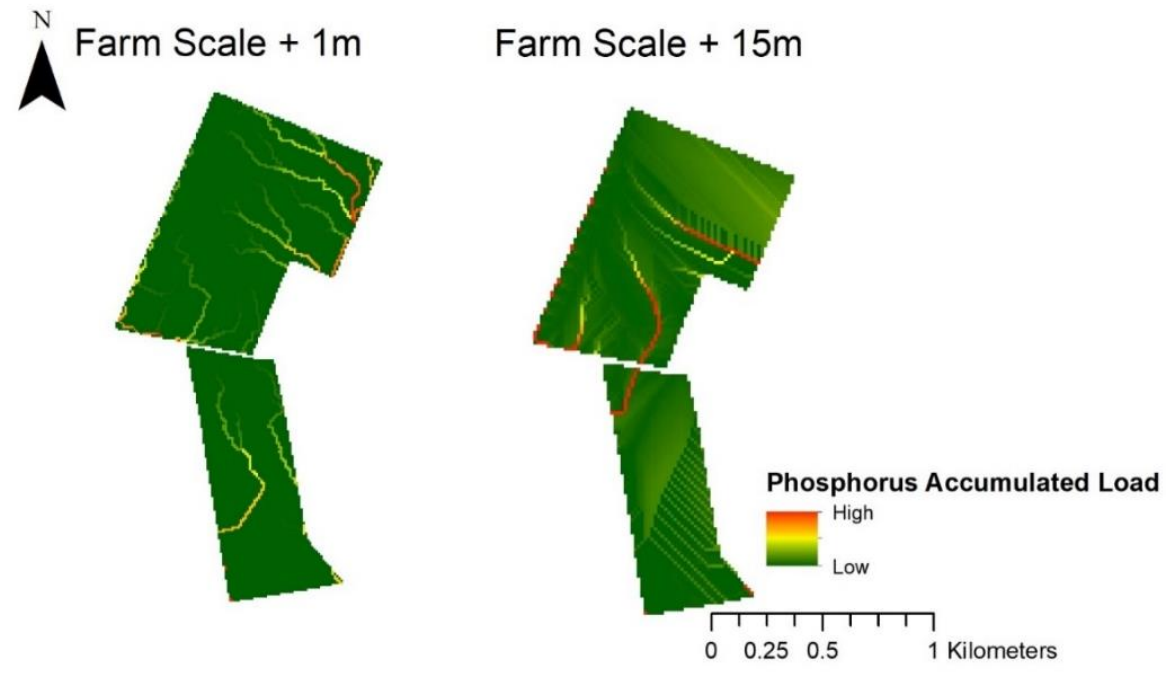

Figure 6.34 Phosphorus accumulated load results for the farm scale soil map scenarios. 

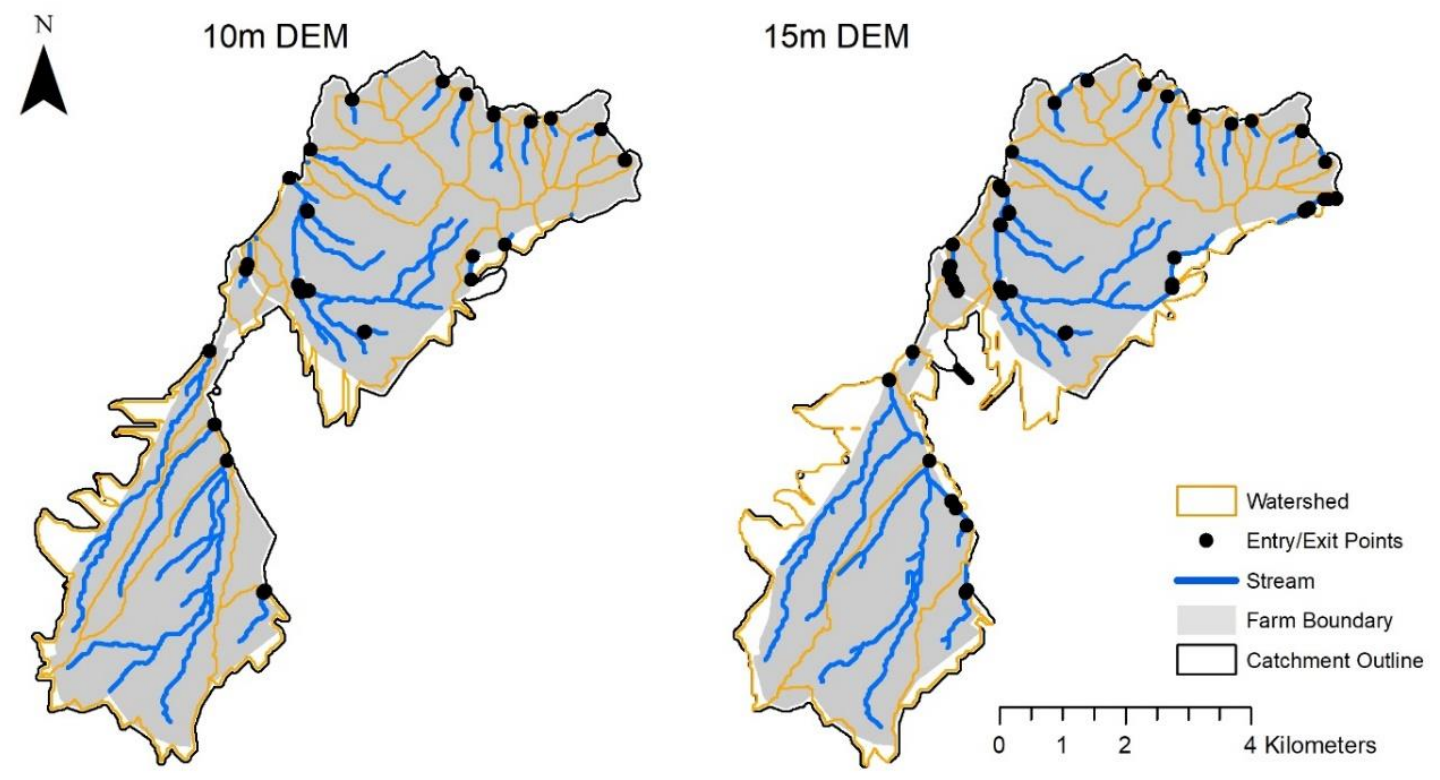

Figure 6.35 Hydrological output of both DEM resolutions tested at this site.

\subsubsection{Nutrient Load Results}

The total nutrient loads for all scenarios are presented in Table 6.6. For nitrogen, all scenarios produce similar total load estimates ranging from 6,178 kg N/yr for S-Map + $10 \mathrm{~m}$ DEM to $6,303 \mathrm{~kg} \mathrm{~N} / \mathrm{yr}$ for FSL + 10m DEM. For phosphorus, the difference between soil maps is more apparent with the $\mathrm{FSL}+10 \mathrm{~m}$ scenario estimating $185 \mathrm{~kg}$ $\mathrm{P} / \mathrm{yr}$ compared to $130 \mathrm{~kg} \mathrm{P} / \mathrm{yr}$ for S-Map scenario with the same DEM resolution. This change in estimated phosphorus load is due to the larger part of the farm classified as pallic soil in the FSL database, which was reclassified as recent soil in the updated SMap data.

Table 6.6 Total nitrogen and phosphorus load results for all scenarios.

\begin{tabular}{|c|c|c|}
\hline LUCI Applications & $\begin{array}{l}\text { Total Nitrogen Load (kg } \\
\mathrm{N} / \mathrm{yr} \text { ) }\end{array}$ & $\begin{array}{l}\text { Total Phosphorus Load (kg } \\
\text { P/yr) }\end{array}$ \\
\hline S-Map + 10m & 6,176 & 130 \\
\hline S-Map + 15m & 6,178 & 129 \\
\hline $\mathrm{FSL}+10 \mathrm{~m}$ & 6,303 & 185 \\
\hline $\mathrm{FSL}+15 \mathrm{~m}$ & 6,261 & 183 \\
\hline
\end{tabular}


The distribution of load results for nitrogen and phosphorus can be seen in Figure 6.36a-d. This shows that the distribution of load results is similar between scenarios, with most of the nitrogen load estimates between $1.5-2.5 \mathrm{~kg} \mathrm{~N} / \mathrm{ha} / \mathrm{yr}$ and most of the phosphorus results estimated between 0-100 g P/ha/yr. Several estimates for nitrogen and phosphorus are much higher than the rest of the nutrient estimates, as shown in Figure $6.36 \mathrm{~b}$ and $6.36 \mathrm{~d}$. These figures show that $98 \%$ of FSL and S-Map scenarios estimates are present at or below $2.5 \mathrm{~kg} \mathrm{~N} / \mathrm{ha} / \mathrm{yr}$ for nitrogen and $100 \mathrm{~g} \mathrm{P} / \mathrm{ha} / \mathrm{yr}$ for phosphorus. The remaining estimates are located around $7 \mathrm{~kg} / \mathrm{ha} / \mathrm{yr}$ for nitrogen and $500 \mathrm{~g} / \mathrm{ha} / \mathrm{yr}$. These outliers are estimated in the two FSL scenarios where semi-arid, irrigated soil is present such areas are prone to slaking, and the input of water through irrigation results in high nutrient loss as this soil type is not as well structured as a brown or recent soil.

\section{Nitrogen}

Nitrogen load and accumulated load outputs are presented in Figure 6.37 and Figure 6.38. Here, the difference between FSL and S-Map scenarios is apparent on the south side of the property through the changing load classification between $4-6 \mathrm{~kg} / \mathrm{ha} / \mathrm{yr}$ on brown soils in S-Map, to $6-8 \mathrm{~kg} / \mathrm{ha} / \mathrm{yr}$ for the recent and semi-arid soil combination in FSL. The parts of the farm that are irrigated by pivot and sprinkler systems are also evident in LUCl's output as high nutrient loss areas due to increased drainage under irrigation systems. The difference in nitrogen loads based on the two DEMs tested are not as apparent as the difference connected to soil type. This is because the boundaries between different nitrogen load estimates appear to be of similar resolution with the $15 \mathrm{~m}$ DEM not producing obvious simplifications in the polygons due to its lower resolution. However, this could also be because both DEMs are of a lower resolution than the LIDAR produced DEMs tested on other sites in this analysis. 
Proportional occurence of load values
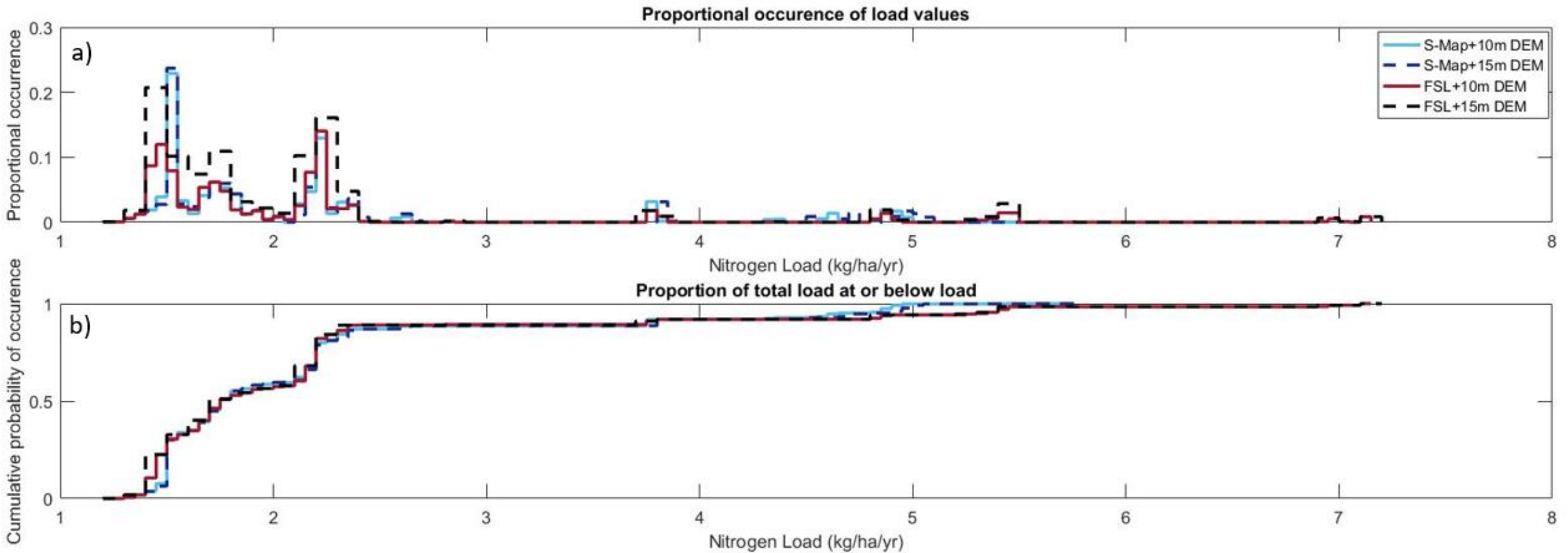

Figure 6.36 (a) proportional occurrence of nitrogen load values in $\mathrm{kg} \mathrm{N} / \mathrm{ha} / \mathrm{yr}$, (b) cumulative probability of occurrence of a nitrogen load at or below a specified load value, (c) proportional occurrence of phosphorus load values in $\mathrm{g} P / \mathrm{ha} / \mathrm{yr}$, (d) cumulative probability of occurrence of a phosphorus load at or below a specified load value. 


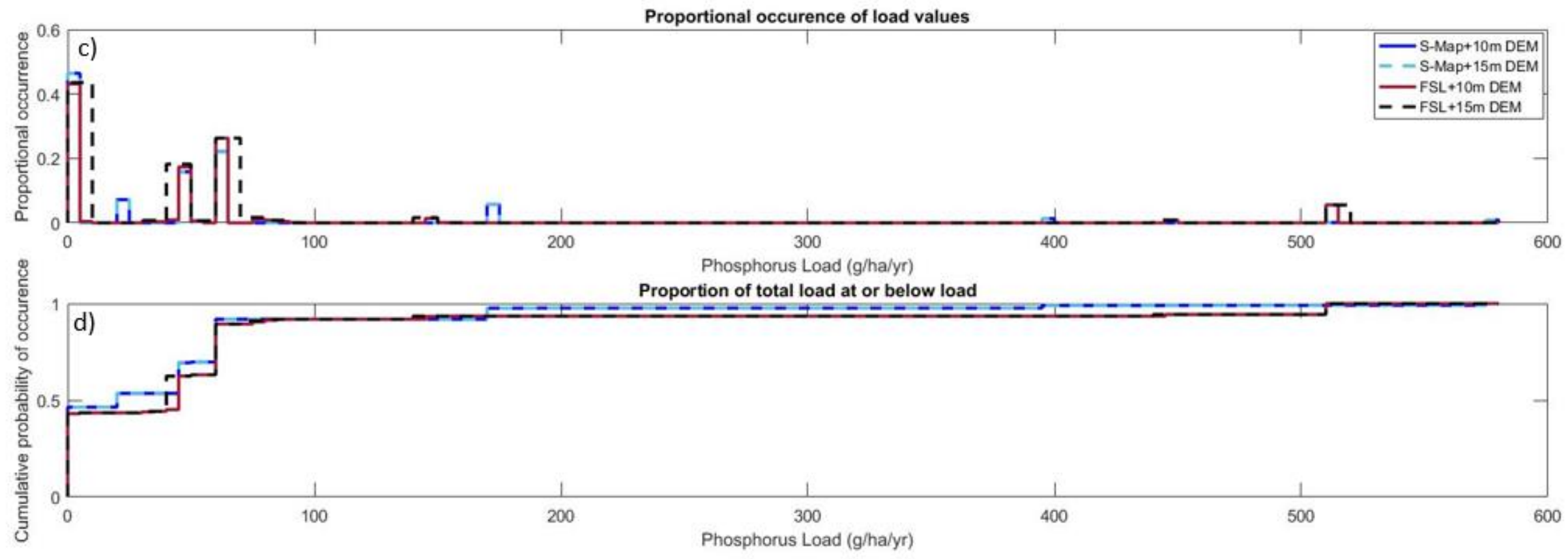

Figure 6.36 Continued. 

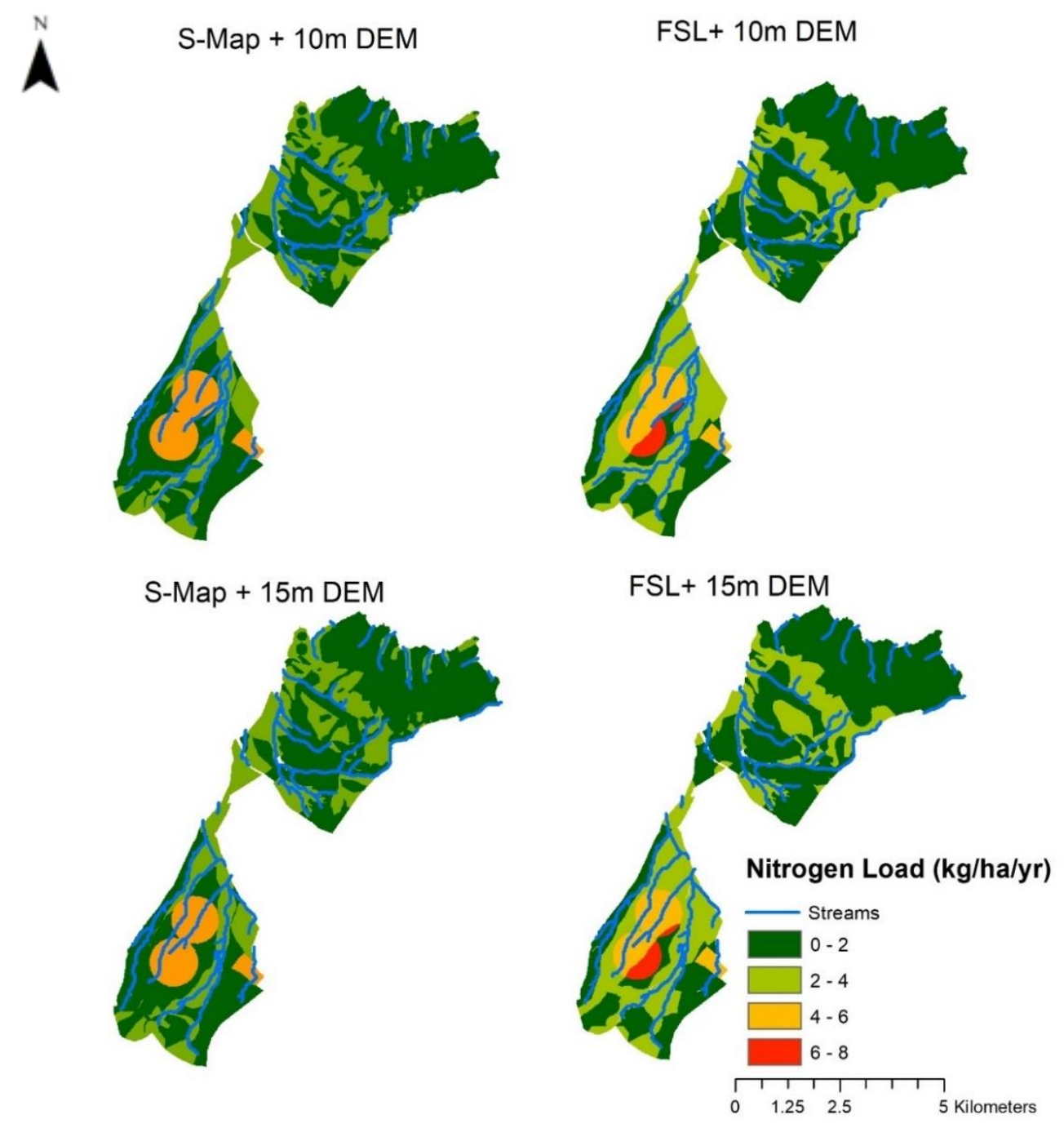

Figure 6.37 Nitrogen load results for all scenarios in $\mathrm{kg} \mathrm{N} / \mathrm{ha} / \mathrm{yr}$.

For nitrogen accumulated load, the complexity of the topography of this farm is shown, with the gullies present on the north side of the farm flowing down into the lake highlighted as pathways for nutrient transport. On the flat, pivot irrigation area in the central south part of the farm, the artefacts associated with low-resolution DEMs modelling flat landscapes are apparent with straight lines of modelled nutrient pathways flowing towards the stream network. In reality, flow accumulation along the pivot area would not result in so many separate pathways of nutrients, especially if irrigation applications were carried out under good management practices. 

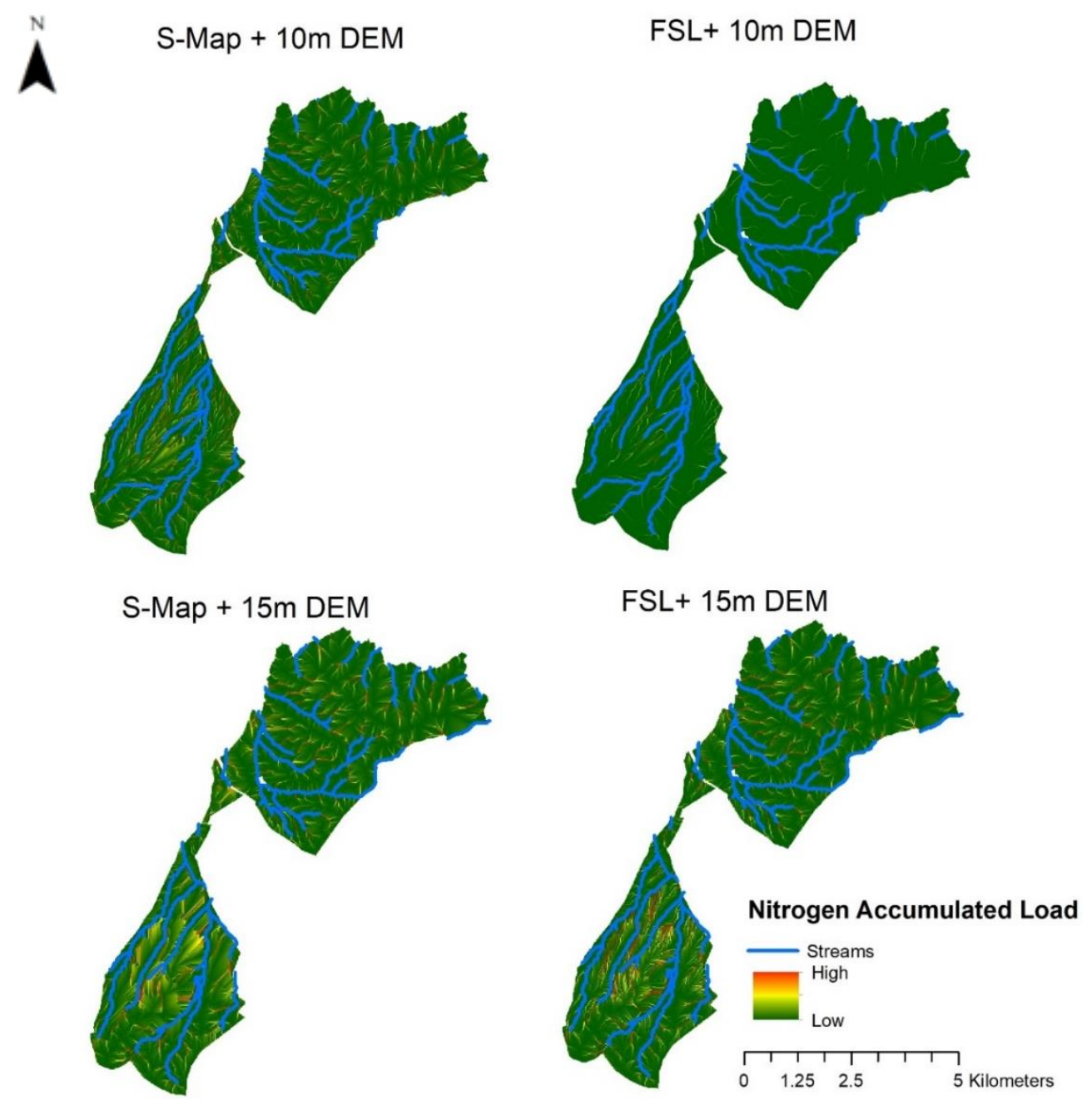

Figure 6.38 Nitrogen accumulated load results for all scenarios.

\section{Phosphorus}

Phosphorus load and accumulated results (Figure 6.39 and Figure 6.40) also show the pattern of high nutrient loads present on the irrigated area with 450-600 g/ha/yr estimated on the irrigated area in the FSL scenarios; $150-300 \mathrm{~g} / \mathrm{ha} / \mathrm{yr}$ estimated on the brown soil in S-Map, and 300-450 g/ha/yr estimated on the irrigated area of pallic soil. The north side of the property with steep hill topography is shown to be a low source of phosphorus on the farm. Given the topography of this area, it was expected that the slopes would be modelled as a source of phosphorus loss from the farm. However, due to the low stocking rate and reduced fertiliser application on the steep hill country, the loss of phosphorus from this area could be masked by the high phosphorus loss modelled due to the combinations of brown and semi-arid soil types and irrigation 
practices on the farm. Looking at the modelled phosphorus accumulated load, some pathways on the northern part of the property are highlighted, but as with nitrogen, the main areas of nutrient movement are located on the flat, southern side of the property.
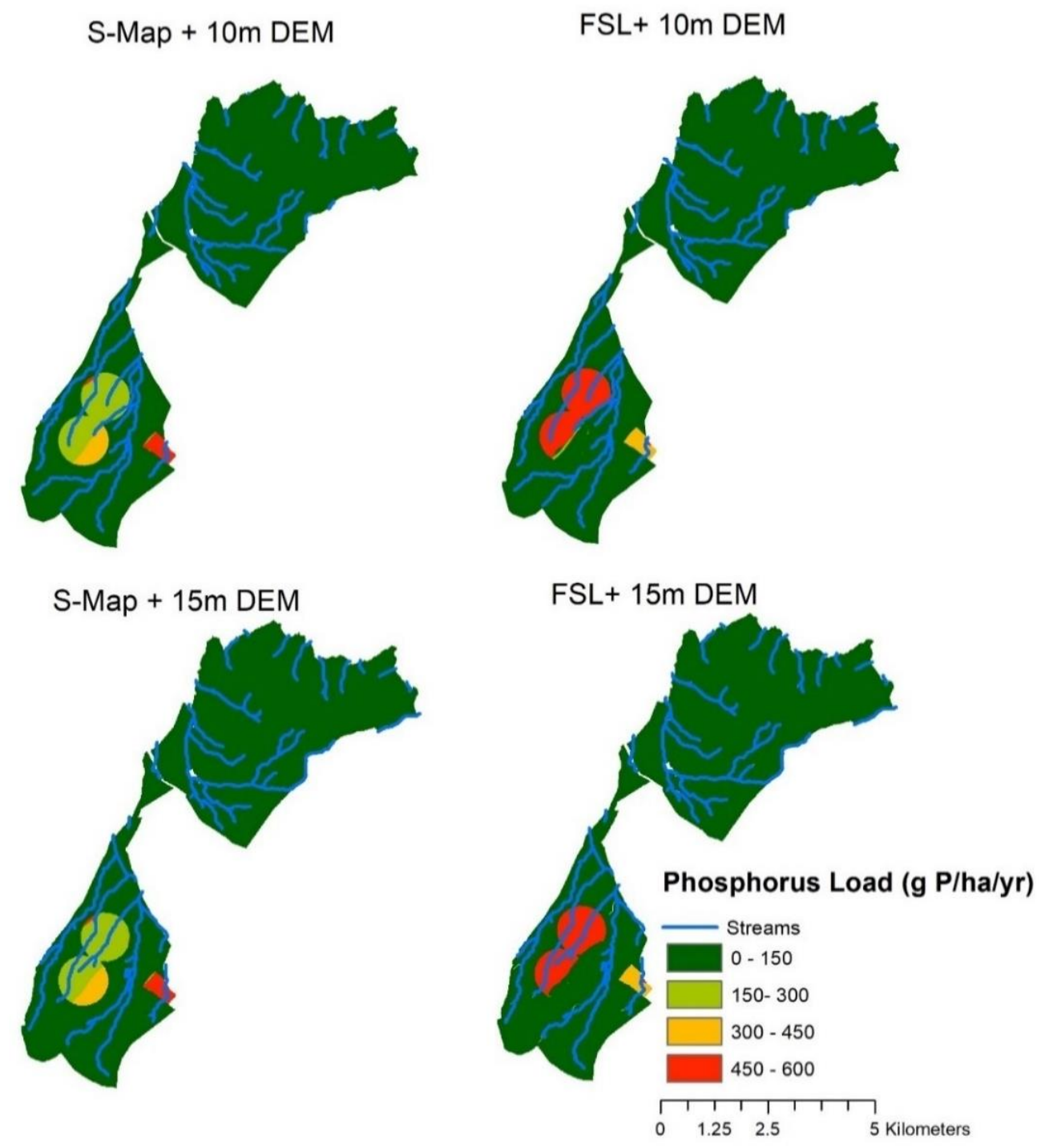

Figure 6.39 Phosphorus load results for all scenarios in $\mathrm{g} P / \mathrm{ha} / \mathrm{yr}$. 

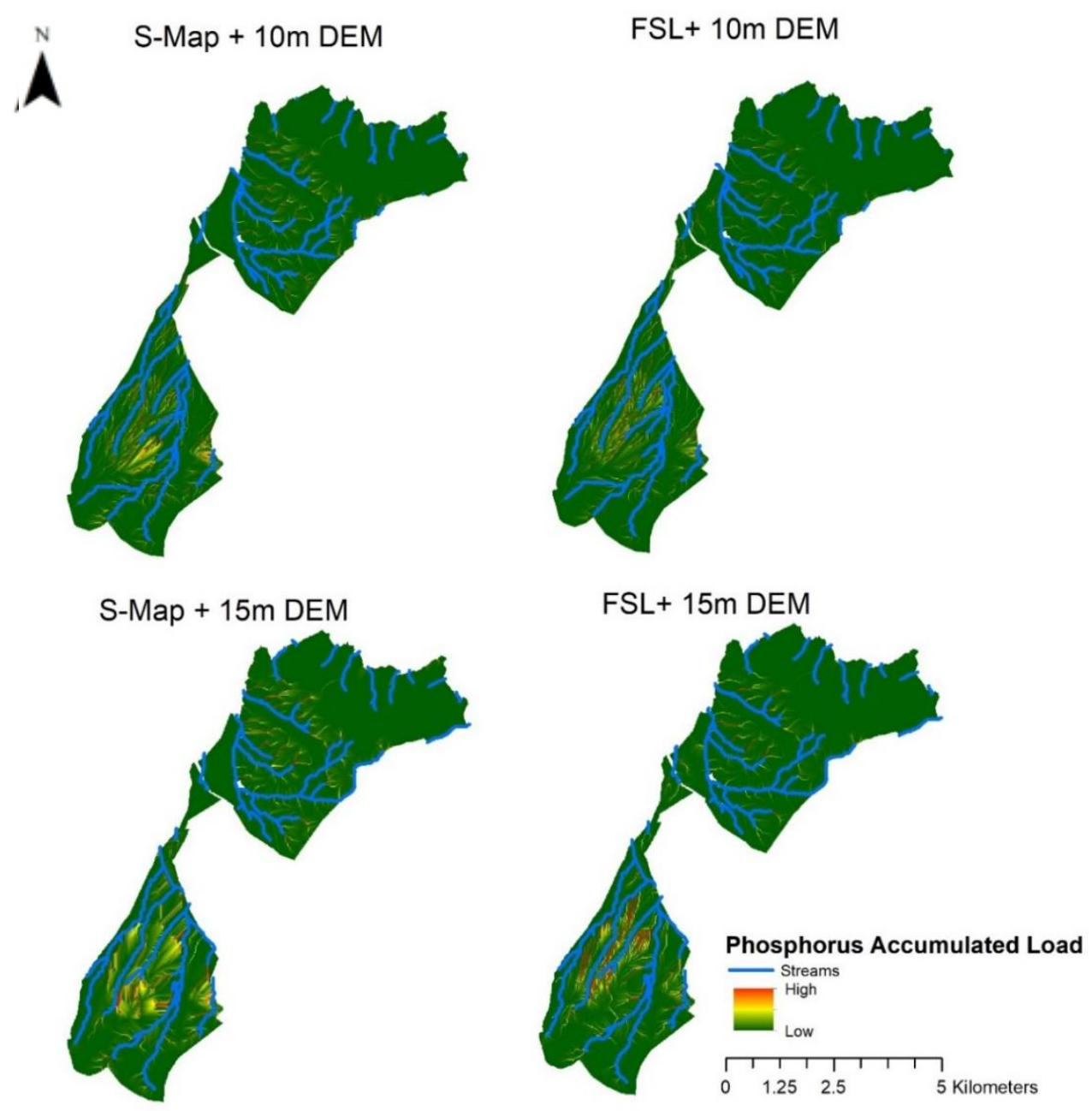

Figure 6.40 Phosphorus accumulated load results for all scenarios.

\subsubsection{Sibling Sensitivity Analysis}

The results presented below were modelled after LUCl's algorithms were updated to include regional specific patterns of rainfall and evaporation instead of a national average rainfall distribution. This makes the drainage calculations in $\mathrm{LUCl}$ more representative of different regions and is part of ongoing development to more accurately model nitrogen and phosphorus movements within the landscape, a core part of this thesis. This update to $\mathrm{LUCl}$ did not alter input requirements for each scenario, but, it should be noted that the scenarios presented below produce slightly different estimates to those run previously at the same site. This can be seen in the SMap $+15 \mathrm{~m}$ DEM total nitrogen load result of 6,178 kg N/yr (Table 6.6) and when this same scenario was rerun as the dominant sibling $+15 \mathrm{~m} \mathrm{DEM}$, the total load result was $6,134 \mathrm{~kg} \mathrm{~N} / \mathrm{ha}$. Total phosphorus load results have not changed as a result of the 
update, with both S-Map $+15 \mathrm{~m}$ DEM and dominant sibling $+15 \mathrm{~m}$ DEM estimating a total loss of $129 \mathrm{~kg} \mathrm{P} / \mathrm{yr}$. All sibling scenarios were tested using the $15 \mathrm{~m}$ DEM and farm specific information from OVERSEER.

For the purpose of this thesis, the change to the $\mathrm{LUCl}$ model will not affect how the results are discussed, as the comparison of the different ways sibling data is incorporated into LUCl is independent of the analysis of LUCl's sensitivity to soil and elevation datasets.

The stream concentration results are compared on this farm as, although there is not in stream measured data available, changing the way S-Map siblings are used in each soil polygon affects the modelled drainage characteristics. This is because PAW is parameterised by the texture and drainage properties of the siblings, and those properties change depending on which sibling is selected to represent the soil polygon. Unlike the stream concentration results for the Tuapaka and Otago case studies, these results are presented to 3 significant figures as the level of variation is an order of magnitude less than the other sites.

\section{$\underline{\text { Nutrient Load Results }}$}

It can be seen in Table 6.7 that there is no difference between the sibling scenarios and total nitrogen load results with all scenarios estimating a loss of 6,134 kg N/yr and only a slight change to phosphorus load; all scenarios except the Random3 model run estimate $129 \mathrm{~kg} \mathrm{P} / \mathrm{yr}$. The load results have not varied as the nitrogen and phosphorus tools are still parameterised by soil order, and the difference in sibling properties may not have been enough to trigger a change in soil order classification between soil polygons. The similarity between scenario runs is also shown in Figure 6.41 where the distribution of nitrogen and phosphorus load results are identical. Because of this, the map outputs generated for these scenarios are not shown as no comparison can be drawn between them. 
Table 6.7 Total nitrogen and phosphorus load results for all sibling scenarios.

\begin{tabular}{|l|r|r|}
\hline Scenario & Nitrogen (kg N/yr) & \multicolumn{2}{l|}{ Phosphorus (kg P/yr) } \\
\hline Dominant & 6,134 & 129 \\
\hline Weighted & 6,134 & 129 \\
\hline Random1 & 6,134 & 129 \\
\hline Random2 & 6,134 & 129 \\
\hline Random3 & 6,134 & 128 \\
\hline
\end{tabular}

\subsubsection{Predicted Stream Concentrations}

LUCls' predictions of stream concentrations for this farm have been weighted according to the flow of each stream, providing a weighted average nutrient loss to water for the whole farm. As shown in Table 6.8, the variation in nitrogen and phosphorus estimates is small; however, it does highlight the changed hydrology between the scenarios and precisely how sibling data is used impact results. The lowest nitrogen and phosphorus estimates were calculated in the dominant sibling scenario, with $1.23 \mathrm{mg} / \mathrm{LL}$ nitrogen and $0.0216 \mathrm{mg} / \mathrm{L}$ phosphorus.

\subsubsection{Testing Sibling Variation in OVERSEER}

OVERSEER allows the user to choose the dominant sibling for each user defined block on the farm, which is the same as LUCls original method of extracting the dominant sibling soil information before the multiple sibling options were coded as this thesis progressed. In Table 6.9 below, the difference in OVERSEER results is shown. Management blocks on the farm were chosen to highlight the difference in model results based on the soil type selected, and the impact on modelled whole farm nutrient loss if three of the largest blocks on the farm, representing $73 \%$ of total farm area are altered. In each of these three blocks, the dominant sibling only covered between $50 \%-65 \%$ of the soil polygon, suggesting that including a multiple sibling option on OVERSEER as well as LUCI could result in more accurate nitrogen and phosphorus modelling on the landscape. 

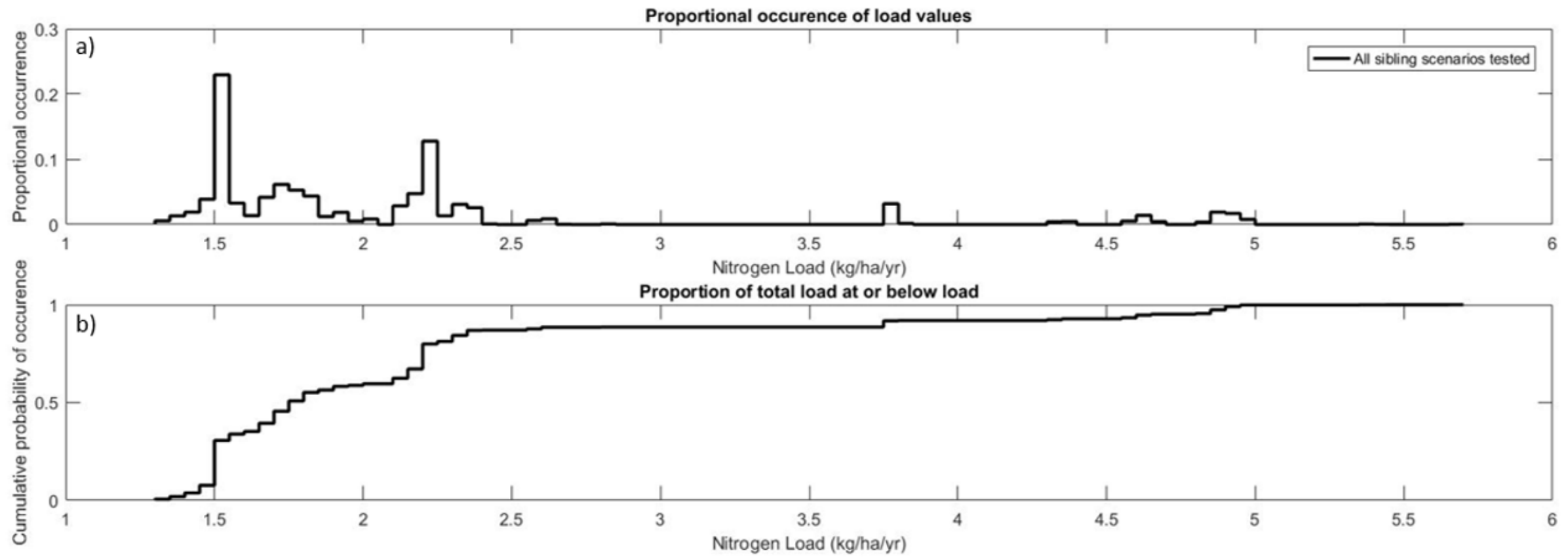

Figure 6.41 (a) proportional occurrence of nitrogen load values in $\mathrm{kg} \mathrm{N} / \mathrm{ha} / \mathrm{yr}$, (b) cumulative probability of occurrence of a nitrogen load at or below a specified load value, (c) proportional occurrence of phosphorus load values in $\mathrm{g} \mathrm{P} / \mathrm{ha} / \mathrm{yr}$, (d) cumulative probability of occurrence of a phosphorus load at or below a specified load value. 

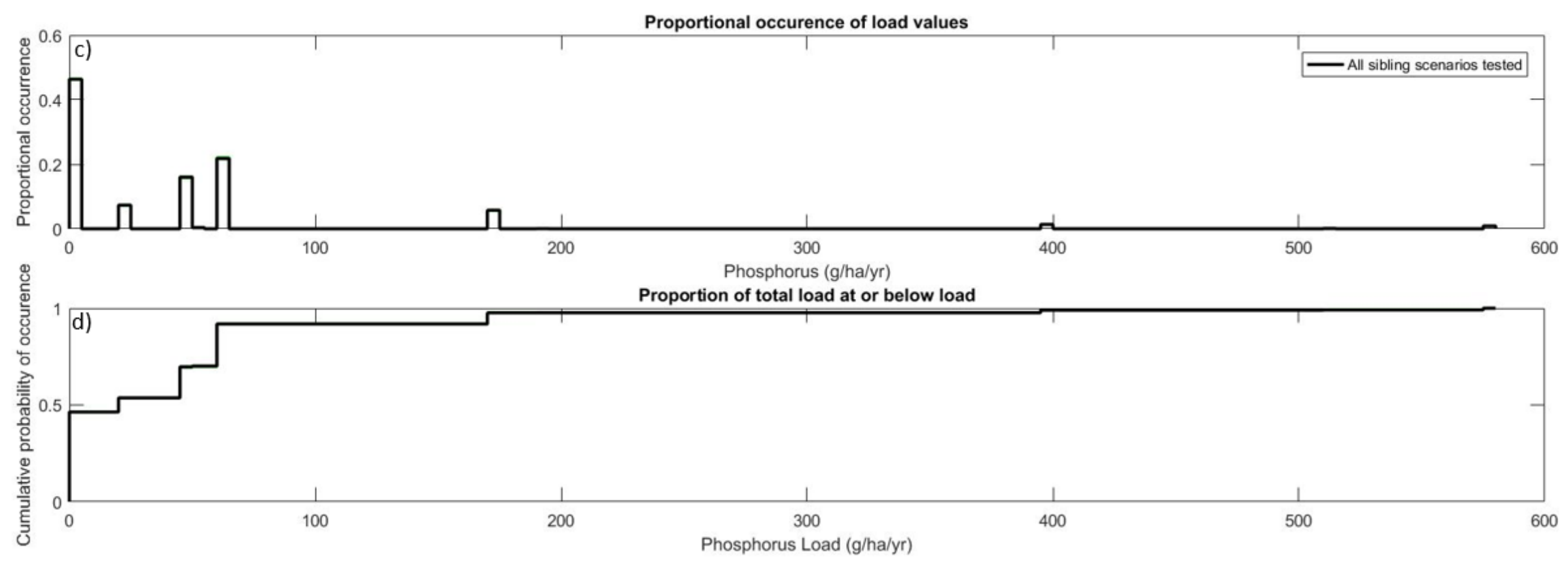

Figure 6.41 Continued. 
Table 6.8 Predicted total nitrogen and phosphorus stream concentrations for all sibling scenarios at this site.

\begin{tabular}{|l|r|r|}
\hline Scenario & Total Nitrogen (mg/L) & \multicolumn{2}{l|}{ Total Phosphorus (mg/L) } \\
\hline Dominant & 1.23 & 0.0216 \\
\hline Weighted & 1.26 & 0.0221 \\
\hline Random1 & 1.24 & 0.0218 \\
\hline Random2 & 1.24 & 0.0217 \\
\hline Random3 & 1.28 & 0.0222 \\
\hline
\end{tabular}

Table 6.9 OVERSEER estimated total nitrogen and total phosphorus load using the dominant and (second sibling) classified in S-Map for three of the South Canterbury pastoral blocks.

\begin{tabular}{|l|r|r|}
\hline Scenario & \multicolumn{1}{|l|}{$\begin{array}{l}\text { Total Nitrogen } \\
\text { Load (kg N/yr) }\end{array}$} & \multicolumn{2}{l|}{$\begin{array}{l}\text { Lotal Phosphorus } \\
\text { Load } \mathbf{k g} / \mathbf{y r})\end{array}$} \\
\hline Pasture1- Omrk_8a.1 to Glenr_5b.1 & $3,053(1,319)$ & $80(17)$ \\
\hline Pasture2- Omrk_8a.1 to Benm_2a.4 & $3,243(1,225)$ & $13(8)$ \\
\hline Pasture3-Otem_2a.1 to Bogr_1a.1 & $2,412(4,686)$ & $478(382)$ \\
\hline Whole farm & $24,913(23,408)$ & \\
\hline
\end{tabular}

\subsection{OTAGO}

\subsubsection{Hydtopo Output}

In this case study, both the $8 \mathrm{~m}$ and $15 \mathrm{~m}$ DEMs produced similar hydrological outputs. There are slight variations in the model's estimation of the catchment boundary, with the $8 \mathrm{~m}$ DEM modelling a larger catchment area on the south side of the farm. The two stream networks generated are located in similar areas with the $15 \mathrm{~m}$ DEM estimating a greater number of watersheds over this farm (Figure 6.42). 


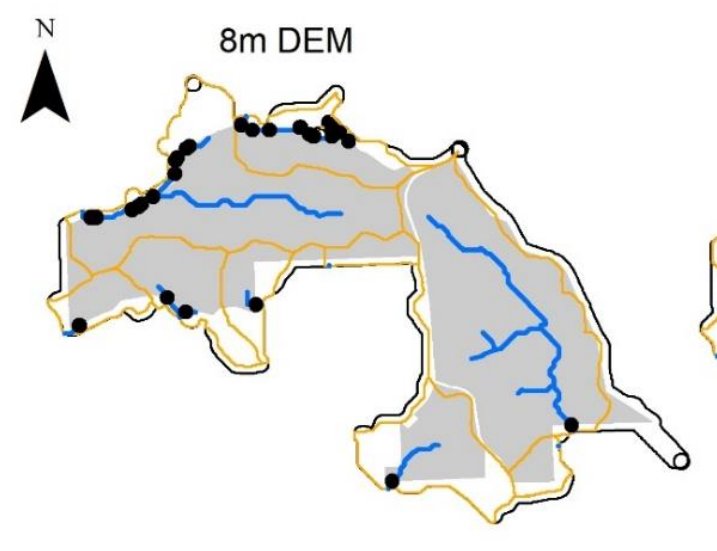

$15 \mathrm{~m}$ DEM

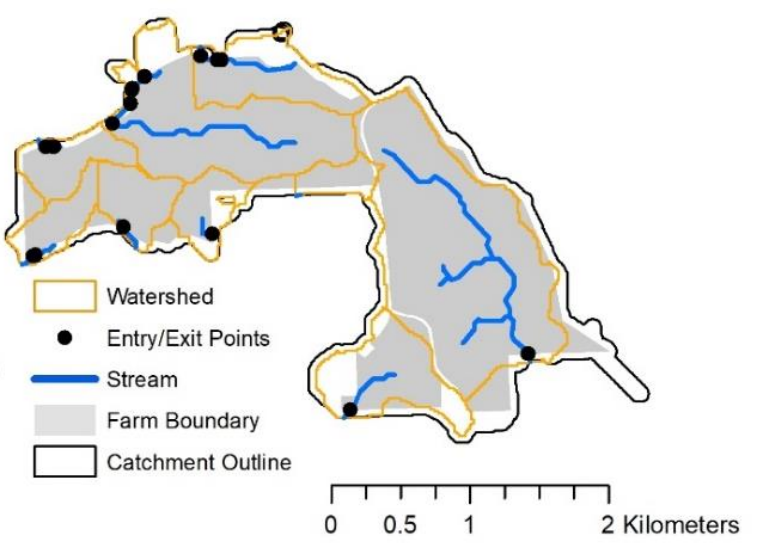

Figure 6.42 Hydrological output of both DEM resolutions tested at this site.

\subsubsection{Nutrient Load Results}

The results of the four scenarios run on this farm are presented below in Table.6.10. The highest total nitrogen load of 4,583 kg N/yr was estimated by the S-Map $+8 \mathrm{~m}$ DEM scenario, with the S-Map $+15 \mathrm{~m}$ scenario estimating 4,545 $\mathrm{kg} \mathrm{N} / \mathrm{yr}$. The two FSL scenarios estimated less total nitrogen, because that dataset classes most of the farm as pallic soil (poor drainage) compared to S-Maps classification of the area as brown soils (well drained), thereby changing the soil water characteristics of the site. The opposite pattern is seen in the total phosphorus load estimates, with the FSL $+8 \mathrm{~m}$ scenario estimating the highest load of $261 \mathrm{~kg} \mathrm{P} / \mathrm{yr}$. Again, this is due to the FSL classifying the majority of the farm as pallic soil. The results are clumped by the soil dataset used as both the DEMs, as mentioned previously, produced similar Hydtopo outputs and therefore do not have a dramatic effect on estimated nitrogen and phosphorus loads.

Table 6.10 Total nitrogen and phosphorus load results for all scenarios

\begin{tabular}{|l|r|r|}
\hline LUCl Applications & Nitrogen (kg N/yr) & Phosphorus (kg P/yr) \\
\hline S-Map $+8 m$ & 4,583 & 210 \\
\hline S-Map $+15 m$ & 4,545 & 210 \\
\hline FSL $+8 m$ & 3,890 & 261 \\
\hline FSL $+15 m$ & 3,860 & 259 \\
\hline
\end{tabular}


The distribution of all nitrogen and phosphorus scenarios tested is shown in Figure 6.43. Here the similarity in results based on the soil dataset is evident. All four scenarios have a high proportion of their results estimated between 9-11 kg N/ha/yr and between 530-540 g P/ha/yr as shown in Figure 6.43a and c. Both S-Map scenarios estimate high nitrogen loads between $15-16 \mathrm{~kg} \mathrm{~N} / \mathrm{ha} / \mathrm{yr}$. The proportional occurrence, Figure $6.43 \mathrm{~b}$ and $d$, indicate that around $98 \%$ of all FSL scenario results are estimated at $10 \mathrm{~kg} / \mathrm{ha} / \mathrm{yr}$ with only $50 \%$ of the S-Map scenarios results at or below $10 \mathrm{~kg} / \mathrm{ha} / \mathrm{yr}$. For phosphorus, both S-Map and FSL scenarios follow the same pattern in cumulative probability of occurrence, as all four scenarios have $98 \%$ of their results at or below $530 \mathrm{~g} / \mathrm{ha} / \mathrm{yr}$.

\section{Nitrogen}

Nitrogen load and nitrogen accumulated load are shown in Figure 6.44 and Figure 6.45 . Here the difference between S-Map and FSL results is evident, as the strip of brown soils on the eastern side of the property is classified as an area of higher nitrogen load (12-16 kg N/ha/yr) than the same area under the FSL classification $(8-12 \mathrm{~kg} / \mathrm{ha} / \mathrm{yr})$. The area with the highest nitrogen load classification is shown in both S-Map scenarios as $15-50 \mathrm{~kg} \mathrm{~N} / \mathrm{ha} / \mathrm{yr}$. This area in the S-Map scenarios is classified with the highest load as it is an effluent block (Figure 5.15). Since this effluent block is classified as having brown soils in S-Map and thus, a higher potential to leach nitrogen, when classified as a pallic soils in the FSL, this effluent block does not have a high risk of nitrogen leaching and therefore is not classified as having a high load in the FSL scenarios. The nitrogen accumulated load outputs for these scenarios show that the areas where load pathways are present in the landscape do not vary greatly between model runs.

Figure 6.46 depicts the same data as the accumulated nitrogen presented above, but uses the histogram equalise method of classifying data, instead of the standard deviation. As for the results shown in the North Canterbury case study, the nutrient pathways estimated with the histogram equalise setting classes more significant areas of the landscape as having high accumulated loads, likely altering where a farmer might choose to place his mitigation strategies. 

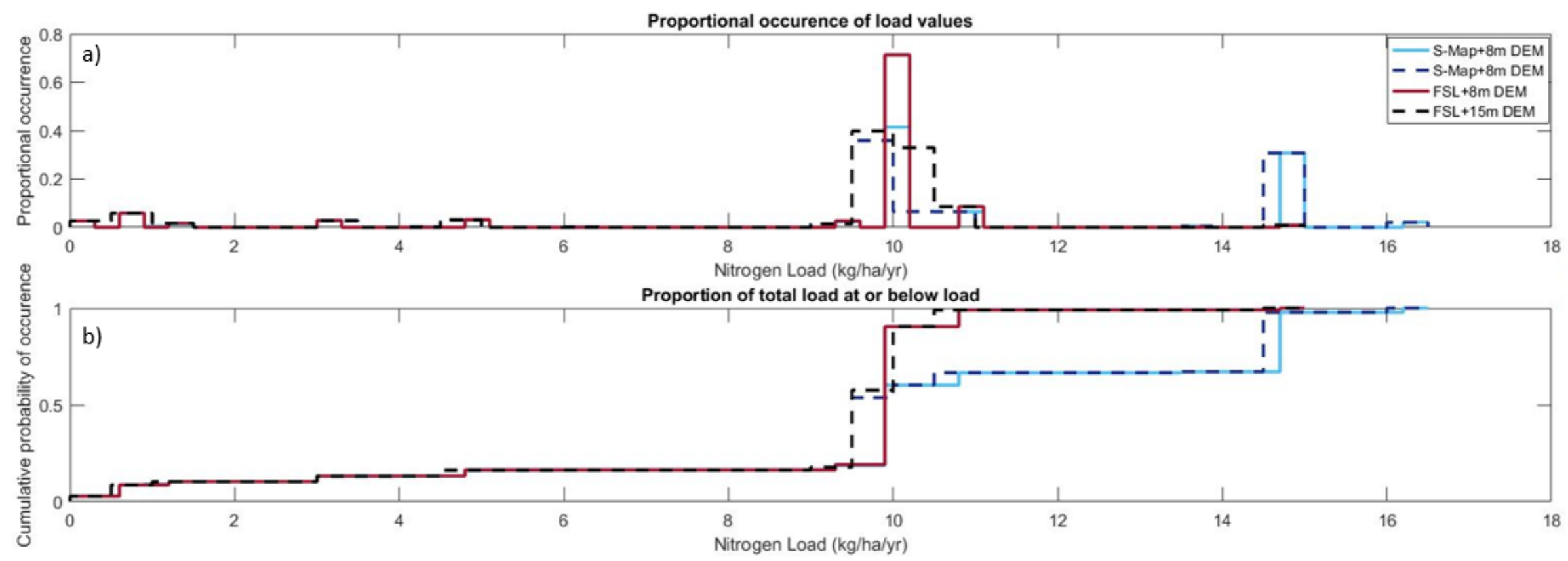

Figure 6.43 (a) proportional occurrence of nitrogen load values in $\mathrm{kg} \mathrm{N} / \mathrm{ha} / \mathrm{yr}$, (b) cumulative probability of occurrence of a nitrogen load at or below a specified load value, (c) proportional occurrence of phosphorus load values in $\mathrm{g} P / \mathrm{ha} / \mathrm{yr}$, (d) cumulative probability of occurrence of a phosphorus load at or below a specified load value. 
Proportional occurence of load values
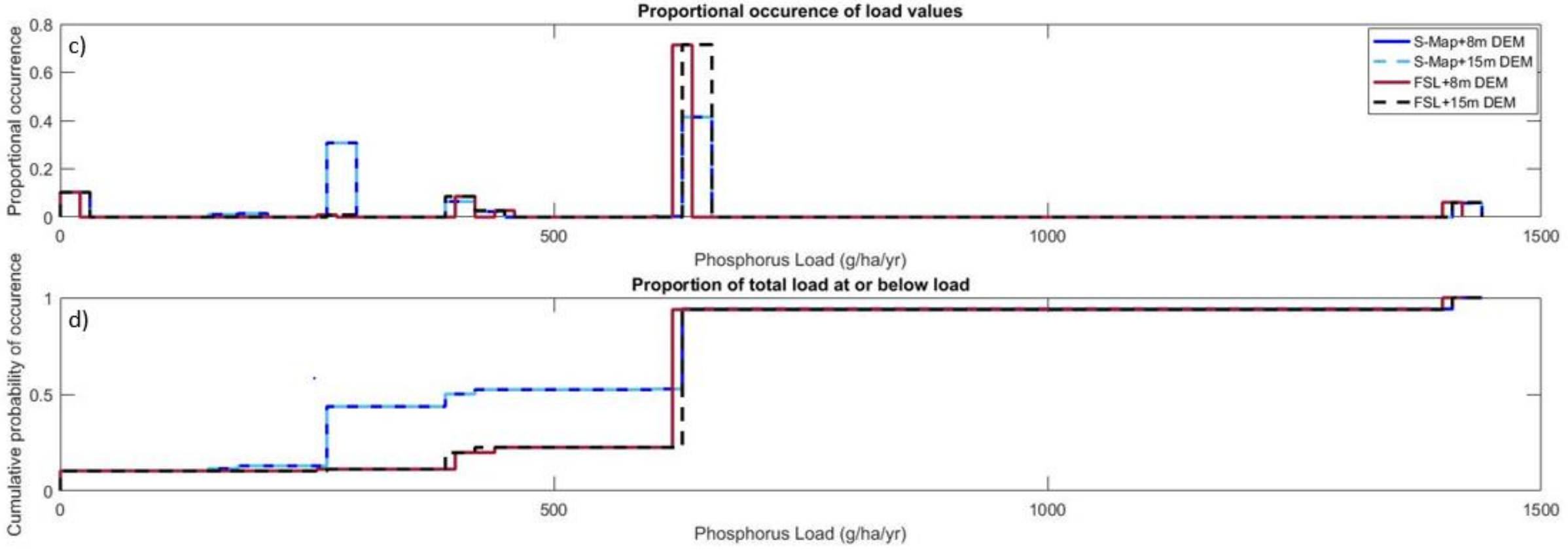

Figure 6.43 Continued. 
$\Lambda^{N}$ S-Map $+8 m$

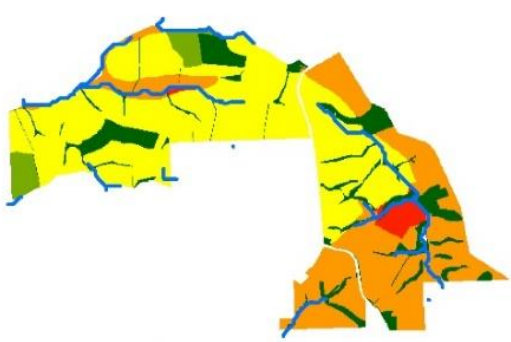

S-Map $+15 m$

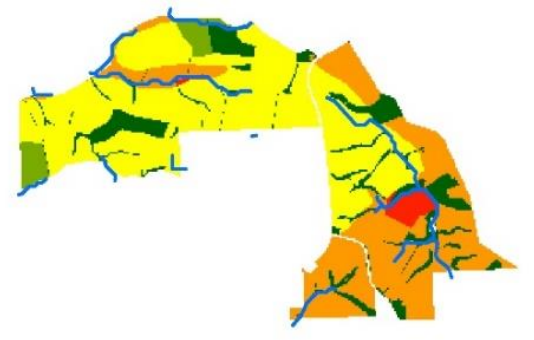

$F S L+8 m$

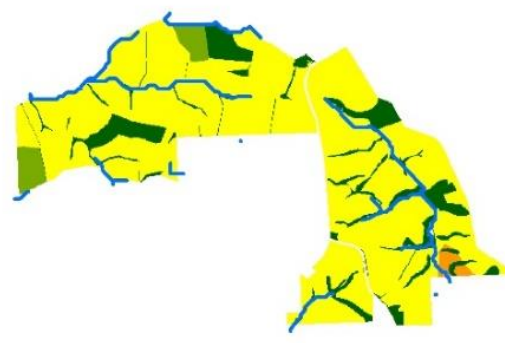

$\mathrm{FSL}+15 \mathrm{~m}$

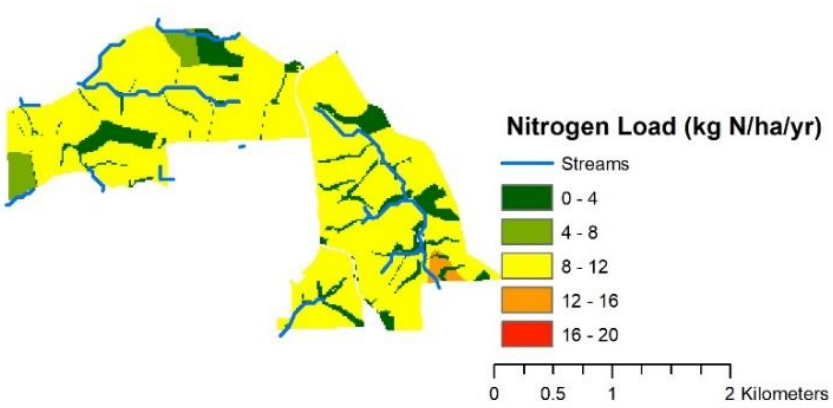

Figure 6.44 Nitrogen load results for all scenarios in kg N/ha/yr.

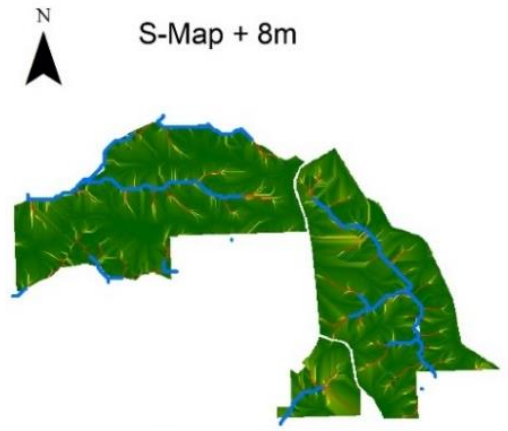

S-Map $+15 m$

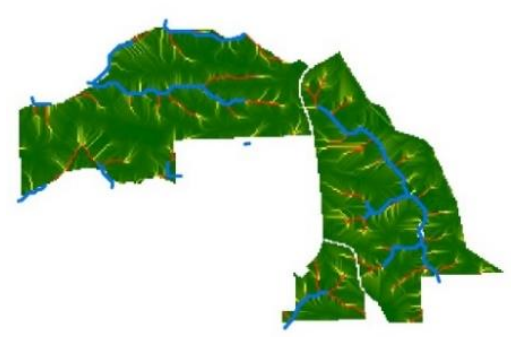

$\mathrm{FSL}+8 \mathrm{~m}$

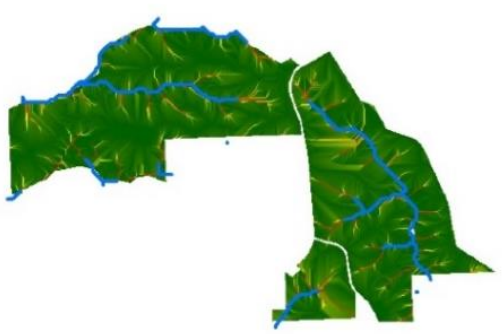

$\mathrm{FSL}+15 \mathrm{~m}$

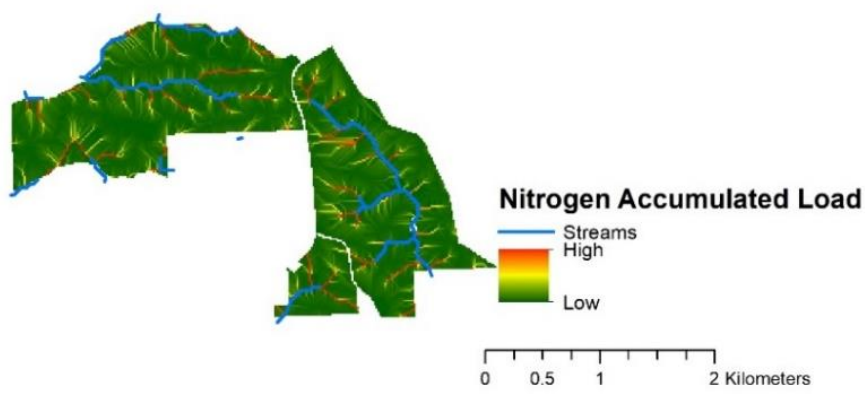

Figure 6.45 Nitrogen accumulated load results for all scenarios. 


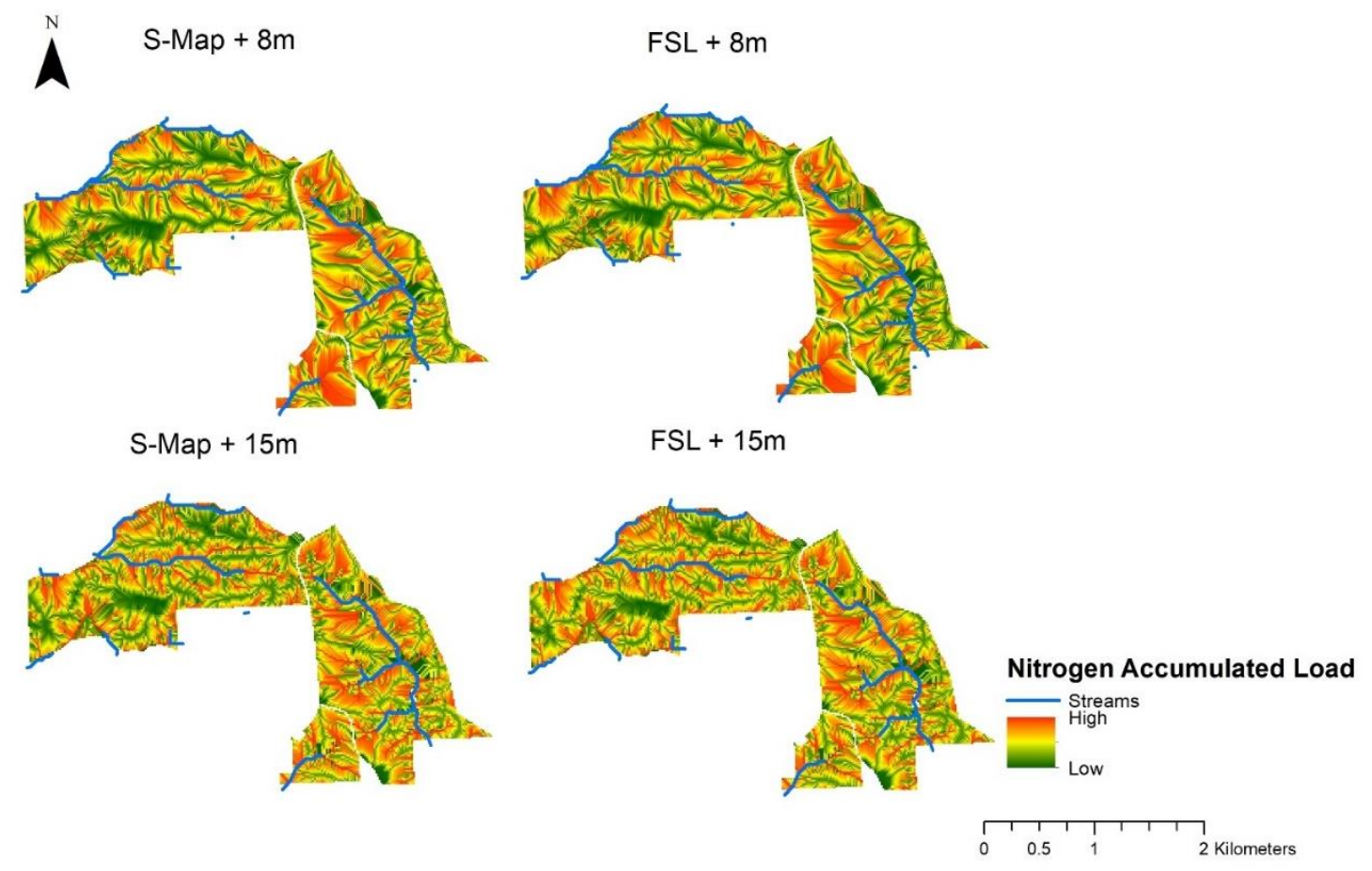

Figure 6.46 Nitrogen accumulated load results for all scenarios using the histogram equalise setting in ArcMap symbology.

\section{Phosphorus}

Phosphorus load and phosphorus accumulated load estimates for this farm are shown in Figure 6.47 and Figure 6.48. As for nitrogen, the variation between brown and pallic soil classification in S-Map and FSL are evident, as well as the location of the OVERSEER management blocks. The areas of the farm classed as cropping rotations have the highest phosphorus loss, because the ground is cultivated, increasing the risk of soil loss to water, whereas trees and riparian planting areas have the lowest phosphorus loss. The areas of pasture classified as brown soils in S-Map have a phosphorus load of 600-900 $\mathrm{g} \mathrm{P} / \mathrm{ha} / \mathrm{yr}$ in the FSL scenarios; this is reduced to 0-300 $\mathrm{g} \mathrm{P} / \mathrm{ha} / \mathrm{yr}$ with the different soil classification. For the phosphorus accumulated load results (Figure 6.49), the location of accumulated load pathways is similar for all applications, with the histogram equalise outputs also consistent between all scenarios. Like nitrogen, however, the areas of high nutrient loads differ from the results produced using the standard deviation setting. 


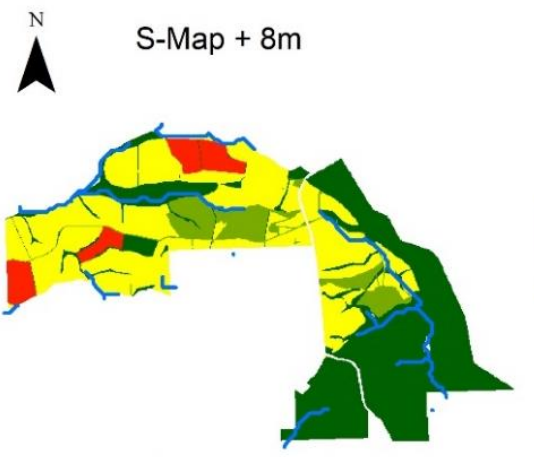

S-Map $+15 m$

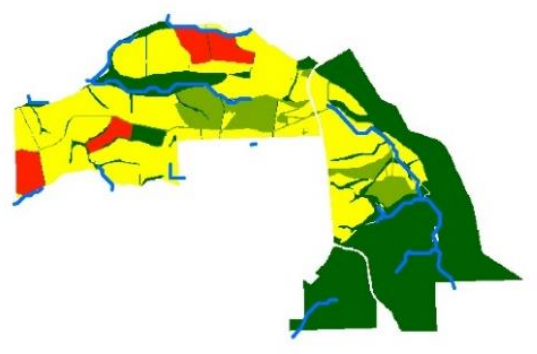

$\mathrm{FSL}+8 \mathrm{~m}$

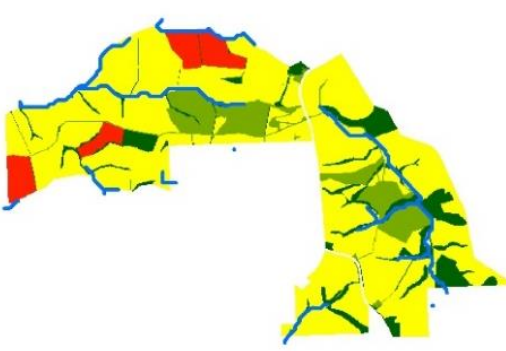

$F S L+15 m$

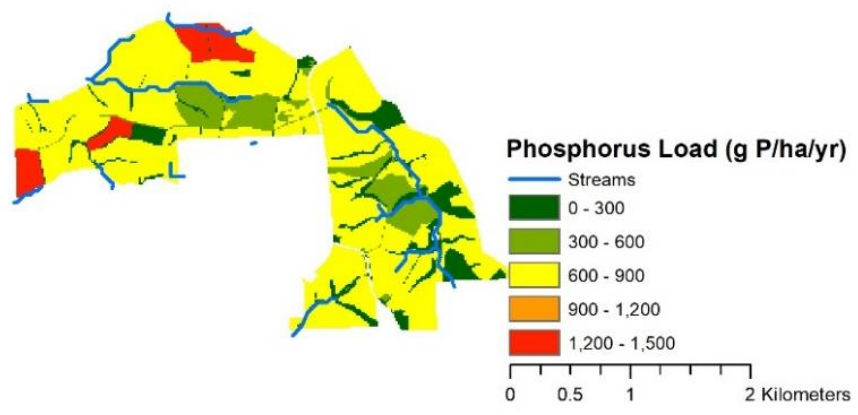

Figure 6.47 Phosphorus load results for all scenarios in $\mathrm{g} P / \mathrm{ha} / \mathrm{yr}$.
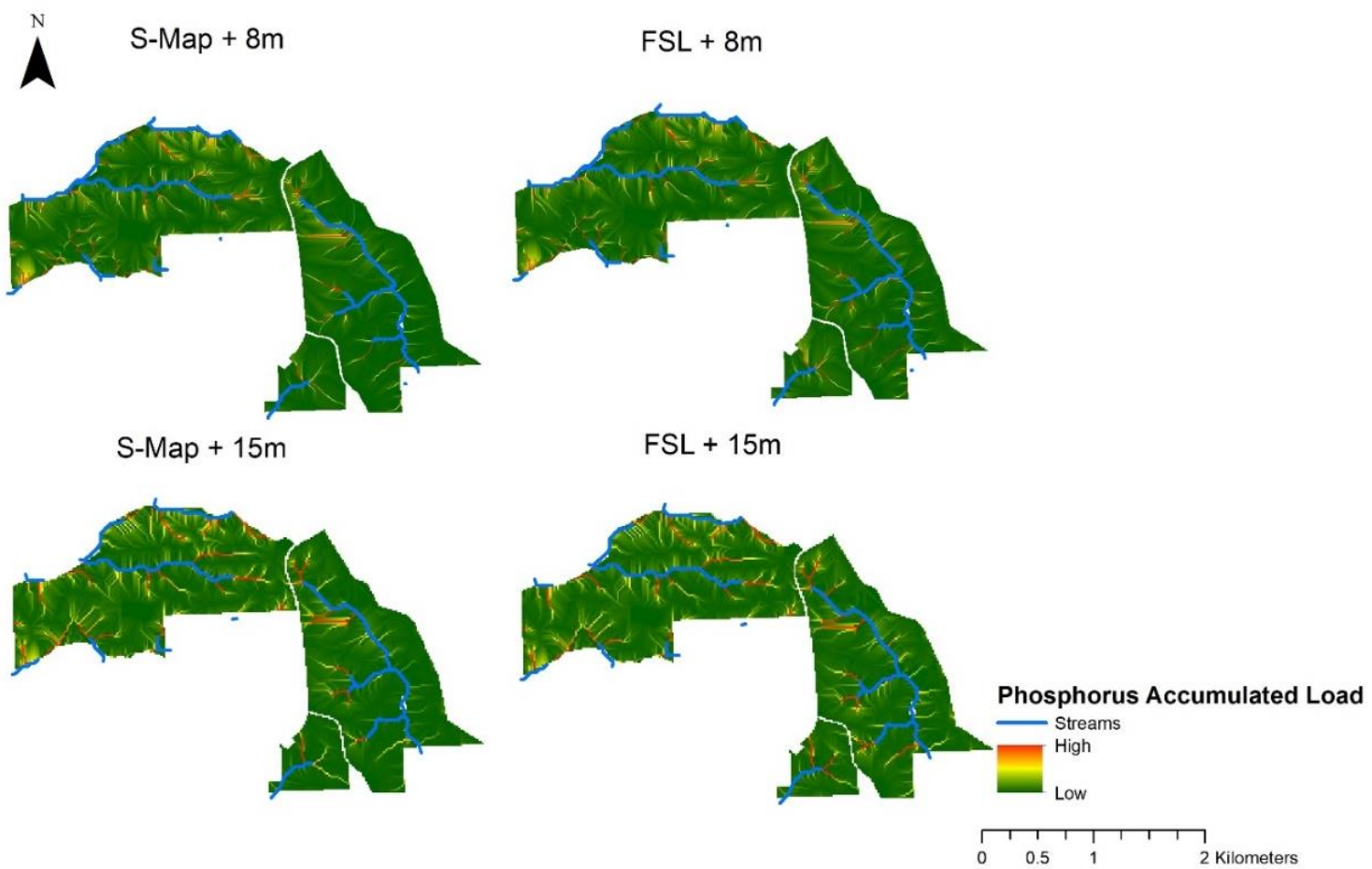

Figure 6.48 Phosphorus accumulated load results for all scenarios. 


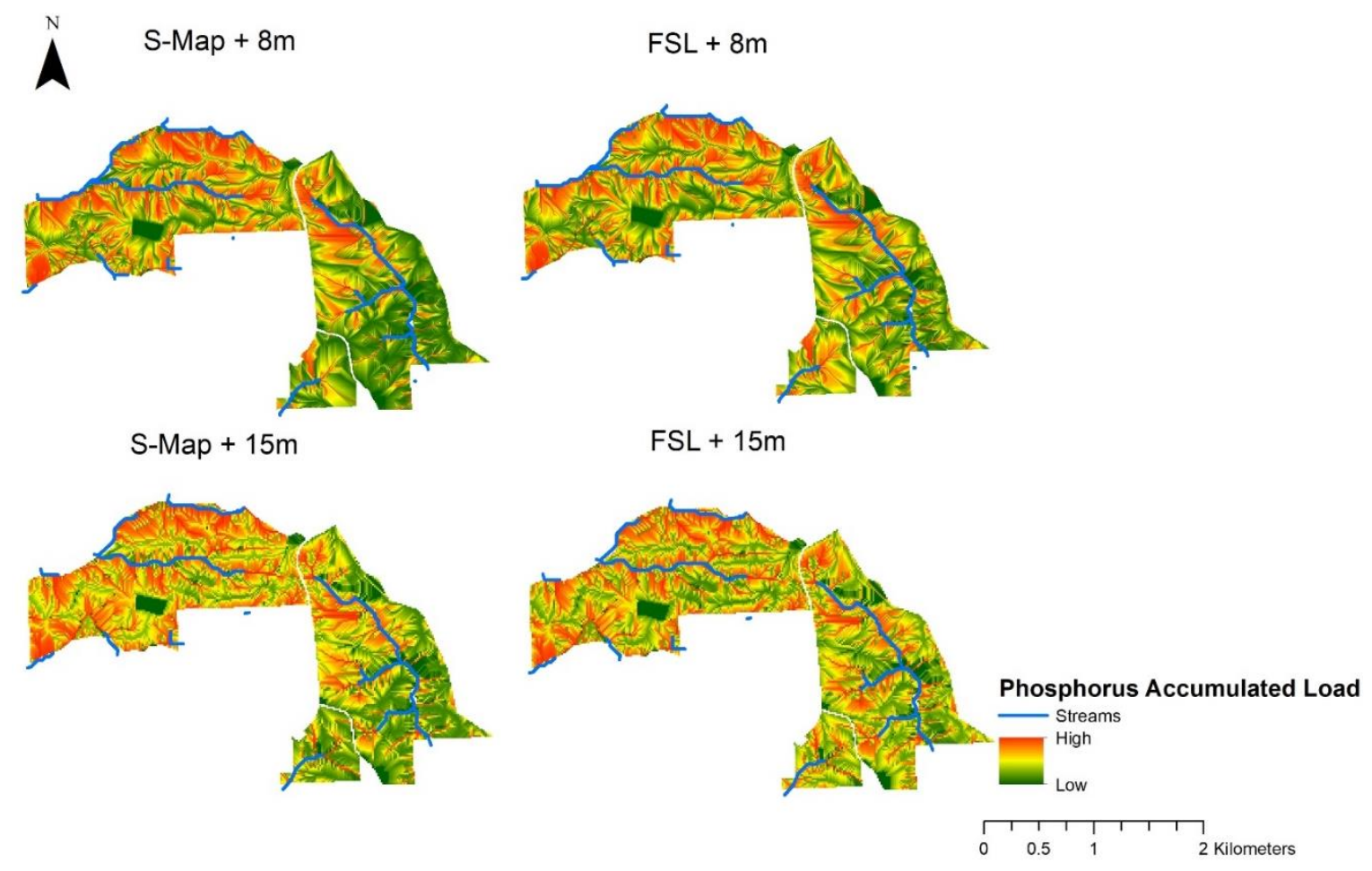

Figure 6.49 Phosphorus accumulated load results for all scenarios using the histogram equalise setting in ArcMap symbology.

\subsubsection{Modelled vs Collected Data Comparison}

Table 6.11 summarises total nitrogen and phosphorus concentrations from measured water quality data and the four LUCI scenarios modelled for this farm. The measured data was taken fortnightly from September 2013 to September 2014; the mean concentrations are shown in row 1, and below that are LUCl's predictions for the watershed on the south side of the property, where the council monitoring site is located for the four scenarios tested (Figure 5.16).

LUCl's water quality predictions for this farm vary from measured council data, with the most variation away from measured data nitrogen estimated by the S-Map $+8 \mathrm{~m}$ scenario $(2.71 \mathrm{mg} / \mathrm{L}$ compared to the measured $3.69 \mathrm{mg} / \mathrm{L})$. For phosphorus, $\mathrm{LUCl}$ varied with S-Map estimates $0.05 \mathrm{mg} / \mathrm{L}$ and $0.03 \mathrm{mg} / \mathrm{L}$ off Otago Regional Council's values. The FSL $+15 \mathrm{~m}$ estimated a slightly higher concentration of $0.11 \mathrm{mg} / \mathrm{L}$, this was the only scenario to overestimate phosphorus load. 
Table 6.11 Observed and predicted total nitrogen and phosphorus loads for all scenarios at this site.

\begin{tabular}{|l|r|r|}
\hline Data Source & Total Nitrogen (mg/L) & \multicolumn{2}{|r|}{ Total Phosphorus (mg/L) } \\
\hline Otago Regional Council (2014) & 3.69 & 0.103 \\
\hline LUCI S-Map + 8m DEM & 2.71 & 0.0547 \\
\hline LUCI S-Map + 15m DEM & 3.74 & 0.0798 \\
\hline LUCI FSL + 8m DEM & 2.90 & 0.0731 \\
\hline LUCI FSL + 15m DEM & 3.07 & 0.110 \\
\hline
\end{tabular}

\subsection{OVERSEER SENSITIVITY}

\subsubsection{Effect of Changing Management Factors}

In Table 6.12 are the results of the management scenarios tested in the hypothetical OVERSEER nutrient budget.

The Nitrogen sub-model within OVERSEER is responsive to changes in the input parameters that would affect the amount of nitrogen leaving the farm system. The baseline value of total nitrogen loss is 53,941 kg N/yr with $54 \mathrm{~kg} \mathrm{~N} / \mathrm{ha} / \mathrm{yr}$ lost to water and $12.6 \mathrm{ppm}$ lost in drainage. These values increased when fertiliser applications are added to the block, showing that the nitrogen sub-model is sensitive to changes, as the scenario shows the expected increase in modelled nitrogen loss associated with increased nitrogen input on the cropping block.

With the addition of 50 units of nitrogen fertiliser at sowing, total nitrogen loss increased $25 \%$ above the original farm, and with 100 units of nitrogen added, total nitrogen lost increased $49 \%$ above the original farm. When another application of 50 units of nitrogen was applied one month after sowing, total nitrogen loss increased $69 \%$ above the original farm value. The amount of nitrogen lost in drainage water also increased proportionally to the increased nitrogen load of the fertiliser applications. 
Table 6.12 OVERSEER Results of management factor scenarios on the hypothetical cropping farm.

\begin{tabular}{|c|c|c|c|c|c|}
\hline \multirow[b]{2}{*}{ Scenario } & \multicolumn{3}{|l|}{ Nitrogen } & \multicolumn{2}{|c|}{ Phosphorus } \\
\hline & $\begin{array}{l}\text { Total N } \\
\text { lost (kg } \\
\mathrm{N} / \mathrm{yr})\end{array}$ & $\begin{array}{l}\mathrm{N} \text { lost to } \\
\text { water (kg } \\
\mathrm{N} / \mathrm{ha} / \mathrm{yr} \text { ) }\end{array}$ & $\begin{array}{l}\mathrm{N} \text { in } \\
\text { Drainage } \\
\text { (ppm) }\end{array}$ & $\begin{array}{l}\text { Total } \\
\text { P lost } \\
\text { (kg } \\
\text { P/yr) }\end{array}$ & $\begin{array}{l}\text { P lost in } \\
\text { water (kg } \\
\mathrm{P} / \mathrm{ha} / \mathrm{yr} \text { ) }\end{array}$ \\
\hline Original Farm & 53,941 & 54 & 12.6 & 388 & 0.4 \\
\hline Fertiliser at sowing & 67,226 & 67 & 15.7 & 435 & 0.4 \\
\hline $\begin{array}{l}\text { Double the amount of fertiliser at } \\
\text { sowing }\end{array}$ & 80,361 & 80 & 18.7 & 483 & 0.5 \\
\hline $\begin{array}{l}\text { Double fertiliser at sowing }+ \\
\text { additional application after } 1 \\
\text { month }\end{array}$ & 89,482 & 89 & 20.8 & 531 & 0.5 \\
\hline Direct Drilled & 48,512 & 49 & 11.3 & 388 & 0.4 \\
\hline 5 years of pasture & 39,549 & 40 & 9.2 & 388 & 0.4 \\
\hline Continuous Cropping & 32,005 & 32 & 6.2 & 1,027 & 1 \\
\hline Fallow prior to planting & 62,062 & 62 & 14.0 & 388 & 0.4 \\
\hline Fallow only & 115,770 & 116 & 20.3 & 403 & 0.4 \\
\hline
\end{tabular}

In these scenarios phosphorus loss also increased $12 \%$ above the original farm value of $388 \mathrm{~kg} \mathrm{P} / \mathrm{yr}$ when 20 units of phosphorus was applied at sowing. This estimated loss then increased $24 \%$ and $37 \%$ respectively, when 40 units and an additional 20 units were applied one month after sowing.

The other scenarios run on this farm also resulted in changes to nitrogen and phosphorus loss from the system. A decrease in nitrogen loss occurred through changing the sowing practice and the block history. Changing from conventional to direct drilled cultivation resulted in a $10 \%$ reduction in the amount of nitrogen lost from the system. This change is realistic, as direct drilling does not disturb the soil as much as conventional cultivation, thereby reducing the amount of nitrogen lost from the top layer of the soil. In this scenario, total phosphorus loss did not change from the 
base value of $388 \mathrm{~kg} \mathrm{P} / \mathrm{yr}$. The lack of variation between this scenario and the base scenario indicates that the phosphorus loss sub-model is insensitive to cultivation, although it would be expected that phosphorus loss would also decrease as the structure of the soil is not compromised, as there is less exposed soil available for erosion.

Changing the block history by reducing the prior years in pasture from the base scenario of ten to five years in pasture, resulted in a $26 \%$ reduction of nitrogen lost. Again, the phosphorus status of the farm remained at the original value.

The total nitrogen lost is further reduced by $41 \%$ under a continuous cropping regime with zero prior years in pasture. This reduction is caused by OVERSEER adjusting the nitrogen mineralisation rate, which is a critical factor to consider if cropping has occurred, especially if it was within two years of the reporting year, which could have a considerable influence on OVERSEER outputs (Watkins et al., 2013).

Whereas previously, changing the block history had no effect on phosphorus loss, for a continuous cropping scenario, phosphorus loss was estimated to be 2.6 times the phosphorus loss on the original farm. This increase is expected, as cropping practices significantly disturb the top soil, resulting in soil exposure and increased background phosphorus loss in the sub-model (i.e. phosphorus that has had the opportunity to react with the soil and then be lost via flow events throughout the year) (Gray et al., 2016b). This pattern is identified in the AgResearch report reviewing the phosphorus loss sub-model (Gray et al., 2016a), as modelled total phosphorus loss incorporates factors that relate to the loss of phosphorus in particulate form due to soil erosion, the soils Olsen P status, and the topography of the block. Nevertheless, despite cropping being identified as impacting the phosphorus status of soil, there is no cropping component in the sub-model. Instead, the pastoral sub-model is used with the exclusion of grazing specific components (dung or effluent return), leading to a mean increase in phosphorus loss that is equivalent to twice the amount of phosphorus loss on pastoral blocks (Gray et al., 2016a). 
In the scenarios with two months fallow prior to planting, and fallow for the entire reporting year, the total nitrogen lost increased $15 \%$ and $1.1 \%$ respectively. This increase is expected, as having a period of the reporting year where no crop is sown will increase the nitrogen pool of the soil, as no nitrogen will be lost through plant uptake. Accordingly, more nitrogen is available for drainage (nitrogen lost in drainage increased from the base value of $12.6 \mathrm{ppm}$ to $14 \mathrm{ppm}$ and $20.3 \mathrm{ppm}$ respectively). There was a $3.8 \%$ increase in the phosphorus sub-model in the fallow-only scenario. In reality a more significant change would be expected as leaving the ground bare for a whole year would dramatically affect the phosphorus cycle.

\subsubsection{Effect of Changing Environmental Factors}

In Table 6.13 are the results of all environmental scenarios tested in the hypothetical OVERSEER nutrient budget.

Table 6.13 Results of environmental factor scenarios on the hypothetical farm.

\begin{tabular}{|c|c|c|c|c|c|}
\hline & Nitrogen & & & Phosphc & rus \\
\hline Scenario & $\begin{array}{l}\text { Total N lost } \\
\text { (kg N/yr) }\end{array}$ & $\begin{array}{l}\mathrm{N} \text { lost to } \\
\text { water (kg } \\
\mathrm{N} / \mathrm{ha} / \mathrm{yr} \text { ) }\end{array}$ & $\begin{array}{l}\mathrm{N} \text { in } \\
\text { Drainage } \\
\text { (ppm) }\end{array}$ & $\begin{array}{l}\text { Total P } \\
\text { lost (kg } \\
\mathrm{P} / \mathrm{yr})\end{array}$ & $\begin{array}{l}\mathrm{P} \text { lost in } \\
\text { water (kg } \\
\mathrm{P} / \mathrm{ha} / \mathrm{yr} \text { ) }\end{array}$ \\
\hline$A S C=50$ & 53,941 & 54 & 12.6 & 281 & 0.3 \\
\hline $\mathrm{ASC}=10$ & 53,941 & 54 & 12.6 & 463 & 0.5 \\
\hline Olsen $\mathrm{P}=20$ & 53,941 & 54 & 12.6 & 391 & 0.4 \\
\hline Olsen $P=100$ & 53,941 & 54 & 12.6 & 510 & 0.5 \\
\hline Rainfall $=400 \mathrm{~mm}$ & 1,000 & 1 & 19.8 & 31 & 0.0 \\
\hline Rainfall $=600 \mathrm{~mm}$ & 5,980 & 6 & 5.5 & 31 & 0.0 \\
\hline Rainfall $=800 \mathrm{~mm}$ & 14,446 & 14 & 6.2 & 130 & 0.1 \\
\hline Brown soil & 46,568 & 47 & 11.3 & 115 & 0.1 \\
\hline $\begin{array}{l}\text { Rainfall }=800 \mathrm{~mm} \\
\text { (brown soil) }\end{array}$ & 12,061 & 12 & 5.5 & 39 & 0 \\
\hline $\begin{array}{l}\text { Rainfall }=1200 \mathrm{~mm} \\
\text { (brown soil) }\end{array}$ & 77,319 & 77 & 11.7 & 205 & 0.2 \\
\hline $\begin{array}{l}\text { Rainfall }=1400 \mathrm{~mm} \\
\text { (brown soil) }\end{array}$ & 103,395 & 103 & 12.0 & 309 & 0.3 \\
\hline
\end{tabular}


The phosphorus sub-model did respond to changes in soil properties that will affect the concentration of phosphorus lost in overland flow. When the ASC was adjusted from the default value for a pallic soil to $50 \%$, the total phosphorus lost from the system decreased $28 \%$. At the other extreme, when ASC was decreased to $10 \%$, the response from the model resulted in $19 \%$ increase in total phosphorus lost to $463 \mathrm{~kg}$ $\mathrm{P} / \mathrm{yr}$.

The same pattern was seen when increasing and decreasing the Olsen $\mathrm{P}$ value of the soil, reflecting how ASC and Olsen $\mathrm{P}$ affects $\mathrm{P}$ retention, and therefore the background rate of phosphorus loss from the soil. While the phosphorus sub-model is sensitive to changes in these inputs, the output provided by OVERSEER does not differentiate between phosphorus lost in surface and subsurface flows. This lack of differentiation between phosphorus loss pathways makes it hard for mitigation strategies to be identified, as viable options differ greatly between pathways (Gray et al., 2016b).

Changing the climatic properties of the farm block, by adjusting the average annual rainfall, indicated that the phosphorus sub-model is sensitive to changes in climatic conditions. As the phosphorus sub-model and other nutrient leaching sub-models are connected to the monthly calculations in the hydrology sub-model, changes in annual rainfall will impact the soil moisture content, the amount of surface runoff, and drainage past the root zone (Wheeler, 2016b). Changes to the flow within the hydrological sub-model are governed by the relationship that drainage or drainage + runoff (surface and subsurface), will occur when surplus precipitation is present (i.e. there is more rainfall and irrigation than actual evapotranspiration) (Gray et al., 2016a). 


\section{CHAPTER 7 DISCUSSION}

The results presented in Chapter 6 demonstrate LUCI's sensitivity to a soil polygon's classification within the NZSC, the effect DEM resolution has on model outputs, how national vs farm specific landcover and management data affects the reliability of load estimates, and finally, provides guidance on where $\mathrm{LUCl}$ can and can't be reliably used to target mitigations.

This chapter summarises the results of the individual case studies and interprets them with a view to understanding the wider implications of applying the LUCI model in New Zealand. The case studies highlight different farm systems, climates, topography and data environments, reflecting the variable nature of agriculture. To be clear, these farms were not selected to be representative of either the full diversity or commonalities within New Zealand's agricultural industry, but rather to provide guidance on LUCl's reliability in different environments. This thesis is the first study to focus on testing LUCl's sensitivity and predictive accuracy against a range of input datasets and farm environments; further research is needed to confirm these initial findings.

The discussion below addresses Objective 2 and 3 in Section 1.2: "To compare LUCl's Nitrogen to Water and Phosphorus to Water tools in case study sites" and "To explore whether available datasets are appropriate for accurate model outputs, and to provide guidance on how LUCI can be adapted to better use these datasets for improved accuracy where appropriate".

\subsection{SENSITIVITY OF LUCI TO SOIL PROPERTIES AND THE RESOLUTION OF ELEVATION DATA USED}

LUCl's Nitrogen to Water and Phosphorus to Water tools, as tested on six farms around New Zealand, highlight the variation in the sensitivity of each site based on its 
topography and the level of variation between FSL and S-Map soil order classifications for the same area. Table 7.1 summarises these differences below.

Table 7.1 Sensitivity of the case study sites to soil and elevation datasets.

\begin{tabular}{|l|r|l|}
\hline Scenario & $\begin{array}{l}\text { Sensitive to soil } \\
\text { dataset used }\end{array}$ & $\begin{array}{l}\text { Sensitive to } \\
\text { DEM used }\end{array}$ \\
\hline Tuapaka Catchment & $\checkmark$ & $\checkmark$ \\
\hline Greater Wellington & $\checkmark$ & $\checkmark$ \\
\hline North Canterbury & $\checkmark$ & $\checkmark$ \\
\hline LUDF & $\checkmark$ & \\
\hline South Canterbury & $\checkmark$ & \\
\hline Otago & & \\
\hline
\end{tabular}

To our knowledge, there is currently no readily available objective assessment to measure sensitivity of accumulated flow in the landscape. Subjective criteria were used to classify if a site was sensitive to soil data or a DEM. While there is established literature on the appropriate method to carry out a sensitivity analysis to highlight calibration process issues for specific model parameters (Nossent \& Bauwnes, 2012), measuring the sensitivity of the spatial configuration of modelled nutrient flows is undefined. Therefore, the subjective assessment of the sensitivity LUCI to soil and elevation data used several model outputs:

Firstly, a comparison of the Hydtopo output for each DEM on a site provided insight on the hydraulic variation in stream placement and watershed delineation based on the different grid sizes. This visual comparison between the DEMs and the known stream position, based on discussions with the landowner, LUCI developers who have carried out site visits, and a comparison to topographic maps, indicates which datasets used in LUCI produce the most accurate representation of the hydraulic properties of the farm. For Tuapaka, it was shown that the 15m DEM produced the most accurate output based on the stream outline provided in Burkitt et al. (2016). The 8m scenarios in the Tuapaka study did, however, represent a realistic watershed as the location where the two streams merged was similar between both DEMs. We concluded, 
therefore, that this site was not sensitive to the resolution of the DEM used. The $15 \mathrm{~m}$ DEM was not, however, the most accurate representation on the North Canterbury cases study site. The fine resolution $2 \mathrm{~m}$ DEM produced the most realistic stream profile and watershed, with the $15 \mathrm{~m}$ DEM greatly underestimating the size of the watershed and the position of the stream in the landscape. These two sites are examples of where $\mathrm{LUCl}$ is considered sensitive or not sensitive to the DEM grid size in the Hydtopo setup. Based on this subjective assessment, it was found that the sites that have rolling topography (except for Greater Wellington) are not sensitive to changes in DEM resolution.

Secondly, the nutrient load results enabled a comparison of total estimated nitrogen and phosphorus loads on each farm. All sites (apart from Greater Wellington) are sensitive to changing soil input datasets, owing to the changing classification of soil orders between FSL, S-Map, and Farm Scale soil maps. Greater Wellington is an exception, as this site has little variation between FSL and S-Map soil classifications, with all of the farm classified as brown soil in FSL. When updated with S-Map, only a strip of recent soil near the stream network is added. This differs from the other sites tested, where soil order classifications are more complex. Since soil order did not change significantly between scenarios, the predicted hydrology of the farm did not result in substantial variation in estimated nutrient loads. Instead, a sensitivity to climate, instead of soil order, was apparent in the load outputs. Results from the other case studies suggest that, when soil datasets are very different, the sensitivity of LUCI to soil parameters dominates other sensitivities. This is a known issue in environmental modelling where sensitivity to multiple parameters exists, but some parameters are more influential the others (Nossent \& Bauwnes, 2012).

Finally, the spatial pattern in load estimates and accumulated flow pathways enabled a visual comparison between scenarios, with the placement of flow paths on the farms with flat topography (North Canterbury and LUDF) shown to be unrealistic, as the lower resolution DEMs are unable to pick up the microtopography of the farm. In contrast, the accumulated load pathways for case studies with rolling to steep hill topography, such as Tuapaka and South Canterbury, did not produce significantly different estimates of accumulated flow with different DEM resolutions. 


\subsubsection{Sensitivity to Soil Order}

The significant sensitivity of most sites to soil order was expected, as the LUCI nitrogen and phosphorus tools are trained to pick up the differences between soil orders and how this might affect nutrient transport. This can be seen in the Tuapaka catchment, where the FSL initially classified 48 ha as pallic soil, and the farm scale soil map classified only 8 ha as pallic. This resulted in significant changes to load estimates, particularly for phosphorus, with high nutrient loads, predicted between 400-450 g $\mathrm{P} / \mathrm{ha} / \mathrm{yr}$, reduced to between 0-200 g P/ha/yr near the outlet of the catchment (Figure 6.5). A similar result between input soil datasets and consequent model output sensitivities is seen in the North Canterbury, LUDF, South Canterbury and Otago sites.

Soil order classifications on the North Canterbury site change between FSL (S-Map) datasets with 51 ha (75 ha) as pallic soil, 156 ha (53 ha) recent soil and 89 ha (167 ha) brown soil. This change in soil classification resulted in different load patterns on the farm with higher nitrogen loads present on areas of brown soil, therefore, nitrogen loss increased as the brown soil area increased in S-Map.

As with the patterns highlighted for Tuapaka and North Canterbury, the changing ratio of brown, pallic, recent (and, for LUDF and South Canterbury, gley and semi-arid soils respectively), resulted in changes to LUCl's predictions of nitrogen and phosphorus loads on the landscape. Whilst the changes to the soil datasets are outlined in Section 5.1.2 and tested in Sections 6.1 to 6.6 of this thesis, implications of the model's parameterisation by soil order and the underlying dataset $\mathrm{LUCl}$ is trained from, are discussed below.

Whilst the newer, S-Map dataset is considered to contain more robust soil property information than FSL, as shown on the LUDF case study (Section 6.4), the nitrogen load estimates from the FSL scenarios more closely resembled the nitrogen estimates produced from the farm scale soil map. When FSL classification for this site were updated to S-Map, 3 ha of recent soil was reclassified as pallic soil. When the farm was surveyed as part of the Barringer et al. (2016) study, 5 ha was classified as recent soil in similar areas on the north side of the farm. This provides an example of an area where S-Map may not necessarily be the best representation of the soil properties on a farm. 
Further research is needed to compare S-Map soil data to farm scale soil maps that represent the most accurate soil information available for a site. As this research is costly and given the aim to provide national S-Map coverage in future this should be a funding priority for councils, central government and industry.

Grealish et al. (2018) outlined farm scale soil mapping protocols to be used nationally for collecting and presenting farm scale soil maps between 1:500 to 1:20,000. These protocols could be used to identify farms which would benefit from farm scale soil mapping based on the minimum level of detail required for each activity, particularly if the farm is applying dairy effluent and requires verification of appropriate areas for application or irrigation planning, and to verify OVERSEER nutrient budgets containing S-Map soil information.

The document goes on to identify a classification of fine, medium and low detail farm scale soil maps which are classified as having one field observation per $1 \mathrm{~cm}^{2}$ of published map area; one field observation per $2 \mathrm{~cm}^{2}$ of published map area; and one field observation per $4 \mathrm{~cm}^{2}$ of published map area respectively (Grealish et al., 2018). In the future, $\mathrm{LUCl}$ could be used by researchers to test the relative difference between these three levels of accuracy. The same level of detail required for OVERSEER nutrient budgets should be applied when creating farm scale soil maps for use in LUCl, with a high level of site density, soil characterisation (soil properties determined from laboratory analysis), and an explicit description of the different soil types on the property.

\section{$\underline{\text { Ravensdown Dataset }}$}

The LUCI model tested in this thesis includes bespoke components beyond the standard implementation. Ravensdown Environmental have a period of exclusive commercial use of this additional functionality. Due to this relationship, $\mathrm{LUCl}$ has been trained off Ravensdown's OVERSEER database which contains over 20,000 management block units. The database includes nitrogen, phosphorus and other outputs responding to variable climates, soils, topography and land cover combinations, as well as many other farm management, farm system and 
environmental input drivers. It should be noted, however, that OVERSEER block information can only be characterised by four slope classes, which is important for the DEM sensitivity discussed in Section 7.1.2. Training the LUCI model on this database was undertaken by Trodahl (2018) and other key LUCI developers over recent years and will continue to be updated.

While this data is divided between the North and South Islands and is representative of many farm management environments, the underlying data is dependent on the assumptions discussed in Sections 3.3. As such, the OVERSEER data $\mathrm{LUCl}$ is trained from was initially calibrated to a limited range of land use, soil and climates. Freeman et al., (2016) highlights that a significant part of the uncertainty in OVERSEER stems from imperfect input information. Errors in parameter values are further compounded by the application of OVERSEER in environments where data has not been collected and therefore cannot be used to calibrate the model. As with all models, including $\mathrm{LUCl}$, the simplification of complex processes involves uncertainties and assumptions.

It was initially decided to train LUCI to the soil properties provided at the soil order level, as soil sibling and series information was not defined for many blocks in the 2016 dataset used by Trodahl (2018). OVERSEER default soil order values, therefore, underpin LUCl's predictions of nitrogen and phosphorus loads on the landscape when both FSL and S-Map soil data is provided (Appendix C). The representativeness of the Ravensdown dataset of these soil orders varies with 3,141 defined as brown soil; 2,801 defined as pallic soil; 1,996 defined as recent soil and 1,715 defined as gley soil. In comparison, only 22 blocks are attributed as semi-arid. Since semi-arid soils only cover $1 \%$ of New Zealand (Landcare Research, 2018d), this value is probably reflective of the number of nutrient budgets completed with this soil type. It does, however, highlight the challenges in modelling an environment based on limited data.

The South Canterbury site in this study has an area of semi-arid soil on the flat, irrigated part of the property in the FSL dataset. In the FSL scenarios LUCI modelled this area as having a nitrogen load between 6-8 $\mathrm{kg} \mathrm{N} / \mathrm{ha} / \mathrm{yr}$ and a low phosphorus load between 0-150 g P/ha/yr (Section 6.5.2). Semi-arid soils are characterised as having a weakly developed soil structure, with high slaking potential, low organic carbon and 
dominated by illite clay minerals (Landcare Research, 2018d). Given this description it is expected that semi-arid soils would contribute more to the total phosphorus on a farm than $\mathrm{LUCl}$ estimated. The lower than expected phosphorus lost from the semiarid soil highlights the need for further calibration of the LUCI model; currently the model has only been trained from 22 blocks in the Ravensdown OVERSEER dataset, which indicates that incomplete soil data is currently limiting further model development.

The values of OVERSEER soil properties based on soil order (Appendix C) imply that a semi-arid soil would produce higher phosphorus loads compared to recent soils, as semi-arid soils have a drainage class of 2 and a structural integrity of 0.94 (Appendix C). These values imply that this soil type is moderately well drained and prone to erosion compared to a recent soil, which has a drainage class of 1 (well drained) and a lower structural integrity of $\mathbf{0 . 8 4}$, implying it is less prone to erosion (Wheeler, 2016a). When this pivot area on the South Canterbury site is modelled as recent soil in OVERSEER, a total of $42 \mathrm{~kg} \mathrm{P} / \mathrm{yr}$ is lost from this block with $0.5 \mathrm{~kg} \mathrm{P} / \mathrm{ha} / \mathrm{yr}$ lost to water, and when the soil order of this block is classified as semi-arid, phosphorus loss is increased to 66 $\mathrm{kg} \mathrm{P} / \mathrm{yr}$ and $0.8 \mathrm{~kg} \mathrm{P} / \mathrm{ha} / \mathrm{yr}$ lost to water.

\section{OVERSEER Sensitivity}

The sensitivity analysis carried out in Section 6.7 supports the findings of the Watkins and Selbie (2015) report on the use of OVERSEER for Regional Councils. It is important to understand that both their results and the OVERSEER sensitivity results produced in this thesis, were created under narrow constraints and are not representative of the full range of New Zealand environmental conditions and farm systems.

In the Watkins and Selbie (2015) report, a sensitivity analysis was carried out to determine the inputs that have the most influence on modelled nutrient loss. The report found that OVERSEER was most sensitive to inputs that influence the magnitude of the source of nutrient (e.g. stocking rates and fertiliser input), and those that influence the transport of nutrients (e.g. soil drainage and slope) (Watkins \& Selbie, 2015). The report highlighted that the key influence on nitrogen is drainage and thus 
the key inputs that influence nutrient loss are climate, those soil parameters that affect PAW estimates (soil order, texture, and depth to sandy or stony subsoils) and irrigation management. Trodahl (2018) found in her sensitivity analysis that phosphorus loss was sensitive to rainfall, irrigation, fertiliser, Olsen $\mathrm{P}$ and effluent, inputs that again, influence the magnitude of the source of a nutrient and its movement through the farm system.

The results for the OVERSEER sensitivity test in this thesis showed that the nitrogen sub-model was sensitive to the inputs identified in Watkins and Selbie (2015), as modelled total nitrogen loss increased when fertiliser inputs were increased and decreased when conventional cultivation and the hypothetical farm's block history was altered. For phosphorus, total phosphorus also increased when fertiliser inputs were increased but the model was insensitive to changes to the farm's cultivation practices and block history. These changes would impact the amount of phosphorus lost from a farm as they affect the structure of the soil and therefore how much sediment is at risk of erosion.

In the scenario with a fallow year, phosphorus loss is expected to be high as exposed sediment increases the risk of phosphorus loss. Nevertheless, total phosphorus loss only increased 3.8\% from the base scenario. OVERSEER's underestimation of the contribution of fallow to total phosphorus loss is linked to how OVERSEER calculates the phosphorus lost from a system. This is determined by the SV of the soil (calculated from the ASC), total organic carbon and clay content of the soil. These properties are used to estimate the inherent soil erosion potential of the block. One problem with this approach, is that it will underestimate the effect of fallow, as soil cover is not taken into account (McDowell et al., 2005). Another approach would be to use the universal soil loss equation, which uses the input parameters slope, soil type, soil cover and rainfall intensity to estimate annual soil erosion (McDowell et al., 2005). Data for this equation is not presently available across New Zealand but it is an approach that may not underestimate the effect of fallow conditions on phosphorus loss.

Further issues with the OVERSEER phosphorus loss sub-model were highlighted in Gray et al. (2016a). They discussed the need for the inclusion of phosphorus inputs from 
organic fertilisers which are currently not considered by the model, unlike nitrogen inputs from these sources. The impact of soil compaction on soil structure reduces the amount of phosphorus lost, as the model takes into account parameters that alter soil drainage. It does not, however, separate the risk of phosphorus loss based on a high or low stocking rate. This could be considered by a probability risk factor dependant on the stocking rate of the farm (Gray et al., 2016a). While this sensitivity analysis did not test the effect of slope, the results for the six case study farms highlight the need for increased sensitivity of both OVERSEER and LUCI to a wider range of topographic descriptors, instead of the current four options currently used by OVERSEER (flat, rolling, easy hill and steep hill).

\section{An Alternative Method to Train LUCl via Sibling Properties}

As described above, due to the lack of information describing sibling and series properties within the Ravensdown OVERSEER database, LUCI was parameterised to the subgroup level for hydrology and soil order for nitrogen and phosphorus predictions. As this thesis progressed, it became apparent that LUCI was not fully utilising the detailed soil data held in S-Map. Incorporating the sibling information into LUCl's hydrology model enabled the nitrogen and phosphorus sub models in LUCI to predict variations in the chemical loading to streams based on PAW variations held in the sibling level hydraulic properties. In this section, the results of adapting $\mathrm{LUCl}$ to incorporate sibling level information is discussed, as well as further suggestions to adapt to subgroup and sibling level detail in future developments.

Soil siblings in the NZSC provide information on the hydraulic properties of a soil. New Zealand does not have detailed field measurements of these soil properties, as it is costly and time consuming to gather this data directly from field measurements (McNeill et al., 2018). Soil hydraulic PTFs are frequently updated to incorporate new scientific understanding of soil water dynamics, but the ability of a modeller to accurately represent complex soil water dynamics is constrained by the scarcity of data on a range of soil characteristics. These constraints on S-Map's derived soil properties means that current PTFs do not account for the effect of environmental conditions, or 
observed moisture dynamics, as S-Map has a limited number of explanatory factors available to base predictions on (McNeill et al., 2018).

$\mathrm{LUCl}$, until the development of the hydrology model as part of this thesis, parameterised soil properties based on the information provided on the soil order or subgroup from S-Map or FSL. From these, estimates of TAW and macroporosity are assigned to each soil polygon depending on its order classification, and then those values are used in LUCl's hydrological equation (Section 3.4) to calculate PAW for the entire polygon.

Adapting the LUCI model to take in the soil water properties classified for each soil sibling in the Hydtopo step of the modelling process, was the first step towards training LUCl against the S-Map dataset at all modelling stages. It is common practice to model a soil polygon based on the characteristics of its dominant sibling. One of the questions that came up as this thesis progressed was the impact that practice has on modelled hydrology at the farm scale. We tested how using two different approaches might change predicted outcomes: a weighted average of sibling properties and a random selection of the sibling representative of a soil polygon. The results from the South Canterbury case study identified variations in LUCl's estimates of nitrogen and phosphorus in the streams on the property. This result is directly related to the variation in modelled hydrology on the farm, specifically the variations in modelled PAW (Figure 7.1). 

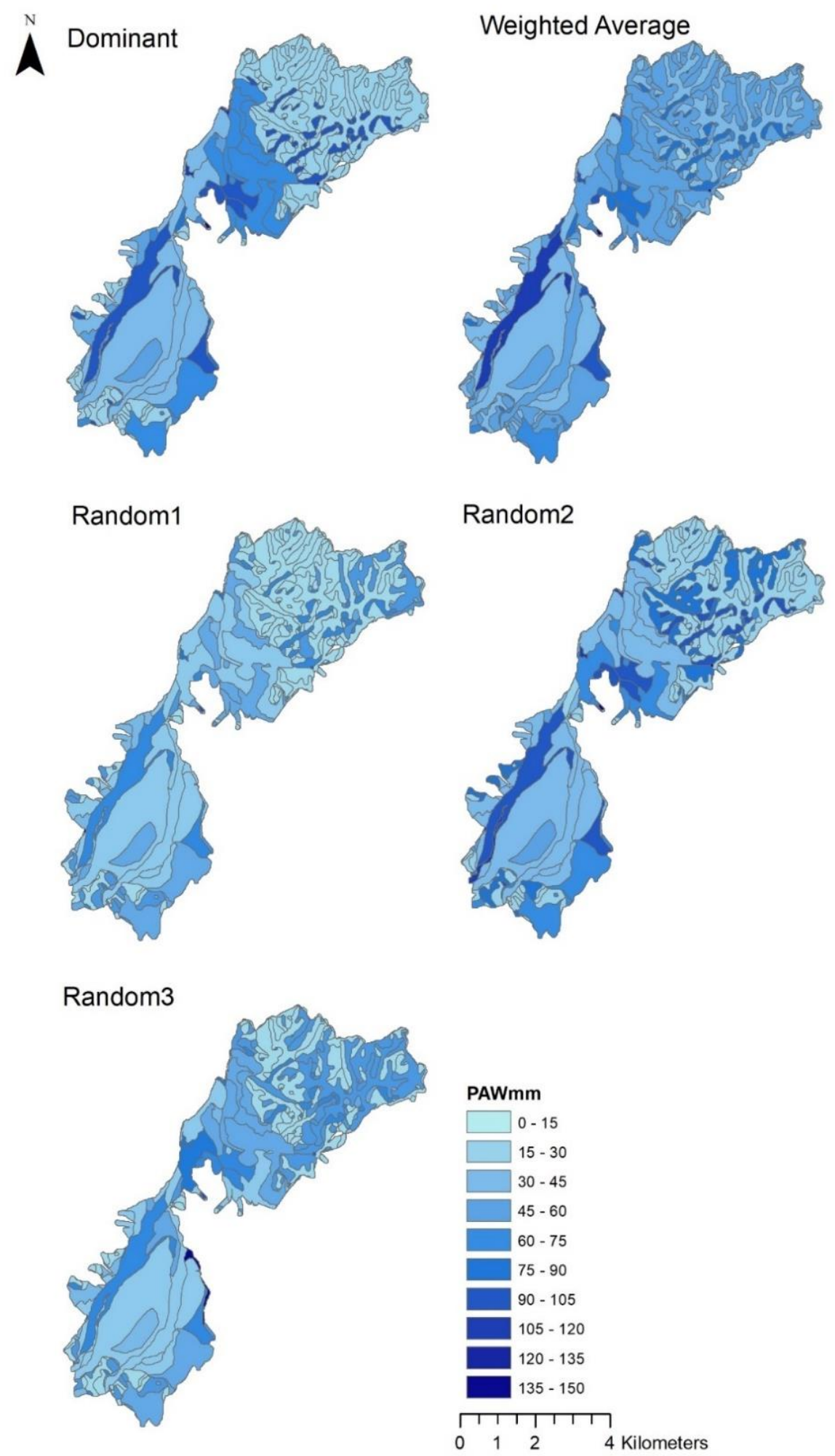

Figure 7.1 Estimated PAW for all sibling scenarios on the South Canterbury case study.

Figure 7.1 highlights the hydraulic variation across the farm for each sibling scenario. This variation propagates through the model process, and results in changing stream 
water quality estimates. At this stage the nitrogen and phosphorus models are still targeting the variations in soil properties at the order level, so it was expected that the estimated load values would not vary between scenarios for nitrogen. Phosphorus loads, however, should vary due to the incorporation of each siblings' ASC value.

In this instance, the site selected did not have significant variation in ASC between the different siblings, as the majority of siblings within a soil polygon were from the same soil order. Thus, there was little impact of sibling selection method on phosphorus load. Future LUCI development could investigate the method developed in this thesis on several farms that are identified to contain contrasting sibling properties within the same soil polygon. Another option is to evaluate, at a sibling level, the relevant soil properties that influence nitrogen and phosphorus movement within a landscape and train the LUCI model on this new dataset.

It would be difficult to develop this training dataset. Sibling properties are accessible through Landcare Research, but uncommon siblings won't have a lot of soil data available to train the ePTFs in S-Map. Also, given the current limitations of the amount of measured soil property data held in the NSD, if LUCI developers were to create this dataset and link it to the farm management information present in the Ravensdown OVERSEER database, it would be difficult to determine if all the properties attributed to the different siblings are accurate, without a significant increase in the amount of measured data held within the NSD.

The sibling analysis conducted in this thesis highlights the potential for LUCI to be trained at the sibling or subgroup level rather than that for soil order. Soil subgroup could be used in the nitrogen and phosphorus models to bring in the additional information on the range of environments for which a soil could form. This subgroup level may be more relevant to predicted nitrogen and phosphorus loads than to soil properties at the sibling level, as detailed hydraulic information at the sibling level is provided to the nitrogen and phosphorus models in the Hydtopo step of the modelling process. 
While work needs to continue to test the relative difference between sibling properties and their effects on modelled nutrient flows in the landscape, the variation in LUCl's hydrology as a result of the different ways siblings were modelled on the South Canterbury site, indicates the potential for LUCI to be developed and become more sensitive to variations in soil properties that adjust PAW in the soil. Figures 7.2 to 7.4 quantify the variation between siblings classified under the same soil order, with the variation in brown, pallic, and recent siblings indicating the potential variation in the landscape that LUCI and OVERSEER do not model at this stage, given the preference for representing a soil polygon by the dominant sibling (the maximum PAW value held in the S-Map Database is $700 \mathrm{~mm}$ ).

Further measured soil data and the ongoing development of PTFs will enable models such as LUCI and OVERSEER to better represent real-world variation in soil characteristics. The range of PAW variation at the South Canterbury site is not extreme between siblings of the same order. There is potential for this analysis to be undertaken on another farm, one that has known significant variation in soil hydraulic properties, to indicate the possible variation in predicted hydrology based on the method of representing the S-Map sibling data in a soil polygon.

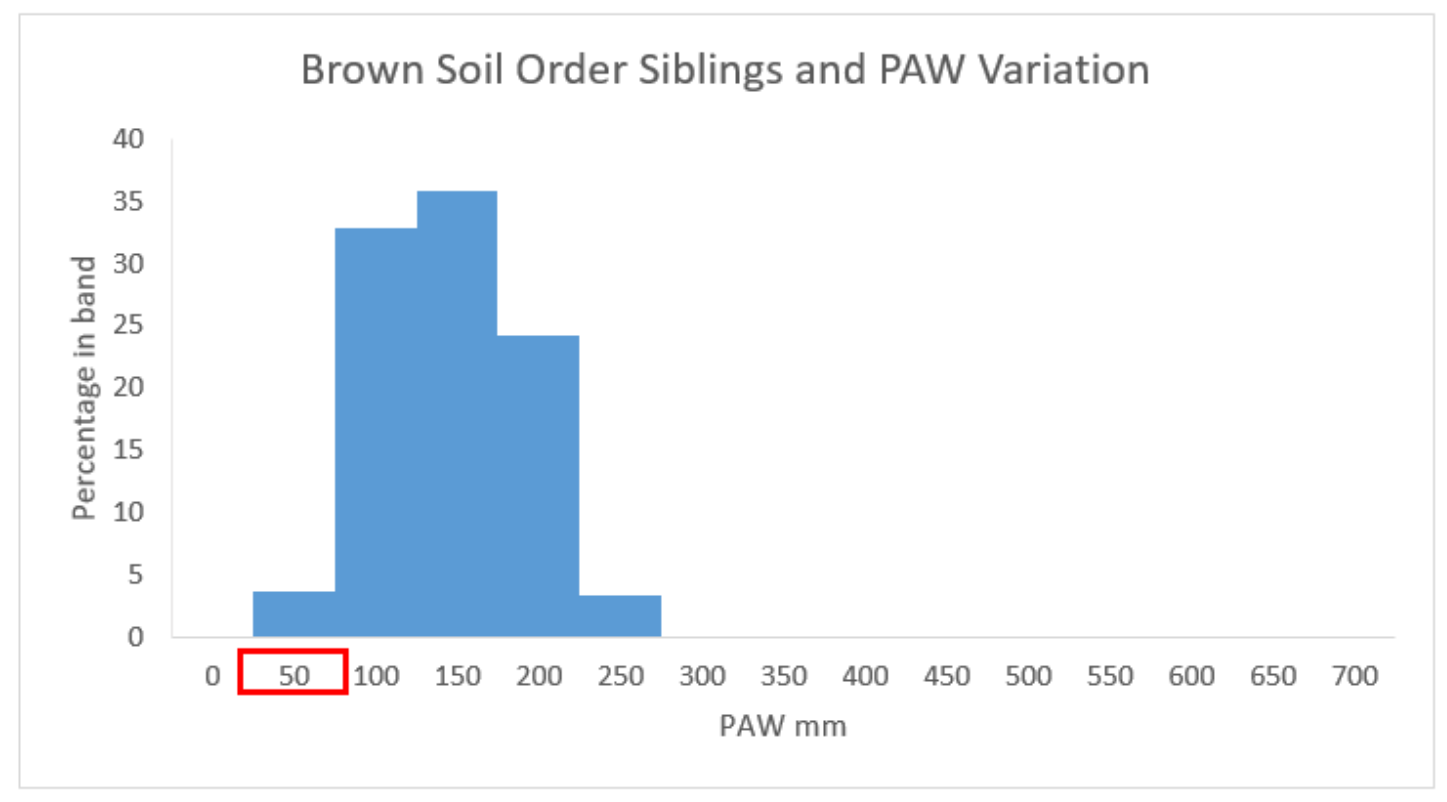

Figure 7.2 Variation in PAW for selected siblings classified as brown soils. Red box indicates range in PAW found at the South Canterbury site. 


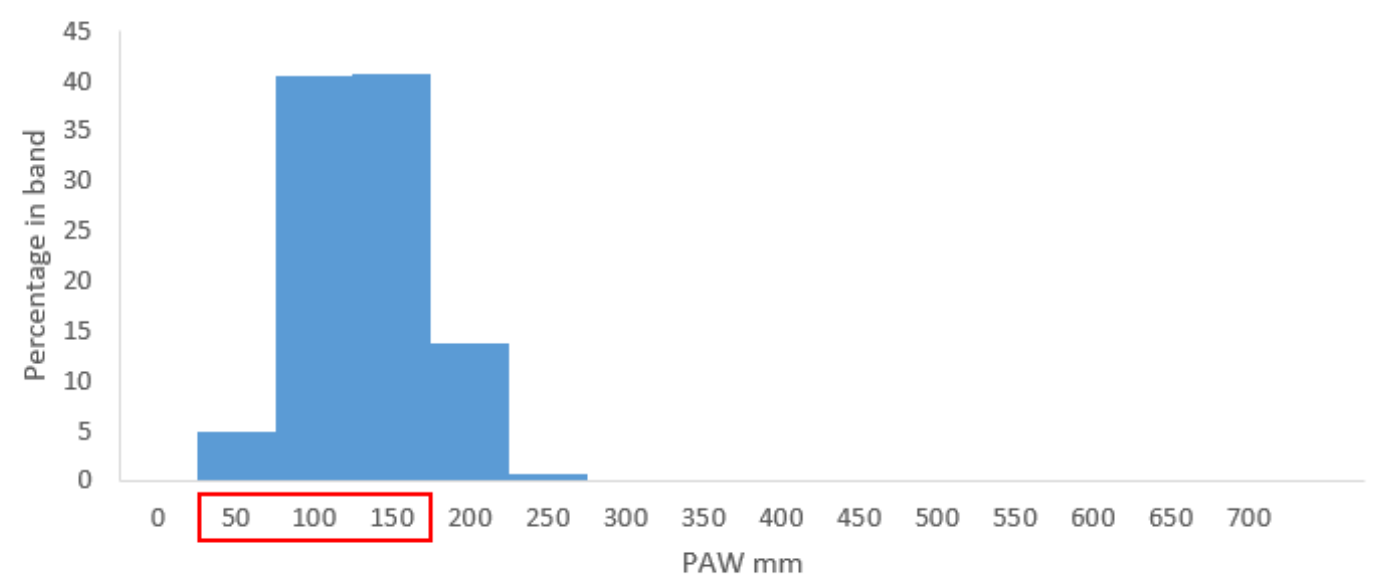

Figure 7.3 Variation in PAW for selected siblings classified as pallic soils. Red box indicates range in PAW found at the South Canterbury site.

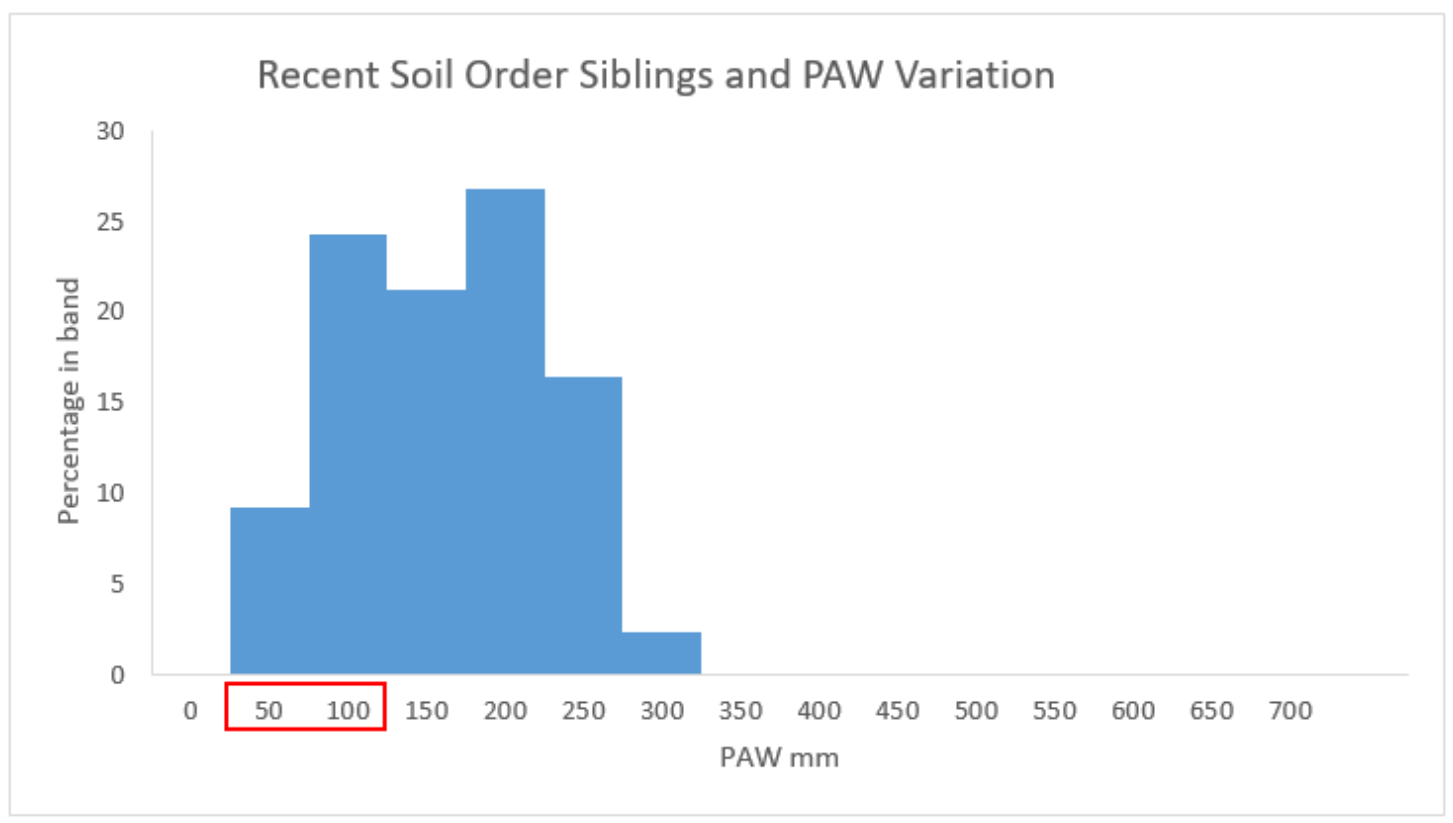

Figure 7.4 Variation in PAW for selected siblings classified as recent soils. Red box indicates range in PAW found at the South Canterbury site.

\subsubsection{Sensitivity to DEM Resolution}

The sensitivity of $\mathrm{LUCl}$ outputs to DEM resolution highlights the importance of using a high-resolution DEM to model flat landscapes. The accumulation flow patterns on LUDF and North Canterbury using the national $15 \mathrm{~m}$ resolution DEM estimated unrealistic flow paths that cut diagonal lines across the landscape (Section 6.3 and 6.4). 
The reduced accuracy of low-resolution DEMs, when used to model flow pathways, is linked to the importance of estimating flow direction, as the extraction of flow direction is confounded by the presence of flat areas in DEMs (Zhang et al., 2017).

\section{Flow Direction}

LUCl, like many other hydrological models, uses the D8 method to calculate flow directions. The D8 method developed by Jenson and Domingue (1988), calculates the flow direction from a pixel based on the elevation of the eight neighbouring pixels around it. One fundamental assumption in this method is that the main flow path in a flat region is a straight line from inlet to outlet (Garbrecht \& Martz, 1997). This assumption was improved when Barnes et al. (2014) imposed a gradient from higher to lower terrain to help guide flow direction on flat areas. While developments to flow direction algorithms have reduced their computational cost, the problem of calculating flow lines on flat landscapes is not currently resolved and therefore still poses a significant problem in hydrological modelling (Zhang et al., 2017).

As seen in the six case studies analysed in this thesis, flow pathways on rolling-steep terrain follow realistic patterns in the landscape. Accumulated nutrient load pathways for Tuapaka, Greater Wellington, South Canterbury and Otago were calculated using the same D8 method as the flat landscapes of LUDF and North Canterbury. Given the variation in slope length and steepness in this type of terrain, the outflow DEM pixel is in the direction of the neighbouring cell with the most downslope angle (Zhang et al., 2017). As water is modelled to flow in one of eight possible directions, the aggregation of data when a DEM has a large grid size compared to a fine resolution DEM on rolling to steep terrain, does not result in significant variations in estimated flow paths unlike the same aggregation of DEM pixels on a flat landscape.

\section{Vertical Accuracy}

Not only does the resolution of a DEM impact hydrological models, the vertical accuracy of a grid cells' elevation can lead to incorrect mode predictions, and researchers should consider the vertical accuracy of a DEM before model processing begins (Vaze et al., 2010). Of all the DEMs tested in this thesis, the lowest vertical 
accuracy was classified from the National 8m DEM with each elevation point having the potential to range $\pm 10 \mathrm{~m}$ from its given value (Section 5.2.1). The National $15 \mathrm{~m}$ DEM has a vertical accuracy of $\pm 5 \mathrm{~m}$; it is thus advised that the $15 \mathrm{~m}$ DEM is used if there is no finer DEM produced from LiDAR or photogrammetry representing the area being modelled by LUCl.

If LiDAR is available for the area being modelled, especially if the farm and/or catchment is characterised as having areas of flat topography, then fine resolution LiDAR data should be used in the Hydtopo setup stage of the LUCI modelling process. Increased generation of LiDAR by researchers and regional councils is encouraged, as for regions such as Canterbury, the fine resolution LiDAR-based DEMs are the most accurate way to model nutrient flows in the landscape. The LiDAR-based DEMs used in this research have a vertical accuracy of $\pm 0.2 \mathrm{~m}$. Given the unrealistic spatial pattern of accumulated loads generated from the $15 \mathrm{~m}$ DEM, care needs to be taken by Ravensdown Consultants if LiDAR data is unavailable when modelling farms with similar environments to the LUDF and North Canterbury case studies.

\section{Estimated Phosphorus Loss Based on Four Slope Classes}

The topography of a block in OVERSEER can be classed as one of four slopes: flat; rolling; easy hill, and steep hill as outlined in Table 4.4. These four slope classes are used in OVERSEER's phosphorus model to subjectively weight the contribution of the separate slopes to phosphorus loss from soils. The weighting of slope classes is defined by McDowell et al. (2005) as flat (0.15), rolling (0.5), easy (0.75) and steep (1.0), from the assumption that, in general, more phosphorus is lost from soils as the slope increases. This weighting is developed from the United States P index, which used a similar blocking technique. The weighting method targets the movement of particulate phosphorus through the landscape. Currently, OVERSEER does not separate phosphorus lost through leaching with total phosphorus lost from the system, as phosphorus loss via runoff includes both dissolved and particulate phosphorus (Gray et al., 2016a). 
The weighting developed by McDowell et al. (2005) and the documentation surrounding the phosphorus model in OVERSEER does not describe how this subjective weighting was chosen to represent New Zealand slopes, as McDowell et al. (2005 p. 133) states:

"A greater weighting, and influence on P loss, is given to steeper slopes". Either the separate weightings for each slope class were calculated from measured data of phosphorus loss from different slopes, or through an assumption of the relative contribution to phosphorus loss from a system. If the weightings were estimated from trends in measured data, then OVERSEER's simplification would not result in elevated levels of uncertainty. However, without further information on the parameterisation of these four slope classes, we must assume that the assumption of the relative contribution of a slope to phosphorus loss was undertaken without measured field data.

LUCI is spatially explicit and calculates an average slope based on the size of a DEM grid in its phosphorus export coefficient equation and uses a continuous function based on the subjective weighting for OVERSEER slope categories (McDowell et al., 2005) (Section 3.2.1). This assumption in OVERSEER and LUCl affects both models' estimates. $\mathrm{LUCl}$ is impacted as the Ravensdown dataset that LUCl's water quality models were trained on contains phosphorus estimates that may over- or underestimate the contribution of slope to phosphorus loss. The model constants calculated by Trodahl (2018) to minimise the difference between LUCI and OVERSEER's predictions may also bias LUCl's predictions.

\subsection{SENSITIVITY TO LANDCOVER DATA}

The Ravensdown dataset represents the farm management practices of real farm systems, containing actual and predictive nutrient budgets completed between 2011 and 2016 by Ravensdown Consultants (Trodahl, 2018). The challenge is to separate this information on different land use types (dairy, sheep and beef) and attribute this information based on a national land use database, which currently is not freely available. 
Since there is no national land use database available, the regional averages estimated from the Ravensdown database are applied across all areas classified as highproducing grassland in the LCDB4. This has implications for LUCl's application in areas where only regional default landcover data is used, as the average irrigation, nitrogen and phosphorus fertiliser use, effluent applications and stocking rate for each region are biased towards intensive farming practices.

Given that Ravensdown is primarily a fertiliser company, the advice and service provided to farmers targets intensive farming practices. This can be seen in the Ravensdown OVERSEER database with $50 \%$ of blocks classed as dairy, $42 \%$ classed as sheep, beef or deer farms, $3 \%$ classed as mixed pastoral, $2 \%$ classed as fodder and $3 \%$ classed as cropping land use (Trodahl, 2018). The over-representation of dairy farms within the Ravensdown OVERSEER database can also be attributed to the emphasis on nutrient budgeting for dairy farms, with other farm types receiving less pressure from industry groups to carry out such monitoring during the 2011 to 2016 period. While $50 \%$ of the blocks in OVERSEER are classed as dairy, this is not representative of New Zealand's national landuse, for which $9.8 \%$ of total land is classed as dairy and $31.9 \%$ classed as sheep and beef farms (Statistics New Zealand, 2018).

When looking to specific regions, the dominance of some farming practices within the database can be seen. Canterbury made up of $44 \%$ dairy only blocks; $41 \%$ sheep, beef or deer and $5 \%$ in mixed pastoral use (Trodahl, 2018). Although this thesis did not test a case study site in the Waikato, $77 \%$ of OVERSEER blocks in that region were classed as dairy, with only $10 \%$ classed as sheep, beef or deer farms.

This risk of overestimating nutrient loads when farm specific OVERSEER information is not used is evident in the North Canterbury case study (Section 6.3). On this site, total nitrogen load estimates for the S-Map $+2 \mathrm{~m}+$ OVERSEER scenario is 1,954 $\mathrm{kg} \mathrm{N} / \mathrm{yr}$, but when the OVERSEER file is removed, the estimated total nitrogen loss increases to $3,691 \mathrm{~kg} \mathrm{~N} / \mathrm{yr}$ (Table 6.4). Using OVERSEER information in this case study masks the difference between the soil order classifications in FSL and S-Map, as the majority of the farm is classed as having a load value between 5-10 kg N/ha/yr instead of $15-20 \mathrm{~kg}$ 
$\mathrm{N} / \mathrm{ha} / \mathrm{yr}$ for brown soils (and 20-25 kg N/ha/yr for recent soils classed as highproducing grassland in the LCDB4).

The reduction in LUCl's estimates of nitrogen load is a direct response to the difference between the regional stocking rate used from the Ravensdown OVERSEER database when no farm specific OVERSEER information is provided. The regional default value for Canterbury is 21.6 RSU (Table 3.2), a value which is significantly biased towards intensive dairy farms. The modelled stocking rate for the farm in OVERSEER is 5.1 RSU, as this case study site is a low intensity sheep and beef farm with no irrigation, thus pasture production is limited compared to an irrigated dairy platform that can support a higher stocking rate. Phosphorus loads between the OVERSEER and the scenarios containing regional landcover did not vary as much as nitrogen, which shows that phosphorus loss in this case study environment is more strongly linked to the soil properties on a farm than landcover data.

When OVERSEER information is used in the LUCI model, the farm tracks, lanes, house and other areas classed as non-productive land are characterised by regional default data. This results in these areas being assessed to contribute high nutrient loads to the environment. In reality, these areas would be contributing only marginal loads to the environment. To date, there has been no standardised naming system used in OVERSEER for such areas. It is vital that Ravensdown Environmental provide a specific naming system for such non-productive areas, for all consultants who will be modelling farms in OVERSEER and LUCI. The LUCI developers can then tag this classification as having a low nutrient load, and the model will no longer automatically default to regional data.

To avoid large variations in modelled results when regional landcover data is used, particularly in regions with pronounced dairy influence, a method of separating out spatial information based on the land use of an area needs to be developed. This would enable separate regional defaults for dairy, sheep, beef and deer farms which would minimise the overestimation of stock units present on a farm for low-intensive systems. As described in a previous section, LUNZ is a spatial database that separates rural land into individual land uses (Section 5.1.1). While LUNZ cannot be used directly, 
owing to the need for landowner privacy, investment should be made in the establishment of land use classes that can be used in the LUCI model. Datasets like LUNZ and Agribase could be aggregated to larger units in the landscape, thereby limiting the risk to privacy, but still improving on the current land cover knowledge held within the LCDB4.

Another possible development to improve the representativeness of models like LUCI is the incorporation of a dataset to estimate a land parcel's contribution to contaminating the environment. A Land Use Suitability (LUS) concept was proposed by McDowell et al. (2018) which incorporates an assessment of the productive potential of a piece of land and its impact on receiving environments, thereby connecting economic, environmental and social impacts. If such a database was available to LUCI, the model would be able to target and identify at-risk areas based on the landscape attributes, and thus remove the model's reliance on regional values.

Developing a national LUS database would require significant investment from government, research institutes and universities. A LUS database requires understanding three contributing factors for a given land parcel (McDowell et al., 2018):

1. The capacity of a land parcel for primary productivity.

2. The potential of a land parcel to contribute contaminants.

3. The response of the receiving environment to that contaminant.

LUCI is well placed to assist with the development of a LUS approach. With its agricultural productivity model and in-stream nutrient estimates, $\mathrm{LUCl}$ can be used to target specific land parcels that could be further studied to confirm their contribution to environmental effects. It will be a while, however before LUS and LUNZ are capable of guiding LUCl's estimates of nitrogen and phosphorus loss. Test farms should be developed to trial the LUS technique, as it is clear that regional default values do not provide enough information to accurately model a low-intensity farm system. 


\subsection{OBSERVED VS PREDICTED NUTRIENT CONCENTRATIONS}

While instream water quality measurements allow the interpretation of water quality trends, collecting field measurements comes at a high cost. Even given multiple site measurements, high temporal variability in the processes and pathways of nutrient transport limit the reliability of results (Drewry et al., 2006). Land management also plays a factor, with Tyson et al. (1997) finding a mean nitrate leaching loss of $12.9 \mathrm{~kg} \mathrm{~N}$ /ha/yr from grass/clover pastures with no fertiliser nitrogen applications over an eightyear period. Nevertheless, mean nitrate leaching increased to $50 \mathrm{~kg} \mathrm{~N} / \mathrm{ha} / \mathrm{yr}$ when 200 $\mathrm{kg} \mathrm{N} / \mathrm{ha} / \mathrm{yr}$ of fertiliser was applied. The variation in stream quality measurement as a result of land use changes makes it difficult to compare the results between studies. Water quality models need to take into account grazing practices, cultivation, effluent and fertiliser management when modelling farm stream systems (Drewry et al., 2006).

LUCl's stream predictions, when compared to measured concentrations at sampling sites for Tuapaka and Otago, highlight the ability of LUCI to support decision-making in this field. Both sites resulted in stream predictions that were close to measured values. Given that the model was not calibrated to either site, these results indicate LUCI's ability to produce realistic nutrient concentrations when inputs are based on detailed farm-specific data, such as OVERSEER.

For the Otago case study, LUCl's predictions of concentration were targeted to the same sub-catchment where Otago Regional Council (2014) collected samples for the Lake Tuakitoto catchment State of the Environment water quality monitoring programme. The spatially-explicit nature of LUCI means that this tool can be used by decision-makers to target high-risk catchments as priorities for mitigation. For Tuapaka, the farm-specific soil map provided the closest estimate of total nitrogen $0.93 \mathrm{mg} / \mathrm{L}$ to the measured concentration of $0.61 \mathrm{mg} / \mathrm{L}$. This highlights the importance of using detailed soil data where available, as the farm scale soil map classified 56 ha of the farm as brown soil, compared to only 15 ha of brown soil in the FSL.

Burkitt et al. (2016) attempted to minimise errors in the measured nutrient and sediment loads in their ongoing water quality monitoring of the Tuapaka catchment (this research compared predicted nitrogen and phosphorus to measurements taken 
between June 2013 to June 2014). Fortnightly samples were taken, with eight additional samples collected during storm events in rising flow conditions, and in dry periods during falling flow conditions. These additional samples increase the representativeness of the measured water quality results, as storm and flood events can account for a large proportion of annual nutrient load (Letcher et al., 2002). It is not only important to sample a stream during high flow events; multiple sample sites within a catchment will provide information as to which sub-catchments may be contributing excess nutrients. Such detailed information would reduce the knowledge gap in contaminant contributions to streams based on land use in their catchment (Drewry et al., 2006).

This thesis found that $\mathrm{LUCl}$ stream nutrient model predictions were very close to observed in-stream concentrations, however, these results should be treated with a degree of caution. Both of the case studies where predicted concentrations are compared to measured stream data were located in headwater catchments. Headwater catchments are not as complicated as receiving environments (valley bottoms or flat alluvial plains), given that steep slopes are characterised by shallow soil layers. The reduced storage capacity of these shallow soils leads to simpler groundwater dynamics (Ala-aho et al., 2017).

The more complex surface water-groundwater interactions are difficult to simulate in hydrology models. Further investigation is needed regarding LUCI's predictions of total nitrogen and phosphorus on a flat landscape. We suggest that a further case study is developed for a receiving environment. This farm should have a network of streams running through the property (unlike our North Canterbury study, where the majority of the watershed was outside the property boundary). The results for such a site can be compared to the findings of this thesis to determine if LUCl's hydrology, nitrogen and phosphorus models predict realistic concentrations in receiving catchments. 


\section{CHAPTER 8 CONCLUSION}

Degradation of water quality is a significant issue in New Zealand, driven by excesses of nitrogen, phosphorus and sediment loss from agricultural systems. The increasing focus on how to mitigate nutrient losses to water demands user-friendly decision support tools with appropriate levels of detail. One tool that is well placed to support such decisions is $\mathrm{LUCl}$. LUCI identifies ecosystem services, trade-offs and synergies, and allows the user to model past, present and future land use scenarios that impact nitrogen and phosphorus loading among other things. While work to improve $\mathrm{LUCl}$ and apply it to different farm environments is ongoing, this thesis has highlighted how valuable LUCI can already be to decision-makers.

This chapter discusses the key conclusions drawn from the research. To begin, key points drawn from the case studies are summarised. Following this, the research objectives and specific findings associated with each are detailed. Key considerations and future development of the LUCI model are also provided.

The spatial nature of $\mathrm{LUCl}$ accompanied with its recent enhancements allowing input of site specific, spatially detailed landcover, soil and farm system data, means that the model can resolve areas of high nutrient loading at a sub-field scale to target mitigation strategies. While the absolute difference in nutrient load predictions based on the different soil order classifications between the S-Map, FSL and farm scale soil datasets is important, and further work needs to be undertaken to understand where absolute numbers can be relied upon, as long as the soil data used highlights the relative differences in drainage, PAW and clay content of the soil, the model will represent realistic patterns of nutrient loads. Representing realistic nutrient load patterns regardless of the absolute predicted load of an area, will still assist decisionmaking on farm. This research highlighted the dramatic impact of using a low resolution $15 \mathrm{~m}$ DEM, particularly in flat areas, on the spatial distribution of modelled accumulated flow pathways. This impact of the DEM is assumed to be associated not 
only with the horizontal resolution of the data, but also the vertical inaccuracies in the utilised DEM. In hill country settings, the impact of vertical accuracy is not as apparent, as the ridges and troughs within the landscape enable realistic flow patterns to be calculated despite this high vertical error.

Results from the case study areas suggest:

- Since nutrient loading predictions in $\mathrm{LUCl}$ are primarily sensitive to soil order, as long as FSL is broadly representative of the soil orders at the site, the resultant $\mathrm{LUCl}$ predictions will not be too dissimilar to predictions using S-Map data. Key factors that influence where to target mitigation strategies are primarily driven by the location of the accumulated flow pathway and the identification of areas were multiple nutrients can be targeted.

- The multiple ecosystem services and other environmental components that LUCI provide makes this model applicable in a range of environments and for multiple purposes. However, LUCl outputs should be interpreted by someone with specialised knowledge in this field, as the sensitivities and assumptions within the model make it difficult to accurately interpret results. The need for specialised advice is likely to be reduced once automated identification of critical source areas and estimates of the relative impact a mitigation strategy will have on a farm's production level is identified to the user. In the near future this is unlikely, as currently there is no established methodology to achieve this automated processing meaning that $\mathrm{LUCl}$ will always require a degree of expert interpretation. $\mathrm{LUCl}$ is one of the few models able to spatially target nutrient movement through a landscape, and few external off the shelf libraries are available to assist such automation. Updates to allow such functionality are likely to require significant effort directly by LUCI developers.

\subsection{RESEARCH OBJECTIVES AND FINDINGS}

As LUCI can use a variety of soil, topography and landcover data, our primary aim was to examine how the changing quality and resolution of New Zealand's soil, elevation, and landcover datasets impacts the uncertainty in LUCl's output. This was addressed in 
three research objectives. A summary of the findings associated with each objective is presented below.

Objective 1: To conduct a review of available soil, topography and landcover datasets that can be used in the LUCI model.

Chapters 2, 3 and 4 achieve this objective. Chapter 2 summarises the ecosystem services concept and its use in decision-making, after which we review the state of freshwater quality in New Zealand and the effect of agricultural activities in degrading water quality. In Chapter 3, an ecosystem service model (LUCI), and a nutrient budgeting tool (OVERSEER) are described, including the soil water calculations that contribute to each model's respective nitrogen and phosphorus predictions. Both models can inform farm management decisions. The spatially-explicit nature of LUCI enables farmers to quantify nutrient flows, and to identify critical source areas and potential mitigations applicable to their land. This spatial output is complementary to the block based nutrient budget provided by OVERSEER. Chapter 3 identifies the minimum data required to run the LUCI model, and describes New Zealand's regional landcover data sets. Chapter 4 reviews the currently available soil and topography datasets identified in Chapter 3. The spatial extent and resolution of each dataset, and their limitations, is discussed.

Objective 2: To compare LUCl's Nitrogen to Water and Phosphorus to Water tools for sites covering a variety of climates, topography and rich or poor data environments.

Chapter 5 and 6 achieve this objective. In Chapter 5, information on six case study sites is provided that includes a map of each soil dataset, details on the dominant soil series or family on each property and the topography of the landscape. Three of the sites are located in the Manawatu, Greater Wellington and Otago regions, with a further three sites analysed in Canterbury (two on the Canterbury plains and another in the high country). At least two soil maps and two DEMs were tested for each site. A comparison of regional landcover information and farm-specific information from OVERSEER was also carried out for several sites. 
The results of the different data scenarios in $\mathrm{LUCl}$ are presented in Chapter 6, as well as the sensitivity of OVERSEER to different input parameters. These applications of the $\mathrm{LUCl}$ model provide detailed maps of nitrogen and phosphorus loss to water. Results indicate that $\mathrm{LUCl}$ nitrogen and phosphorus results are primarily sensitive to soil order, which often masks the sensitivity of the tools to other datasets. The relative sensitivity of soil and elevation datasets varies between farming systems, indicating that a fine spatial scale and vertically accurate DEM is necessary to model flat landscapes.

Objective 3: To explore whether available datasets are appropriate for accurate model outputs, and how LUCI can be adapted to better use these datasets for improved accuracy where appropriate.

Chapter 7 achieves this objective. Each case study was classified, based on a subjective analysis (Section 7.1). Sites were found to be most sensitive to either soil data or DEM resolution (or in the case of North Canterbury and LUDF, sensitive to both soil and DEM resolution). Tuapaka, South Canterbury and Otago were found to be most sensitive to the soil datasets used, as the rolling-steep hill terrain enabled the lower resolution $15 \mathrm{~m}$ DEM to still realistically model nutrient flows in the landscape. Greater Wellington was most sensitive to the DEM used, as soil order classifications did not vary greatly between FSL and S-Map. Finally, North Canterbury and LUDF were sensitive to both the soil dataset and DEM resolution, due to the flat topography and substantial variation between soil classification in FSL and S-Map. The flat topography at these sites highlights the inability of the low resolution $15 \mathrm{~m}$ DEM to model microtopography and nutrient pathways that a finer resolution and more vertically resolved DEM will pick up.

Compared to in-stream water quality measurements, LUCI predictions at the Tuapaka and Otago case study sites were very similar to the measured values. This result is encouraging but should still be treated with caution until comparisons between observed and modelled data are carried out at a broader range of sites. Issues regarding the representativeness of in-stream water quality measurements exist, such as the representativeness of stream measurements during low and high flow events. Both sites tested in this thesis were located in headwater catchments that, by nature, 
are easier to represent in a hydraulic model due to their more resolved topography and simple groundwater characteristics than those of flat landscapes. Further testing is required to better understand how changing input datasets impacts $\mathrm{LUCl}^{\prime}$ 's hydrology model, particularly in receiving environments.

Over the course of this research, it was highlighted that LUCI might be improved if hydraulic soil data (held at the sibling level in S-Map) was incorporated in LUCl's hydrology model. Different methods of incorporating sibling level data were investigated as well as the default approach used by other models to incorporate only the properties of the dominant sibling. These different methods where: a weighted average approach to sibling soil properties and a random selection of sibling properties to represent a single soil polygon. The variation in PAW, as a result of the different sibling methods used, is represented by the variation in predicted nitrogen and phosphorus concentrations at the South Canterbury site. This site is classified as a mix of brown, recent and pallic soils, with a range of sibling information in each soil polygon, yet the variation in sibling PAW is not extreme. Further study of these three methods of incorporating sibling level information for a site with known variation in soil properties within a soil polygon is recommended as the method developed in the thesis could be used to inform other models that represent soil water dynamics in a landscape, such as OVERSEER.

\subsection{KEY CONSIDERATIONS FOR LUCI MODELLING}

The following considerations, developed through this thesis, should be taken into account before $\mathrm{LUCl}$ is applied to a farm or catchment:

- After collecting all available data for the site (soil, DEM and an OVERSEER file), it is important to discuss with the farmer the available data and identify areas prone to flooding, drought or at risk of soil erosion. While the farmer won't necessarily be able to confirm the precise soil classification mapped on the farm, their understanding of seasonal patterns will help inform the representation of their farm system in LUCl and identify whether soil and other data available for their site is generally correct. 
- Whilst nutrient load results are primarily sensitive to soil order, and thus incorrect soil classifications will impact LUCl's estimates, predicted accumulation nutrient load pathways are generally more sensitive to the DEM used. To accurately target areas that mitigations can be applied to, it is more important to have accurate hydrological information and a fine resolution DEM (when modelling a flat landscape). Regardless of relative load estimates across the farm, mapped accumulated load pathways are the key output to inform the farmer where best to mitigate nutrient loss.

- LUCI produces numerous maps and tables of hydraulic, landcover, soil and nutrient loads on the landscape. Instead of presenting a full portfolio of figures to the farmer, the consultant should consider what is most relevant for each site. It is recommended that a map of the predicted stream paths and concentrations is discussed first, to identify any discrepancies that require model adjustments. Afterwards, load and accumulated load maps should be provided highlighting potential at-risk areas identified by the farmer during the data collection process.

\subsection{FUTURE DEVELOPMENT OF THE LUCI MODEL}

This thesis explored the sensitivity of LUCI to input datasets. The spatially explicit nature of LUCI, unlike OVERSEER, means that the model can be used in conjunction with data representing our best understanding of farm practices. Before this project, advice given to users was to incorporate the finest level of data available, and LiDAR data was considered desirable over the use of a national scale DEM. The results from the six case studies suggests that the national DEM is sufficient to model hill country, but finer resolution such as LiDAR derived datasets is required to pick up the microtopography present on flat landscapes, as shown in the two sites on the Canterbury Plains.

While some areas of future work have been identified in Chapter 7, key recommendations for the development of the LUCI model are:

- To invest more resources in the NSD to increase the number of samples held and the level of analysis carried out at sample sites. Improving our 
understanding of actual measured soil water properties will enhance models like LUCI and OVERSEER and improve the reliability of PTFs that underlie the models' understanding of the soil profile.

- LUCl developers should consider a more explicit way of communicating the sensitivity of LUCI with different datasets. One option is to create a spatial tool that overlays LUCI outputs, and highlights areas where predictions differ significantly. Such a tool would provide similar results to this thesis and would enable the user to quickly communicate uncertainties rather than have to compare the distribution of loads in the underlying model data. The tool could also highlight the differences in the hydrological and topographic outputs on a farm, which would be particularly useful when sibling data is incorporated into the model.

- To test the model in further regions and environments. This thesis applied LUCI in four different regions of New Zealand, including high country and lowland Canterbury. Further work is needed to understand where the model performs best, and where further refinement of the Ravensdown OVERSEER regional information is required. Whilst the stream predictions, for the two case studies with measured stream values, were close to those observed, it is advised that farms with flat topography and measured stream quality data are selected for further analysis and these results compared to what may be more accurate predictions in headwater catchments, such as the two sites tested in this thesis.

\subsection{SUMMARY}

This thesis has successfully tested the sensitivity of LUCI to input soil, elevation and landcover datasets in a range of climates, farm management practices and data-rich vs data-poor environments. The resolution of a DEM was found to be a key determinant of how realistic LUCl's predictions of accumulated load were. This DEM resolution was shown to be particularly important for flat landscapes. The incorporation of sibling level soil information highlights an avenue for future research. Nevertheless, $\mathrm{LUCl}$ as it currently stands is already a useful tool to represent nutrient load and accumulation in the landscape. The explicit spatial nature of the model, combined with the farm management information from OVERSEER, enables the user to map the sources, 
pathways and sinks of nutrients. This thesis has shown the potential LUCI has to represent farm systems under a range of data inputs, suggesting that LUCI has great potential to play a key role, not only in farm scale environmental management, but in the regulation and management of New Zealand's fresh water resources. 


\section{REFERENCES}

Abell, J. M., Özkundakci, D., \& Hamilton, D. P. (2010). Nitrogen and Phosphorus Limitation of Phytoplankton Growth in New Zealand Lakes: Implications for Eutrophication Control. Ecosystems, 13, 966-977.

Abell, J. M., Özkundakci, D., Hamilton, D. P., \& Miller, S. D. (2011). Relationships between land use and nitrogen and phosphorus in New Zealand lakes.

Adams, J. (1980). Contemporary uplift and erosion of the Southern Alps, New Zealand. Geological Society of America Bulletin, 91(1 Part II), 1-114.

Ala-aho, P., Soulsby, C., Wang, H., \& Tetzlaff, D. (2017). Integrated surface-subsurface model to investigate the role of groundwater in headwater catchment runoff generation: a minimalist approach to parameterisation. Journal of Hydrology, 547, 664-677.

Anderson, E. S., J. A. Thompson, D. A. Crouse \& R. E. Austin. (2005). Horizontal resolution and data density effects on remotely sensed LIDAR-based DEM, Geoderma, 132(3-4), 406-415.

Arbuckle, C. (2015). 2015 Stocktake of Regional Council Uses of OVERSEER, Aspiring Environmental Ltd.

Arun, P. V. (2013). A comparative analysis of different DEM interpolation methods. The Egyptian Journal of Remote Sensing and Space Science, 16, 133-139.

Bagstad, K. J., Semmens, D. J., Waage, S., \& Winthrop, R. (2013). A comparative assessment of decision-support tools for ecosystem services quantification and valuation. Ecosystem Services, 5, 27-39.

Ballantine, D. J., \& Davies-Colley, R. J. (2014). Water quality trends in New Zealand rivers: 1989-2009. Environmental Monitoring and Assessment, 186, 1939-1950.

Barnes, R., Lehman, C. \& Mulla, D. (2014). Priority-flood: an optimal depression-filling and watershed-labelling algorithm for digital elevation models. Computers \& Geosciences, 62, 117-127.

Barringer, J. R. F., \& Lilburne, L. (1997). An evaluation of digital elevation models for upgrading New Zealand land resource inventory slope data. GeoComputation, $97,15-22$. 
Barringer, J., Hewitt, A., Lynn, I., \& Schmidt, J. (2008). National mapping of landform elements in support of S-Map, a New Zealand soils database. Advances in Digital Terrain Analysis, 443-458.

Barringer, J.R.F., Lilburne, L., Carrick, S., Webb, T., \& Snow, V. (2016). What difference does detailed soil mapping make? A Canterbury case study. In Integrated nutrient and water management for sustainable farming. (Eds L.D. Currie and R. Singh). http://flrc.massey.ac.nz/publication.html. Occasional Report No. 29. Fertilizer and Lime Research Centre, Massey University, Palmerston North, New Zealand. 12 pages.

Basher, L. R. (2013). Erosion processes and their control in New Zealand. Ecosystem Services in New Zealand-conditions and trends, 363-374.

Beef and Lamb New Zealand. (2018). Compendium of New Zealand Farm Facts $42^{\text {nd }}$ Edition. Publication No. P18010.

Breure, A. M., De Deyn, G. B., Dominati, E., Eglin, T., Hedlund, K., Van Orshoven, J., \& Posthuma, L. (2012). Ecosystem services: a useful concept for soil policy making! Current Opinion in Environmental Sustainability, 4, 578-585.

Buol, S. W., Southard, R. J., Graham, R. C., \& McDaniel, P. A. (2011). Soil Genesis and Classification. John Wiley \& Sons.

Burkitt, L., M. Bretherton, R. Singh \& M. Hedley. (2016). Comparing Nutrient Loss Predictions Using OVERSEER and Stream Water Quality in a Hill Country SubCatchment. In: Currie, L. D. \& R. Singh (eds) Integrated Nutrient and Water Management for Sustainable Farming, Massey University, Palmerston North. Fertilizer and Lime Research Centre, p 9.

Burman, R.D., \& Pochop, L.O. (1994). Evaporation, evapotranspiration and climate data. In Elsevier Science, 22, Amsterdam, Netherlands.

Carrick, S., Hainsworth, S., Lilburne, L., \& Fraser, S. (2014). S-MAP@ THE FARM-SCALE? TOWARDS A NATIONAL PROTOCOL FOR SOIL MAPPING FOR FARM NUTRIENT BUDGETS. Nutrient Management for the Farm, Catchment and Community. Landcare Research, New Zealand

Carrick, A, S., Vesely, B, É.T., \& Hewitt, A, A. (2010). Economic value of improved soil natural capital assessment: a case study on nitrogen leaching. In 19th World Congress of soil science, soil solution for a changing world, Brisbane, Australia. 
Cerovski-Darriau, C., \& Roering, J. J. (2016). Influence of anthropogenic land-use change on hillslope erosion in the Waipaoa River Basin, New Zealand. Earth Surface Processes and Landforms, 41(15), 2167-2176.

Cichota, R., Vogeler, I., Snow, V., \& Webb, T. (2013). Ensemble PTFs to derive hydraulic properties for New Zealand soils. Soil Research, 51(2), 94-111.

Columbus, J., Sirguey, P., \& Tenzer, R. (2011). A Free Fully Assessed 15 m DEM for New Zealand. Survey Quarterly, 66, 16-19.

Cornforth, I.S. \& Sinclair, A.G. (1982). Model for calculating maintenance phosphate requirements for grazed pastures. New Zealand Journal of Experimental Agriculture, 10, 53-61.

Cosgrove, G.P., Clark, D.A. \& Lambert, M.G. (2003). High production dairy-beef cattle grazing systems: a review of research in the Manawatu. Proceedings of the New Zealand Grassland Association, 65, 21-28.

Cressie, N. (2015). Statistics for spatial data. John Wiley \& Sons.

Davies-Colley, R. J. (2013). River water quality in New Zealand: an introduction and overview. Ecosystem Services in New Zealand: Conditions and Trends. Manaaki Whenua Press, Lincoln, 432-447.

Derose , R. C., Trustrum , D.A., Thomson, N.A. \& Roberts A,H,C. (1995). Effect of landslide erosion on Taranaki hill pasture production and composition, New Zealand Journal of Agricultural Research, 38 (4), 457-471.

Dominati, E. J. (2013). Natural capital and ecosystem services of soils. In Dymond, J.R. ed. Ecosystem services in New Zealand-Conditions and trends. Manaaki Whenua Press, Lincoln, New Zealand (pp. 132-142).

Dong, P., \& Chen, Q. (2017). LiDAR Remote Sensing and Applications. CRC Press. Douglas, G. B.; Trustrum, N. A.; \& Brown, I. C. (1986). Effect of soil slip erosion on Wairoa hill pasture production and composition. New Zealand Journal of Agricultural Research, 29, 183-192.

Drewry J. J., Newham L. T. H., Greene R. S. B., Jakeman A. J. \& Croke B. F. W. (2006). A review of nitrogen and phosphorus export to waterways: context for catchment modelling. Marine and Freshwater Research, 57, 757-774. 
Drewry, J. J. (2006). Natural recovery of soil physical properties from treading damage of pastoral soils in New Zealand and Australia: A review. Agriculture, Ecosystems \& Environment, 114(2-4), 159-169.

Duncan, R. (2017). Rescaling Knowledge and Governance and Enrolling the Future in New Zealand: A Co-Production Analysis of Canterbury's Water Management Reforms to Regulate Diffuse Pollution. Society and Natural Resources, 30(4), 436-452. https://doi.org/10.1080/08941920.2016.1265187

Elkhrachy, I. (2017). Vertical accuracy assessment for SRTM and ASTER Digital Elevation Models: A case study of Najran city, Saudi Arabia. Ain Shams Engineering Journal. https://doi.org/10.1016/J.ASEJ.2017.01.007

Elsheikh, S. \& Guercio, R. (1997). GIS topographical analysis applied to unit hydrograph models: Sensitivity to DEM resolution and threshold area. In Baumgartner $M F$, Schultz G A, and Johnson I (eds) Remote Sensing and Geographic Information Systems for Design and Ope ation of Water Resources Systems. Wallingford, International Association of Hydrological Sciences Publication No 242: 245-253.

Emmett, B. A., Cooper, D., Smart, S., Jackson, B., Thomas, A., Cosby, B., ... \& Jones, D. L. (2016). Spatial patterns and environmental constraints on ecosystem services at a catchment scale. Science of The Total Environment, 572, 1586-1600.

FAO. (2014). The State of Food and Agriculture: Innovation in family farming. Rome. Retrieved from http://files/21/a-i4040e.pdf

FAO. (2016). The State of Food and Agriculture: Climate change, agriculture and food security. Rome: FAO. Retrieved from http://files/19/a-i6030e.pdf

Ferrier, S., Ninan, K. N., Leadley, P., Alkemade, R., Acosta, L. A., Akçakaya, H. R., ... \& Kabubo-Mariara, J. (2016). The Methodological Assessment Report on Scenarios and Models of Biodiversity and Ecosystem Services. Secretariat of the Intergovernmental Platform for Biodiversity and Ecosystem Services, Bonn, Germany.

Fertiliser and Lime Research Centre. (2016). Sustainable Nutrient Management in New Zealand Agriculture. Massey University, Palmerston North, New Zealand.

Fertiliser Association of New Zealand. (2009). Fertiliser Use on New Zealand Sheep and Beef Farms. Wellington, New Zealand. 
Fisher, P.F. \& Tate, N.J. (2006). Causes and consequences of error in digital elevation models. Progress in Physical Geography, 30 (4), 467-489.

Foote, K. J., Joy, M. K., \& Death, R. G. (2015). New Zealand Dairy Farming: Milking Our Environment for All Its Worth. Environmental Management, 56, 709-720.

Freeman, M., Robson, M., Lilburne L., McCallum-Clark, M., Cooke, A. \& McNae, D. (2016). Using OVERSEER in regulation - technical resources and guidance for the appropriate and consistent use of OVERSEER by regional councils, August 2016. Report prepared by Freeman Environmental Ltd for the OVERSEER Guidance Project Board.

Fryer, J. G., Chandler, J. H., \& Cooper, M. A. R. (1994). On the accuracy of heighting from aerial photographs and maps: Implications to process modellers. Earth Surface Processes and Landforms, 19(6), 577-583.

Garbrecht, J. \& Martz, L.W. (1997). The assignment of drainage direction over flat surfaces in raster digital elevation models. Journal of Hydrology, 193(1-4), 204213.

Geographx. (2017). Geographx Home. In http://geographx.co.nz. Accessed 26 Oct 2017.

Giltrap, D. J., \& Hewitt, A. E. (2003). Pedotransfer functions for soil moisture, porosity and bulk density. Manual for national soils database. Landcare Research,(NZ) Ltd, 18-33.

Gray, C., Wheeler, D. \& McDowell, R. (2016a). Review of the phosphorus loss submodel in OVERSEER. AgResearch.

Gray, C. W., Wheeler, D. M., Mcdowell, R. \& Watkins, N. L. (2016b). OVERSEER and Phosphorus : Strengths and Weaknesses. In Integrated Nutrient and Water Management for Sustainable Farming. (Eds L.D. Currie and R.Singh). http://flrc.massey.ac.nz/publications.html. Occasional Report No. 29. Fertilizer and Lime Research Centre, Massey University, Palmerston North, New Zealand. 7 pages.

Grealish, G., Carrick, S. \& Manderson, A. (2018). Farm-scale soil mapping protocols for New Zealand. In Farm environmental planning - Science, policy and practice. (Eds L. D. Currie and C. L. Christensen). http://flrc.massey.ac.nz/publications.html. 
Occasional Report No. 31. Fertilizer and Lime Research Centre, Massey University, Palmerston North, New Zealand. 7 pages.

Groffman, P. M. \& E. J. Rosi-Marshall. (2012). The Nitrogen Cycle. In Weathers, K. C., D. L. Strayer \& G. E. Likens (eds) Fundamentals of Ecosystem Science. Elsevier, Boston.

Hewitt, A. (2010). New Zealand Soil Classification. Lincoln, New Zealand: Manaaki Whenu Landcare Research New Zealand Ltd.

Hewitt, A. (2013). Survey of New Zealand Soil Orders. In Ecosystem services in New Zealand: conditions and trends (pp. 121-131). Lincoln, New Zealand: Manaaki Whenua Press.

Hewitt, A., Barringer, J. R. F., Claydon, J. J., Campbell, S., Carrick, S., Fraser, S., ... Ritchie, A. (2012). National soils database- a review and process for development (Landcare Research Contract Report No. LC 1033). Lincoln, New Zealand: Landcare Research.

Hewitt, A.E. (1989). New Zealand Soil Classification (version 2.0). DSIR Division of Land and Soil Sciences, Technical Record DN2. 93 p.

Hodgson, M.E., Jensen, J.R., Schmidt, L., Schill, S. \&Davis, B. (2003). An evaluation of LiDAR and IFSAR-derived digital elevation models in leaf-on conditions with USGS Level 1 and Level 2 DEMs. Remote Sensing of Environment, 84 (2), 295-308. Holmes, K. W., Chadwick, O. A. \& Kyriakidis, P. C. (2000). Error in a USGS 30-meter digital elevation model and its impact on terrain modeling. Journal of Hydrology, 233(1-4), 154-173.

Hooke R.L. (2000). On the history of human as geomorphic agent. Geology, 28: 843846.

Hutchinson, M. (2011). User guide. ANUDEM VERSION 5.3 USER GUIDE (Vol. 1). https://doi.org/10.4337/9781782545583.00006

Jackson, B., Metherell, A., Roberts, A., Trodahl, M. \& White, M. (2016). ADAPTION OF THE LUCI FRAMEWORK TO ACCOUNT FOR DETAILED FARM MANAGEMENT: A CASE STUDY EXPLORING POTENTIAL FOR NUTRIENT MITIGATION USING DATA FROM THE SOUTHLAND DEMONSTRATION FARM. In Integrated nutrient and water management for sustainable farming. Retrieved from http://files/47/Paper_Jackson_2016.pdf 
Jackson, B., Pagella, T., Sinclair, F., Orellana, B.M., Henshaw, A., Reynolds, B, ..., \& Eycott, A. (2013). Polyscape: A GIS mapping framework providing efficient and spatially explicit landscape-scale valuation of multiple ecosystem services. Landscape and Urban Planning, 112, 74-88.

Jay, M. (2007). The political economy of a productivist agriculture: New Zealand dairy discourses. Food Policy, 32(2), 266-279.

Jenson, S.K. \& Domingue, J.O. (1988). Extracting topographic structure from digital elevation data for geographic information system analysis. Photogrammetric engineering and remote sensing, 54(11), 1593-1600.

Jones, H., Clough, P., Hock, B., \& Phillips, C. (2008). Economic costs of hill country erosion and benefits of mitigation in New Zealand: Review and recommendation of approach. Report by Scion, NZIER and Landcare Research Ltd to Ministry of Agriculture and Forestry.

Journeaux, P. (2016). Valuation of the Benefits of the OVERSEER ${ }^{\circledR}$ Nutrient Budget Model. Agfirst Waikato Ltd.

Kienzle, S. (2004). The effect of DEM raster resolution on first order, second order and compound terrain derivatives. Transactions in GIS, 8,83-112.

Kienzle, S.W. (1994). The application of a GIS-Grid system for hydrological and geomorphological analysis. In Proceedings of the Fourth Symposium on Terrain Evaluation and Data Storage, 3-5 August, Midrand, South Africa.

Konarska, K. M., Sutton, P. C. \& Castellon, M. (2002). Evaluating scale dependence of ecosystem service valuation: a comparison of NOAA-AVHRR and Landsat TM datasets. Ecological Economics, 41(3), 491-507.

Kummu, M., de Moel, H., Porkka, M., Siebert, S., Varis, O. \& Ward, P. J. (2012). Lost food, wasted resources: Global food supply chain losses and their impacts on freshwater, cropland, and fertiliser use. Science of The Total Environment, 438, 477-489.

Land and Water Forum. (2017). In http://www.landandwater.org.nz/. Accessed 01 Nov 2017.

LINZ. (2017a). Elevation data. In https://data.linz.govt.nz/group/nationalelevation/data/category/elevation/. Accessed 18 Oct 2017. 
LINZ. (2017b). LINZ Data Service. In https://data.linz.govt.nz/layer/51768-nz-8mdigital-elevation-model-2012/metadata/. Accessed 18 Oct 2017.

LINZ. (2017c). NZ 8m Digital Elevation Model (2012). In

https://www.linz.govt.nz/data/linz-data/elevation-data. Accessed 18 Oct 2017.

LRIS. (2018). https://Iris.scinfo.org.nz/layer/48423-Icdb-v41-land-cover-databaseversion-41-mainland-new-zealand/metadata/. Accessed 24 April 2018.

LRIS. (2017). FSL New Zealand Soil Classification. In

https://Iris.scinfo.org.nz/layer/48079-fsl-new-zealand-soil-classification/. Accessed 05 Aug 2017.

LRIS. (2018). NZDEM 25metre. In https://Iris.scinfo.org.nz/layer/48131-nzdem-northisland-25-metre/. Accessed 10 June 2018.

Landcare Research. (2012). Review of soil carbon measurement methodologies and technologies, including nature and intensity of sampling, their uncertainties and costs. Landcare Research Contract Report: LC0910/083.

Landcare Research. (2017a). NSDR Viewer. In

https://viewernsdr.landcareresearch.co.nz/search. Accessed 05 Aug 2017.

Landcare Research. (2017b). S-Map Online. In https://smap.landcareresearch.co.nz/. Accessed 05 Aug 2017.

Landcare Research. (2018a). Soil Report. Generated by https://smap.landcareresearch.co.nz

Landcare Research. (2018b). Describing Soils. In https://soils.landcareresearch.co.nz/index.php/describing-soils/about-soilnames/. Accessed 25 April 2018.

Landcare Research. (2018c). National Soils Data Repository. https://viewernsdr.landcareresearch.co.nz/search. Accessed 25 April 2018.

Landcare Research. (2018d). Describing Soils, Semiarid Soils. In https://soils.landcareresearch.co.nz/describing-soils/nzsc/soil-order/semiaridsoils. Accessed 30 May 2018.

Letcher, R. A., Jakeman, A.J., Calfas, M., Linforth, S., Baginska, B. \& Lawrence, I. (2002). A comparison of catchment water quality models and direct estimation techniques. Environmental Modelling \& Software, 17, 77-85. 
Lilburne, L., Hewitt, A., \& Ferriss, S. (2009). Progress with the design of a soil uncertainty database, and associated tools for simulating spatial realisations of soil properties. In 7th International Symposium on Spatial Accuracy Assessment in Natural Resources and Environmental Sciences, (pp. 5510-5519).

Lilburne, L., Hewitt, A., Webb, T. H., \& Carrick, S. (2004). S-Map: a new soil database for New Zealand. In SuperSoil 2004: Proceedings of the 3rd Australian New Zealand Soils Conference, Sydney, Australia (pp. 5-9).

Lilburne, L., Webb, T., Palmer, D., McNeill, S., Hewitt, A., \& Fraser, S. (2014). Pedotransfer functions from S-Map for mapping water holding capacity, soilwater demand, nutrient leaching vulnerability and soil services. Nutrient Management for the Farm, Catchment and Community.

Lilburne, L.R., Hewitt, A.E., Webb, T.H. (2012). Soil and informatics science combine to develop S-map: a new generation soil information system for New Zealand. Geoderma 170, 232-238.

Lindeman, R. (1942). The trophic-dynamic aspect of ecology. Ecology, 23, 399-418. Liu, X., Zhang, Z., Peterson, J., \& Chandra, S. (2007). The effect of LiDAR data density on DEM accuracy (pp. 1363-1369). Modelling and Simulation Society of Australia and New Zealand Inc. Retrieved from https://eprints.usq.edu.au/00003781/

Lloyd, C., \& Atkinson, P. M. (2006). Deriving ground surface digital elevation models from LiDAR data with geostatistics. International Journal of Geographical Information Science, 20(5), 535-563.

Longhurst, R. D., Roberts, A. H. C., \& O'Connor, M. B. (2000). Farm dairy effluent: a review of published data on chemical and physical characteristics in New Zealand. New Zealand Journal of Agricultural Research, 43(1), 7-14.

Macara, G.R. (2015). The climate and weather of Otago. NIWA Science and Technology Series 67.

Marsh, G. P. (1864). Man and Nature. New York: Charles Scribner.

Martin, A. P., Turnbull, R. E., Rattenbury, M. S., Cohen, D. R., Hoogewerff, J., Rogers, K. M., ... Christie, A. B. (2016). The regional geochemical baseline soil survey of southern New Zealand: Design and initial interpretation. Journal of Geochemical Exploration, 167, 70-82. 
Mascara, G.R. (2016). The climate and weather of Canterbury. NIWA Science and Technology Series, number 68.

Massey University. (2018). Tuapaka Farm. http://www.massey.ac.nz/massey/aboutmassey/subsidiaries-commercial-ventures/massey-agricultural-experimentstation/tuapaka-farm/tuapaka-farm.cfm Accessed 26042018.

McCauley, A., Jones, C., \& Jacobsen, J. (2005). Basic soil properties (Soil and Water Management Module 1). Montana State University.

McDowell, R. W., Monaghan, R. M., \& Wheeler, D. (2005). Modelling phosphorus losses from pastoral farming systems in New Zealand. New Zealand Journal of Agricultural Research, 48(1), 131-141.

McDowell, R. W., Snelder, T., Harris, S., Lilburne, L., Larned, S. T., Scarsbrook, M., ... \& Taylor, K. (2018). The land use suitability concept: Introduction and an application of the concept to inform sustainable productivity within environmental constraints. Ecological Indicators, 91, 212-219.

McLaren, R., \& Cameron, K. (1996). Soil Science : Sustainable Production and Environmental Protection / R.G. McLaren, K.C. Cameron.

McNeill, S. J., Lilburne, L. R., Carrick, S., Webb, T. H., \& Cuthill, T. (2018). PTFs for the soil water characteristics of New Zealand soils using S-map information. Geoderma, 326, 96-110.

McRae, A. (2003). Historical and practical aspects of profitability in commercial beef production systems. Proceedings of the New Zealand Grassland Association. 65: 29-34.

Meng, X., Currit, N., \& Zhao, K. (2010). Ground filtering algorithms for airborne LiDAR data: A review of critical issues. Remote Sensing, 2(3), 833-860.

Menneer, J., Ledgard, S., McLay, C., \& Silvester, W. (2001). What impact does dairy cow pugging have on clover $\mathrm{N} \sim 2$ fixation and long-term farm production? In PROCEEDINGS OF THE CONFERENCE-NEW ZEALAND GRASSLAND ASSOCIATION (pp. 63-68).

Metherell, A.K. \& Morrison, J.D. (1984). "Guidelines for the MAF Computerised Fertiliser Advisory Service (CFAS)." 23 pp. Ministry of Agriculture and Fisheries, Wellington. 
Millennium Ecosystem Assessment. (2005). Ecosystem and Human Wellbeing (Vol 5). Island Press, Washington, DC.

Ministry for the Environment. (2001). Valuing New Zealand's clean green image: Consultation document. ME 405, Wellington: Ministry for the Environment. Ministry for the Environment. (2006). Lake water quality in New Zealand. Status in 2006 and recent trends 1990-2006. Ministry for the Environment, Wellington, New Zealand. 74 p.

Ministry for the Environment. (2007). Snapshot of Lake Water Quality in New Zealand4 State and Trends of New Zealand: Consultation document. Wellington: Ministry for the Environment.

Ministry for the Environment. (2016). Next steps for fresh water: Consultation document. Wellington: Ministry for the Environment

Moir, J. L., Cameron, K. C., \& Di, H. J. (2007). Nutrient management on the Lincoln University dairy farm:" nutrient budgeting for efficient production". Centre for Soil and Environmental Research, Lincoln University.

Monaghan, R. M., Laurenson, S., Dalley, D. E., \& Orchiston, T. S. (2017). Grazing strategies for reducing contaminant losses to water from forage crop fields grazed by cattle during winter. New Zealand Journal of Agricultural Research, 60(3), 333-348.

Monaghan, R. M., Wilcock, R. J., Smith, L. C., Tikkisetty, B., Thorrold, B. S., \& Costall, D. (2007). Linkages between land management activities and water quality in an intensively farmed catchment in southern New Zealand. Agriculture, Ecosystems \& Environment, 118, 211-222.

Mooney, H., \& Ehrlich, P. (1997). Ecosystem Services: A Fragmented History. In in Nature's Services: Societal Dependence on Natural Ecosystems, 11-19. Island Press.

Moore, I. D., Grayson, R. B., \& Ladson, A. R. (1991). Digital Terrain Modelling : A Review of Hydrological Geomorphological and Biological Applications. Hydrological Processes, 5(1), 3-30.

NIWA. (2015). Fine sediment effects on freshwaters, and the relationship of environmental state to sediment load: A literature review. Hamilton: National Institute of Water and Atmospheric Research Ltd. 
Nossent, J., \& Bauwens, W. (2012). Multi-variable sensitivity and identifiability analysis for a complex environmental model in view of integrated water quantity and water quality modeling. Water science and technology, 65(3), 539-549.

Octariady, J., Hikmata, A., Widyaningruma, E., Mayasaria, R. \& Fajaria, M.K. (2017). VERTICAL ACCURACY COMPARISON OF DIGITAL ELEVATION MODEL FROM LIDAR AND MULTITEMPORAL SATELLITE IMAGERY. The International Archives of the Photogrammetry, Remote Sensing and Spatial Information Sciences. Volume XLII1/W1, 2017 ISPRS Hannover Workshop: HRIGI 17 - CMRT 17 - ISA 17 - EuroCOW 17, 6-9 June 2017, Hannover, Germany.

OpenTopography. (2018). SRTM Version 3.0 Global (90m). In

http://www.opentopography.org/news/srtm-version-30-global-90m-and-unitedstates-30m-elevation-data-now-available. Accessed: 10 June 2018.

Otago Regional Council. (2014). Water quality and ecosystem health in the Lake Tuakitoto catchment. Otago Regional Council, Dunedin.

OVERSEER. (2017). OVERSEER ${ }^{\circledR}$ Nutrient Budgets: supporting New Zealand's primary industries. In https://www.OVERSEER.org.nz/. Accessed 31 Oct 2017.

OVERSEER. (2018). User Guides. In https://www.OVERSEER.org.nz/users-guides. Accessed 07 March 2018.

Paerl, H. W. (2009). Controlling Eutrophication along the Freshwater-Marine Continuum: Dual Nutrient ( $\mathrm{N}$ and $\mathrm{P}$ ) Reductions are Essential. Estuaries and Coasts, 32(4), 593-601.

Parliamentary Commissioner for the Environment. (2012). Water Quality in New Zealand: Understanding the Science. Wellington, Ministry for the Environment. Parliamentary Commissioner for the Environment. (2016). The state of New Zealand's environment: Commentary by the Parliamentary Commissioner for the Environment on 'Environment Aotearoa 2015'. Wellington, Ministry for the Environment.

Parris, K. (2011). Impact of Agriculture on Water Pollution in OECD Countries: Recent Trends and Future Prospects. International Journal of Water Resources Development, 27(1), 33-52. 
Pearse, G., Moltchanova, E., \& Bloomberg, M. (2015). Assessment of the accuracy of profile available water and potential rooting depth estimates held within New Zealand. Soil Research, 53(7), 737-744.

Pollacco, J.A.P., Lilburne, L.R., Webb, T.H. \& Wheeler, D.M. (2014). Preliminary assessment and review of soil parameters in OVERSEER.6. Landcare Research.

Pollok, J. \& McLaughlin, B. (1986). A user-friendly guide to the soils of Tuapaka Farm, Publication No. 3. Massey University Tuapaka Farm Series, Palmerston North.

Power, A. G. (2010). Ecosystem services and agriculture: trade-offs and synergies. Philosophical Transactions of the Royal Society B: Biological Sciences, 365, 29592971.

Qiu, W., Curtin, D., Johnstone, P., Beare, M., \& Hernandez-Ramirez, G. (2016). SmallScale Spatial Variability of Plant Nutrients and Soil Organic Matter: An Arable Cropping Case Study. Communications in Soil Science and Plant Analysis, 47(19), 2189-2199.

Roberts, L., Brower, A., Kerr, G. N. \& Wratten, S. (2015). The nature of wellbeing: how nature's ecosystem services contribute to the wellbeing of New Zealand and New Zealanders. Department of Conservation, Wellington.

Rutledge, D., Price. R., Briggs, C. \& Cowell, S. (2009). Geospatial Land-use Classification for New Zealand: review and recommendations. Official Statistics Research Series, 5

Ruttenberg. K.C. (2003). The Global Phosphorus Cycle. In Treatise on Geochemistry, 8, $585-643$.

Schilling, K. E., Gassman, P. W., Kling, C. L., Campbell, T., Jha, M. K., Wolter, C. F., \& Arnold, J. G. (2014). The potential for agricultural land use change to reduce flood risk in a large watershed. Hydrological Processes, 28(8), 3314-3325.

Semadeni-Davies, A., Hughes, A., \& Elliott, S. (2015). Assessment of the CLUES model for the implementation of the National Policy Statement on Freshwater Management in the Auckland region. Prepared by NIWA for Auckland Council. Auckland Council technical report, TR2015/014 (Vol. 4525).

Sharps, K., Masante, D., Thomas, A., Jackson, B., Redhead, J., May, L., Prosser, H., Cosby, B., Emmett, B., \& Jones, L. (2017). Comparing strengths and weaknesses 
of three ecosystem services modelling tools in a diverse UK river catchment. Science of the Total Environment, 584,118-130.

Shepherd, M., Wheeler, D, and Selbie, D, Buckthought L., \& Freeman, M. (2013).

OVERSEER $^{\circledR}$ : Accuracy, precision, error and uncertainty. In: Accurate and efficient use of nutrients on farms. (Eds L.D. Currie and C L. Christensen). http://flrc.massey.ac.nz/publications.html. Occasional Report No. 26. Fertilizer and Lime Research Centre, Massey University, Palmerston North, New Zealand. 8 pages.

SIDDC. (2018). LU Dairy Farm. http://www.siddc.org.nz/lu-dairy-farm/. Accessed: 19 March 2018.

Statistics New Zealand. (2018). Agricultural and horticultural land use.

http://archive.stats.govt.nz/browse for stats/environment/environmentalreporting-series/environmental-indicators/Home/Land/land-use.aspx. Accessed: 19 June 2018.

Study of Critical Environmental Problems. (1970). Man's Impact on the Global Environment. Cambridge, Mass: MIT Press.

Sulieman, S., \& Tran, L. (2015). Legume Nitrogen Fixation in a Changing Environment Achievements and Challenges. Springer International Publisher.

Sustainable Agriculture and Education. (2012). Management of Nitrogen and Phosphorus. In Building Soils for Better Crops 3rd Edition.

https://www.sare.org/Learning-Center/Books/Building-Soils-for-Better-Crops3rd-Edition/Text-Version/Management-of-Nitrogen-and-Phosphorus

Tanner, C., Muirhead, R., Burger, D., Carrick, S., \& Close, M. (2017). a Framework for Understanding the Linkages Between Land and Water Quality Impacts. Science and policy: Nutrient management challenges for the next generation, 1-10.

Taylor, N.H. (1948). Soil Map of New Zealand, 1:2,027,520 scale. DSIR, Wellington. Thompson, J. A., Bell, J. C., \& Butler, C. A. (2001). Digital elevation model resolution: Effects on terrain attribute calculation and quantitative soil-landscape modelling. Geoderma, 100(1-2), 67-89.

Trodahl, M. I., Jackson, B. M., Deslippe, J. R., \& Metherell, A. K. (2017). Investigating trade-offs between water quality and agricultural productivity using the Land 
Utilisation and Capability Indicator (LUCI)-A New Zealand application. Ecosystem Services, 26, 388-399.

Trodahl, M.I. (2018). Improving and parameterising nitrogen and phosphorus modelling for application of $\mathrm{LUCl}$ in New Zealand (unpublished doctoral dissertation). Victoria University of Wellington, Wellington.

Trodahl, M.I., Deslippe, J.R. \& Jackson, B.M. (2017). Improving predictions of N \& P export to waterways from rural landscapes in New Zealand using LUCI. In: Integrated nutrient and water management for sustainable farming. (Eds L.D. Currie and R. Singh). http://flrc.massey.ac.nz/publication.html. Occasional Report No. 29. Fertilizer and Lime Research Centre, Massey University, Palmerston North, New Zealand. 7 pages.

Trustrum, N. A., Thomas, V. J. \& Lambert, M. J. (1984). Soil slip erosion as a constraint to hill country pasture production. Proceedings of the New Zealand Grassland Association, 45, 66-71.

Tscharntke, T., Klein, A. M., Kruess, A., Steffan-Dewenter, I. \& Thies, C. (2005). Landscape perspectives on agricultural intensification and biodiversity ecosystem service management. Ecology Letters, 8, 857-874.

Tyson, K. C., Scholefield, D., Jarvis, S. C., and Stone, A. C. (1997). A comparison of animal output and nitrogen leaching losses recorded from drained fertilized grass and grass/clover pasture. The Journal of Agricultural Science, 129, 315-323. United Nations Population Division. (2015). World Population Prospects: The 2015 Revision, Key Findings and Advance Tables. Retrieved from https://esa.un.org/Unpd/wpp/Publications/Files/Key_Findings_WPP_2015.pdf Vadas, P. A., Busch, D. L., Powell, J. M., \& Brink, G. E. (2015). Monitoring runoff from cattle-grazed pastures for a phosphorus loss quantification tool. Agriculture, Ecosystems \& Environment, 199, 124-131.

Van Bysterveldt, A. (2005). Lincoln University dairy farm, now a cropping farm? South Island Dairy Event. http://www.side.org.nz/Papers

Vaze, J., Teng, J., \& Spencer, G. (2010). Impact of DEM accuracy and resolution on topographic indices. Environmental Modelling \& Software, 25(10), 1086-1098.

Vogt, W. (1948). Road to Survival. New York: William Sloan. 
Wallace, K. J. (2007). Classification of ecosystem services: Problems and solutions. Biological Conservation, 139(3-4), 235-246.

Watkins, N. \& Selbie, D. (2015). Technical Description of OVERSEER for Regional Councils. AgResearch Contract Report RE500/2015/084.

Watkins, N., Smith, C., \& Brown, H. (2013). Crop input guidelines for OVERSEER Nutrient Budgets' model (No. RE500/2013/071). Foundation of Arable Research. Watson, D.F. (1992). Contouring: A Guide to the Analysis and Display of Spatial Data, Pergamon Press, London.

Webb, T.H. (2003). Identification of functional horizons to predict physical properties for soils from alluvium in Canterbury, New Zealand. Australian Journal of Soil Research, 41, 1005-1019.

Webb, T.H., \& Lilburne, L.R. (2011). Criteria for defining the soil family and soil sibling : the fourth and fifth categories of the New Zealand Soil Classification. Lincoln, N.Z. : Manaaki Whenua Press, Landcare Research.

Webb, T.H., Claydon, J.J. \& Harris, S.R. (2000). Quantifying variability of soil physical properties within soil series to address modern land-use issues on the Canterbury Plains, New Zealand. Soil Research, 38(6), 1115-1129.

Webb, T.H., \& Wilson, A.D. (1995). A manual of land characteristics for evaluation of rural land. Manaaki Whenua Press.

Wheeler, D. (2016a). OVERSEER Technical Manual: Characteristics of Soils. AgResearch. Wheeler, D. (2016b). OVERSEER Technical Manual: Hydrology. AgResearch White, M., Harmel, D., Yen, H., Arnold, J.G., Gambone, M. \& Haney, R. (2015). Development of sediment and nutrient export coefficients for US ecoregions. JAWRA Journal of the American Water Resources Association, 51(3), 758-775.

Wilde, R. H. (2003). Manual for national soils database. Landcare Research: Palmerston North, New Zealand. Retrieved from http://files/162/nsd manual v1.pdf Wilkinson, B. H. \& McElroy, B. J. (2007). The impact of humans on continental erosion and sedimentation. Bulletin of the Geological Society of America, 119, 140-156.

Wösten, J. H. M., Pachepsky, Y. A., \& Rawls, W. J. (2001). Pedotransfer functions: bridging the gap between available basic soil data and missing soil hydraulic characteristics. Journal of Hydrology, 251(3), 123-150. 
Zhang, H., Yao, Z., Yang, Q., Li, S., Baartman, J. E., Gai, L., ... \& Geissen, V. (2017). An integrated algorithm to evaluate flow direction and flow accumulation in flat regions of hydrologically corrected DEMs. Catena, 151, 174-181.

Zhang, W. \& Montgomery, D. R. (1994). Digital elevation model grid size, landscape representation, and hydrologic simulations. Water Resources Research, 30, 1019-28.

Zhang, W., Ricketts, T. H., Kremen, C., Carney, K. \& Swinton, S. M. (2007). Ecosystem services and dis-services to agriculture. Ecological Economics, 64(2), 253-260. 


\section{APPENDIX A: THE FIFTEEN KEY ATTRIBUTES USED TO DESCRIBE SOILS IN THE FSL.}

These fall into three categories: soil fertility/toxicity (F); soil physical properties (P), and topography/ climate $(\mathrm{T})$. Unless otherwise stated, the source of this information is Webb and Wilson (1995).

\begin{tabular}{|c|c|}
\hline Soil attribute & Description \\
\hline Slope (T) & $\begin{array}{l}\text { The topography of a landscape affects management and production costs } \\
\text { as the land's susceptibility to erosion increases with an increase in slope. } \\
\text { Also, an increase in slope reduces the ease of access to a piece of land by } \\
\text { heavy machinery. }\end{array}$ \\
\hline $\begin{array}{l}\text { Potential } \\
\text { rooting depth } \\
\text { (P) }\end{array}$ & $\begin{array}{l}\text { Depth to a layer within the soil subsurface that may physically impede } \\
\text { root extension. The soil characteristics known to influence root } \\
\text { development are penetration resistance, aeration, water retention and } \\
\text { sharp contrasts between soil horizons (e.g. compact horizons and } \\
\text { cemented layers). Calculation of potential rooting depth is achieved } \\
\text { through the measurement of penetrability with depth (penetration } \\
\text { resistance or density estimates through the soil column, with the layer } \\
\text { that restricts root penetration defined when the penetration resistance } \\
\text { exceeds } 3000 \mathrm{kPa} \text { ). }\end{array}$ \\
\hline $\begin{array}{l}\text { Topsoil gravel c } \\
\text { content }(\mathrm{P})\end{array}$ & $\begin{array}{l}\text { Percentage of gravel content in the top } 20 \mathrm{~cm} \text { of the soil profile. The } \\
\text { degree of stoniness affects the hydraulic characteristics of the soil, having } \\
\text { both positive and negative effects on crop production and land } \\
\text { management. Stony topsoils can damage instruments, and in very } \\
\text { extreme levels have marked negative effects on plant growth. However, } \\
\text { positive effects of high quantities of stones in topsoils are seen in soil } \\
\text { temperature and drainage properties. }\end{array}$ \\
\hline $\begin{array}{l}\text { Proportion of } \\
\text { rock outcrop }(\mathrm{P})\end{array}$ & $\begin{array}{l}\text { These represent practical problems of access and hazards to crop } \\
\text { cultivation and are defined as a percentage of the land cover made up of } \\
\text { rock outcrops (this includes surface boulders). Areas that have more than } \\
25 \% \text { of the landscape covered in rock outcrops are determined to be an } \\
\text { extremely rocky environment. }\end{array}$ \\
\hline $\mathrm{pH}(\mathrm{F})$ & $\begin{array}{l}\text { The } \mathrm{pH} \text { value of a soil affects plant growth through its influence on } \\
\text { nutrient availability and the presence of toxins. Since it is difficult to alter }\end{array}$ \\
\hline
\end{tabular}




\begin{tabular}{|c|c|}
\hline & $\begin{array}{l}\text { the } \mathrm{pH} \text { level below the topsoil, adverse } \mathrm{pH} \text { levels have a dramatic effect } \\
\text { on the productivity of an area. }\end{array}$ \\
\hline Salinity (F) & $\begin{array}{l}\text { Estimates of salinity are calculated through the measurement of soluble } \\
\text { salts and electrical conductivity of the soil water extracted from the soil } \\
\text { profile. The salinity of soil is determined by the horizon with the highest } \\
\text { conductivity in the upper } 0.6 \mathrm{~m} \text { of the soil. }\end{array}$ \\
\hline $\begin{array}{l}\text { Cation } \\
\text { exchange } \\
\text { capacity (F) }\end{array}$ & $\begin{array}{l}\text { Estimating the cation exchange capacity of a soil provides information on } \\
\text { its buffering capacity, as the higher the cation exchange capacity, the } \\
\text { greater a soil's ability to absorb chemical contaminants. This greater } \\
\text { absorption capability means that these soils can retain nutrients (such as } \\
\text { calcium, magnesium and potassium) and cations against leaching. Cation } \\
\text { exchange sites are present on the surface of clay particles and organic } \\
\text { matter, consequently, soils with large amounts of clay or organic matter } \\
\text { have a high cation exchange capacity. }\end{array}$ \\
\hline Tota & $\begin{array}{l}\text { Quantifying soil carbon stocks and rates of change is important } \\
\text { knowledge for national greenhouse gas inventories. The calculation } \\
\text { involves multiplying the mass of the material collected from within a } \\
\text { known ground area by the carbon concentration of that material, this is } \\
\text { then scaled spatially over the area of interest (Landcare Research, 2012). }\end{array}$ \\
\hline $\begin{array}{l}\text { Phosphorus } \\
\text { retention (F) }\end{array}$ & $\begin{array}{l}\text { Phosphorus retention is closely linked to the cation exchange capacity as } \\
\text { the higher the cation exchange capacity, the higher the phosphorus } \\
\text { retention. The retention of phosphorus in topsoil horizons is an important } \\
\text { determinant of the structural stability of the soil. }\end{array}$ \\
\hline $\begin{array}{l}\text { Flood return } \\
\text { interval }(T)\end{array}$ & $\begin{array}{l}\text { Flooding is defined as the temporary covering of the soil surface by } \\
\text { flowing water from any source. The probability of an area flooding is } \\
\text { important to understand when making land management decisions as it } \\
\text { will influence what type of land use is applied to an area. In the absence } \\
\text { of flood risk data from regional councils, estimates of flood frequency can } \\
\text { be gauged from soil profile and vegetation data. Different risk } \\
\text { classifications are derived for an area based on the calculated flood } \\
\text { return interval. An area that has a flood return interval of less than } 1 \text { in } 5 \\
\text { years is classed as having a very severe flood risk, with an area with a } \\
\text { flood return interval of } 1 \text { in } 60 \text { years classed as having a slight risk. }\end{array}$ \\
\hline
\end{tabular}




\begin{tabular}{|l|l|}
\hline $\begin{array}{l}\text { Soil } \\
\text { temperature (T) }\end{array}$ & $\begin{array}{l}\text { Soil temperature regimes are based on the mean annual soil temperature } \\
\text { at } 0.3 \mathrm{~m} \text { depth and the number of days above } 5^{\circ} \mathrm{C} \text { and } 20^{\circ} \mathrm{C} \text {. The number } \\
\text { of days above } 5^{\circ} \mathrm{C} \text { denotes time above biological zero, which is important } \\
\text { as growing conditions are not present below this temperature. }\end{array}$ \\
\hline $\begin{array}{l}\text { Total profile } \\
\text { available water }\end{array}$ & $\begin{array}{l}\text { The amount of soil water available for plant growth (stored within the top } \\
\text { one meter of soil) is an important part of maximising crop production, } \\
\text { and determining the frequency of irrigation required to maintain growth. }\end{array}$ \\
\hline Profile readily & $\begin{array}{l}\text { While this attribute is similar to total profile available water, it denotes } \\
\text { the amount of water held in the soil that is easily absorbed by plants (not } \\
\text { (P) wust an estimate of the potential water available). Conditions that affect } \\
\text { the availability of water within the soil are the presence of root barriers } \\
\text { (as plants can only extract water where roots can grow), and as soil dries } \\
\text { out it becomes more difficult for plants to extract water. }\end{array}$ \\
\hline Drainage (P) & $\begin{array}{l}\text { The drainage characteristics of a soil provide an indication of how long a } \\
\text { soil or part of a soil is saturated, and how quickly it can rid itself of the } \\
\text { excess water. Drainage is an important factor in the supply of oxygen to } \\
\text { the plant root zone and how often the soil is saturated. The division of } \\
\text { soils into different drainage classes is determined by looking at the colour } \\
\text { (chroma) of soil with depth. }\end{array}$ \\
\hline deep) (P) & $\begin{array}{l}\text { Macroporosity is a measure of the proportion of large pores in the soil } \\
\text { and is usually expressed as a percentage of the total volume of soil. } \\
\text { Macroporosity details the air-filled porosity of the soil at field capacity, } \\
\text { where large soil pores are filled with both air and water and the small } \\
\text { pores are still full of water as the water has yet to drain. }\end{array}$ \\
\hline
\end{tabular}




\title{
APPENDIX B: PAPER SUBMITTED TO MASSEY UNIVERSITY'S FERTILISER AND LIME RESEARCH CENTRE WORKSHOP 2018
}

Taylor, A. I, Jackson. B.M. and Metherell, A. K 2018. Evaluating the uncertainties in New Zealand's GIS datasets; understanding where and when framewodks such as LUCI can enable robust decisions surrounding farm monagement practices. In: Farm onironmwntal pilovining Science, policy and practice (Eds L. D. Curie and C. L Christensen). hitp://frc massey. ac nzpublications hrml. Occasional Report No. 31. Fertilizer and Lime Research Centre, Massey University, Palmerston North. New Zealand. 12 pages

EVALUATING THE UNCERTAINTIES IN NEW ZEALAND'S GIS DATASETS; UNDERSTANDING WHERE AND WHEN FRAMEWORKS SUCH AS LUCI CAN ENABLE ROBUST DECISIONS SURROUNDING FARM MANAGEMENT PRACTICES

\author{
Alicia Taylor ${ }^{1,2}$, Bethanna Jackson ${ }^{1}$ \& Alister Metherell ${ }^{2}$ \\ ${ }^{I}$ School of Geography, Environment \& Earth Sciences, Victoria University of Wellington, Wellington \\ ${ }^{2}$ Ravensdown Ltd, Christchurch \\ Email:Alicia.Taylor@ravensdown.co.nz
}

\section{Introduction}

The connection between agricultural activities and water quality degradation is not new, with many studies identifying forms of diffuse pollution such as nitrogen, phosphorus and sediment emitted from intensive agriculture. While the quantities of nutrients lost from agriculture are not large compared to the total nutrients residing in the soil-plant-animal system, the transfer of nutrients from agricultural land to water causes significant environmental impact (Monaghan et al., 2007). With increasing attention on more sustainable land-use practices and mitigating the impact of agricultural intensification on the environment, decision support tools like the Land Utilisation and Capability Indicator (LUCI) are well suited to aid agricultural management, at both small and large scales (Trodahl et al., 2017).

This paper discusses how the varying quality and resolution of New Zealand's soil and elevation datasets impact LUCI's output. One case study is presented on the application of LUCI's Nitrogen to Water and Phosphorus to Water tools to a farm located on the Canterbury plains. Four different data combinations are carried out, using both freely and nationally available topography and soil data in the form of the NZSoSDEM $15 \mathrm{~m}$ national digital elevation model (DEM) generated by the Otago School of Surveying (available from koordinates.com) and the Fundamental Soil Layer (FSL- available from https://ris.scinfo.org.nz/). The two remaining datasets are not currently freely available or of full national coverage, with the $2 \mathrm{~m}$ DEM sourced from Environment Canterbury and S-Map soil data available under license from Landcare Research (smap.landcareresearch.co.nz).

\section{LUCI}

LUCI, described in detail in Jackson et al. (2013); Sharps et al. (2017); and Trodahl et al. (2017) is a GIS-based framework that explores land management scenarios to identify locations where changes in land use might deliver improvements in ecosystem services, or where trade-offs between services are present (Sharps et al., 2017). The algorithms in LUCI include an exploration of the impacts of land management changes on flood risk, habitat connectivity, erosion and sedimentation, nutrient movements, carbon sequestration and agricultural productivity. This research is solely focused on LUCI's ability to model and track the flow of nitrogen, phosphorus and sediment across the landscape to waterways.

A benefit of using LUCI to model and understand the complex interaction between nutrients, sediment and water quality on a farm system is that it is spatially explicit. Using the different 
tools within the framework the user can track changes across the entire farm, or within smaller blocks, enabling mitigation strategies that improve water quality to be effectively targeted. Minimum base data required for LUCI is a DEM, soil and land cover data. These can be sourced from nationally available datasets. However, the addition of further national or local data along with stakeholder consultation can improve the accuracy of LUCI's output (Figure 1).

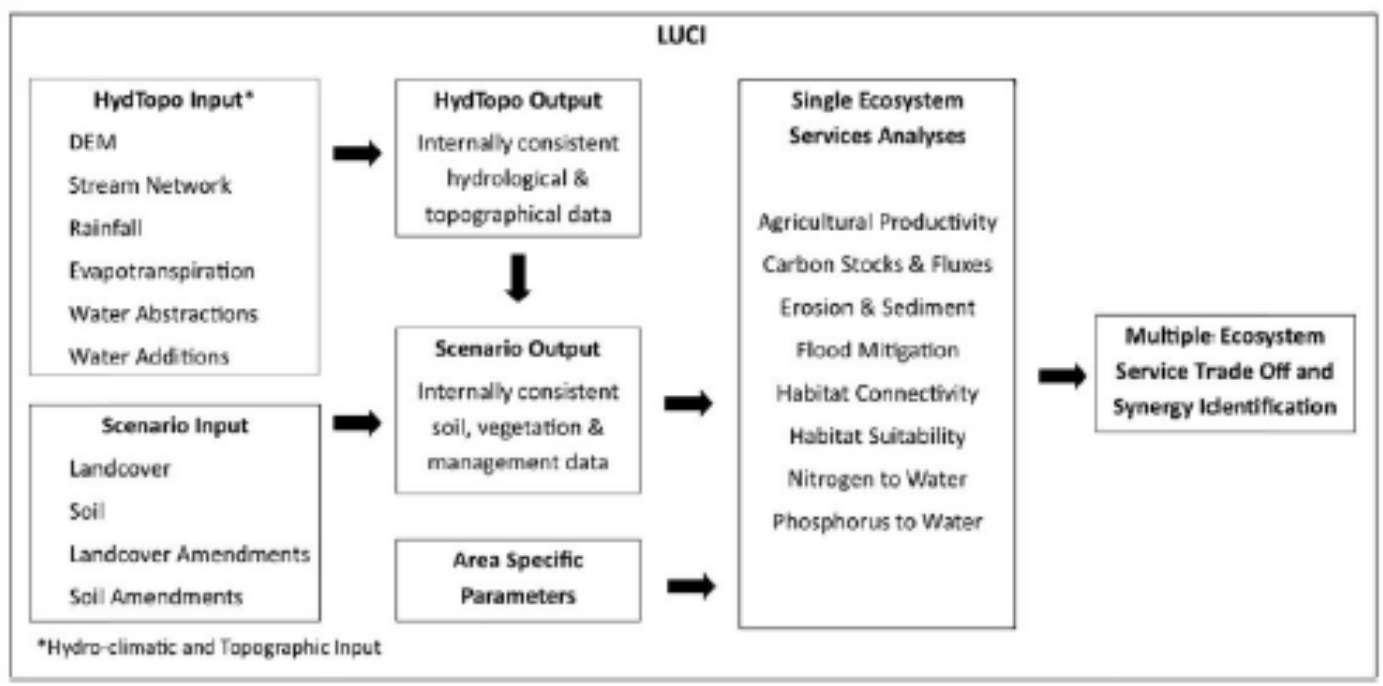

Figure 1- LUCI process diagram, based on Figure 1 in Trodahl et al. (2017)

The Nitrogen to Water and Phosphorus to Water tools use an export coefficient approach to model nitrogen and phosphorus lost to water in $\mathrm{kg} / \mathrm{ha} / \mathrm{yr}$. The export coefficient approach describes the rate at which a contaminant is input into a water body per unit of source area, in this case, the unit area is one DEM grid cell (White et al. 2015). These export coefficients are linked to land cover classification, climate and region being modelled and are commonly used to represent the movement of diffuse pollution in the landscape (Trodahl et al., 2017).

\section{Soil Data}

To test how varying quality and resolution of New Zealand's soil data effects LUCI's output, two soil maps were used to produce estimates of nitrogen and phosphorus lost from one site. The Fundamental Soil Layer combines the polygons in the New Zealand Land Resource Inventory (NZLRI) with the soil data from the National Soil Database (NSD). In the Canterbury region, this information was based on the original Plains and Downs Survey at a scale of 1:126 720 (Kear et al. 1967). Expert knowledge along with consultation with stakeholders merged the existing soil profiles and determined the seventeen soil attributes that the FSL describes (Barringer et al., 2016). The second dataset used, S-map, has been under development since 2003 and is the newest soil database covering New Zealand. This dataset incorporates the historic data held within the NSD with new soil surveys and fills in data gaps with an inference engine which uses rule-based validation to infer soil properties if unavailable from the measured data (Lilburne et a1., 2012). S-Map is designed to be used at scales between 1:50 000 and 1:20 000 and users need to consider the implications of using this dataset outside of the scale of analysis it was designed for (S-MapOnline, 2018).

\section{Topographic Data}

The only nationally available DEMs are derived from the LINZ NZTopo50 database with 20 $\mathrm{m}$ contours. Columbus et al. (2011) interpolated a $15 \mathrm{~m}^{2} \mathrm{DEM}$ from this data choosing this resolution as a balance providing a DEM of reasonable spatial resolution, without creating a 
file so large that it would often be impractical to be used in research. National coverage of LiDAR (Light Detecting and Ranging) data is not yet available. However, regional councils hold LiDAR data over some or (in the case of Greater Wellington) all of their region, which can be used to create fine resolution DEMs if researchers are allowed access. LINZ is actively procuring LiDAR data from the separate databases held by councils and private companies to facilitate access (LINZ, 2018).

\section{Case Study: North Canterbury}

The study site is a 309 ha sheep and beef farm located in North Canterbury in the Ashley watershed (Figure 2). The terrain is mostly flat, with a mix of brown, pallic and recent soil orders (Figure 3). There is a steep escarpment and one permanent stream on the property. FSL and S-Map soil datasets and DEMs at $15 \mathrm{~m}$ and $2 \mathrm{~m}$ resolution are available for this study site. For the results presented in this paper land cover data is taken from the national LCDB4 database which classed $67 \%$ of the farm area as high producing grassland and $23 \%$ as rotational cropland (Figure 4). The other smaller areas classified were exotic forest, gorse and deciduous hardwoods.

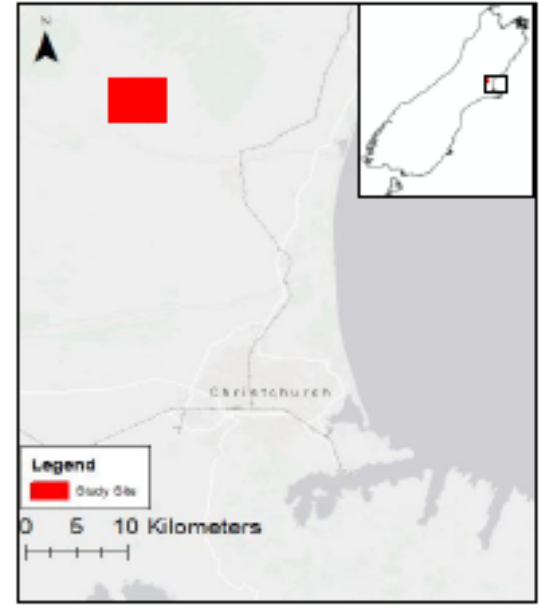

Figure 2- Location of study site.

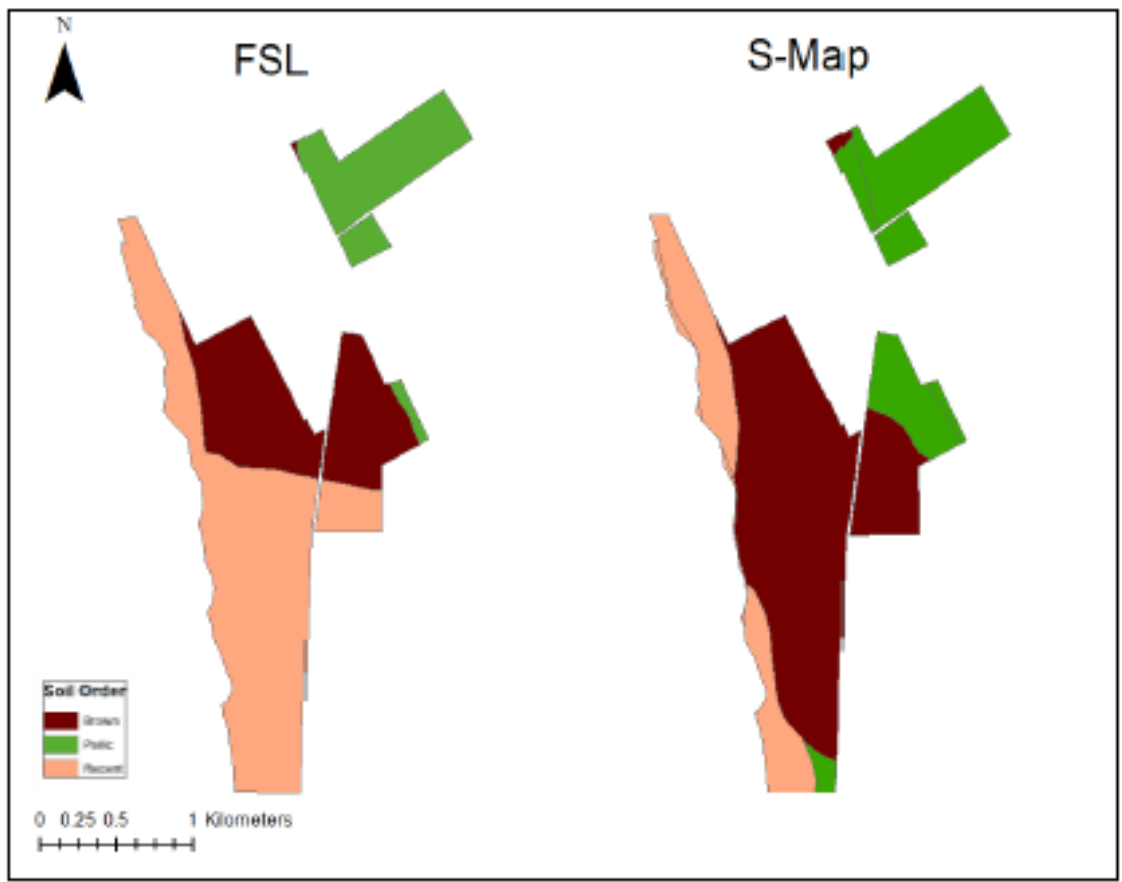

Figure 3- Soil order classification in FSL and S-Map. 


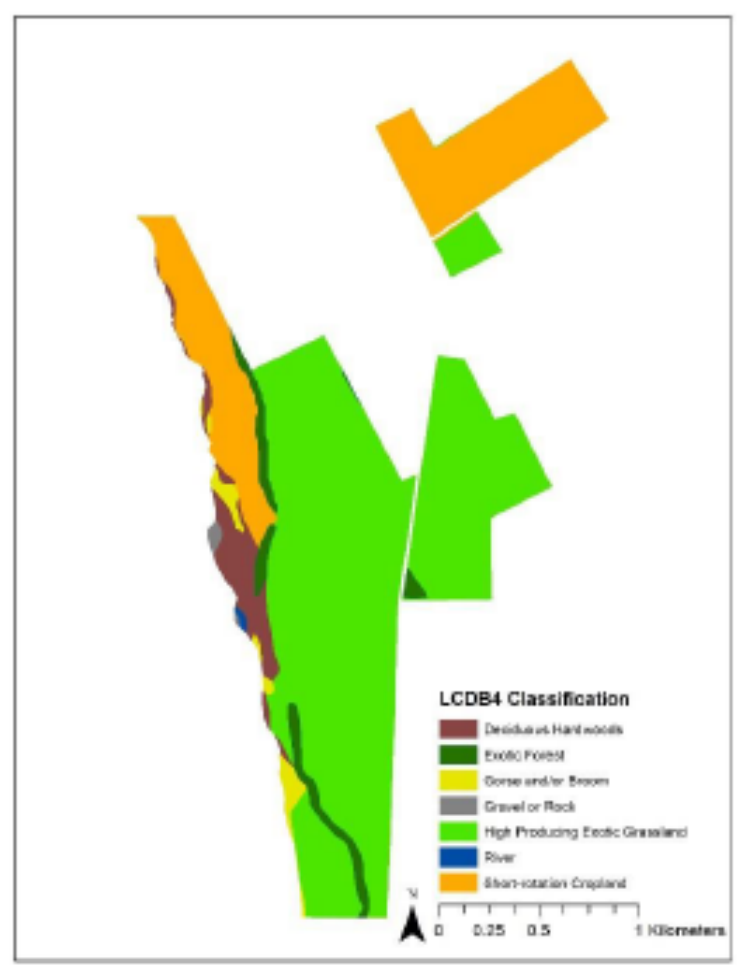

\section{Method}

LUCI water quality models (Nitrogen to Water and Phosphorus to Water) were run using four combinations of soil and topographic data (Table 1). In general, default parameters were used, except when the default values clearly showed a deviation from the real word characteristic of the landscape. The nitrogen and phosphorus load estimates were then analysed in Matlab to understand the distribution of load estimates and the probability of a loads occurrence on the landscape. In Matlab the load results from each cell were then summed across the landscape to calculate the total load on the farm in $\mathrm{kg}$ $\mathrm{N}(\mathrm{P}) / \mathrm{yr}$.

Figure 4- Land use classification in the LCDB4

Table 1- Data input for the four LUCI applications

\begin{tabular}{|l|l|l|}
\hline LUCI Application & Soil Data & Topographic Data \\
\hline S-Map $2 \mathrm{~m}$ & S-Map $(1: 50000)$ & LiDAR $(2 \mathrm{~m})$ \\
\hline S-Map $15 \mathrm{~m}$ & S-Map $(1: 50000)$ & National DEM $(15 \mathrm{~m})$ \\
\hline FSL $2 \mathrm{~m}$ & FSL $(1: 126720)$ & LiDAR $(2 \mathrm{~m})$ \\
\hline FSL $15 \mathrm{~m}$ & FSL $(1: 126720)$ & National DEM $(15 \mathrm{~m})$ \\
\hline
\end{tabular}

\section{Results and Discussion}

LUCI Nitrogen to Water and Phosphorus to water tools produce a variety of outputs that allow the user to explore total nitrogen and phosphorus loads on the landscape $(\mathrm{kg}$ nutrient $/ \mathrm{ha} / \mathrm{yr})$ and accumulated total loads ( $\mathrm{kg}$ nutrient $/ \mathrm{yr}$ ). Accumulated load considers the nutrient load at any point plus the contribution to that cell from "uphill" sources (Jackson et al., 2013). The results are represented by a traffic light colour scheme where red indicates high nutrient loads and green indicates low nutrient loads (note this is a reversal of the original colour scheme presented in Jackson et al. (2013), in use until a change in 2017).

Nitrogen loads from the four applications are shown in Figure 5 and nitrogen accumulated load is shown in Figure 6. The distribution of high and low nitrogen loads can be seen to follow the pattern of each applications input soil data (Figure 3). The changing ratio of brown, pallic and recent soil order classifications across the farm when using the newer, S-Map dataset, resulted in the reduction in the high load estimates classified as recent soil in the FSL as this area was reclassified as a brown soil. The area classified as pallic soil remained as a low nitrogen load. This was expected as pallic soils leach less nitrogen due to increased denitrification and lower drainage rates compared to well drained recent and brown soils (Pollacco et al., 2014). 
While the highest estimates of total nitrogen load remain the same for the applications using identical soil data, the two FSL applications estimated a higher total nitrogen load, as shown in Table 2. The highest total nitrogen load was $4,443 \mathrm{~kg} \mathrm{~N} / \mathrm{yr}$ calculated from FSL $15 \mathrm{~m}$, with the second highest estimate from FSL $2 \mathrm{~m}$, this pattern is present in the total estimates of phosphorus as well. This indicates that the source of soil data plays a more significant role on the results of total nutrient loads then the resolution of the DEM.

However, when looking at the outputs of accumulated nutrient load on the landscape, the effect of the different soil datasets is not apparent and instead, the changing resolution of the DEM is the main cause of difference between the applications. When looking at the accumulated loads of S-Map $2 \mathrm{~m}$ and S-Map $15 \mathrm{~m}$, it is apparent that the $15 \mathrm{~m}$ DEM is estimating different pathways to the $2 \mathrm{~m}$ DEM and this is the same when comparing FSL $2 \mathrm{~m}$ and FSL $15 \mathrm{~m}$. Since LUCI estimates accumulated load using a topographic routing algorithm that associates soil, climate, slope based on the grid size of the DEM provided, when using a lower resolution DEM, the microtopography present on the farm is not picked up by the algorithm and the accumulated load patterns are not realistic in this relatively flat landscape. LUCI's estimates of accumulated load differ between DEM resolution regardless of what soil dataset is used. 


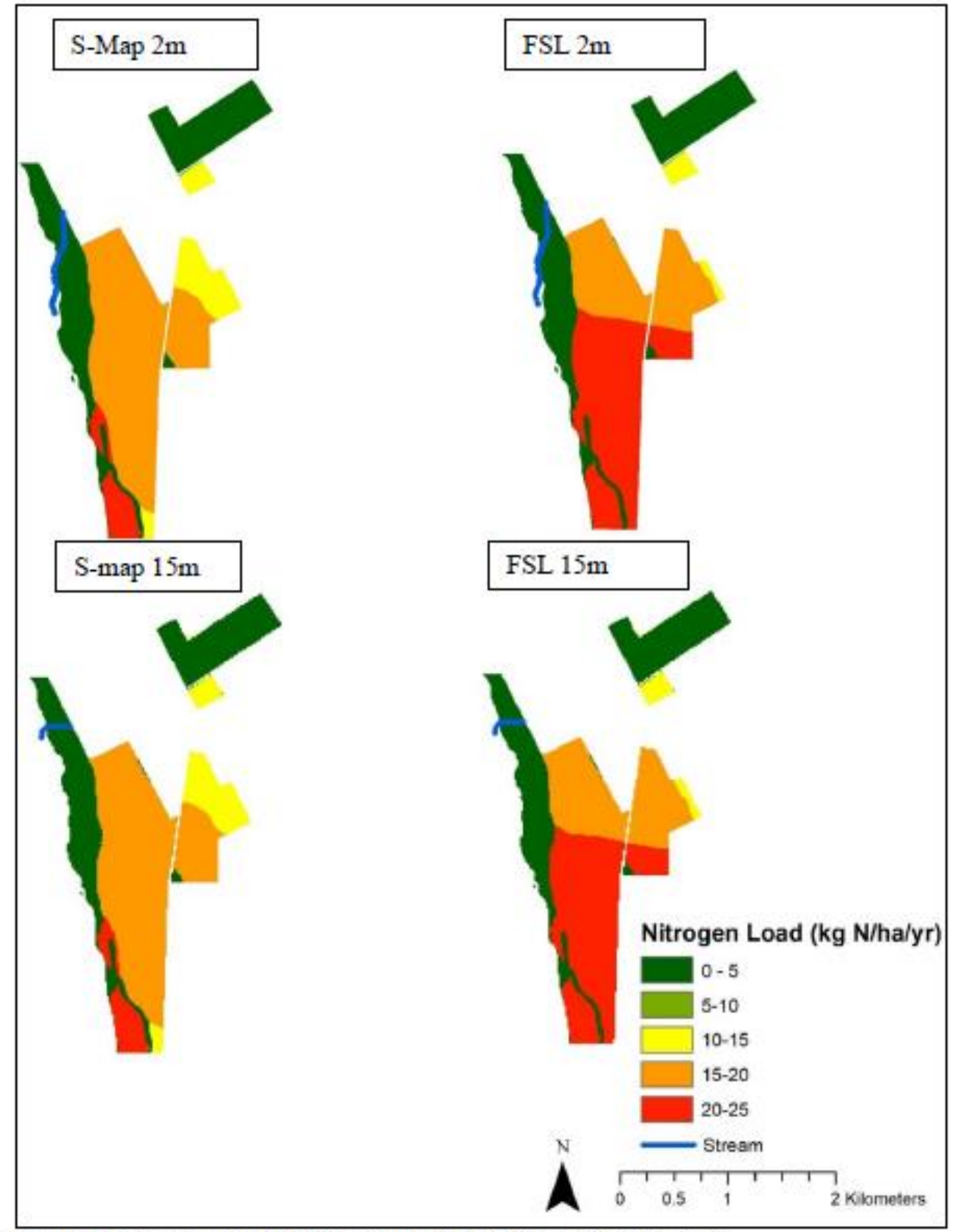

Figure 5-LUCI's estimates of Nitrogen Load using all data input scenarios. 


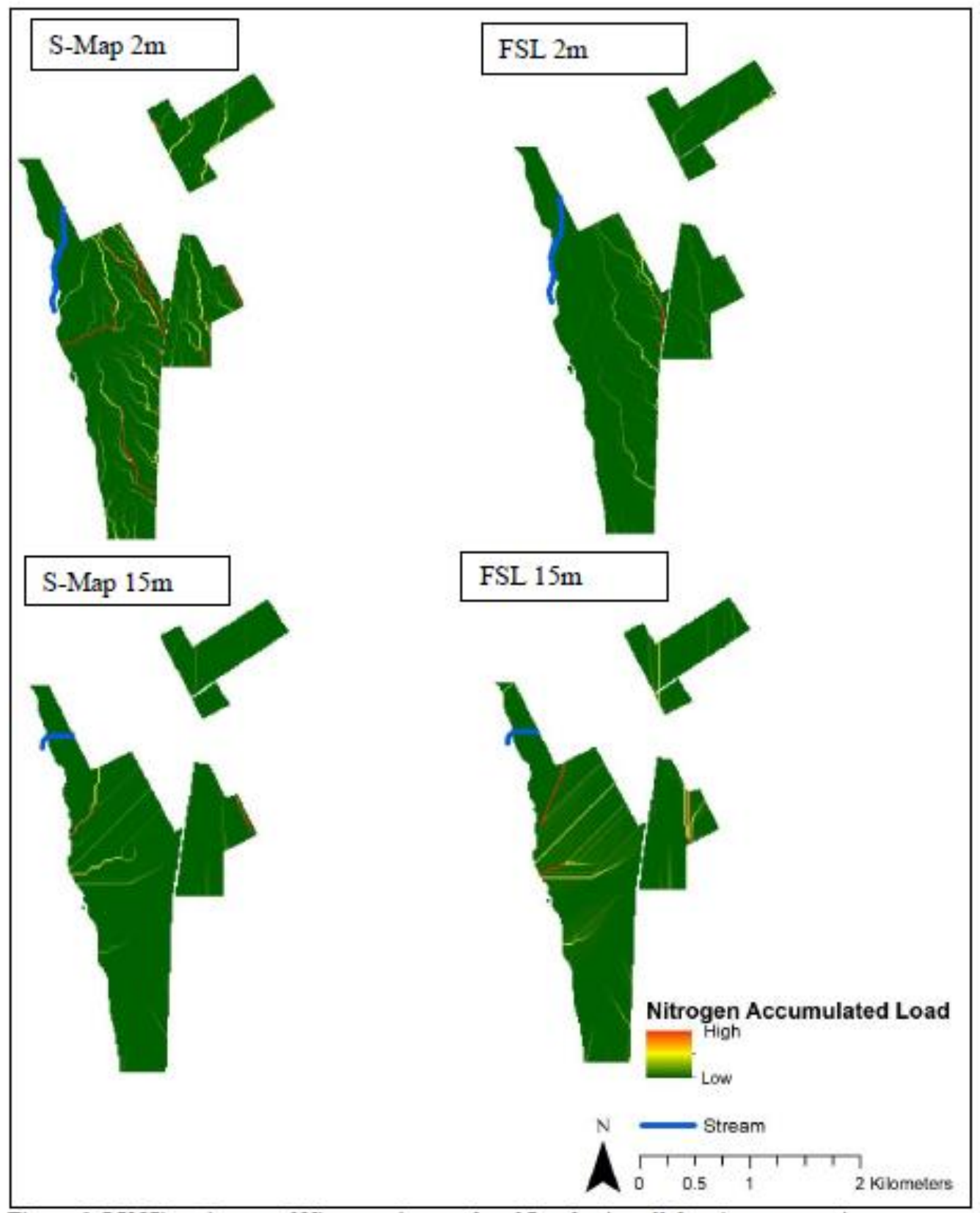

Figure 6-LUCT's estimates of Nitrogen Accumulated Load using all data input scenarios.

Table 2- Total Nitrogen Loads calculated from all applications

\begin{tabular}{|l|r|r|}
\hline LUCI Application & $\begin{array}{l}\text { Total Nitrogen } \\
\text { Load (kg N/yr) }\end{array}$ & $\begin{array}{l}\text { Total Phosphorus } \\
\text { Load (kg P/yr) }\end{array}$ \\
\hline S-Map 2m & 3,691 & 57.2 \\
\hline S-Map 15m & 3,713 & 57.8 \\
\hline FSL 15m & 4,401 & 89.2 \\
\hline FSL 15m & 4,443 & 90.1 \\
\hline
\end{tabular}


Not only is soil classification effecting LUCI's estimates of nitrogen loads but the land cover classification in the LCDB4 has resulted in load inconsistencies. The estimates of nitrogen loads along the river flat on the western edge of the farm vary despite being classed as recent soils in both FSL and S-Map datasets. The reason for the different loading estimates along this block is the classification of the upper northern part as cropland and the southern half as high producing grassland (Figure 4). In reality, the entire river flat is covered by high producing grassland, showing the importance of understanding the underlying data used in models such as LUCI, and if available, the importance of using high resolution, site specific land cover data. For farm scale use land use information would normally be derived from an Overseer nutrient budget and associated farm management block map as these provide LUCI with information on the cropping practices, fertiliser and irrigation management present on this farm.

Phosphorus load estimates also follow the pattern in soil input data (Figure 7). Again, FSL $2 \mathrm{~m}$ and FSL $15 \mathrm{~m}$ estimate higher phosphorus loads then their S-map counterparts, with FSL $2 \mathrm{~m}$ estimating $89.2 \mathrm{~kg} \mathrm{P} / \mathrm{yr}$ and S-Map $2 \mathrm{~m}$ estimating $57.2 \mathrm{~kg} \mathrm{P} / \mathrm{yr}$ (Table 2). Comparing the load of individual cells with the same soil order between applications, the values are similar, so the reason for the $32 \mathrm{~kg} \mathrm{P} / \mathrm{yr}$ difference between S-Map and FSL applications can be attributed to the classification change from recent to brown soil over the main block of the farm (this is the most significant area of difference between the two soil maps). The accumulated phosphorus load results show a similar pattern to the accumulated nitrogen load output, where the effect of the lower resolution DEM results in a different representation of accumulated load across the landscape (Figure 8). 


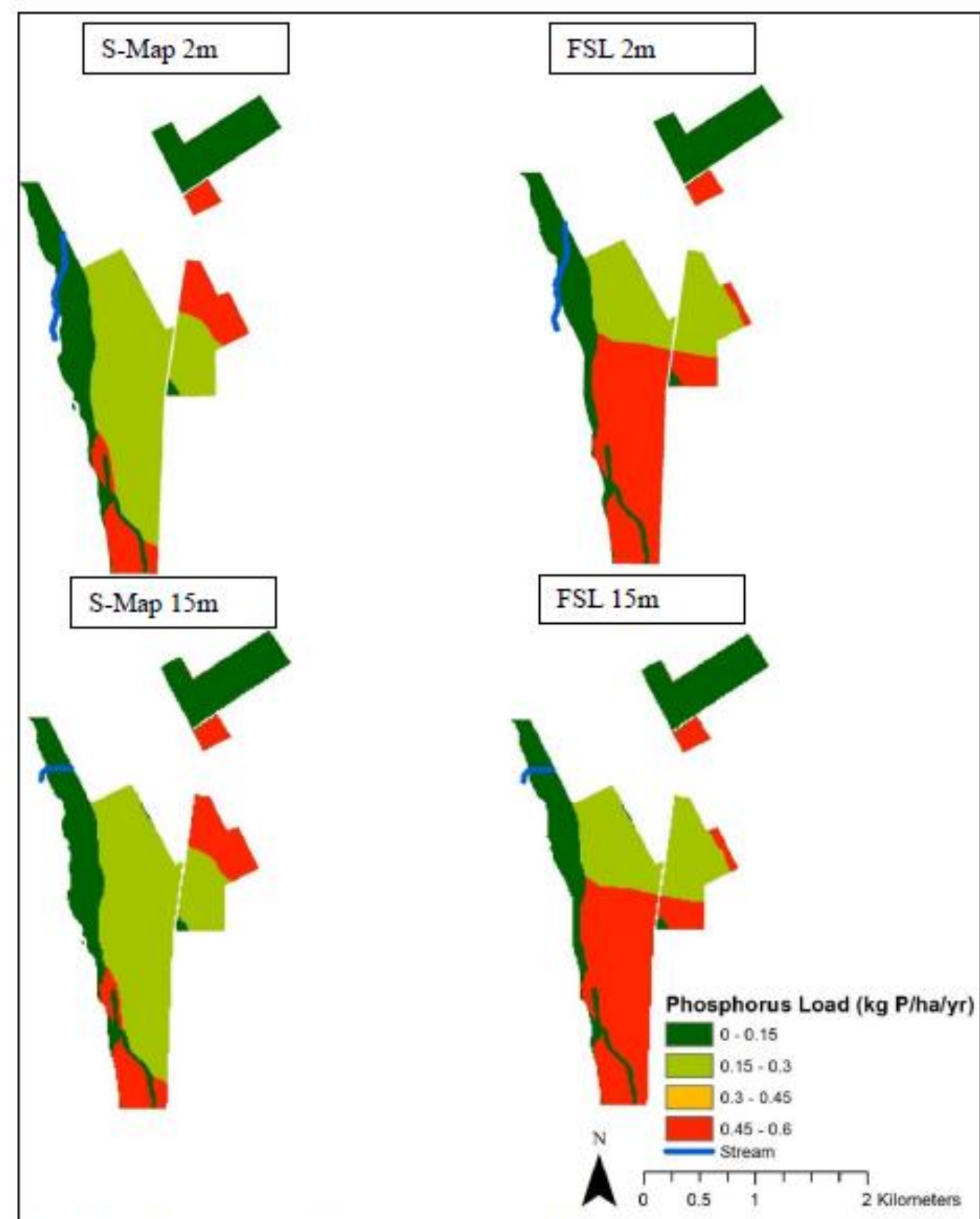

Figure 7-LUCI's estimates of Phosphorus Load using all data input scenarios. 


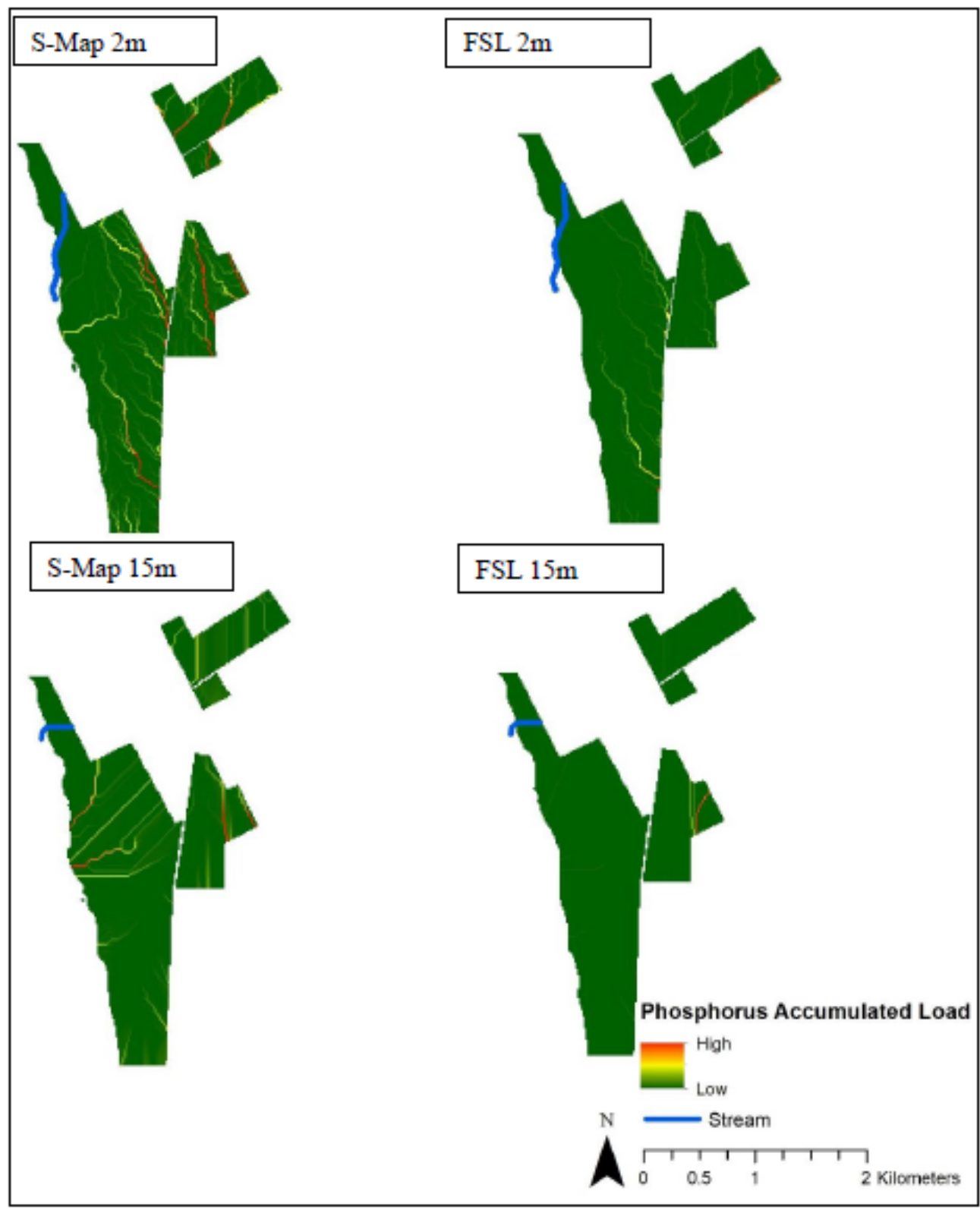

Figure 8-LUCI's estimates of Phosphorus Accumulated Load using all data input scenarios.

It is important to note the different pathways of nutrient movement through a farm system. Nitrogen is easily lost by leaching to ground water, whereas, phosphorus is mainly lost through runoff and erosion (McDowell and Condron, 2004). While phosphorus loss from farm is in smaller quantities then the total amount present in the soil, only a small quantity of phosphorus entering a water body causes significant environmental damage through the enhanced growth of aquatic weeds and algae (McDowell and Condron, 2004). The area of pallic soil has been classified as cropland in the LCDB4, resulting in low predicted phosphorus losses on this site, again highlighting the importance of site specific landcover data. Pallic soils are naturally prone to pugging due to the impermeable nature of the soil, this means that surface water rich in 
phosphorus can be lost to water bodies via surface runoff (FLRC, 2016). Pallic soils have low $P$ retention meaning that little phosphorus is removed from the soil solution and held on the surface of soil colloids. Given this case study has a flat topography, with the only area of major elevation change (the river escarpment) covered in forest, phosphorus loss on this site is not as large or complex as expected loss from a site with rolling, steep hill topography.

\section{Conclusion}

In this case study, LUCI's estimates of nitrogen and phosphorus load lost from the landscape are affected by the soil data used as input to the model. The changing classification from recent to brown soil with the newer, S-Map dataset, results in reduced estimates of nitrogen and phosphorus loads on this farm. Load estimates are also dependant on land use. Accumulated load patterns however, are not sensitive to changing the source of the soil data and instead, the resolution of the DEM used in each application had the most pronounced effect. These relationships between difference soil datasets and DEM resolutions are being explored further in five other case studies. These sites are located in both the North and South Island, ensuring different climates, land management practices, soil datasets and topography are incorporated this analysis of the LUCI model.

\section{Acknowledgements}

Thanks to Ravensdown, Callaghan Innovation and Victoria University for supporting this project. S-Map and FSL data used in this research reproduced with the permission of Landcare Research New Zealand Limited. The LiDAR data for this site is part of the 2005 Waimakariri LiDAR survey, owned by Waimakariri District Council and Environment Canterbury and the National $15 \mathrm{~m}$ DEM was created by the University of Otago School of Surveying. Both datasets are licensed under Creative Commons Attribution 3.0 New Zealand.

\section{References}

Barringer, J.R.F., Lilburne, L., Carrick, S, Webb, T., \$ Snow, V. (2016). What difference does detailed soil mapping information make? A Canterbury case study. In: Integrated nutrient and water management for sustainable farming. (Eds L.D. Currie and R.Singh).

http://flrc.massey.ac.nz publications.html. Occasional Report No. 29. Fertilizer and Lime Research Centre, Massey University, Palmerston North, New Zealand. 12 pages.

Columbus, J., Sirguey, P., \& Tenzer, R. (2011). A Free Fully Assessed 15 m DEM for New Zealand. Survey Quarterly, (66), 16-19.

Fertiliser and Lime Research Center. (2016). Sustainable Nutrient Management in New Zealand Agriculture. Massey University, Palmerston North, New Zealand.

Jackson, B., T. Pagella, F. Sinclair, B. Orellana, A. Henshaw, B. Reynolds, N. Mcintyre, H. Wheater \& A. Eycott. (2013). Polyscape: A GIS mapping framework providing efficient and spatially explicit landscape-scale valuation of multiple ecosystem services. Landscape and Urban Planning 112:74-88.

Kear, B.S., Gibbs, H.S., \& Miller, R.B. (1967). Soils of the downs and plains, Canterbury and North Otago, New Zealand. Soil Bureau Bulletin 14, New Zealand Soil Bureau, Department of Scientific and Industrial Research, Wellington. 92 p. 
Lilburne, L.R., Hewitt, A.E., \& Webb, T.H. (2012). Soil and informatics science combine to develop S-map: a new generation soil information system for New Zealand. Geoderma 170, 232-238.

Land Information New Zealand (LINZ). (2018). LINZ Data Service. In https://data.linz.govt.nz/group/national-elevation/data/category/elevation/. Accessed $20 \mathrm{Feb}$ 2018.

R. W. McDowell \& L. M. Condron .(2004). Estimating phosphorus loss from New Zealand grassland soils, New Zealand Journal of Agricultural Research, 47:2, 137-145, DOI$10.1080 / 00288233.2004 .9513581$

Monaghan, R. M., Wilcock, R. J., Smith, L. C., Tikkisetty, B., Thorrold, B. S., \& Costall, D (2007). Linkages between land management activities and water quality in an intensively farmed catchment in southern New Zealand. Agriculture, Ecosystems \& Environment, 118, pp.211-222. https://doi.org/10.1016/j.agee.2006.05.016

Pollacco, J.A.P., Lilburne, L.R., Webb, T.H., \& Wheeler, D.M. (2014). Preliminary assessment and review of soil parameters in OVERSEER \& 6. Landcare Research Contract Report LC2002, Landcare Research, Lincoln, New Zealand.

Sharps, K., Masante, D., Thomas, A., Jackson, B., Redhead, J., May, L., Prosser, H., Cosby, B., Emmett, B. \& Jones, L. (2017). Comparing strengths and weaknesses of three ecosystem services modelling tools in a diverse UK river catchment. Science of the Total Environment, 584 , pp. $118-130$

S-MapOnline. (2018). Data Provenance. https://smap.landcareresearch.co.nz/dataprovenancel. Accessed 21 February 2018.

Trodahl, M. I., Jackson, B. M., Deslippe, J. R., \& Metherell, A. K. (2017). Investigating trade-offs between water quality and agricultural productivity using the Land Utilisation and Capability Indicator (LUCI)-A New Zealand application. Ecosystem Services, http://dx. https://doi.org/10.1016/j.ecoser.2016.10.013

White, M., D. Harmel, H. Yen, J. G. Arnold, M. Gambone \& R. Haney. (2015). Development of sediment and nutrient export coefficients for U.S. Ecoregions. Journal of the American Water Resources Association 51(3):758-775. 
APPENDIX C: SOIL PROPERTIES BASED ON SOIL ORDER IN OVERSEER. SOURCE: WHEELER (2016A).

\begin{tabular}{|c|c|c|c|c|c|c|c|}
\hline Property & $\begin{array}{l}\text { Alloph- } \\
\text { anic }\end{array}$ & Brown & Gley & $\begin{array}{l}\text { Granu- } \\
\text { lar }\end{array}$ & Melanic & Organic & Oxidic \\
\hline slowP & 3 & 3 & 3 & 3 & 3 & 3 & 3 \\
\hline Ploss & 0.05 & 0.04 & 0.04 & 0.05 & 0.04 & 0.04 & 0.05 \\
\hline olsenf & 19 & 25 & 25 & 19 & 25 & 25 & 19 \\
\hline olseng & 1.2 & 1.7 & 1.7 & 1.2 & 1.7 & 1.7 & 1.2 \\
\hline hydroclass & 0.51 & 0.56 & 0.64 & 0.74 & 0.62 & 0.58 & 0.75 \\
\hline dispindex & 0.2 & 0.2 & 0.4 & 0.4 & 0.2 & 1 & 0.2 \\
\hline RunoffClass & 1 & 1 & 2 & 2 & 1 & 4 & 1 \\
\hline kcurvature & 0.00231 & 0.00183 & 0.00183 & 0.00231 & 0.00183 & 0.00167 & 0.00231 \\
\hline kmaxlevel & 2 & 1.5 & 1.5 & 2 & 1.5 & 3 & 2 \\
\hline Pchange & 11 & 5 & 5 & 11 & 5 & 7 & 11 \\
\hline Kchange & 60 & 60 & 60 & 60 & 60 & 45 & 60 \\
\hline $\mathrm{CaW}$ & 0.068 & 0.111 & 0.111 & 0.068 & 0.111 & 0.024 & 0.068 \\
\hline $\mathrm{MgW}$ & 0.048 & 0.174 & 0.174 & 0.048 & 0.174 & 0.006 & 0.048 \\
\hline $\mathrm{NaW}$ & 0.124 & 0.105 & 0.105 & 0.124 & 0.105 & 0.043 & 0.124 \\
\hline Dep & 0.1857 & 0.2384 & 0.2384 & 0.1857 & 0.2384 & 0.0473 & 0.1857 \\
\hline origBC & 0.314 & 0.393 & 0.393 & 0.314 & 0.393 & 0.077 & 0.314 \\
\hline $\mathrm{MC}$ & 0.1281 & 0.1635 & 0.1635 & 0.1281 & 0.1635 & 0.0326 & 0.1281 \\
\hline temp & 0.1306 & 0.1666 & 0.1666 & 0.1306 & 0.1666 & 0.0339 & 0.1306 \\
\hline $\operatorname{adj} \mathrm{Ca}$ & 0 & 35.2 & 35.2 & 0 & 35.2 & 42.6 & 0 \\
\hline adj $\mathrm{Mg}$ & 0 & 22 & 22 & 0 & 22 & 26.8 & 0 \\
\hline $\mathrm{adjja}_{j}$ & 0 & 30.3 & 30.3 & 0 & 30.3 & 10 & 0 \\
\hline QTCaconv & 140 & 198 & 180 & 190 & 220 & 80 & 196 \\
\hline QTMgconv & 5.6 & 7.9 & 7.2 & 7.6 & 8.8 & 3.2 & 7.8 \\
\hline QTNaconv & 6.7 & 9.5 & 8.6 & 9.1 & 10.6 & 3.8 & 9.4 \\
\hline SMwp & 22.0 & 18.0 & 18.8 & 23.3 & 19.5 & 15.2 & 24.8 \\
\hline SMfc & 40.2 & 35.3 & 39.7 & 34.0 & 34.3 & 48.5 & 36.0 \\
\hline SMsat & 57.5 & 48.3 & 50.8 & 48.3 & 45.0 & 68.3 & 50.8 \\
\hline Soil N & 0.315 & 0.204 & 0.235 & 0.187 & 0.213 & 0.832 & 0.184 \\
\hline Soil P & 0.087 & 0.088 & 0.081 & 0.044 & 0.116 & 0.104 & 0.078 \\
\hline Soil K & 1.277 & 1.293 & 1.582 & 0.529 & 1.526 & 0.917 & 0.056 \\
\hline Soil S & 0.104 & 0.044 & 0.436 & 0.061 & 0.067 & 0.068 & 0.000 \\
\hline Soil Ca & 1.455 & 0.934 & 1.042 & 0.396 & 1.153 & 1.268 & 0.133 \\
\hline Soil Mg & 0.493 & 0.738 & 0.657 & 0.174 & 0.728 & 0.465 & 0.167 \\
\hline Soil Na & 1.406 & 1.668 & 1.682 & 0.903 & 1.919 & 1.101 & 0.436 \\
\hline BD & 764 & 1004 & 859 & 1010 & 984 & 428 & 961 \\
\hline ASC & 83 & 43 & 43 & 49 & 32 & 57 & 59 \\
\hline carbon & 9.4 & 6.1 & 8.8 & 9.5 & 5.5 & 28.7 & 6 \\
\hline clay & 23 & 24 & 33 & 44 & 36 & 24 & 48 \\
\hline Sand & 39 & 33 & 19 & 11 & 19 & 31 & 8 \\
\hline $\mathrm{Kc}$ & 0.13 & 0.31 & 0.32 & 0.16 & 0.49 & 0.1 & 0.05 \\
\hline drainageclass & 2 & & 4 & 2 & 2 & & \\
\hline $\begin{array}{l}\text { Macro- } \\
\text { porosity }\end{array}$ & 13.4 & 12.2 & 8.6 & 6.3 & 8.4 & 16.3 & 11.3 \\
\hline structinteg & 0.44 & 0.66 & 0.61 & 0.59 & 0.68 & 0.51 & 0.47 \\
\hline group & 2 & 1 & 1 & 2 & 1 & 6 & \\
\hline
\end{tabular}




\begin{tabular}{|c|c|c|c|c|c|c|c|}
\hline Property & Pallic & Podzols & Pumice & Raw & Recent & $\begin{array}{l}\text { Semi- } \\
\text { arid }\end{array}$ & Ultic \\
\hline slowP & 3 & 3 & 3 & 3 & 3 & 3 & 3 \\
\hline Ploss & 0.04 & 0.1 & 0.07 & 0.04 & 0.04 & 0.04 & 0.04 \\
\hline olsenf & 25 & 21 & 14 & 25 & 25 & 25 & 25 \\
\hline olseng & 1.7 & 1.3 & 1.3 & 1.7 & 1.7 & 1.7 & 1.7 \\
\hline hydroclass & 0.56 & 0.47 & 0.31 & 0.49 & 0.49 & 0.45 & 0.63 \\
\hline dispindex & 0.6 & 1 & 0.4 & 0.6 & 0.6 & 0.8 & 0.8 \\
\hline RunoffClass & 3 & 5 & 5 & 3 & 3 & 4 & 4 \\
\hline kcurvature & 0.00183 & 0.00116 & 0.00186 & 0.00183 & 0.00183 & 0.00183 & 0.00231 \\
\hline kmaxlevel & 1.5 & 4 & 2.6 & 1.5 & 1.5 & 1.5 & 2 \\
\hline Pchange & 5 & 5 & 7 & 5 & 5 & 5 & 5 \\
\hline Kchange & 60 & 60 & 45 & 60 & 60 & 60 & 60 \\
\hline $\mathrm{CaW}$ & 0.111 & 0.024 & 0.024 & 0.333 & 0.333 & 0.111 & 0.111 \\
\hline $\mathrm{MgW}$ & 0.174 & 0.006 & 0.006 & 0.522 & 0.522 & 0.174 & 0.174 \\
\hline $\mathrm{NaW}$ & 0.105 & 0.043 & 0.043 & 0.315 & 0.315 & 0.105 & 0.105 \\
\hline Dep & 0.2384 & 0.0473 & 0.0473 & 0.2384 & 0.2384 & 0.2384 & 0.2384 \\
\hline origBC & 0.393 & 0.077 & 0.077 & 0.393 & 0.393 & 0.393 & 0.393 \\
\hline $\mathrm{MC}$ & 0.1635 & 0.0326 & 0.0326 & 0.1635 & 0.1635 & 0.1635 & 0.1635 \\
\hline temp & 0.1666 & 0.0339 & 0.0339 & 0.1666 & 0.1666 & 0.1666 & 0.1666 \\
\hline $\mathrm{adj} \mathrm{Ca}$ & 35.2 & 42.6 & 42.6 & 35.2 & 35.2 & 35.2 & 35.2 \\
\hline adj $\mathrm{Mg}$ & 22 & 26.8 & 26.8 & 22 & 22 & 22 & 22 \\
\hline adj $\mathrm{Na}$ & 30.3 & 10 & 10 & 30.3 & 30.3 & 30.3 & 30.3 \\
\hline QTCaconv & 244 & 171 & 156 & 228 & 228 & 271 & 215 \\
\hline QTMgconv & 9.7 & 6.8 & 6.2 & 9.1 & 9.1 & 10.8 & 8.6 \\
\hline QTNaconv & 11.7 & 8.2 & 7.5 & 11 & 11 & 13.1 & 10.3 \\
\hline SMwp & 14.2 & 13.8 & 8.7 & 9.7 & 9.7 & 9.2 & 19.3 \\
\hline SMfc & 28.5 & 36.3 & 29.0 & 25.0 & 25.0 & 24.0 & 35.2 \\
\hline SMsat & 40.0 & 50.8 & 54.2 & 45.0 & 45.0 & 35.8 & 42.5 \\
\hline Soil N & 0.113 & 0.206 & 0.178 & 0.143 & 0.143 & 0.067 & 0.103 \\
\hline Soil P & 0.058 & 0.043 & 0.022 & 0.074 & 0.074 & 0.055 & 0.032 \\
\hline Soil K & 1.611 & 1.229 & 1.828 & 1.826 & 1.826 & 1.611 & 0.443 \\
\hline Soil S & 0.019 & 0.037 & 0.043 & 0.036 & 0.036 & 0.014 & 0.015 \\
\hline Soil Ca & 0.961 & 0.751 & 1.714 & 1.213 & 1.213 & 0.961 & 0.077 \\
\hline Soil Mg & 0.606 & 0.368 & 0.444 & 0.888 & 0.888 & 0.606 & 0.225 \\
\hline Soil Na & 2.050 & 1.249 & 2.710 & 2.123 & 2.123 & 2.050 & 0.486 \\
\hline $\mathrm{BD}$ & 1236 & 875 & 866 & 1110 & 1110 & 1373 & 1064 \\
\hline ASC & 21 & 32 & 49 & 23 & 23 & 9 & 26 \\
\hline carbon & 3.5 & 11.1 & 6.6 & 4.1 & 4.1 & 2 & 3.8 \\
\hline clay & 23 & 12 & 19 & 19 & 19 & 17 & 27 \\
\hline Sand & 24 & 46 & 65 & 40 & 40 & 48 & 9 \\
\hline $\mathrm{Kc}$ & 0.45 & 0.13 & 0.12 & 0.43 & 0.43 & 0.54 & 0.18 \\
\hline drainageclass & 3 & 3 & 1 & 1 & 1 & 2 & 3 \\
\hline $\begin{array}{l}\text { Macro- } \\
\text { porosity }\end{array}$ & 9.5 & 12.9 & 24.5 & 14.8 & 14.8 & 10.4 & 5.6 \\
\hline structinteg & 0.81 & 0.77 & 0.66 & 0.84 & 0.84 & 0.94 & 0.76 \\
\hline group & 7 & 4 & 3 & 7 & 7 & 7 & 1 \\
\hline
\end{tabular}

